UNIVERSIDAD NACIONAL DE LA PLATA - ARGENTINA

FACULTAD DE CIENCIAS AGRARIAS Y FORESTALES

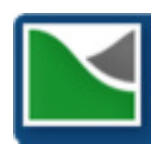

MAGISTER SCIENTIAE EN MANEJO INTEGRAL DE CUENCAS HIDROGRÁFICAS

EVALUACIÓN ESPACIO TEMPORAL DE LA PRODUCTIVIDAD AGRÍCOLA CON ÍNDICES DE VEGETACIÓN DE DIFERENCIAS NORMALIZADAS (NDVI) COMO HERRAMIENTA PARA EL ORDENAMIENTO TERRITORIAL.

CASO DE ESTUDIO: CUENCA ALTA DEL ARROYO NAPALEOFÚ, PROVINCIA DE BUENOS AIRES, ARGENTINA.

TESIS PARA OBTENER EL GRADO DE MAGISTER EN MANEJO INTEGRAL DE CUENCAS HIDROGRÁFICAS

Presenta

FABIO ALEJANDRO MONTEALEGRE MEDINA ING CATASTRAL Y GEODESTA

Director: DR. FERNANDA GASPARI

Co Director: DR. CHRISTIAN WEBER

La Plata - Argentina, 2017 


\title{
EVALUACIÓN ESPACIO TEMPORAL DE LA PRODUCTIVIDAD AGRÍCOLA CON ÍNDICES DE VEGETACIÓN DE DIFERENCIAS NORMALIZADAS (NDVI) COMO HERRAMIENTA PARA EL ORDENAMIENTO TERRITORIAL. \\ CASO DE ESTUDIO: CUENCA ALTA DEL ARROYO NAPALEOFÚ, PROVINCIA DE BUENOS AIRES, ARGENTINA.
}

\section{RESUMEN}

En la presente tesis se trabajaron e implementaron diversas metodologías geomáticas al interior de la cuenca hidrográfica del arroyo Napaleofú en la provincia de Buenos Aires Argentina, generando herramientas que contribuyan a mejorar la toma de decisiones en el ordenamiento y planificación de la misma respecto al ámbito de productividad agrícola. Se procesó información geográfica tal como lo son mapas de rendimiento de productividad provenientes de cultivos de cebada y trigo de la zona, junto con información obtenida de imágenes de satélite, donde se correlacionó el rendimiento con el índice de vegetación NDVI, para así proponer modelos óptimos de regresión clásicos y espaciales que permitieron caracterizar, al igual que calcular, el rendimiento de productividad sobre los mencionados cultivos. Esta herramienta permite generar información de rendimiento en zonas donde se carece o se desea evaluar el comportamiento agrícola al interior de la cuenca hidrográfica o en cualquier zona en donde se posea la información satelital necesaria.

Palabras clave: Cuenca Hidrográfica, NDVI, Modelo de Regresión, Mapa de Rendimiento, Imagen de Satélite.

\begin{abstract}
In this thesis, several geomatic methodologies were developed and implemented in the Napaleofú river basin in the province of Buenos Aires - Argentina, generating tools in order to improve the decision making in the land planning of the basin respect the agricultural productivity. Geographic information such as productivity yield maps of barley and wheat crops in the study area were processed, along with information obtained from satellite images, where the yield was correlated with the NDVI vegetation index, in order to propose optimal classic and spatial regression models that allowed characterizing, likewise calculate, the yield of productivity on the mentioned crops. This tool allows the generation of performance information in areas where agricultural behavior is lacking or desirable within the river basin or in any area where the necessary satellite information is available.
\end{abstract}

Key words: Hydrographic Basin, NDVI, Regression Model, Yield Map, Satellite Image. 


\section{ÍNDICE GENERAL}

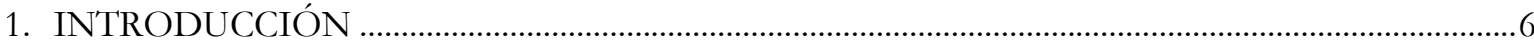

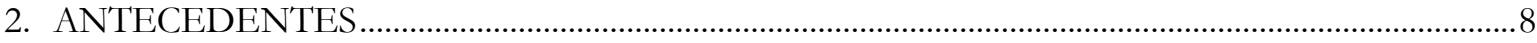

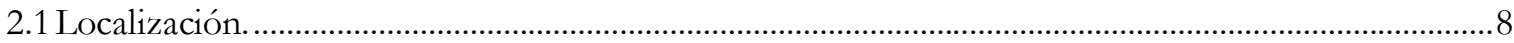

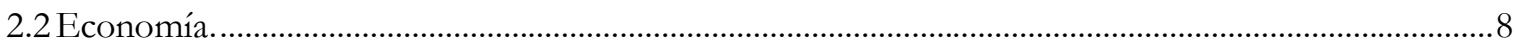

2.3 Clima.

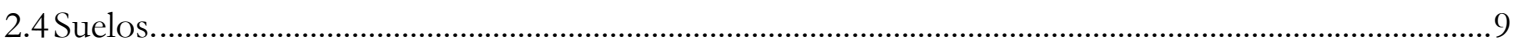

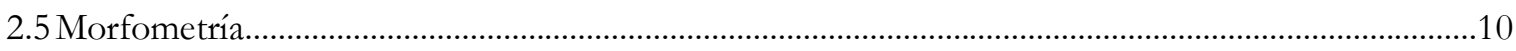

2.6 Marcos y sistemas de referencia de la información. .............................................................................11

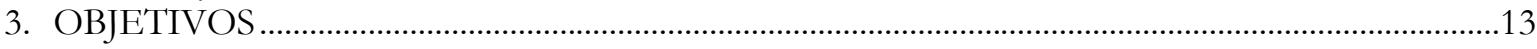

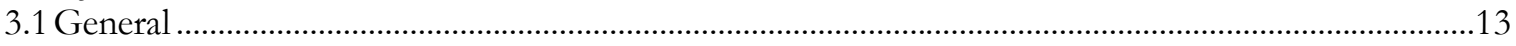

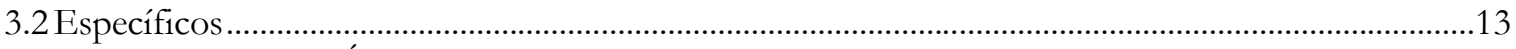

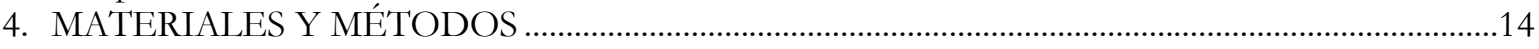

4.1 Identificación y definición de los límites de las parcelas de estudio........................................................14

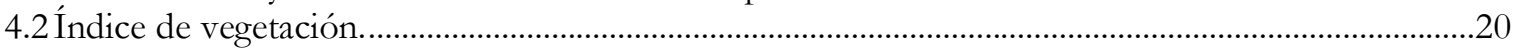

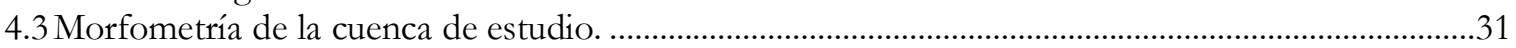

4.4 Correlación del NDVI con la topografía de la cuenca. .............................................................................33

4.5 Procesamiento de datos de rendimiento agrícola.....................................................................................34

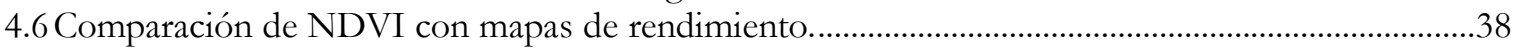

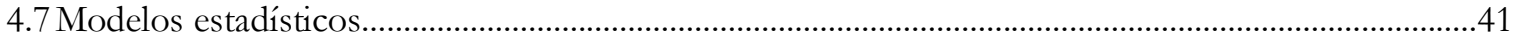

4.8 Integración de los resultados alcanzados para la contribución de la predicción de productividad agrícola al ordenamiento territorial de la cuenca hidrográfica..................................................................4

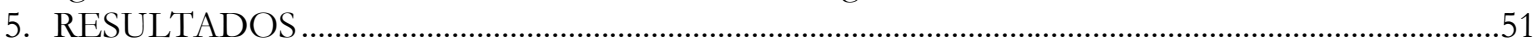

5.1 Identificación y definición de los límites de las parcelas de estudio....................................................51

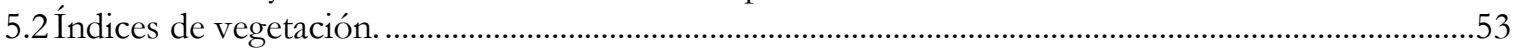

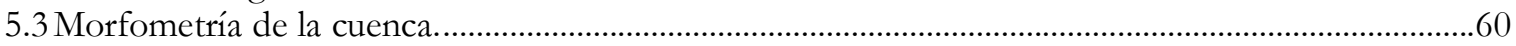

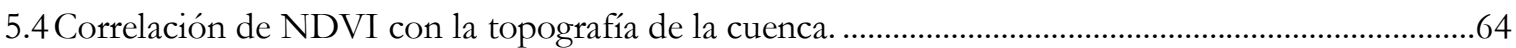

5.5 Procesamiento de datos de rendimiento agrícola.....................................................................................69

5.6 Comparación de NDVI con datos depurados de productividad...........................................................78

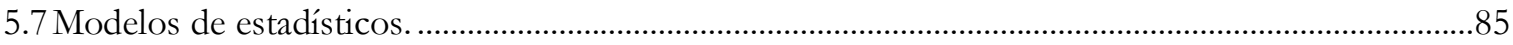

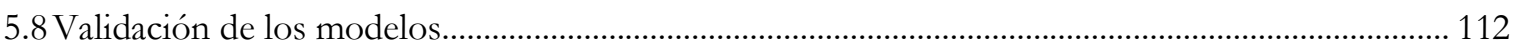

5.9 Integración de los resultados alcanzados para la contribución de la predicción de productividad agrícola al ordenamiento territorial de la cuenca hidrográfica............................................................... 115

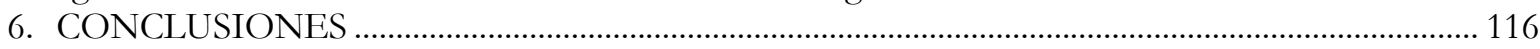

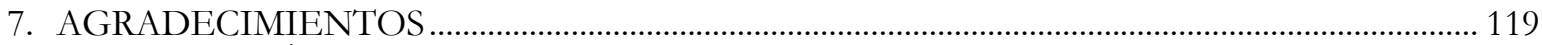

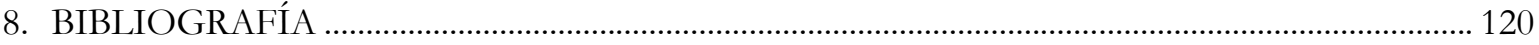

9. ANEXOS 124

9.1 Anexo 1. Descripción técnica de los sensores remotos Landsat y Spot.

9.2 Anexo 2. Gráficos de dispersión de valores NDVI vs Rendimiento. Metodología a nivel pixel. . 127

9.3 Anexo 3. Gráficos de dispersión de valores NDVI vs Rendimiento. Metodología a nivel zonal. 134

9.4 Anexo 4. Datos para el cálculo del coeficiente Nash-Sutcliffe.

\section{ÍNDICE DE FIGURAS}

Figura 1. Ubicación de la Cuenca alta del arroyo Napaleofú - Argentina. ............................................... 8

Figura 2. Tipo de relieves presentes en la cuenca alta del arroyo Napaleofú..........................................10

Figura 3. Jerarquización de la red de drenaje según Stralher (1964).....................................................11

Figura 4. Conversión de Bandas Landsat 8 a valores de reflectancia en el techo de la atmósfera

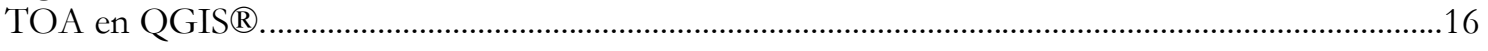

Figura 5. Localización de los cultivos de la estancia La Esperanza en la cuenca hidrográfica.............18

Figura 6. Información Vectorial inicial suministrada por el productor. ....................................................18

Figura 7. Imagen Spot 5 (resolución espacial $10 \mathrm{~m}$ ) a izquierda y Landsat 8 (resolución espacial 30

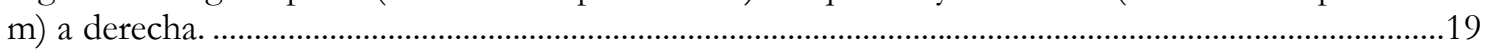

Figura 8. Cálculo del índice de vegetación NDVI por medio de QGIS ${ }^{\circ}$................................................23 
Figura 9. Extracción de valores NDVI con respecto a los polígonos de las parcelas........................23

Figura 10. Almacenamiento de información en el software CyberTracker@ ......................................25

Figura 11. Captura de información en campo con espectro radiómetro..............................................25

Figura 12. Formatos planos .txt con la información espectral del radiómetro.....................................26

Figura 13. Localización de los puntos de muestreo junto con el catastro parcelario en la Estancia La

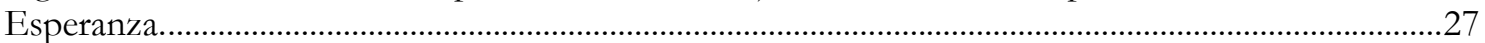

Figura 14. Etapas del ciclo de cultivo de trigo y generación de componentes numéricos del

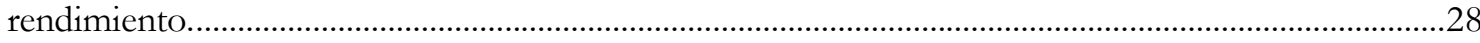

Figura 15. Selección de valores NDVI provenientes de las imágenes de satélite por punto de

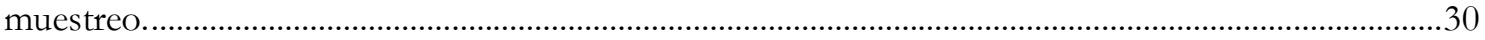

Figura 16. Mapa de rendimiento y detalle de puntos...........................................................................36

Figura 17. Visualización de la metodología a nivel pixel.......................................................................39

Figura 18. Visualización de la metodología a zonal. ...........................................................................40

Figura 19. Tipos de vecindad para los datos considerados en la matriz de pesos espaciales W........45

Figura 20. Diagrama de decisión para modelos espaciales basados en multiplicadores de Lagrange.

Figura 21. Digitalización de parcelas, primera etapa (izquierda) - segunda etapa (derecha)..............52

Figura 22. Parcelas digitalizadas y nomenclador según su cultivo e identificador. ..............................52

Figura 23. Cobertura del suelo en los viajes de campo correspondiente al punto de muestreo 1 ......56

Figura 24. Cobertura del suelo en los viajes de campo correspondiente al punto de muestreo 2......56

Figura 25. Cobertura del suelo en los viajes de campo correspondiente al punto de muestreo 3......57

Figura 26. Cobertura del suelo en los viajes de campo correspondiente al punto de muestreo $4 \ldots . . .57$

Figura 27. Cobertura del suelo en los viajes de campo correspondiente al punto de muestreo $5 \ldots . . .57$

Figura 28. Cobertura del suelo en los viajes de campo correspondiente al punto de muestreo 6 .......58

Figura 29. Cobertura del suelo en los viajes de campo correspondiente al punto de muestreo 8 ......58

Figura 30. Cobertura del suelo en los viajes de campo correspondiente al punto de muestreo 8......59

Figura 31. Configuración de subcuencas de la cuenca alta del arroyo Napaleofú. .............................60

Figura 32. Espacialización de la zonificación de altura. .....................................................................65

Figura 33. Resultados e información proveniente de la conversión de formatos Log a Shp..............70

Figura 34. Representación de los puntos de rendimiento originales sectorizados al interior de las

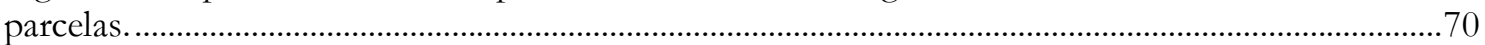

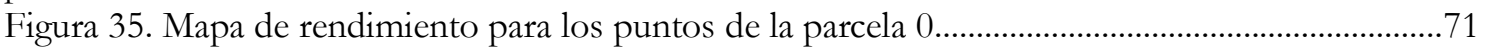

Figura 36. Datos atípicos con valores de rendimiento 0 y diferentes a ancho de franja 8 metros.....72

Figura 37. Descarte de puntos al exterior de los polígonos digitalizados de las parcelas de estudio. 73

Figura 38. Valores atípicos de rendimiento por fuera del rango biológico de los cultivos..................74

Figura 39. Espacialización de Valores atípicos identificados estadísticamente.....................................77

Figura 40. Conflicto de valores de rendimiento en parcelas contiguas.................................................78

\section{ÍNDICE DE TABLAS}

Tabla 1. Imágenes satelitales Spot 5 disponibles que coinciden con las visitas a campo....................14

Tabla 2. Asociación de información catastral de cultivos con las parcelas de estudio.........................35

Tabla 3. Rangos de validación por el criterio de Nash-Sutcliffe ............................................................48

Tabla 4. Imágenes satelitales Landsat 8 que intervienen en el estudio................................................51

Tabla 5. Total de datos NDVI al interior de cada parcela ......................................................................53

Tabla 6. Estadística descriptiva de los valores NDVI para el cultivo de cebada respecto a las fechas

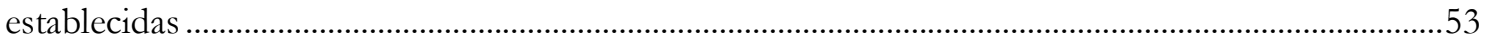

Tabla 7. Estadística descriptiva de los valores NDVI para el cultivo de trigo respecto a las fechas

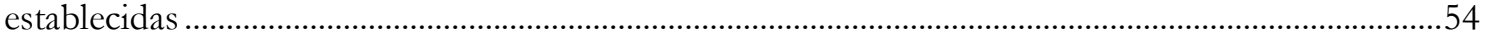

Tabla 8. Estadio de los cultivos en los viajes de campo.......................................................................55

Tabla 9. Compilación de valores NDVI obtenidos del radiómetro e imágenes de satélite..................60

Tabla 10. Parámetros morfométricos de forma por subcuenca............................................................61

Tabla 11. Parámetros morfométricos de relieve por subcuenca.............................................................62

Tabla 12. Parámetros morfométricos de drenaje por subcuenca.........................................................63 
Tabla 13. Zonificación y rangos de altura de la cuenca por el método de rupturas naturales. ............64

Tabla 14. Coeficientes de correlación de Pearson para la altura vs NDVI por zonas. ..........................65

Tabla 15. Estadística descriptiva inicial de los set de datos por parcela. ..................................................75

Tabla 16. Cuartiles y rangos interquartílicos por parcela...........................................................................76

Tabla 17. Estadística descriptiva de los datos depurados y totalidad de datos atípicos encontrados

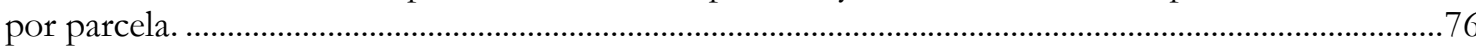

Tabla 18. Total de puntos de rendimiento y cantidad de pixeles o valores NDVI por parcela respecto a la metodología a nivel pixel en las fechas establecidas. ...........................................................78

Tabla 19. Valores de ajuste lineal $\mathrm{R}^{2}$ para las parcelas respecto a los datos de la metodología a nivel

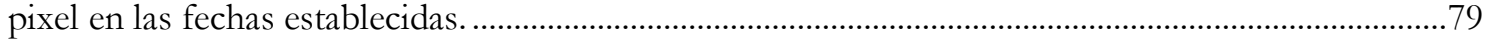

Tabla 20. Coeficientes de Pearson por parcela según la metodología a nivel pixel en las fechas establecidas

Tabla 21. Total de puntos de rendimiento y cantidad de pixeles o valores NDVI por parcela respecto a la metodología a nivel zonal en las fechas establecidas.

Tabla 22. Valores de ajuste lineal $\mathrm{R}^{2}$ para las parcelas respecto a los datos de la metodología a nivel zonal en las fechas establecidas.

Tabla 23. Coeficientes de Pearson por parcela según la metodología a nivel zonal en las fechas establecidas.

Tabla 24. Resultados de los estadísticos y test generales de los modelos MCO por parcela para la metodología a nivel pixel.

Tabla 25. Resultados de los coeficientes y estadísticos para las variables de los modelos MCO por

parcela para la metodología a nivel pixel.

Tabla 26. Resultados de los estadísticos para evaluar la heterocedasticidad y no normalidad de los modelos MCO por parcela para la metodología a nivel pixel.

Tabla 27. Resultados del estadístico I de Moran para evaluar la autocorrelación en los residuales de los modelos MCO por parcela para la metodología a nivel pixel..........................................................90

Tabla 28. Resultados de los Multiplicadores de Lagrange pertenecientes a los modelos MCO por parcela para la metodología a nivel pixel.

Tabla 29. Resultados de los estadísticos y test generales de los modelos espaciales Error por parcela

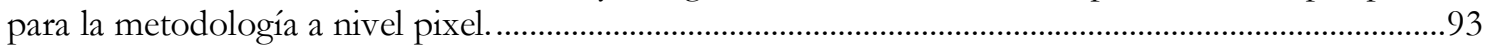

Tabla 30. Resultados de los coeficientes y estadísticos para las variables de los modelos espaciales

Error por parcela para la metodología a nivel pixel. ............................................................................. 95

Tabla 31. Resultados de los estadísticos para evaluar la heterocedasticidad de los modelos espaciales

Error por parcela para la metodología a nivel pixel..................................................................................

Tabla 32. Resultados de los estadísticos y test generales de los modelos espaciales Lag para las

parcelas de cebada según la metodología a nivel pixel. .............................................................................98

Tabla 33. Resultados de los coeficientes y estadísticos para las variables de los modelos espaciales

Lag para las parcelas de cebada según para la metodología a nivel pixel................................................99

Tabla 34. Resultados de los estadísticos para evaluar la heterocedasticidad de los modelos espaciales

Lag para las parcelas de cebada según la metodología a nivel pixel. ......................................................100

Tabla 35. Resultados de los estadísticos y test generales de los modelos MCO por parcela para la

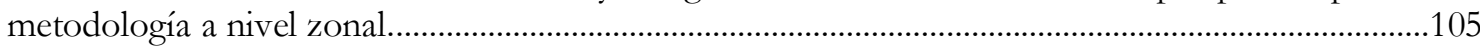

Tabla 36. Resultados de los coeficientes y estadísticos para las variables de los modelos MCO por

parcela para la metodología a nivel zonal. .........................................................................................107

Tabla 37. Resultados de los estadísticos para evaluar la heterocedasticidad y no normalidad de los

modelos MCO por parcela para la metodología a nivel zonal. .............................................................108

Tabla 38. Resultados del estadístico I de Moran para evaluar la autocorrelación en los residuales de

los modelos MCO por parcela para la metodología a nivel zonal........................................................110

Tabla 39. Ecuaciones seleccionadas de modelos MCO para los cultivos de cebada y trigo según la

metodología a nivel zonal

Tabla 40. Resultado de la validación por medio del coeficiente Nash-Sutcliffe con base en los

modelos MCO planteados para cada tipo de cultivo mediante la metodología zonal.........................113

Tabla 41. Especificaciones técnicas del sensor pasivo Spot 5..........................................................124

Tabla 42. Descripción de las características pertenecientes a las imágenes satelitales Spot 5

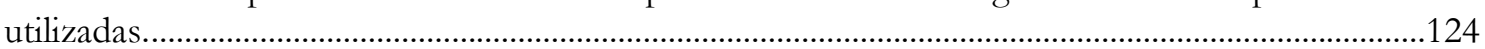

Tabla 43. Especificaciones técnicas del sensor pasivo Landsat 8 …………………….........................125 
Tabla 44. Descripción de las bandas espectrales del sensor Landsat 8 OLI y TIRS.

Tabla 45. Valores de rendimiento observado y simulado de los modelos MCO escogidos según la metodología zonal para cada parcela en la fecha 17 de noviembre.

Tabla 46. Valores de rendimiento observado y simulado de los modelos MCO escogidos según la metodología zonal para cada parcela en la fecha 26 de noviembre........................................................142 Tabla 47. Valores de rendimiento observado y simulado de los modelos MCO escogidos según la metodología zonal para cada parcela en la fecha 03 de diciembre.

\section{ÍNDICE DE GRÁFICOS}

Gráfico 1. Espectro típico de reflectancia de una planta saludable y otra en condiciones de estrés. 21 Gráfico 2. Firmas espectrales de los puntos de muestreo para los viajes de recolección de datos en campo.

Gráfico 3. Variación de coeficientes de Pearson en las zonas por mes..................................................66 Gráfico 4. Evolución de los valores de coeficientes Pearson por zona en el transcurso de los meses.

Gráfico 5. Compilación de los gráficos de dispersión NDVI vs altura topográfica en cada zona por

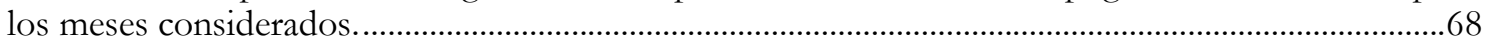
Gráfico 6. Diagrama de cajas por parcela con base en los valores de los puntos de rendimiento....75 Gráfico 7. Variación del coeficiente Pearson para las parcelas de según la metodología a nivel pixel en las fechas establecidas.

Gráfico 8. Variación del coeficiente Pearson para las parcelas de según la metodología a nivel zonal en las fechas establecidas....................................................................................................................... 83

Gráfico 9. Compilación de gráficos de dispersión entre los valores de NDVI y puntos de rendimiento junto con su ajuste lineal para la parcela 3 en las fechas establecidas según la metodología a nivel pixel.

Gráfico 10. Compilación de gráficos de dispersión entre los valores de NDVI y puntos de rendimiento junto con su ajuste lineal para la parcela 4 en las fechas establecidas según la metodología a nivel pixel.

Gráfico 11. Compilación de gráficos de dispersión entre los valores de NDVI y puntos de rendimiento junto con su ajuste lineal para la parcela 5 en las fechas establecidas según la metodología a nivel pixel.

Gráfico 12. Compilación de gráficos de dispersión entre los valores de NDVI y puntos de rendimiento junto con su ajuste lineal para la parcela 0 en las fechas establecidas según la metodología a nivel pixel..

Gráfico 13. Compilación de gráficos de dispersión entre los valores de NDVI y puntos de rendimiento junto con su ajuste lineal para la parcela 2 en las fechas establecidas según la metodología a nivel pixel.

Gráfico 14. Compilación de gráficos de dispersión entre los valores de NDVI y puntos de rendimiento junto con su ajuste lineal para la parcela 6 en las fechas establecidas según la metodología a nivel pixel.

Gráfico 15. Compilación de gráficos de dispersión entre los valores de NDVI y puntos de rendimiento junto con su ajuste lineal para la parcela 7 en las fechas establecidas según la metodología a nivel pixel.

Gráfico 16. Compilación de gráficos de dispersión entre los valores de NDVI zonales y sus promedios de puntos de rendimiento junto con su ajuste lineal para la parcela 3 en las fechas establecidas según la metodología a nivel zonal.

Gráfico 17. Compilación de gráficos de dispersión entre los valores de NDVI zonales y sus promedios de puntos de rendimiento junto con su ajuste lineal para la parcela 4 en las fechas establecidas según la metodología a nivel zonal.

Gráfico 18. Compilación de gráficos de dispersión entre los valores de NDVI zonales y sus promedios de puntos de rendimiento junto con su ajuste lineal para la parcela 5 en las fechas establecidas según la metodología a nivel zonal. 
Gráfico 19. Compilación de gráficos de dispersión entre los valores de NDVI zonales y sus promedios de puntos de rendimiento junto con su ajuste lineal para la parcela 0 en las fechas establecidas según la metodología a nivel zonal

Gráfico 20. Compilación de gráficos de dispersión entre los valores de NDVI zonales y sus promedios de puntos de rendimiento junto con su ajuste lineal para la parcela 2 en las fechas establecidas según la metodología a nivel zonal.

Gráfico 21. Compilación de gráficos de dispersión entre los valores de NDVI zonales y sus promedios de puntos de rendimiento junto con su ajuste lineal para la parcela 6 en las fechas establecidas según la metodología a nivel zonal.

Gráfico 22. Compilación de gráficos de dispersión entre los valores de NDVI zonales y sus promedios de puntos de rendimiento junto con su ajuste lineal para la parcela 7 en las fechas establecidas según la metodología a nivel zonal.

\section{ÍNDICE DE ECUACIONES}

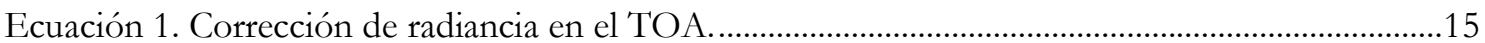

Ecuación 2. Cálculo del índice de vegetación NDVI. .......................................................................22

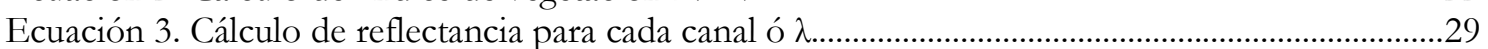

Ecuación 4. Límites para la obtención de valores atípicos leves y extremos.........................................38

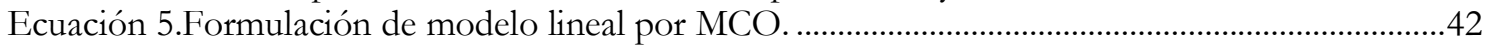

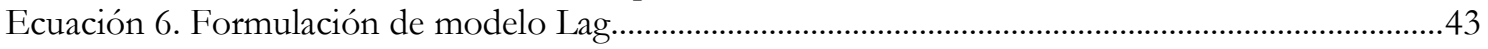

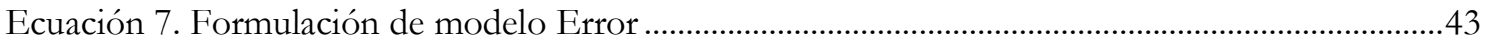

Ecuación 8. Modelo espacial Error escogido para el cultivo de trigo....................................................102

Ecuación 9. Modelo espacial Error escogido para el cultivo de cebada...............................................103

Ecuación 10. Modelo espacial Lag escogido para el cultivo de cebada...............................................103 


\section{EVALUACIÓN ESPACIO TEMPORAL DE LA PRODUCTIVIDAD AGRÍCOLA CON ÍNDICES DE VEGETACIÓN DE DIFERENCIAS NORMALIZADAS (NDVI) COMO HERRAMIENTA PARA EL ORDENAMIENTO TERRITORIAL. CASO DE ESTUDIO: CUENCA ALTA DEL ARROYO NAPALEOFÚ, PROVINCIA DE BUENOS AIRES, ARGENTINA.}

\section{INTRODUCCIÓN}

En la actualidad las tecnologías son parte importante del progreso agrario, con las cuales es posible monitorear, detectar y planificar las distintas etapas evolutivas de los cultivos. Gracias a los avances y disponibilidad de las imágenes satelitales (de alta resolución espacial, espectral y temporal) es posible cubrir grandes extensiones de áreas y coberturas de la superficie terrestre, brindando diferentes tipos de información útil, la cual hay que interpretar dependiendo del tema de estudio que se quiera realizar.

Echevarría (2010) plantea la teledetección remota como la observación de la superficie terrestre que engloba los procesos de captura de imágenes, al igual que su posterior tratamiento, en el contexto de una determinada aplicación (Chuvieco, 2002). En el presente trabajo se utilizaron imágenes satelitales las cuales permiten, como lo menciona Hall et al. (2002), reducir la cantidad de muestreos de coberturas de suelo requerido para caracterizar adecuadamente y delinear las zonas de estudio.

Con herramientas geomáticas como es el procesamiento digital de imágenes satelitales y la fotointerpretación es posible clasificar las coberturas y el uso del suelo. Si se considera la reflectancia de las hojas de las plantas o canopy en comparación al suelo, éstas presentan una mayor absorción de la energía del sol en el espectro infrarrojo comparado con el rojo. La reflectancia de estas regiones del espectro es frecuentemente utilizada para la determinación de algunos índices vegetativos. Existen multitud de índices que indican tanto condiciones hídricas como vegetativas de los cultivos, uno de los índices más empleados corresponde al “Índice Vegetativo Diferencial Normalizado" (NDVI por sus siglas en inglés) el cual es asociado a distintas categorías de vigor (Best et al., 2006). En el proceso de la tesis se utilizó dicho índice de verdor con el cual se buscó encontrar la relación con el rendimiento productivo de diferentes parcelas con cultivos de cebada y trigo pertenecientes a una estancia agrícola al interior de la cuenca hidrográfica en estudio. 
Para entender la zona planteada en el trabajo fue necesario establecer un enfoque sistémico del concepto de cuenca hidrográfica, la cual supera la idea de reducirla a una superficie de convergencia del escurrimiento hídrico superficial, ya que considera a todo el complejo biogeomórfico y humano. La misma constituye un instrumento valioso para el Estado y la sociedad para administrar su actividad, conciliar intereses económicos y sociales, conservar la biodiversidad y permitir un uso sostenido de los recursos naturales representando a una unidad de planificación y gestión para el manejo de los recursos naturales (Gaspari, 2002). De esta forma para poder entender la dinámica de una cuenca hidrográfica y buscar relación entre las actividades desarrolladas en su interior (para el presente caso la agricultura) por medio de índices de vegetación se describieron las principales características físicas relacionadas a la morfometría de la cuenca: forma, relieve y red de drenaje, derivadas de su geomorfología. Las cuales permiten comparar cuencas hidrográficas a partir de la descripción precisa de la geometría de las formas superficiales, alcanzando conclusiones preliminares sobre las características ambientales del territorio (Senisterra et al., 2014).

$\mathrm{Al}$ realizar la anterior comparación de características morfométricas, rendimiento agrícola y el índice NDVI se buscó plantear modelos espaciales predictivos que permitan inferir valores de rendimiento en zonas donde se siembre cultivos de trigo y cebada en lugares donde no se posee información ya sea por inexistencia de datos o por difícil accesibilidad, utilizando imágenes de satélite de acceso público de diferentes fechas, permitiendo contribuir a la toma de decisiones en la administración de áreas de la cuenca hidrográfica ayudando así a la mejora del ordenamiento territorial tanto de la cuenca en estudio como a la región que se encuentra. 


\section{ANTECEDENTES}

En las últimas décadas se han producido transformaciones en la estructura productiva del sudeste bonaerense que ha derivado de la introducción de tecnología y de la adopción de técnicas de los productores agropecuarios. En ese sentido, se puede mencionar que el partido de Tandil, en el cual se encuentra la zona de estudio, posee una estructura económica diversificada, dentro de la cual las actividades primarias como la agricultura y ganadería son las que ejercen supremacía sobre las demás (Senisterra et al., 2014).

\subsection{Localización.}

La zona de estudio en que se trabajó es en la cuenca alta del arroyo Napaleofú, ubicada en el sudeste de la provincia de Buenos Aires, Argentina (Figura 1), considerada como un área experimental, debido a que desde la década de 1980 ha manifestado cambios en el uso del suelo por las transformaciones en la estructura productiva regional, derivadas de la adopción de capacidades tecnológicas de los productores agropecuarios. Esta transformación puede incidir en la dinámica hídrica superficial (Senisterra et al., 2014).

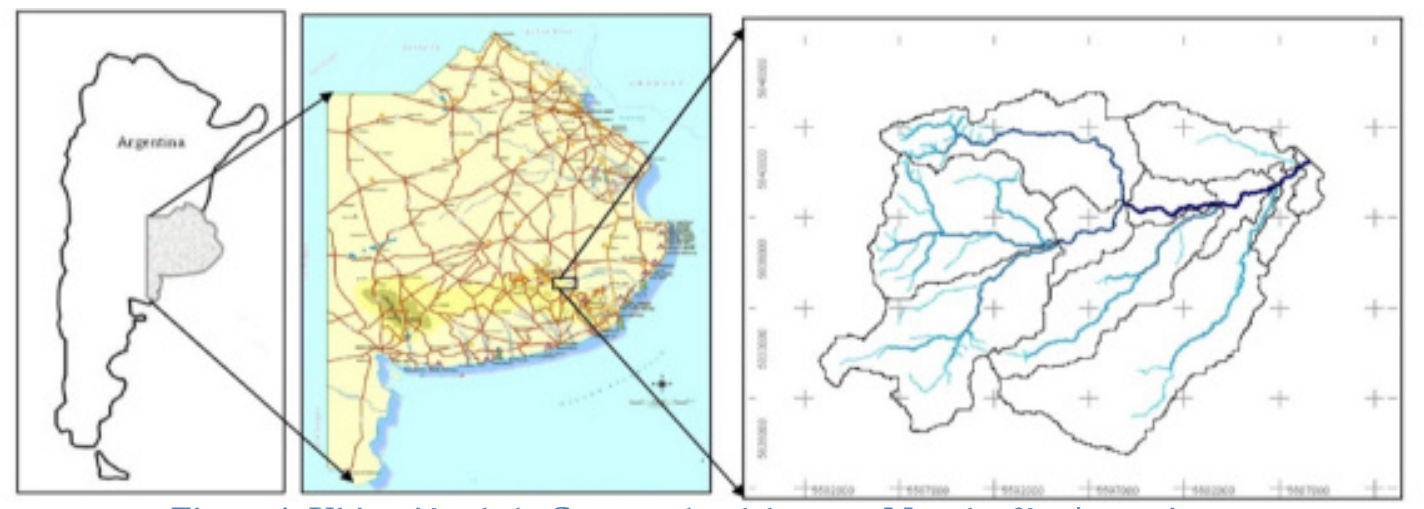

Figura 1. Ubicación de la Cuenca alta del arroyo Napaleofú - Argentina. Fuente: Senisterra et al., 2014.

\subsection{Economía.}

La producción agrícola está diversificada, según la extensión de las tierras, las características del suelo y la fluctuación de los mercados. Se practica la rotación de cultivos: trigo de invierno o primavera, avena para pastoreo, maíz para grano o forraje, girasol y papa. Esta zona está fuera del denominado proceso de sojización (sembrado exclusivo de soja). En la zona hay silos que permiten almacenar la producción de los cultivos de verano como reserva para el invierno o para suplementar las raciones alimenticias del ganado. De este modo, se logra aumentar el rendimiento promedio por hectárea. Los productores realizan 
el control químico de malezas y plagas con equipos terrestres o aéreos; también usan abonos y fertilizantes. Con respecto a las actividades pecuarias, se realiza la cría de vacas para tambos o producción de carne. La totalidad de lo producido es comercializado en el Mercado de Liniers o en los frigoríficos. Ha disminuido la cría de ovinos manteniéndose la misma sólo para consumo familiar. Los tambos varían de tamaño, desde los más grandes que cuentan con moderna tecnología hasta los más pequeños tienen un estricto control de calidad por parte de las empresas lácteas líderes en Argentina. También hay cabañas de empresas dedicadas a la producción de reproductores vacunos que comercializan sus animales en ferias o exposiciones rurales ${ }^{1}$.

En los últimos años se ha registrado una importante actividad forestal que ha ido modificando el típico paisaje de estepa de gramíneas sin árboles de la llanura pampeana. Fueron plantados bosques de eucaliptos y acacias, y desaparecieron los «pajonales» que dificultaban el arreo de ganado ${ }^{2}$.

\subsection{Clima.}

El clima manifiesta un régimen hídrico subhúmedo - húmedo. La precipitación media anual es de $850 \mathrm{~mm}$, siendo los meses más lluviosos de enero a marzo, y el trimestre más seco de junio a agosto. La temperatura media anual varía entre $8-13^{\circ} \mathrm{C}$. El período medio libre de heladas abarca desde octubre a mayo (Senisterra et al., 2014).

Según López de Sabando \& Arriaga (2015), en cultivos de trigo y cebada para la zona de Tandil y Necochea en el periodo 2014 - 2015, el balance hídrico fue positivo durante todo el ciclo para dichos cultivos. Las precipitaciones fueron frecuentes desde la siembra hasta mediados de noviembre. Las temperaturas fueron mayores al promedio histórico (datos no presentados) produciendo un adelanto del desarrollo del cultivo y en consecuencia menor crecimiento acumulado.

\subsection{Suelos.}

Senisterra et al. (2014) menciona que litológicamente, la cuenca en estudio se desarrolla sobre las sierras del Sistema de Tandilia, formado por un zócalo de basamento cristalino (edad precámbrica), que presenta, desde el punto de vista hidrogeológico, un comportamiento acuífugo y una cubierta o cobertura sedimentaria (edad paleozoica

\footnotetext{
${ }^{1}$ Escuela de Enseñanza Media № 1 Napaleofú Provincia de Buenos Aires. «El trabajo en Napaleofú hoy». Consultado el 6 de abril de 2009. http://es.wikipedia.org/wiki/Napaleof\%C3\%BA. Consulta 15/04/2014.

${ }^{2}$ IBIDEM
} 
inferior) que, en algunos sectores, da origen a acuíferos fisurados. Sobre éstos se depositaron sedimentitas cuaternarias (Pleistoceno y Holoceno). De acuerdo con la Carta de Línea de Base Ambiental 3760-IV, Tandil (Tchilinguirian et al., 2004), se definen en el área de estudio, dos grandes unidades geológicas-geotectónicas: rocas metamórficas y plutónoicas y sedimentos cuaternarios (loessicos y aluviales). Se han desarrollado predominantemente, suelos Argiudoles y Hapludoles (INTA, 1989).

\subsection{Morfometría.}

El área de estudio en la cual se abordó la problemática fue el límite de la cuenca alta del arroyo Napaleofú, cuya superficie total de la cuenca es de $347,73 \mathrm{~km}^{2}$ (Senisterra et al., 2014).

Senisterra et al. (2014) describe la parte alta de la cuenca cuenta con cotas superiores a los $350 \mathrm{msnm}$ (metros sobre el nivel del mar) y el cierre de la cuenca es a los $139 \mathrm{msnm}$. Al aumentar la pendiente media y el desnivel de la cuenca, mayor será la posibilidad de generar crecidas (Gaspari et al., 2009). La cuenca posee variaciones mínimas de pendiente, contribuyendo a que los picos de crecidas sean menos violentos.

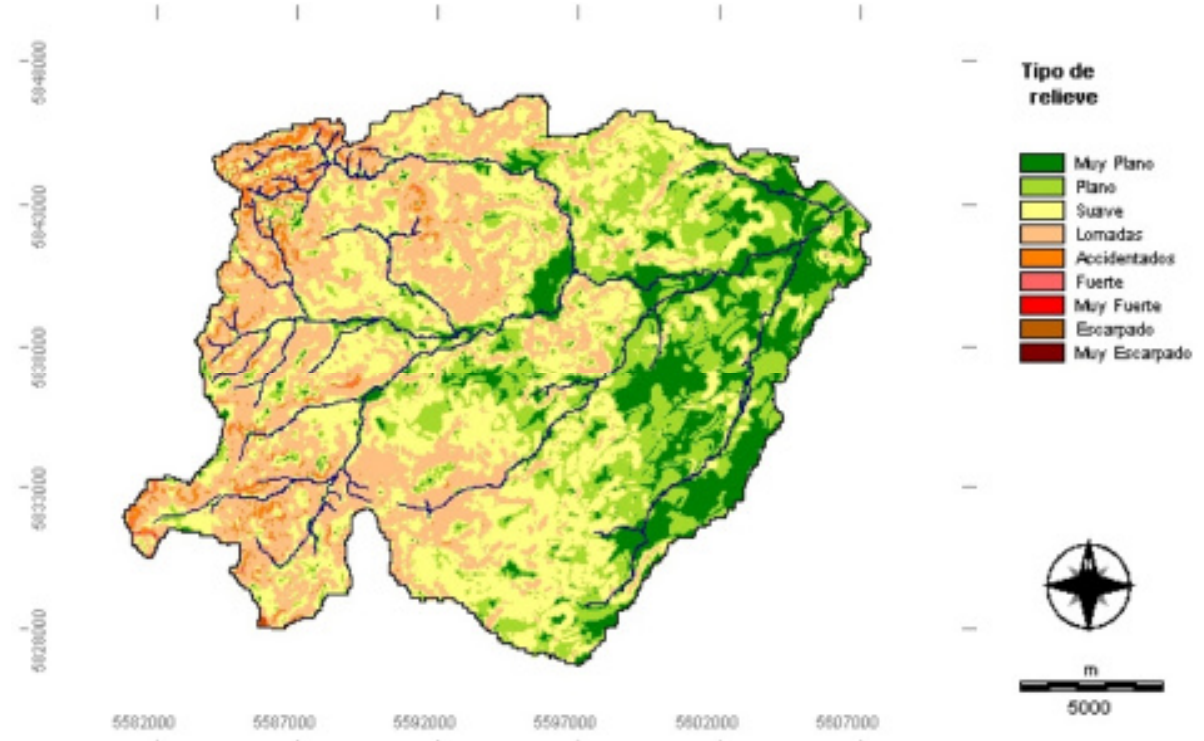

Figura 2. Tipo de relieves presentes en la cuenca alta del arroyo Napaleofú. Fuente: Senisterra et al., 2014.

Los relieves (Figura 2) provienen del procesamiento de un modelo digital de elevación (MDE) y reclasificación según López Cadenas de Llano (1998), cuyos porcentajes de ocupación en la cuenca son: $13,1 \%$ muy plano, 21,3\% plano, 34,9\% suave, 28,1\% lomadas, 2,3\% accidentado, $0,27 \%$ fuerte, $0,01 \%$ muy fuerte, $0,03 \%$ escarpado y $0,01 \%$ muy escarpado (Senisterra et al., 2014). 
El número de orden de los cursos de agua o jerarquización, está estrechamente relacionado con el número de ramificaciones de la red de drenaje, siendo para la cuenca en estudio el número máximo de orden tres (Figura 3). Gaspari et al. (2009) mencionan que a mayor número de orden, mayor será el potencial erosivo, mayor el transporte de sedimentos y mayor el escurrimiento directo que en otra cuenca de similar área. Para el caso en estudio el número de orden tres refleja una cuenca con un nivel erosivo bajo (Senisterra et al., 2014).

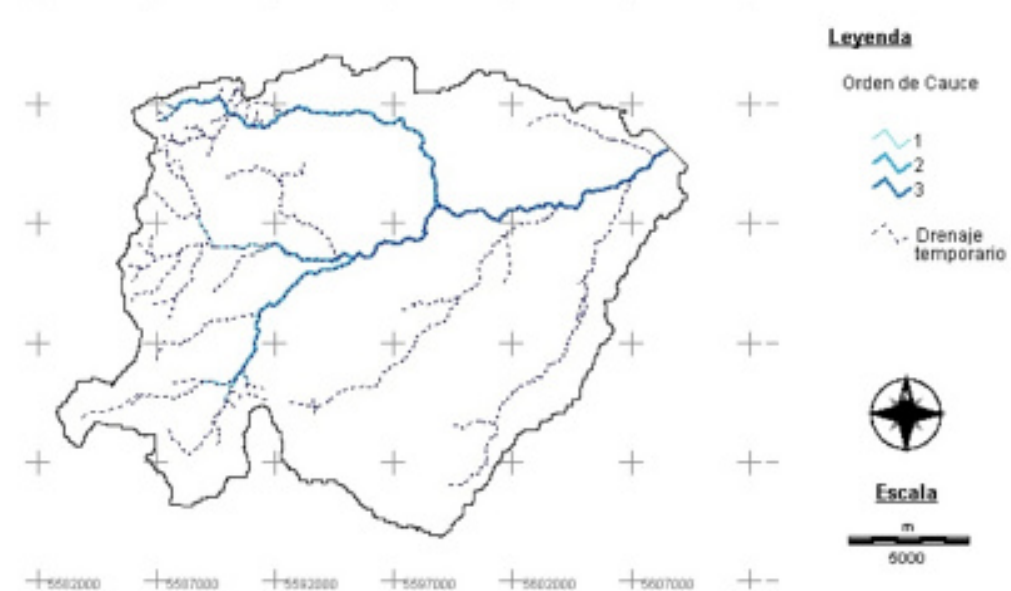

Figura 3. Jerarquización de la red de drenaje según Stralher (1964). Fuente: Senisterra et al., 2014.

Es conocido, que la escorrentía se ve afectada por la densidad de drenaje, en zonas con alta densidad de drenaje la escorrentía rápidamente circula por la superficie, disminuyendo el tiempo de concentración e incrementando el caudal pico (Gaspari et al., 2009).

La morfometría definida permitió inferir que la cuenca se encuentra en una zona de bajo relieve, en equilibrio dinámico del sistema según las características de relieve y geomorfológicas (Senisterra et al., 2014).

\subsection{Marcos y sistemas de referencia de la información.}

Un sistema de referencia es una terna de ejes cartesianos ortogonales X Y Z, cuyo origen 0 se encuentra ubicado en la intersección de los ejes, por ejemplo un sistema de referencia geocéntrico tiene su centro geométrico en el medio del elipsoide de representación matemática de la Tierra. Las coordenadas X e Y cartesiana ortogonal se encuentran en un Sistema de Referencia y coordenadas cartesiana x e y planas se encuentran en un Sistema de Representación Cartográfica (Ramos, 2003).

La información base para el desarrollo del trabajo se encuentra en coordenadas geográficas WGS-84. El acrónimo WGS-84 deviene de World Geodetic System 1984 (Sistema geodésico mundial 1984). Se trata de un sistema de referencia creado por la Agencia de Mapeo del 
Departamento de Defensa de los Estados Unidos de América (DMA) para sustentar la cartografía producida en dicha institución y las operaciones del Departamento de Defensa (DoD) (IGN, 1999).

La información necesaria para el desarrollo de los procesos para el presente trabajo, como lo son datos tomados en campo, proveniente de la producción agrícola junto con los puntos de control o muestreo con radiómetro de la zona de estudio, fueron recolectados mediante Sistema de Posicionamiento Global (GPS por sus siglas en inglés) con sistema de coordenadas geográficas WGS 84.

Las imágenes satelitales SPOT y Landsat utilizadas en el presente trabajo están referidas a la proyección cartográfica U.T.M. (proyección Mercator Transversa Universal) georreferenciada a WGS84, cuya referenciación viene por defecto de la fuente de descarga online de dicha información raster.

Debido a que la región donde se ubica la zona de estudio es la provincia de Buenos Aires la información base se proyectó al sistema POSGAR (POSiciones Geodésicas Argentinas). Para la mayoría de las aplicaciones prácticas (catastro, levantamientos topográficos, etc.), los usuarios utilizan el marco de referencia POSGAR 94, declarado estándar nacional por el IGM a comienzos de 1997. Las diferencias entre las coordenadas geocéntricas POSGAR 94 y 98 se mantienen por debajo de 1.5 metros en las tres componentes, lo cual no produce efectos apreciables sobre la cartografía hasta la escala 1:5000. La precisión interna de POSGAR 98 es varias veces superior a la de POSGAR 94, particularmente para la componente vertical. Recientemente el Subcomité de Geodesia del Comité Nacional de la Unión Geodésica y Geofísica Internacional ha recomendado el uso del nuevo marco de referencia POSGAR 98 para las aplicaciones geodésicas de alta precisión (Brunini, 2002).

La información se trabajó en coordenadas planas Gauss-Krüger referidas a POSGAR 98, la cual está definida como conforme, cilíndrica y transversa. Conforme por lo expresado previamente, cilíndrica pues se trata de una transferencia analítica del terreno a un cilindro tangente al elipsoide de referencia. La tangencia al producirse sobre un meridiano le imprime la condición de transversa o transversal (IGN, 1999). En la cual para Argentina se establecieron 7 fajas de tres grados de ancho cada una. La zona de estudio corresponde a la faja número 5 . 


\section{OBJETIVOS}

\subsection{General}

- Desarrollar de una herramienta para predecir la productividad agrícola mediante NDVI que aporte al ordenamiento territorial de la cuenca hidrográfica del arroyo Napaleofú.

\subsection{Específicos}

- Procesar información geográfica y satelital para definir parcelas representativas.

- Obtener el NDVI mediante la utilización de imágenes satelitales.

- Capturar y validar información de firmas espectrales en campo con radiómetro sobre los cultivos en estudio y obtener valores puntuales de NDVI.

- Relacionar parámetros morfométricos con NDVI para la cuenca hidrográfica.

- Establecer la relación entre el rendimiento agrícola y NDVI.

- Formular modelos de regresión clásicos y espaciales para la predicción de rendimiento de cultivos de cebada y trigo a partir de NDVI. 


\section{MATERIALES Y MÉTODOS}

\subsection{Identificación y definición de los límites de las parcelas de estudio.}

\subsubsection{Procesamiento de imágenes satelitales.}

Una forma versátil para poder analizar el territorio y abarcar grandes extensiones de superficie es la utilización y procesamiento de imágenes provenientes de sensores remotos en plataformas satelitales. En el presente trabajo se procesaron y utilizaron imágenes satelitales provenientes de los programas satelitales Spot y Landsat.

Las imágenes satelitales del sensor Spot fueron suministradas mediante un convenio entre la Universidad Nacional de La Plata (UNLP) y la Comisión Nacional de Actividades Espaciales (CONAE). Las imágenes pertenecen al programa Spot 5, siendo estas pancromáticas y multiespectrales con una resolución espacial de 5 y 10 metros respectivamente y un nivel de procesamiento y precisión de localización 2A (Corrección radiométrica de las distorsiones y corrección geométrica dentro de la proyección estándar UTM WGS84 sin puntos de apoyo) (Martínez Muñoz y Díaz Ponce., 2005). Las anteriores características de dicho sensor se especifican en el Anexo 1. A continuación en la Tabla 1 se listan las imágenes de este sensor utilizadas en el estudio.

Tabla 1. Imágenes satelitales Spot 5 disponibles que coinciden con las visitas a campo.

\begin{tabular}{ccclcc} 
Sensor & Fecha & $\begin{array}{c}\text { Resolución } \\
\text { espacial }\end{array}$ & Modo espectral & K-J & $\begin{array}{c}\text { Tipo de } \\
\text { producto }^{3}\end{array}$ \\
\hline \hline & 16-Sep-2014 & $5 \mathrm{~m}$ & Pancromática & $699-426$ & $\mathrm{~A}$ \\
& $8-$-Oct-2014 & $5 \mathrm{~m}$ & Pancromática & $699-425$ & $\mathrm{~A}$ \\
& $8-$ Oct-2014 & $10 \mathrm{~m}$ & Multiespectral & $699-425$ & $\mathrm{~J}$ \\
\multirow{3}{*}{ Spot5 } & 8 -Oct-2014 & $5 \mathrm{~m}$ & Pancromática & $699-426$ & $\mathrm{~A}$ \\
& 8-Oct-2014 & $10 \mathrm{~m}$ & Multiespectral & $699-426$ & $\mathrm{~J}$ \\
& 17-Oct-2014 & $5 \mathrm{~m}$ & Pancromática & $699-426$ & $\mathrm{~A}$ \\
& 17-Oct-2014 & $10 \mathrm{~m}$ & Multiespectral & $699-426$ & $\mathrm{~J}$ \\
& 22-Nov-2014 & $10 \mathrm{~m}$ & Multiespectral & $699-425$ & $\mathrm{~J}$ \\
\hline
\end{tabular}

Las imágenes se solicitaron de acuerdo a la cercanía cronológica con las visitas a campo, con eso se pudo identificar claramente los elementos en la imagen una vez se observó la realidad del terreno en las visitas. De igual forma las imágenes pancromáticas, gracias a su resolución espacial de 5 metros, contribuyeron a delimitar precisamente los linderos de las parcelas a utilizar en el proceso.

\footnotetext{
${ }^{3} \mathrm{M}: 10 \mathrm{~m}$ pancromática (SPOT4), J: $10 \mathrm{~m}$ multiespectral (SPOT5), A o B: $5 \mathrm{~m}$ pancromática, T: 2,5 m pancromática.
} 
Respecto a las imágenes Landsat utilizadas, las cuales fueron un insumo importante en el estudio debió a su resolución temporal y radiométrica, aunque su resolución espacial (30m) sea menor a las Spot. Las imágenes se obtuvieron del servidor del Servicio Geológico de los Estados Unidos (USGS en sus siglas en inglés) mediante la aplicación EarthExplorer ${ }^{4}$. En dicha aplicación se asignaron las coordenadas geográficas del centroide de la zona de estudio (cuenca hidrográfica) y se buscaron las imágenes del sensor Landsat 8 OLI/TIRS 5 pertenecientes a este lugar, teniendo en cuenta que un porcentaje de nubes mínimo (5\%) y existencia de una imagen por mes como a partir de julio hasta diciembre de 2014, con el fin de llevar el seguimiento y análisis temporal de los cultivos sembrados en el segundo semestre del año en la estancia La Esperanza.

Una vez seleccionadas las imágenes se descargaron en formato comprimido, las cuales poseen 11 bandas en formato Tiff. Las características que poseen las imágenes son de tipo de sensor combinado OLI/TIRS siendo un producto de nivel 1 Terrain (L1T) los cuales poseen correcciones geométricas aplicadas, con proyección cartográfica georreferenciada a WGS84, junto con correcciones topográficas debido al desplazamiento del terreno, dichas especificaciones se muestra detalladamente en el Anexo 1.

Gracias a que Landsat 8 posee una óptima resolución radiométrica se pudo calcular y obtener los índices de vegetación que permitieron desarrollar los procesos previstos en el trabajo. Dichas imágenes contienen una serie cuantificada, calibrada y escalada de niveles digitales ND, los cuales representan los datos de una imagen multiespectral adquirida por ambos sensores: OLI y TIRS (Ariza, 2013).

Ariza (2013) menciona que los datos de las bandas del sensor TIRS y OLI están derivados en 16 bits en formato no cifrado y pueden ser reescalados a los valores de reflectancia y o radiancia en el techo de la atmósfera TOA, usando para ello los coeficientes radiométricos provistos en el archivo de metadato MTL.txt, tal y como se describe en la Ecuación 1.

$$
L_{\lambda}=M_{L} Q_{c a l}+A_{L}
$$

Ecuación 1. Corrección de radiancia en el TOA.

Dónde:

\footnotetext{
${ }^{4}$ La aplicaciones encuentra en la dirección web http://earthexplorer.usgs.gov/

${ }^{5}$ Sensores de observación del programa satelital Landsat 8 denominados OLI (Operational Land Imager) y TIRS (Thermal Infrared Sensor).
} 
$\mathrm{L} \lambda=$ Es el valor de radiancia espectral en el techo de la atmósfera (TOA) medida en valores de (Watts $/ \mathrm{m} 2 * \operatorname{srad} * \mu \mathrm{m}))$.

$\mathrm{ML}=$ Banda - Es el factor multiplicativo de escalado especifico obtenido del metadato

(RADIANCE_MULT_BAND_x, donde x es el número de la banda).

$\mathrm{AL}=$ Banda - Es el factor aditivo de escalado especifico obtenido del metadato

(RADIANCE_ADD_BAND_x, donde x es el número de la banda).

Q cal = Producto estándar cuantificado y calibrado por valores de pixel (DN). Este valor se refiere a cada una de las bandas de la imagen.

Existen varios software geográficos que permiten realizar de forma automática dicha corrección radiométrica por cada banda de la imagen. Uno de ellos es QGIS®, el cual posee un módulo específico llamado Semi-Automatic Classification (Figura 4) para realizar este proceso, con el cual se llevó a cabo la corrección y procesamiento respectivo de las imágenes satelitales como se detalla en la documentación de dicha herramienta realizada por Congedo (2015). En dicho modulo se incorporaron los archivos de las bandas de cada imagen a corregir junto con su archivo de metadatos MTL correspondiente en el cual se almacenan información propia del sensor al momento de la toma de la imagen como la fecha, elevación del sol, distancia tierra sol y otros necesarios para ejecutar la conversión.

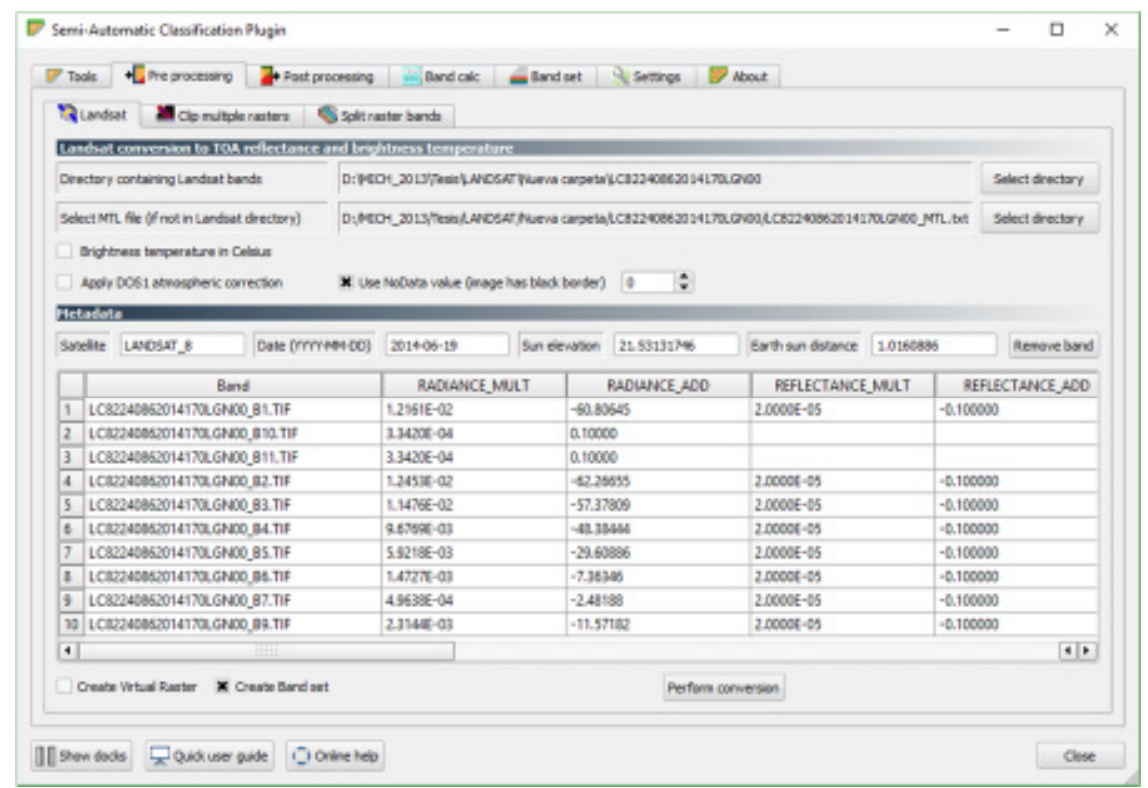

Figura 4. Conversión de Bandas Landsat 8 a valores de reflectancia en el techo de la atmósfera TOA en QGIS®.

Fuente: elaboración propia.

Las imágenes satelitales del sensor Spot 5 mencionadas en la Tabla 1 no se les realizo correcciones o procesamientos diferentes al de combinación de bandas para la mejor visualización de la zona de estudio y apoyo para la digitalización de las parcelas. La 
combinación utilizada fue la correspondiente a falso color, en la cual intervienen las bandas infrarrojo, rojo y verde (4, 3 y 2) en los cañones RGB respectivamente, la cual contribuye a diferencia con mayor facilidad la cobertura vegetal, para este caso los cultivos de estudio contenidos en las parcelas.

\subsubsection{Identificación y definición de los límites de las parcelas de estudio}

El proceso de digitalización depende de las fuentes de información disponibles. Existen dos grandes tipos de fuentes de datos: un primer tipo, el registro de datos de campo, y por otro lado, el uso de formatos analógicos, fotografías aéreas, y documentos numéricos que recogen información temática, de manera que los registros se puedan representar espacialmente (Keith, 2000) .

La digitalización se realizó en software geográficos QGIS® 2.14 .0 y $\operatorname{ArcGIS}{ }^{\circledR} \quad 10.0$ (licencia estudiantil de la cátedra de manejo de cuencas de la facultad de agronomía de la UNLP). La información se generó en formato *.shp (shapefile).

Se generó información vectorial adicional o temática, como lo son las parcelas al interior de la estancia La Esperanza las cuales están relacionadas a la información de rendimiento agrícola, respecto a las imágenes satelitales o información cartográfica de otras fuentes, que permitió complementar los análisis geográficos necesarios en el proceso de la investigación.

Inicialmente se localizó al interior de la cuenca la estancia La Esperanza, de la cual se obtuvieron los datos iniciales necesarios para el estudio, como se observa en la Figura 5. Para esto se utilizó como guía información vectorial topográfica base y catastral de la estancia La Esperanza suministrada por el productor, la cual al estar en formato CAD se transformó a formato shp y se le asigno coordenadas geográficas WGS84, siendo este el sistema original de dicha información levantada en campo (Figura 6). Con la información georreferenciada se localizó el catastro de parcelas al interior de la cuenca. 


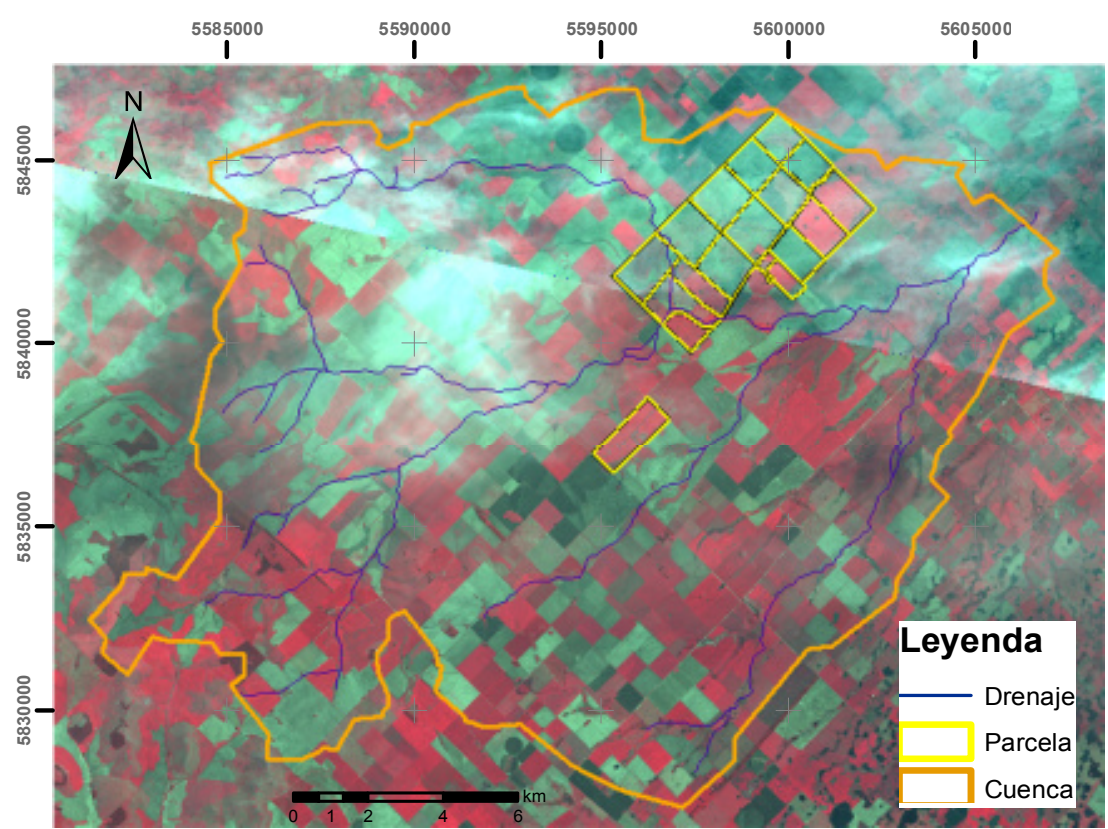

Figura 5. Localización de los cultivos de la estancia La Esperanza en la cuenca hidrográfica.

Fuente: elaboración propia a partir de Senisterra (2014)

Imagen base: Spot multiespectral 16-Sep-2014 y 8-Oct-2014

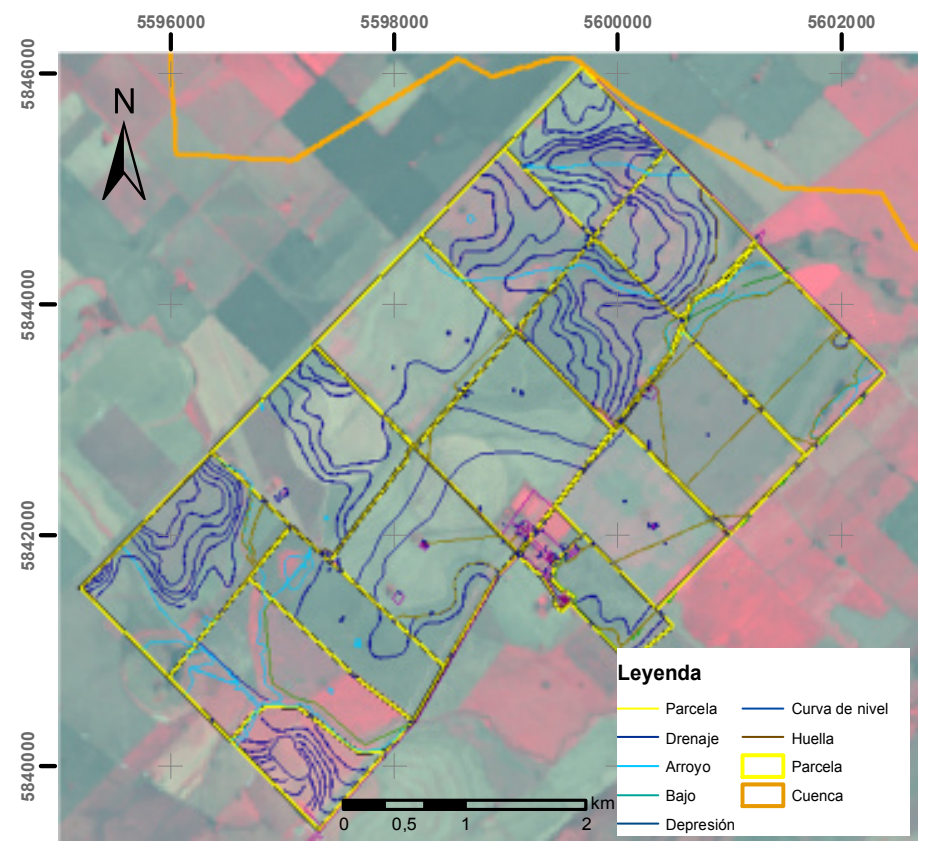

Figura 6. Información Vectorial inicial suministrada por el productor.

Fuente: elaboración propia.

Imagen base: Landsat 22-Nov-2014

Esta información sirvió como guía y referencia para la digitalización de las parcelas y para localización de los lugares en donde se tomaron los puntos de muestreo con el espectro radiómetro sobre los cultivos y para la contextualización de los mismos en el sistema productivo de la estación y en la cuenca hidrográfica. Posteriormente, utilizando e interpretando las imágenes satelitales de los sensores Landsat 8 y Spot 5 para la zona en cuestión, se procedió a realizar dicha digitalización, dándole prioridad para esta tarea la referencia brindada por las imágenes Spot ya que su mayor resolución espacial permitió 
definir con más detalle los límites de las parcelas, no obstante también se basó en las características espaciales observadas en las imágenes Landsat, como se observa en la Figura 7.
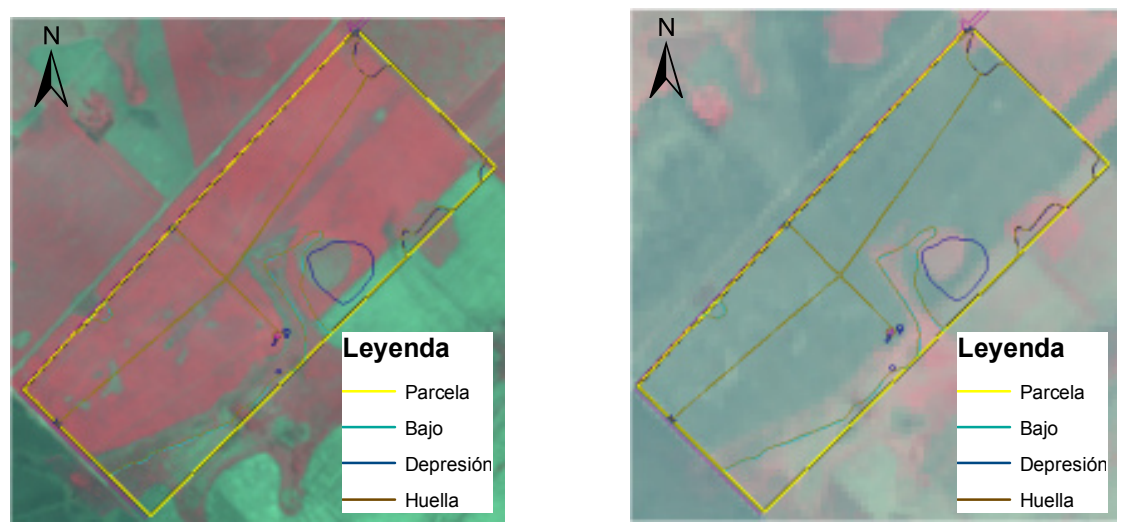

Figura 7. Imagen Spot 5 (resolución espacial $10 \mathrm{~m}$ ) a izquierda y Landsat 8 (resolución espacial 30 m) a derecha.

Fuente: elaboración propia. Imagen base: Spot 8-Oct-2014 - Landsat 22-Nov-2014.

En la Figura 7 se identifica la localización de la información vectorial de referencia, la cual se encontraba desplazada. Por este motivo dicha vectorización solo fue utilizada como referencia en la delimitación de las parcelas y se digitalizo los límites de las mismas con respecto a los detalles geográficos encontrados en las imágenes satelitales.

Con asesoría del productor de la estancia se seleccionaron las parcelas que intervendrán en los procesos, las cuales poseen información suficiente para objetivo planteado y sus cultivos se encontraban en el estadio apropiado para las mediciones de campo y seguimiento temporal con las imágenes de satélite. Una vez identificadas las zonas de estudio en las imágenes se procedió a hacer la digitalización de las parcelas, las cuales en su mayoría siguen la misma forma del catastro del cultivo que administra el productor.

Se realizaron 2 etapas de digitalización, la primera se basó en la información suministrada por el productor y por las imágenes de satélite previas a la fecha de recorrido de campo para la captura de firmas espectrales de los cultivos, esta digitalización plasmo la ubicación en campo de la zona de estudio y permitió la contextualización de las parcelas al interior de la estancia y de la cuenca hidrográfica; la segunda etapa consto en el refinamiento de la primera digitalización, ya que se realizaron algunos ajustes posteriores basados en lo observado en los viajes de campo a la estancia, para la recolección de información con el radiómetro. 


\section{2 Índice de vegetación.}

Se define índice de vegetación (IV) a un parámetro calculado a partir de los valores de la reflectividad a distintas longitudes de onda y que pretende extraer de los mismos la información relacionada con la vegetación minimizando la influencia de perturbaciones como las debidas al suelo y a las condiciones atmosféricas (Gilabert et al., 1997).

El índice de vegetación ideal ha sido descrito por Jackson et al. (1983) como "aquél particularmente sensible a la cubierta vegetal, insensible al brillo y color del suelo y poco afectado por la perturbación atmosférica, los factores medioambientales y las geometrías de la iluminación y de la observación"(Gilabert et al., 1997).

Los cultivos, en cada uno de sus estadios particulares de crecimiento, reflejan una cantidad de luz diferente, ya que la planta absorbe y refleja la luz solar dependiendo a sus necesidades de crecimiento. La reflectancia es la fracción de energía reflejada por un objeto posteriormente a la incidencia de la misma en la superficie (Verhulst et al., 2010). La vegetación es única en su partición en la parte visible del espectro (400-700nm), la reflectancia es baja, la transmitancia cercana a cero y la absorción alta, la principal causa de las interacciones energía-materia en esta parte del espectro son los pigmentos de la vegetación. En las longitudes de onda largas del infrarrojo cercano (700-1350) el espectro de la vegetación está caracterizado por la transmisión. El pigmento dominante en las plantas es la Clorofila. Este tiene una pronunciada absorción en las longitudes de onda de los azules (400-500 nm) y de los rojos (600-700 nm), esta absorción es requerida para realizar el proceso de fotosíntesis (Gráfico 1). Como se mencionó anteriormente la transmitancia de la vegetación en el rango visible es muy baja, la irradiancia que no es absorbida es reflejada, entonces el contenido de clorofila en la vegetación aparece verde como resultado de una menor reflectancia en el pico de los 500-600nm. (Mehl, H. Peinado, O.) (Perona, 2016). 


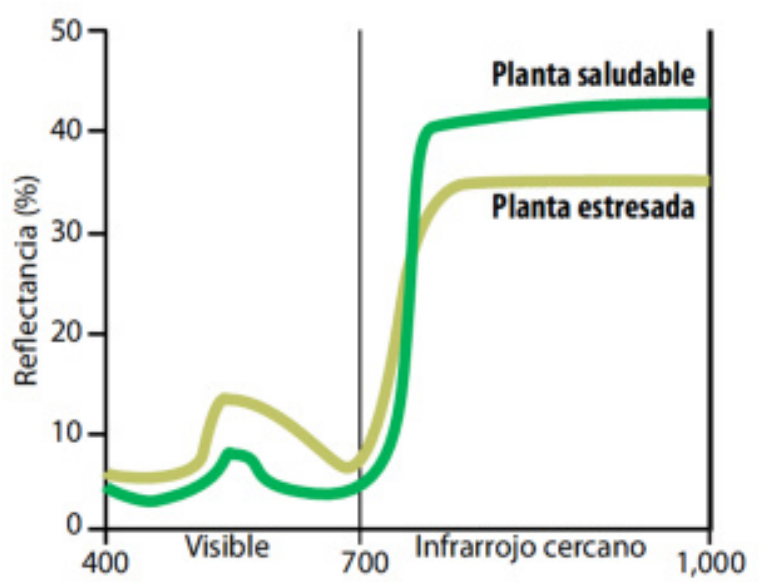

Gráfico 1. Espectro típico de reflectancia de una planta saludable y otra en condiciones de estrés. Fuente: Verhulst et al., 2010.

La absorción de radiación solar de las plantas es realizada mediante interacciones moleculares al interior de los componentes vegetales, donde dicho proceso es administrado por enlaces químicos y estructurales. La absorción en las hojas, en el visible, es esencialmente, una función de los cambios en los estados de los electrones en moléculas particulares (las clorofilas a y b, los carotenos, los pigmentos marrones o taninos y otros pigmentos accesorios). En el infrarrojo cercano y medio se debe a variaciones en los modos vibro-rotacionales dentro de moléculas poliatómicas. Las propiedades ópticas de las plantas no solo son función de la concentración de pigmentos, sino también de su estructura interna. Así las propiedades ópticas de los tejidos individuales de las hojas determinan cuanta luz es transmitida, absorbida o reflejada por la planta. (Weber et al., 2008).

Estas características anatómicas son afectadas por factores medioambientales como la humedad del suelo, la cantidad disponible de nutrientes, la salinidad y la etapa foliar en que se encuentra la planta (Ma et al., 2001). El máximo contraste de reflectancia entre la vegetación y el suelo ocurre en la región del rojo y del infrarrojo cercano. Por tanto, los datos de reflectancia espectral pueden utilizarse para computar una gama de índices de vegetación, los cuales están correlacionados con características agronómicas y biofísicas de la planta, así como asociados con la actividad fotosintética y productividad de la planta (Ma et al., 2001)( Verhulst et al., 2010).

Analizando las respuestas obtenidas de las firmas espectrales de los cultivos se pudo observar en qué estado se encontraban y cómo se relacionan con su futura producción, realizando seguimiento de crecimiento de los cultivos y comparando con imágenes de sensores remotos. 


\subsection{1 Índice de Vegetación de Diferencia Normalizada (NDVI).}

El NDVI logra representar la actividad fotosintética de la planta, ya que este índice de vegetación incluye tanto el rango del infrarrojo cercano como la luz roja. La actividad fotosintética de las plantas es determinada por el contenido y la actividad de la clorofila (Verhulst, et al., 2010).

El NDVI se calculó a partir de las mediciones de la reflectancia en el rango rojo e infrarrojo cercano (NIR, por sus siglas en inglés) del espectro (Ecuación 2).

$$
\text { NDVI }=(\text { RNIR }- \text { R Red }) /(\text { RNIR }+ \text { R Red })
$$

Ecuación 2. Cálculo del índice de vegetación NDVI.

Donde R NIR es la reflectancia de la radiación NIR y $\mathrm{R}$ Red es la reflectancia de la radiación del rojo visible.

El NDVI ha sido correlacionado con numerosas variables como: la deficiencia de nutrientes en los cultivos, el rendimiento y el estrés abiótico de las plantas. Sin embargo, más que reflejar el efecto de un solo parámetro, el NDVI tiene que ser considerado como una medida del crecimiento integral de la planta, incluyendo factores que intervienen en dicho crecimiento. Es probable que las características físicas detectadas por medio del índice estén relacionadas con propiedades que determinan la densidad del follaje (por ejemplo, la superficie foliar o el porcentaje de cobertura) o con la biomasa total. La variabilidad de un índice no está relacionada con una sola característica de la planta o del suelo, por lo cual es necesario tener una idea del factor limitante de crecimiento del cultivo (Verhulst, et al., 2010).

Existen diferentes índices de vegetación. No obstante, aquellos cuya fuente principal sean la reflectancia del rojo visible e infrarrojo cercano producirán información similar a la del NDVI. Una de las razones de la amplia aceptación del NDVI es que muchos sensores (desde portátiles hasta satelitales) hacen mediciones en el rango espectral de luz roja e infrarrojo cercano (Verhulst et al., 2010).

La obtención de índices NDVI para el presente trabajo se realizó por medio de cálculos a nivel de pixeles de las bandas de las imágenes satelitales corregidas atmosféricamente, específicamente la banda 4 perteneciente al rojo y la banda 5 al infrarrojo cercano perteneciente al sensor OLI de Landsat 8, siguiendo la formula descrita en la Ecuación 2. 
Este proceso se ejecutó automáticamente en el software QGIS® con el modulo Calculadora raster (Figura 8), donde se incorporó la fórmula del índice junto con las bandas correspondientes. Se generó una imagen raster con los valores de NDVI para cada mes de estudio.

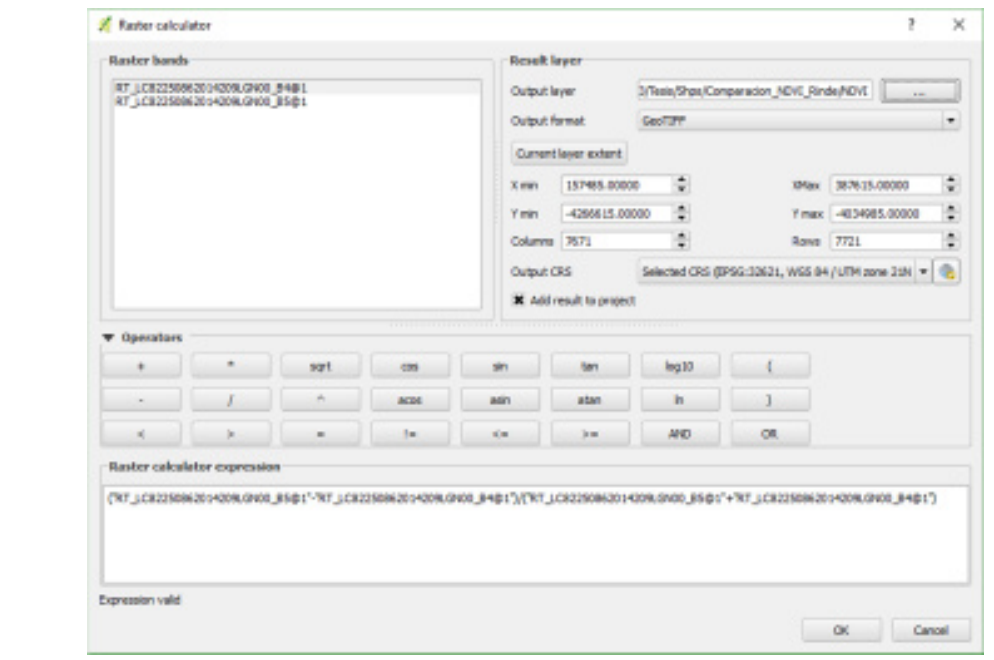

Figura 8. Cálculo del índice de vegetación NDVI por medio de QGIS®.

Fuente: elaboración propia.

Los raster resultantes fueron las imágenes de entrada para realizar la comparación con el rendimiento. Puesto que cada escena de las imágenes de Landsat 8 posee dimensiones de 170 por 185 kilómetros se efectuó un recorte de la zona de interés, específicamente sobre las parcelas digitalizadas, ayudando a agilizar el procesamiento de la información y focalizándose en los datos contenidos al interior de los polígonos digitalizados. En la Figura 9 se muestra la extracción de la información por medio de las máscaras de las parcelas y su localización en las subcuencas.

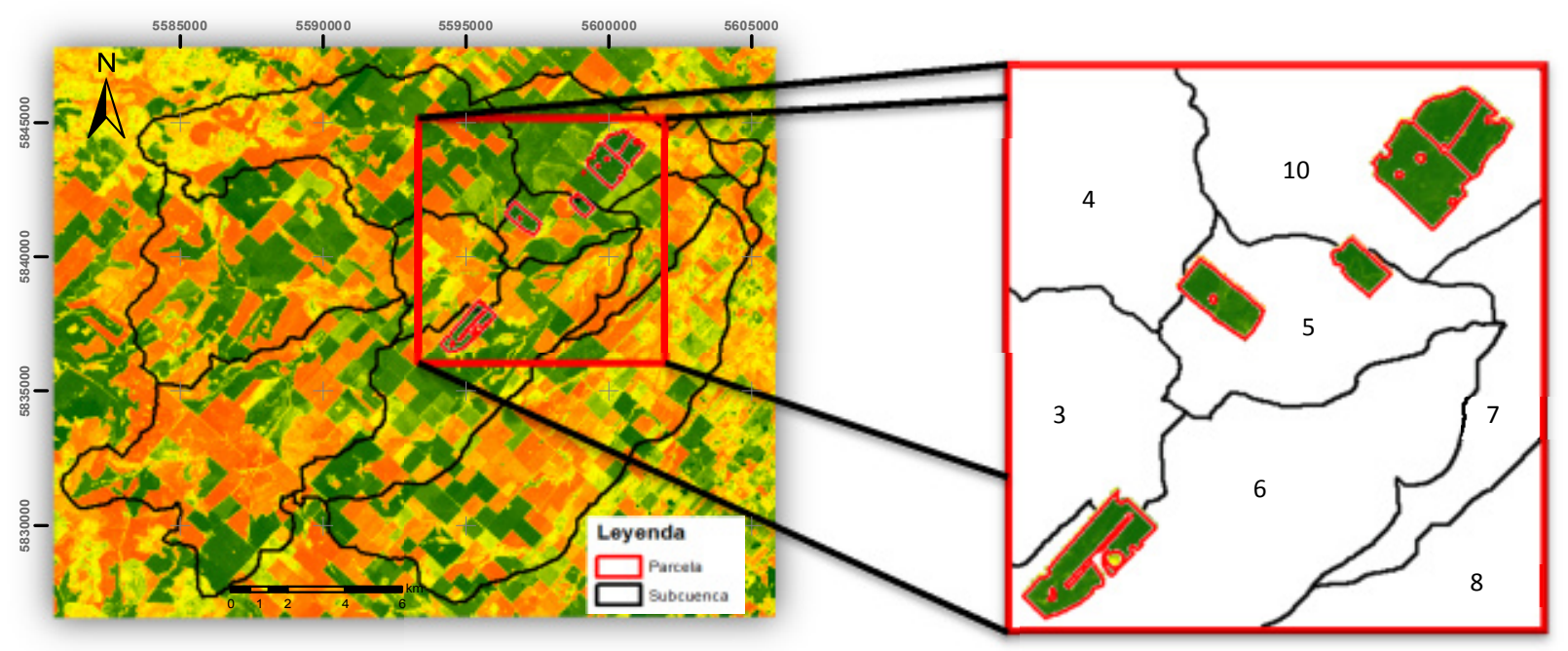

Figura 9. Extracción de valores NDVI con respecto a los polígonos de las parcelas. Nota: La numeración corresponde al identificador de las subcuencas en la zona de estudio Fuente: elaboración propia.

Imagen base: Valores NDVI provenientes de la imagen Landsat 22-Nov-2014 


\subsubsection{Captura de datos radiométricos en campo.}

Con el propósito de validar la información contenida en las imágenes satelitales Landsat 8, al igual que observar y conocer la realidad del contexto en el cual están inmersas las parcelas, se realizaron 2 viajes a campo para recorrer la zona de estudio y tomar datos con un radiómetro Ocean Optics USB 2000 con rango espectral de 300-1000 nm y resolución de $1 \mathrm{~nm}, \mathrm{FOV}^{6} 25^{\circ}$, suministrado por la Facultad de Ciencias Agrarias y Forestales de la Universidad de Nacional La Plata.

Los viajes se programaron: el primero el 21 de octubre y el segundo el 14 el noviembre del 2014. Consultando el pronóstico meteorológico, donde se evaluó que las variables climáticas (especialmente nubosidad) para esas fechas fueran favorables para la toma de datos con el radiómetro, debido a que este instrumento es un ser un sensor pasivo y requiere de una adecuada exposición a la radiación solar, tanto directa al sensor como reflejada sobre la cobertura del suelo. Estas fechas además coinciden con los estadios fenológicos del cultivo en los que los mismos se encuentran alrededor de su máximo índice de área foliar, razón por la cual es menor la incidencia del suelo en las mediciones.

Cada viaje de campo se planificó para que coincidieran aproximadamente con los días en que se dispusiera de una imagen de satélite, para así poder comparar y validar de forma más precisa la información obtenida desde las imágenes satelitales, al igual que observar la evolución y los diferentes estadios fenológicos de los cultivos a lo largo del estudio (véase Figura 14).

Para la georreferenciación de los sitios de muestreo se utilizó el software Cyber'Tracker@, el cual es una aplicación para smartphone con sistema operativo Android. Dicha aplicación permitió diseñar un formulario con el cual se registró la información alfanumérica y espacial de cada punto de muestreo, como lo son la identificación del punto, tipo de cultivo, fecha y hora de la toma de datos, fotografía del cultivo, observaciones respecto al estado del cultivo, etc. Asociándoles coordenadas geográficas en el sistema de referencia WGS84 (Figura 10).

\footnotetext{
${ }^{6}$ Siglas en ingles de Field Of View (campo de visión)
} 


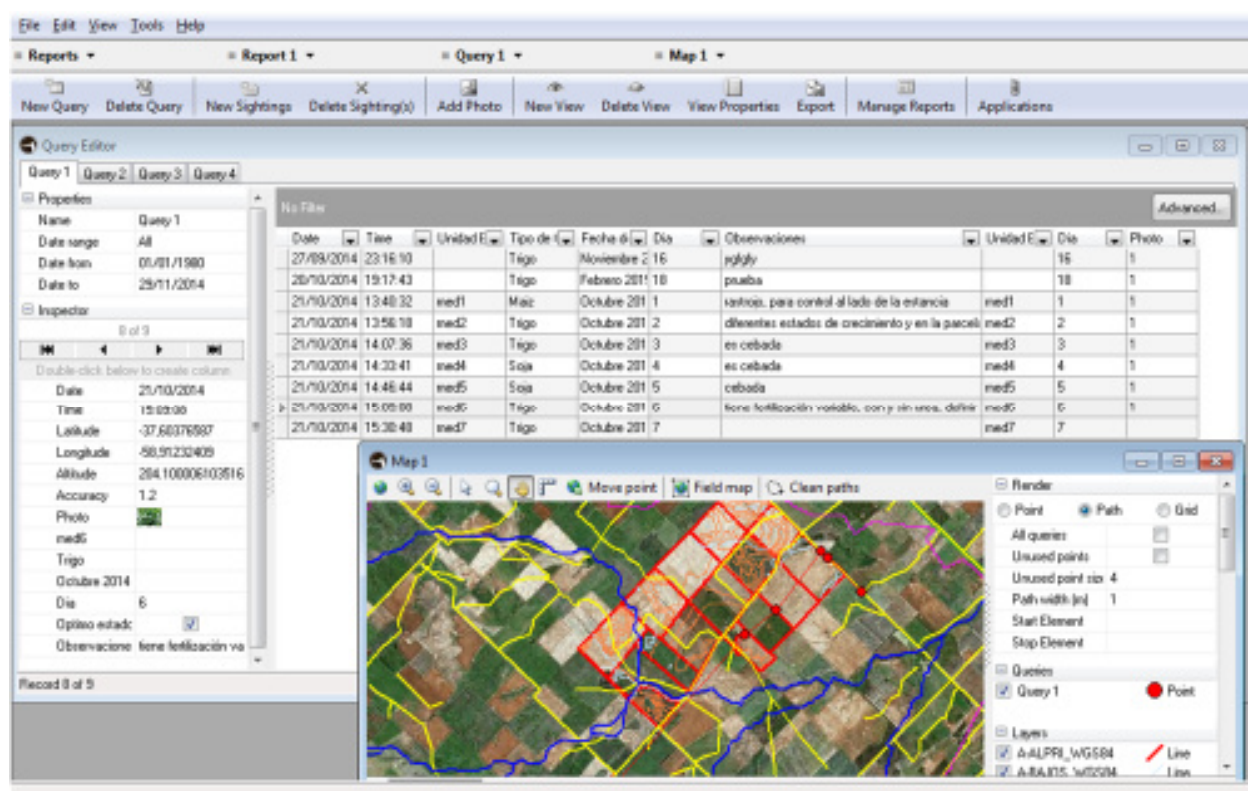

Figura 10. Almacenamiento de información en el software Cyber'Tracker@ .

Fuente: elaboración propia.

Para la toma de información en campo, respecto a firmas espectrales, se utilizó el radiómetro precitado, una computadora portátil la cual almacena y procesa las firmas espectrales capturadas por dicho instrumental por medio del software SpectraSuite ${ }^{\circledR}$. El radiómetro se colocó sobre el cultivo, de forma horizontal, aproximadamente a una altura de 1.70 metros del suelo, garantizando que el sensor capte un área representativa de la cobertura vegetal sin presencia de suelo descubierto, evitando dar sombra sobre el área de muestreo; capturando los datos por medio del software SpectraSuite con la computadora portátil (Figura 11).

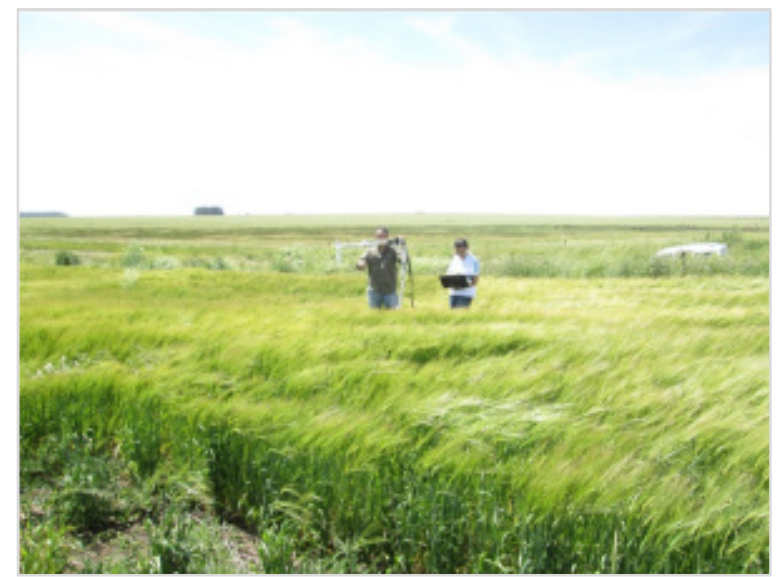

Figura 11. Captura de información en campo con espectro radiómetro.

Fuente: elaboración propia.

Debido a que las firmas espectrales tomadas con el radiómetro se planearon comparar con las imágenes satelitales Landsat 8, los datos con el instrumento se tomaron como mínimo a 15 metros al interior del cultivo, para así garantizar que la información capturada fuese 
representativa del mismo y pudiese ser comparada con los pixeles de las imágenes satelitales, ya que al ser la resolución espacial de 30 metros se homogenizó la información espacial contenida en estas áreas.

Se definieron 7 puntos de muestreo al interior de la estancia, donde se tomaron 10 firmas espectrales de cada cultivo por punto de muestreo, para así obtener suficientes mediciones con las cuales realizar un promedio para definir la firma espectral representativa de cada punto, junto con firmas espectrales de referencia tomadas por el sensor superior del espectro radiómetro. Esto último para normalizar los datos a los cuales se les resto los valores de corriente oscura o ruido electrónico.

Los datos capturados fueron almacenados en formatos planos de texto .txt (Figura 12) mediante el software SpectraSuite ${ }^{\circledR}$, donde se almacenan los parámetros al momento de la captura de las firmas junto con la respuesta espectral de cada una.

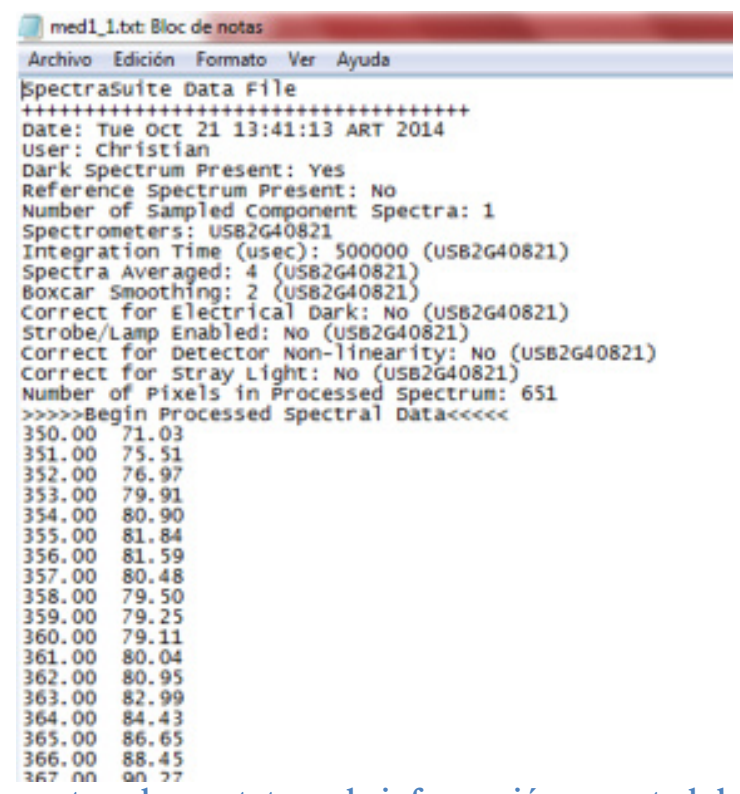

Figura 12. Formatos planos .txt con la información espectral del radiómetro.

Fuente: elaboración propia.

El procedimiento para normalizar las mediciones constó en tomar cada valor de intensidad reflejada y dividirla por un factor de corrección el cual se obtuvo multiplicando la intensidad de referencia del sensor superior del radiómetro por el cociente entre el tiempo de integración de las intensidades reflejadas e incidente. Debido a que se tomaron 10 mediciones por punto de la intensidad reflejada y 2 mediciones de referencia de la intensidad incidente, se utilizaron para la corrección de las 5 primeras mediciones reflejadas los datos de la primera intensidad incidida de referencia, la cual se tomó antes de iniciar las mediciones, y para las 5 restantes se utilizó la segunda intensidad incidida la cual se capturo al finalizar todas las mediciones. Esto se hizo debido a que en el transcurso del tiempo en 
que se tomaron las mediciones en cada punto los factores climáticos pudieron cambiar ligeramente, así se reduce el error en la captura de los datos originados por variaciones en la iluminación.

Con el acompañamiento del asesor técnico del productor, el señor Dr. Gabriel Vázquez Amábile, se definió en que lotes era relevante tomar los datos. En el viaje se definieron 7 puntos de muestreo, el primero fue sobre suelo desnudo, con el fin de realizar pruebas de funcionamiento del equipo en campo y de tener un valor de referencia para suelo con y sin cobertura en el caso que fuese requerido. Los otros puntos contienen información de un cultivo en particular en diferentes parcelas de la estancia. Los puntos de medición 2, 6 Y 7 pertenecen al cultivo de Trigo y los puntos 3, 4 y 5 son cultivos de cebada. Los puntos 6 y 7 pertenecen a una misma parcela, sin embargo el punto 7 es una zona en la cual el cultivo se realizó sin fertilización nitrogenada, ya que se evidencio que las plantas en el área del punto 7 eran de menor tamaño que las plantas del punto 6. En la Figura 13 se muestra la localización de los puntos visitados al interior de la estancia.

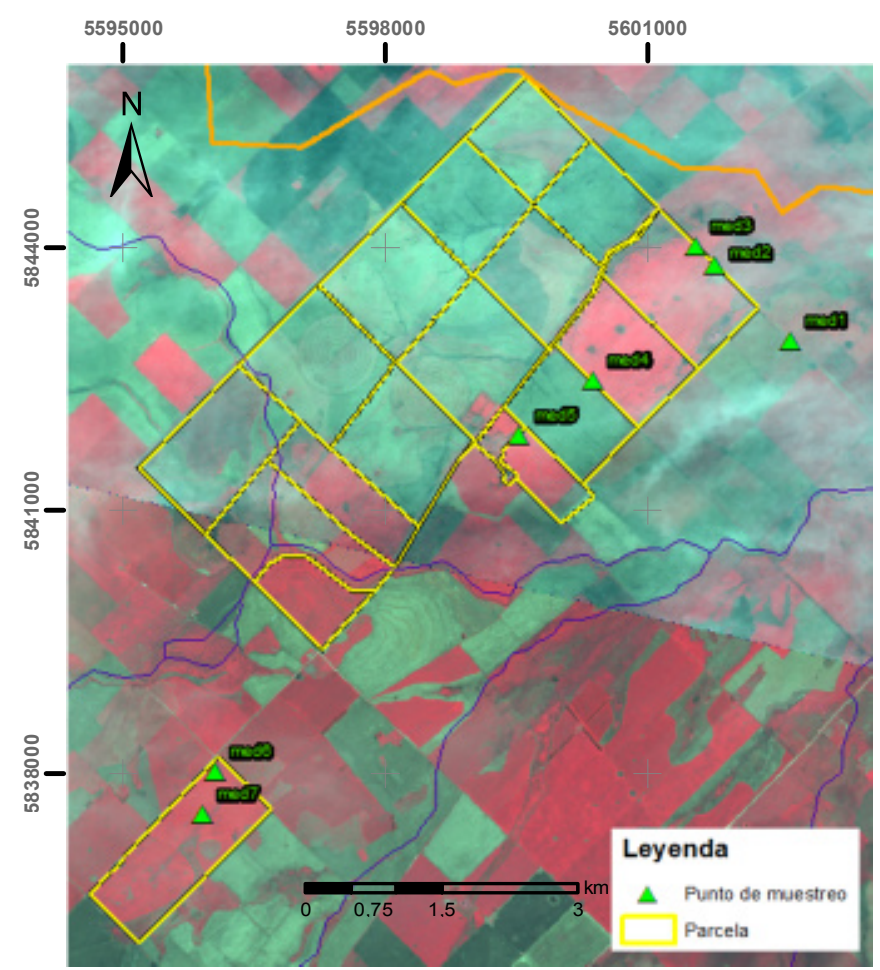

Figura 13. Localización de los puntos de muestreo junto con el catastro parcelario en la Estancia La Esperanza.

Fuente: elaboración propia. Imagen base: Spot multiespectral 16-Sep-2014 y 8-Oct-2014

A medida que se establecieron los puntos, en cada viaje se observó el estado fenológico y fitosanitario de los cultivos visitados. Por lo tanto se conoció cómo se comportan los cultivos de trigo y cebada al igual que sus estadios de crecimiento en el transcurso del estudio. 
Según Miralles et al. (1994) el ciclo de trigo y cebada puede dividirse en seis etapas de desarrollo (Figura 14):

- Establecimiento (ES, entre siembra y emergencia).

- Pre-Macollaje (PM, entre emergencia e inicio de macollaje).

- Macollaje (MC, entre inicio de macollaje e inicio de encañazón).

- Encañazón (EN, entre inicio de encañazón e inicio de espigazón).

- Espigazón/Antesis (EA, entre inicio de espigazón y fin de antesis).

- Llenado de grano (LLG, entre fin de antesis y madurez fisiológica).

Finalizado el LLG, continúa una etapa de secado del grano (SC), donde el rendimiento ya fue definido y el grano sólo pierde humedad, según el Manual de trigo y cebada para el Cono Sur (Miralles et al., 1994).

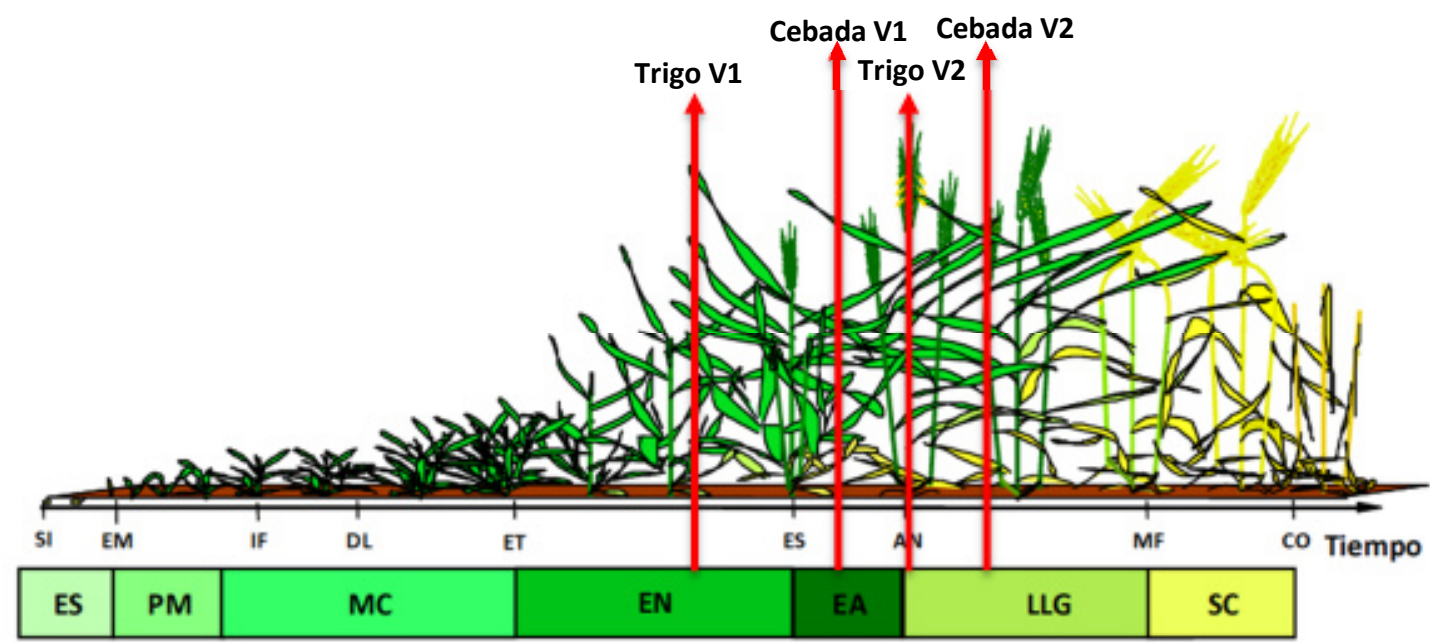

Figura 14. Etapas del ciclo de cultivo de trigo y generación de componentes numéricos del rendimiento.

Nota: Manual de trigo y cebada para el Cono Sur: procesos fisiológicos y bases de manejo). SI: siembra, EM: emergencia, IF: iniciación floral, DL: doble lomo, ET espiguilla terminal, ES: espigazón, AN: antesis, MF: madurez fisiológica, CO: cosecha. Fuente: Miralles et al., 1994.

Adaptación: Las líneas rojas indican el estadio que se encontraban los cultivos en los diferentes viajes de campo realizados. V: viaje.

Cada estadio refleja una cantidad de luz diferente, ya que la planta absorbe y refleja la luz solar dependiendo a sus necesidades de crecimiento. El radiómetro mide la reflectancia dada por la cobertura del suelo, en este caso las plantas del cultivo de estudio, de esta forma se puede analizar las características propias de los mismos.

\subsubsection{Cálculo de NDVI con datos radiométricos in situ.}

Una vez obtenida la información del NDVI proveniente del procesamiento de imágenes satelitales, se validó dicha información con mediciones de campo utilizando el radiómetro. 
El desarrollo de equipos de medición de la reflectancia espectral portátiles (hand held radiometers) permite el uso de esta técnica de detección remota a escala predial. Además, la combinación de estos radiómetros con instrumentos de posicionamiento global satelital (GPS) permite un manejo de recursos con buena resolución espacial para cultivos pequeños (Raun et al., 2002).

La biosfera recibe radiación solar y la incidencia de la misma sobre los organismos vivos no es homogénea, aspecto que concierne tanto a su calidad como a la intensidad. La homogeneidad y calidad espectral de la luz incidente dependen en primer lugar de la latitud, la altitud, del tipo de ambiente (agua, atmósfera) y de su claridad o transparencia (Iqbal, 1983). Ello se debe a que los objetos dispersores de luz (típicamente nubes) afectan de manera desigual a las bandas o rangos de bandas considerados (Kriebel, 1976; Weber et al., 2008). Fundamentalmente la mayor proporción de la energía (cerca del 45\%) está concentrada entre los 380 y los $710 \mathrm{~nm}$ (que constituye el rango de absorción de las clorofilas y los pigmentos accesorios (Salisbury \& Ross, 1992). Dada esta heterogeneidad, las señales de reflectancia obtenidas mediante cualquier sensor pasivo, deben ser normalizadas siguiendo el patrón de intensidad de la luz incidente, debido a que variaciones en la intensidad de esta luz incidente, pueden ser erróneamente interpretadas como cambios en los parámetros vegetales que pretendan ser estudiados mediante reflectancia (grado de cobertura, estatus nitrogenado, etc.).

Los valores de reflectancia fueron calculados con el radiómetro de campo como factores, entre la señal del objeto en estudio y la obtenida mediante la duplicación de los canales ubicados hacia la radiación incidente (cielo), obteniéndose así una detección sincrónica de señales, objeto y fuente (Weber et al., 2008). La fórmula para la reflectancia calculada se presenta en la Ecuación 3.

$$
\mathrm{R}_{\lambda}=\frac{R_{S \lambda}-Z_{\lambda}}{R_{i \lambda}-Z_{\lambda}}
$$

Ecuación 3. Cálculo de reflectancia para cada canal ó $\lambda$.

Donde $R_{S \lambda}$ es la señal desde la vegetación y el suelo en la banda $\lambda, R_{i \lambda}$ es la señal de luz incidente o referencia (cielo en este caso) para la misma $\lambda$, y finalmente $Z_{\lambda}$ es la medida oscura o corriente oscura en ese canal y para ambos referencia y objeto de estudio por separado. 
Los valores de las bandas individuales obtenidas mediante el sensor se transformarán en valores de reflectancia según Weber et al. (2008), con la metodología de normalización de señales y posteriormente combinados en el índice NDVI.

Teniendo la información espectral capturada por el radiómetro se procedió a calcular el valor particular de NDVI para cada punto muestreado, esto se efectuó teniendo en cuenta los anchos de longitud de las bandas rojo e infrarrojo cercano del sensor Landsat 8 (0.64 $0.67 \mu \mathrm{m}$ y $0.85-0.88 \mu \mathrm{m}$ respectivamente). Se ubicó estos rangos en los datos obtenidos con el radiómetro y se promedió los valores de la intensidad reflejada corregida en un rango medio de los anchos de banda respectivos. Se realizó el promedio de intensidad entre los 0.65-0.66 $\mu \mathrm{m}$ para la banda rojo y 0.86-0.87 $\mu \mathrm{m}$ para la banda infrarrojo. De esta forma e implementando la Ecuación 2 se obtuvo un valor único de NDVI por cada medición realizada en campo con el radiómetro.

\subsubsection{Validación de valores NDVI satelital con NDVI radiómetro.}

Con el propósito de validar los NDVI obtenidos con las imágenes satelitales se realizó una correlación con los valores encontrados en los puntos de muestreo in situ. Para tal fin se transformó los pixeles de las máscaras o recortes de los raster por parcela en polígonos vectoriales de formato shp, cuyos polígonos contienen los valores de NDVI de su pixel correspondiente con el fin de superponer la información. El propósito de asociar los anteriores valores de NDVI del radiómetro fue promediar los valores circundantes de NDVI obtenidos de las imágenes respecto a los puntos de muestreo en campo, para esto se realizó un buffer o zona de influencia de 45 metros para cada punto. Considerando que los puntos de muestreo se tomaron en las márgenes de las parcelas y la resolución espacial de los pixeles de las imágenes Landsat son 30 metros, en los cuales se homogeniza la cobertura para obtener un único valor de NDVI, se descartaron los pixeles que poseían mayor área al exterior de las parcelas. En la Figura 15 se ilustra la selección y depuración de los pixeles por cada punto de muestreo al interior de las parcelas.
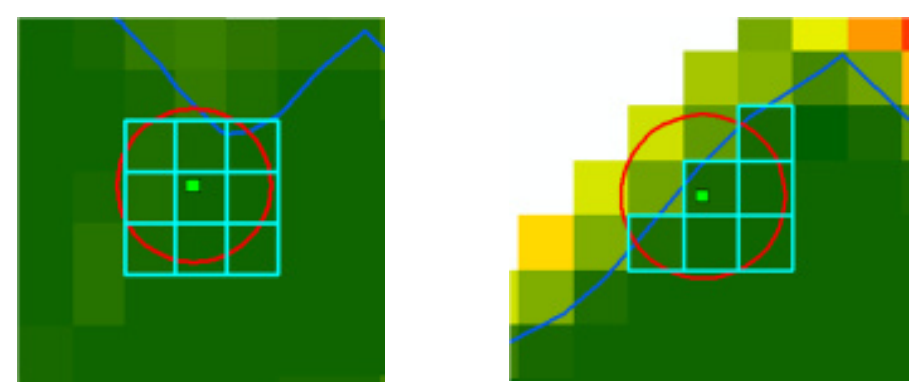

Figura 15. Selección de valores NDVI provenientes de las imágenes de satélite por punto de muestreo.

Fuente: elaboración propia. 
Para este proceso se seleccionaron las imágenes Landsat con fecha de captura cercanas a la toma de las muestras con el radiómetro, dichas imágenes poseen fecha de 16 de octubre (para el primer viaje a campo) y 26 de noviembre (para el segundo viaje).

Una vez se tuvo los valores NDVI provenientes de las imágenes satelitales y el radiómetro se realizó el test de correlación de Pearson para evaluar el grado de similitud que existe entre los índices, de esta forma se puedo analizar qué tan cercanos son los valores obtenidos por las imágenes satelitales (las cuales son a nivel general) con valores puntuales tomados en campo sobre los cultivos estudiados.

\subsection{Morfometría de la cuenca de estudio.}

Las propiedades morfométricas de una cuenca hidrográfica proporcionan una descripción física espacial que permite realizar comparaciones entre distintas cuencas hidrográficas. Al mismo tiempo, pueden proporcionar conclusiones preliminares sobre las características ambientales del territorio a partir de la descripción precisa de la geometría de las formas superficiales (Gaspari, et al., 2012). Conociendo estas características fue posible identificar el contexto de la cuenca, de esta forma evaluar si los parámetros topográficos pueden influir en la cobertura del suelo y en los índices de vegetación presentes en la zona.

El análisis de las características morfométricas y funcionales de una cuenca hidrográfica a través de parámetros de forma, relieve y red de drenaje, es básico en la modelación hidrológica para determinar el movimiento y captación del agua de lluvia (Gaspari et al., 2009). En el presente trabajo se determinaron dichos parámetros en la extensión de toda la cuenca de estudio según las metodologías referidas por Gaspari et al. (2012), los cuales se mencionan a continuación:

\subsubsection{Parámetros de forma.}

- Área (A) $\left(\mathrm{km}^{2}\right)$ : Es la superficie encerrada por la divisoria de aguas.

- Perímetro (P) $(\mathrm{km})$ : Es la medición de la línea envolvente de la cuenca hidrográfica, a lo largo de la divisoria de aguas topográficas.

- Longitud Axial (La) (km): Es la distancia existente entre la desembocadura y el punto más lejano de la cuenca. Es el mismo eje de la cuenca. Es la longitud de la línea recta que conecta los puntos extremos de la cuenca en forma aproximadamente paralela al curso principal. 
- Ancho promedio (Ap) (km): Es la relación entre la superficie de la cuenca por su longitud axial (La).

- Factor de forma (IF): Es un factor adimensional que indica cómo se regula la concentración del escurrimiento superficial en la cuenca hidrográfica. Se expresa como la relación entre el ancho promedio de la cuenca y su longitud axial. Manifiesta la tendencia de la cuenca hacia las crecidas.

- Coeficiente de compacidad de Gravelius (Kc): Este parámetro es adimensional y relaciona el perímetro de la cuenca con el perímetro de un círculo teórico de área equivalente al de la cuenca. El círculo teórico representa un límite que define la forma y la superficie que abarca la cuenca vertiente, teniendo influencia sobre los escurrimientos y sobre la marcha del hidrograma resultante de una precipitación.

\subsubsection{Parámetros de relieve.}

- Pendiente media de la cuenca (PM): Es el producto entre la equidistancia de las curvas de nivel y su longitud en relación de la superficie de ocupación de cada una. PM se expresan en porcentaje.

- Coeficiente de rugosidad (Ra): Es la relación adimensional existente entre el desnivel de la cuenca $(H)$ y su densidad de drenaje (Dd). En cuencas muy disectadas con bajo relieve se presentan un Ra similar a cuencas moderadamente disectadas y con un alto relieve.

- Altura máxima (Hmax): mayor punto altitudinal al interior en la cuenca medido sobre el nivel del mar

- Altura mínima (Hmin): menor punto altitudinal al interior en la cuenca medido sobre el nivel del mar

\subsubsection{Parámetros de drenaje.}

- Longitud del cauce principal (Ln) (m): Es la longitud del río desde el punto más distante de la cuenca hasta la desembocadura.

- Pendiente media del cauce (J): Se deduce a partir del desnivel topográfico sobre el cauce principal y la longitud del mismo (L). Se expresa en porcentaje.

- Densidad de drenaje (Dd): Está definida para cada cuenca como la relación entre la suma de las longitudes de todos los cursos de agua que drenan por la cuenca con respecto al área de la misma. Caracteriza cuantitativamente la red 
hidrográfica de la cuenca, por medio del grado de relación entre el tipo de red y la clase de material predominante. Resaltando que se denomina red hidrográfica a la totalidad de drenaje natural, permanente o temporal, por el que fluye el escurrimiento superficial.

- Tiempo de concentración (Tc): El tiempo que tarda el flujo superficial en contribuir al caudal de salida, desde el punto más alejado hasta la desembocadura de la cuenca. El tiempo de concentración depende directamente de la forma de la cuenca.

Los parámetros anteriormente mencionados se obtuvieron mediante herramientas geográficas hidrológicas tal como lo es Arc $\mathrm{Hydro}^{7}$ diseñada para el software ArcGIS®. Para el cálculo de los parámetros se utilizó información base de entrada, como lo es la configuración o red de drenajes existente proveniente de Senisterra (2016) y un modelo digital de elevación (DEM por sus siglas en inglés) STRM $^{8}$ de resolución espacial 30 metros. Euillades et al. (2003) definen como modelo digital de elevación a una grilla regular georreferenciada donde a cada celda le corresponde un valor de cota o altura.

\subsubsection{Correlación del NDVI con la topografía de la cuenca.}

Históricamente, los modelos digitales de elevaciones se han dividido básicamente en dos grupos en función de la concepción básica de la representación de los datos: vectorial y raster. En el modelo vectorial los atributos del terreno se representan mediante puntos acotados, líneas o polígonos. En el modelo raster, los datos se interpretan como el valor medio de unidades elementales de superficie con una distribución regular, sin solapamiento y con recubrimiento total del área representada (Felicísimo, 1994).

Para analizar la superficie topográfica de la cuenca se utilizó el modelo de elevación o STRM con resolución espacial de 10 metros y las imágenes Landsat 8 para cada fecha estudiada. Inicialmente se buscó relacionar un valor de NDVI a cada valor de pixel de altura, pero al encontrarse una gran cantidad de datos en la superficie de la cuenca (mayor a

\footnotetext{
${ }^{7}$ Las herramientas de Arc Hydro funcionan en el entorno de ArcGIS. Algunas de las funciones requieren la extensión Spatial Analyst. La mayoría de las herramientas se accede a través de la barra de herramientas Arc Hydro Tools, donde se agrupan por funcionalidad en seis menús y nueve herramientas. Se han desarrollado herramientas adicionales en el entorno de geoprocesamiento y están disponibles en la caja de herramientas Arc Hydro Tools que se puede utilizar tanto en ArcMap como en ArcCatalog (Djokic et al., 2011)

${ }^{8}$ Acrónimo en inglés de Shuttle Radar Topography Mission. Misión topográfica la cual es un proyecto internacional entre la Agencia Nacional de Inteligencia-Geoespacial, NGA, y la Administración Nacional de la Aeronáutica y del Espacio, NASA.
} 
3 millones de datos) se efectuó un resampleo del modelo de elevación a 30 metros de tamaño de pixel, con esto coinciden la resolución de las dos fuentes de análisis, del DEM y de las imágenes Landsat 8.

El lapso de tiempo del estudio es de 6 meses, desde julio hasta diciembre, sin embargo para este análisis se utilizaron 3 fechas representativas: 28 de julio, 16 de octubre y 12 de diciembre. En dichas fechas se marca el cambio de estaciones climáticas, con lo cual es notable el cambio de verdor en la vegetación y por ende en el NDVI.

Los patrones espaciales y temporales de la reflectancia de la superficie a lo largo de un transecto topográfico revelan efectos claros sobre el momento de crecimiento de la vegetación de la zona al igual que en cambio gradiente del NDVI (Gamon et al., 2013). En la cuenca de estudio se evaluó si existen dichos cambios o variaciones de cobertura vegetal reflejados en los índices de vegetación respecto al desnivel o altimetría de la cuenca mediante alguna correlación entre estos factores.

Según los antecedentes de la cuenca presentados anteriormente, esta no posee un gran porcentaje de desnivel y se tiene una pendiente en general muy pequeña catalogada como plana. Esto origina que las coberturas al interior de la cuenca sean muy similares y dispersas en toda su superficie, en su mayoría de origen antrópico como lo son los cultivos. Por este motivo se dividió la superficie de la cuenca en rangos de altura definiendo 6 zonas, para este propósito se utilizó el método de clasificación de datos denominado rupturas naturales en el software $\operatorname{ArcGIS}{ }^{\circledR}$, de esta forma se agrupan con mayor ajuste las alturas con diferencias considerables, maximizando así las diferencias entre los rangos.

Teniendo definidas las zonas se realizó la correlación lineal por medio de gráficos de dispersión y coeficientes de correlación Pearson para los índices de vegetación y la altura de cada pixel con el fin de evaluar si los cambios topográficos infieren en los valores del NDVI obtenidos al interior de la cuenca de estudio, dándole importancia a las zonas o subcuencas en donde se encuentran las parcelas que hacen parte del análisis del presente trabajo.

\subsection{Procesamiento de datos de rendimiento agrícola.}

\subsubsection{Análisis de bases de datos de rendimiento agrícola.}

Los datos de productividad fueron suministrados por el asesor técnico del productor de la estancia La Esperanza. Dicha información se encontraba en formato .log la cual proviene 
del monitor de rendimiento SENSOR ${ }^{\circledR}$, en sus diferentes versiones (integral V1550, integral VAX7500 y autónomo) instalados en las máquinas cosechadoras de la estancia. Los archivos venían discriminados por tipo cultivo, cebada y trigo, codificados con el nombre y nomenclatura de la parcela, que utilizaba el productor en la administración agrícola de la estancia. Junto con los datos del cultivo provenientes de cuaderno de campo del proceso del cultivo utilizado por el asesor, donde se obtuvieron las especificaciones y detalles del proceso productivo, se homólogo los datos a la distribución o nomenclatura de las parcelas definidas en el proceso de digitalización del presente trabajo. La relación mencionada se presenta en la Tabla 2.

Tabla 2. Asociación de información catastral de cultivos con las parcelas de estudio.

\begin{tabular}{|c|c|c|c|c|c|c|}
\hline Nomenclatura & Parcela & Cultivo & Variedad & $\begin{array}{l}\text { Datos } \\
\text { Rinde }\end{array}$ & $\begin{array}{c}\text { Fecha de } \\
\text { siembra }\end{array}$ & $\begin{array}{r}\text { Fecha de } \\
\text { cosecha }\end{array}$ \\
\hline $36 \mathrm{a}$ & $\overline{00}$ & Trigo & Baguette 9 & 10624 & $29-07-14$ & $02-01-15$ \\
\hline $17 \mathrm{a}$ & 2 & Trigo & Baguette 601 & 8300 & $25-07-14$ & 03-01-15 \\
\hline $31 \mathrm{a}$ & 3 & Cebada & Shakira & 7973 & 04-07-14 & $26-12-14$ \\
\hline $17 \mathrm{~b}$ & 4 & Cebada & Shakira & 15445 & $30-06-14$ & $24-12-14$ \\
\hline Esperanza chica & 5 & Cebada & Shakira & 6096 & $26-07-14$ & $26-12-14$ \\
\hline 31 & 6 y 7 & Trigo & Baguette 9 & 21648 & $28-07-14$ & $29-12-14$ \\
\hline
\end{tabular}

Para el procesamiento y visualización de los archivos fue necesaria la conversión a formato compatible con software de sistemas de información geográfica, para esto los monitores de rendimiento SENSOR ${ }^{\circledR}$ poseen la herramienta denominada CONVERSOR LOG A SHP®. Según Piuma (2010), consiste en un programa que convierte el archivo con formato SENSOR® (.log) en otro archivo con un formato vectorial shapefile (.shp). Los monitores de rendimientos vienen equipados con receptores GPS, por lo tanto la información posee coordenadas geográficas referidas al sistema WGS84. Además para facilitar la importación, los datos almacenados en el shp deben tener ciertas cualidades, como lo son los factores de medición, datos corregidos por factores, etc. Todos estos requisitos han sido tomados en cuenta en el CONVERSOR LOG A SHP®. Según el manual de usuario de esta herramienta, la misma se ha desarrollado y ensayado con el programa SMS (Ag Leader).

Los datos, en su formato shp con geometría punto, pueden ser visualizados y procesados de forma práctica por el software ArcGIS® o cualquier otro software geográfico. Sin embargo estos archivos no poseen proyección cartográfica asociada al momento de ser exportados, no obstante se sabe, por lo mencionado anteriormente y por consulta al asesor del productor, que la información está referida a coordenadas geográficas WGS 84, por lo cual se asignó esta proyección a los datos mediante el ArcGIS®. Una vez establecido el 
sistema de referencia se procedió a transformar y proyectar los datos a coordenadas planas POSGAR 98 franja 5 por medio de las herramientas del software para tal fin.

La representación geográfica vectorial de la producción es denominada mapas de rendimiento (Figura 16), en la cual cada registro o punto geográfico posee información de producción en toneladas por hectárea, para el caso de estudio, junto con datos del monitor de rendimiento como los es altura de cabezal, ancho de franja, distancia recorrida, velocidad de avance, flujo de granos, humedad de grano, pérdidas de cosecha, entre otros. Por recomendación del asesor del productor de la estancia se trabajó con el dato de masa de rendimiento húmedo para hacer los respetivos procesos de análisis.

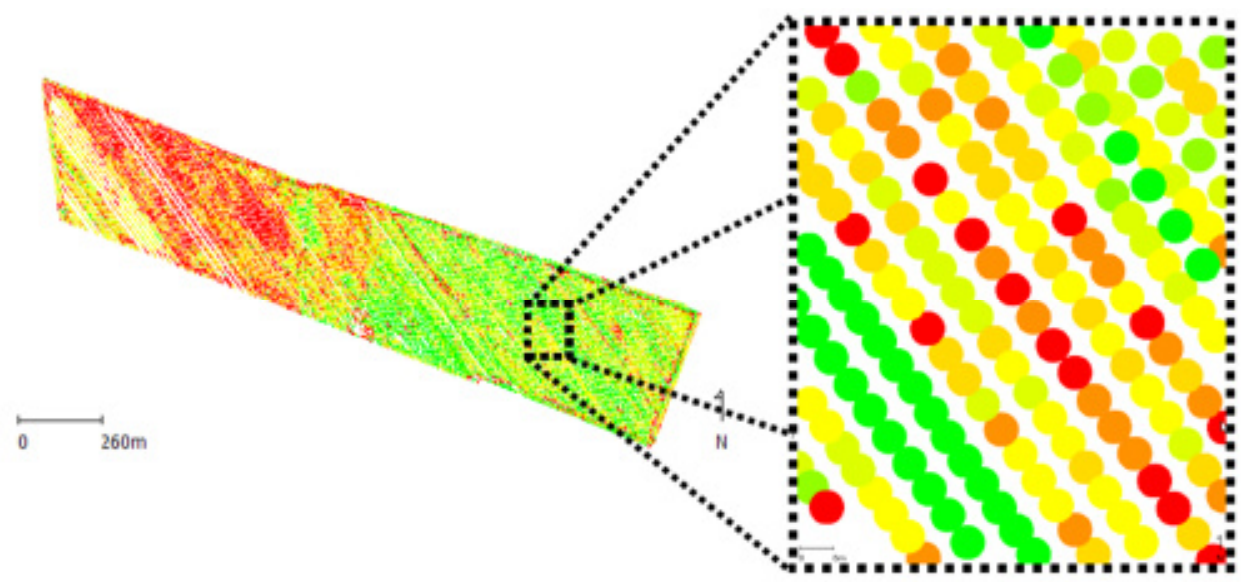

Figura 16. Mapa de rendimiento y detalle de puntos. Fuente: Albarenque \& Vélez (2011).

Nota: La simbología de los puntos denota un valor de rendimiento dado por el autor

\subsubsection{Limpieza de mapa de rendimiento o depuración de valores atípicos (outliers).}

Previo a los análisis de correlación de las variables fue necesario depurar la información base de rendimiento, ya que los datos originales poseen variaciones provenientes del proceso de recolección por los monitores de rendimiento. Estos eventos aleatorios típicamente ocurren en parches pequeños, como fallas de siembra y en el establecimiento del cultivo, fertilización desuniforme, daños de herbicidas, daños de enfermedades, entre otros. Los errores de medición incluyen errores de sensores de flujo y humedad de granos, errores debidos a la georreferenciación y el movimiento de la cosechadora, errores de operario, y errores del procesamiento de los datos (Albarenque \& Vélez, 2011).

Las fuentes de error comúnmente encontradas en los monitores de rendimiento, como lo explica Albarenque \& Vélez (2011), son errores de registro por altura de cabezal, retardos en el inicio y fin de la cosecha, valores fuera de rango (outliers), rendimientos fuera de rango biológico definido por el usuario, pequeñas franjas angostas con rendimientos 
extremadamente altos o bajos que no están relacionados con sus vecinos inmediatos, segmentos y puntos de rendimientos superpuestos (grabados con iguales coordenadas). Algunas de estas fuentes descritas por Albarenque \& Vélez (2011) se exponen a continuación:

- Errores de registro por altura de cabezal: El sensor de posición del cabezal controla el cálculo de superficie cosechada. Cuando se levanta el cabezal, el sensor suspende la medición de área, cuando el cabezal baja el equipo comienza a contar distancia recorrida y área, registrando datos para esos puntos. Si se avanza con el cabezal bajo aun cuando no se está cosechando se generan puntos sin datos de rendimiento que luego se visualizan en el mapa como rendimiento cero.

- Retardos en el inicio y fin de la cosecha: este se manifiesta en el mapa como puntos faltantes en el inicio de una franja de cosecha y puntos demás en el fin de la franja. Cuando la cosechadora comienza a cosechar y el monitor a registrar datos el flujo de granos no es suficiente como para generar datos al inicio de la franja, y finalizar el monitor sigue registrando aun cuando ya no se está cosechando debido a que el sensor sigue recibiendo granos. Los nuevos monitores de rendimiento tienen un software que le permite al operador estimar el retraso de paso, hasta que el grano llega desde el cabezal hasta el sensor de flujo. Otros ya incluyen un comienzo de retraso de paso para permitir que el flujo inicial de grano dentro de la cosechadora sea adecuadamente georreferenciado.

- Valores fuera de rango (outliers): datos de los distintos atributos que no se ubican dentro del valor promedio más y menos tres desvíos estándar, rango en el que se ubica el $99 \%$ de los datos.

- Rendimientos fuera del rango biológico: este es definido por el usuario para una zona y lote determinado. Esto es, definir un rendimiento máximo alcanzable en el lote y un mínimo que resulte de interés mapear. (Ejemplo, 15.5 tn/ha y $0.5 \mathrm{tn} / \mathrm{ha}$ )

- Rendimientos extremadamente altos o bajos: pequeños parches o franjas angostas que no están relacionados con sus vecinos inmediatos.

- Superposición o duplicidad de puntos: Pequeños segmentos y puntos de rendimientos superpuestos, esto es, grabados con iguales coordenadas. Usualmente esta edición hay que hacerla manual observando los punto que no corresponde a una localización espacial determinada. 
La depuración o limpieza de los mapas de rendimientos se realizó por parcelas, identificando los valores atípicos por partes según las fuentes de error anteriormente mencionadas. Este proceso se realizó de forma automática en el software estadístico $R \circledR$, mediante la identificación de valores atípicos por medio de creación de limites definidos por cuartiles, junto con el análisis exploratorio por medio de diagramas de caja.

Comúnmente se usa la fórmula de Tukey, basada en los cuartiles de la distribución o los valores que subdividen el conjunto de datos ordenados en cuatro partes, cada una con el mismo porcentaje de datos. Tomando como referencia la diferencia entre el primer cuartil Q1 y el tercer cuartil Q3, o el rango intercuartil (IQR), se considera un valor extremo o atípico aquel que se encuentra a 1,5 veces esa distancia de uno de esos cuartiles (atípico leve) o a 3 veces esa distancia (atípico extremo) según se muestra en la Ecuación 4. Sin embargo, dependiendo de la distribución de los datos, este método puede fallar. Si el rango intercuartil resulta ser cero, cualquier valor diferente de cero se tomaría como atípico. Por lo tanto, en estos casos, es recomendable usar otro método (Uribe \& Ramírez, 2009; AyalaPérez et al., 2012)

$$
\begin{aligned}
& \text { Atípico leve: < Q1-1.5* IQR, > Q3+1,5* IQR } \\
& \text { Atípico extremo: < Q1-3* IQR, > Q3+3* IQR }
\end{aligned}
$$

Ecuación 4. Límites para la obtención de valores atípicos leves y extremos.

Siendo Q1 y Q3 los valores de los quartiles primero y tercero respectivamente y IQR el intervalo interquartílico Q3-Q1.

Una vez identificados los valores atípicos por este método se suprimieron sus registros, ya sea por selección automática o manual, dejando únicamente los datos filtrados contenidos en cada parcela con un mínimo de error.

La aplicación de la limpieza de mapas de rendimiento genera una secuencia de resultados parciales los cuales permitieron lograr un resultado final que es el utilizado para la implementación de la sección 4.6.

\subsection{Comparación de NDVI con mapas de rendimiento.}

Con los datos depurados de rendimiento se continuó con la correlación con los valores de NDVI de las imágenes satelitales utilizadas para la zona de estudio. Para esto se consideró los valores de NDVI pertenecientes a cada parcela, para los meses de julio hasta diciembre según la resolución temporal y disponibilidad de las imágenes Landsat 8 mencionadas previamente, en una grilla de formato vectorial con geometría polígono (cada pixel 
corresponde a un polígono cuadrado de 30 metros cuadrados de superficie). Superponiendo las grillas de cada mes con los puntos de rendimiento fue posible asociar espacialmente los puntos que corresponden a cada valor de NDVI.

Se propusieron dos metodologías o formas de comparación de los datos, la primera consistió en evaluar los datos de rendimiento pertenecientes a cada pixel individual, considerando el valor del NDVI tal cual como es arrojado al momento del cálculo del índice de vegetación (cada pixel posee un valor propio respetando la cantidad de decimales provenientes de la operación de bandas con la finalidad que sea lo más particular posible de sus valores vecinos al interior de la parcela); comparándolo con el promedio de los valores de masa de rendimiento húmedo que se encuentran contenidos en cada pixel. En la Figura 17 se expone dicha comparación por pixel y los datos de rendimiento considerado para cada valor de NDVI.

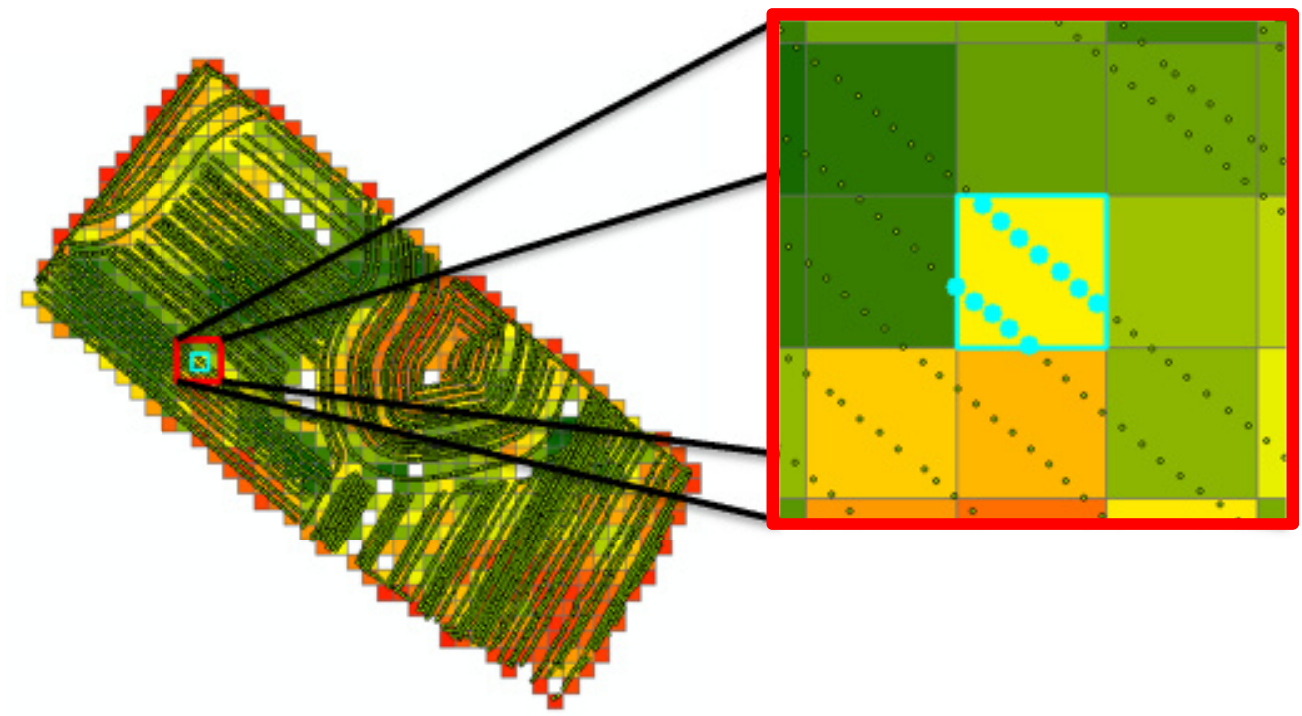

Figura 17. Visualización de la metodología a nivel pixel.

Nota: Puntos de rendimiento seleccionados por pixel individual. Fuente: elaboración propia.

La segunda comparación se efectuó realizando la agrupación de valores iguales de NDVI, generando zonas homogéneas por dicho valor. Esto se efectuó reduciendo a 2 cifras significativas los valores de NDVI con el objetivo de hacer los valores comparables entre vecinos y así generando diferentes zonas, contiguas o dispersas, al interior de las parcelas. De igual forma se consideró que a un mismo valor de NDVI se debe tener un rendimiento similar, por lo cual se promediaron los valores de rendimiento al interior de cada zona homogénea NDVI y de esta forma se obtuvo un único valor de rendimiento asociado a cada valor de NDVI. En este proceso se encontraron datos de zonas con valores bajos de rendimiento y con pocos pixeles agrupados (menores a 4 pixeles), lo cuales se localizaban 
en la periferia de la parcela indicando ser valores atípicos residuales, estos registros se descartaron de los datos zonales totales. En la Figura 18 se explica gráficamente la anterior forma de comparación de los datos, en la cual una zona con un único valor de NDVI posee varios puntos de rendimiento asociados.

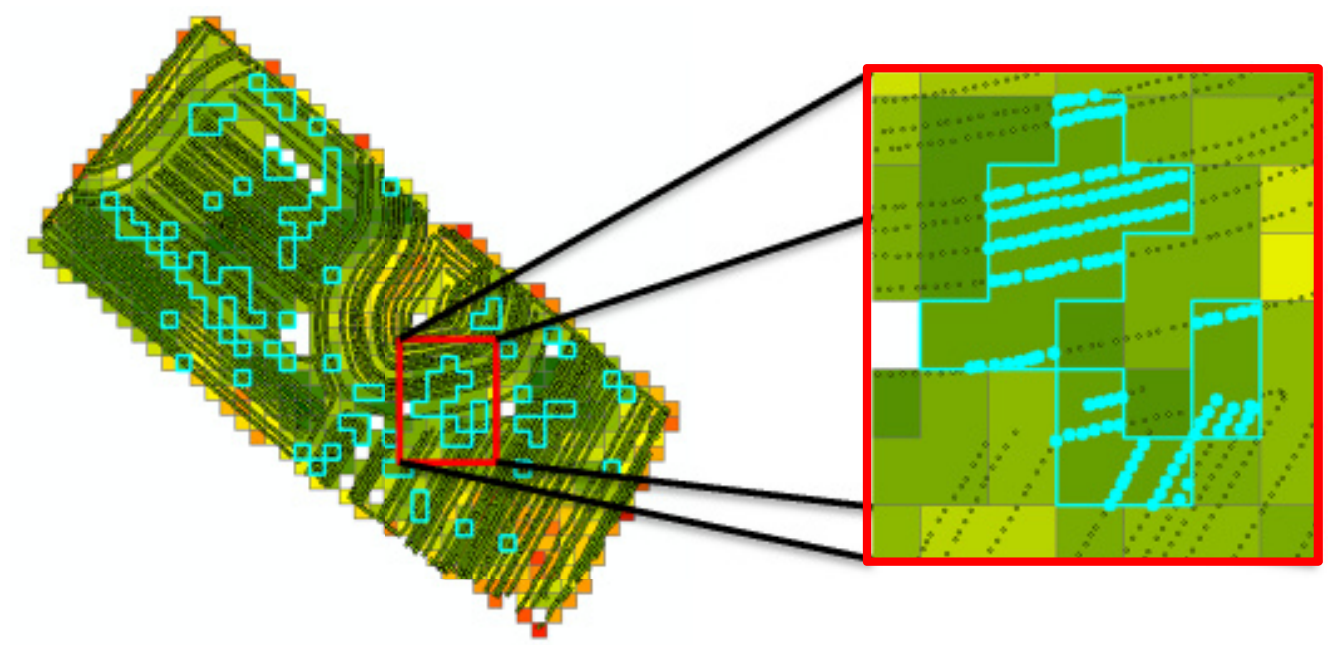

Figura 18. Visualización de la metodología a zonal.

Nota: Puntos de rendimiento seleccionados al interior de zonas homogéneas con igual valor NDVI.

Fuente: elaboración propia.

Con los valores asociados espacialmente se prosiguió exportando dicha información en tablas de hojas de cálculo para de esta forma correlacionarlos estadísticamente por medio de correlaciones lineales y coeficientes de Pearson.

El coeficiente de correlación de Pearson, pensado para variables cuantitativas, es un índice que mide el grado de covarianza entre distintas variables relacionadas linealmente. El valor de este coeficiente oscila entre $-1 \mathrm{y}+1$. No obstante ha de indicarse que la magnitud de la relación viene especificada por el valor numérico del coeficiente, reflejando el signo la dirección de tal valor. En este sentido, tan fuerte es una relación de +1 como de -1 . En el primer caso la relación es perfecta positiva y en el segundo perfecta negativa (Camacho, 2007).

Los coeficientes de Pearson encontrados para cada set de datos por mes permitieron identificar en cuál de los meses estudiados el rendimiento tiene mayor correlación con los índices de vegetación de las imágenes. Este fue un análisis exploratorio con el propósito de utilizar la información de los meses con mayor correlación por tipo de cultivo en la construcción de modelos de regresión los cuales permitieron inferir la productividad o rendimiento de los cultivos de trigo y cebada, cuya información servirá de herramienta para el ordenamiento territorial de la cuenca de estudio. 


\subsection{Modelos estadísticos.}

Una vez definido cuales fueron los datos de NDVI más apropiados para relacionar con el rendimiento según la fecha de captura de la imagen, se procedió a realizar modelos estadísticos que permitieran evaluar cómo responden los valores de NDVI al buscar inferir valores de rendimiento en una determinada zona. Al utilizar datos con naturaleza o distribución espacial, la cual puede influir considerablemente en la predicción de los datos, fue necesario considerar los efectos espaciales, los cuales separan los modelos de regresión clásicos (econometría clásica) a los modelos de regresión espacial (econometría espacial).

Teniendo claro los meses con mayor correlación entre el rendimiento y el NDVI para ambos cultivos se procedió a realizar modelos de regresión (clásicos y espaciales) para los diferentes set de datos por parcela, considerando los dos tipos de metodologías de análisis, por pixel y zonal. Con el propósito de evaluar cual modelo basado en los set datos establecidos se ajusta mejor a la productividad del área de estudio, se realizaron diversos test estadísticos con el propósito de no violar ningún principio fundamental o supuesto estadístico de los modelos establecidos.

Los set de datos se estructuraron en formato shp. Esta información fue insumo ingresado en el software $\mathrm{GeoDa}{ }^{\circledR}$, en donde se realizó la ejecución y las definiciones de los modelos.

El GeoDa ${ }^{\circledR}$ tiene la opción de generar modelos clásicos $\mathrm{MCO}$ o espaciales, sin embargo para la segunda clase de modelos es necesario considerar la relación geográfica que posee la información, dándose mediante el análisis de matrices de pesos espaciales W. Con la información georreferenciada fue posible la creación de dicha matriz por medio de mismo $\mathrm{GeoDa}{ }^{\circledR}$. Al poseer información en forma reticular (pixeles de una imagen satelital) se optó por la relación tipo Queen de primer orden para la generación de las matrices, como se explica en la sección de materiales y métodos, ya que un pixel con información espacial puede estar relacionado con sus vecinos colindantes. Se realizó una matriz por cada parcela, la cual se almaceno en un archivo plano de texto la cual contiene la relación espacial de cada elemento, para posteriormente ser utilizada en el proceso de definición de los modelos.

\subsubsection{Modelos clásicos MCO.}

Inicialmente se cuantifico la productividad agrícola al interior de una cuenca hidrográfica por medio de técnicas estadísticas, utilizando como variable independiente valores de NDVI obtenidos de insumos de imágenes satelitales. Para esto se procedió realizar un 
modelo econométrico lineal, estimado por Mínimos Cuadrados Ordinarios (MCO) para lograr relacionar las variables en cuestión. Posteriormente, se incluyó el efecto de autocorrelación espacial que presenta la productividad en cada parcela de estudio. El modelo de regresión linear básico está especificado por la Ecuación 5.

$$
Y=\beta * X+\varepsilon
$$

Ecuación 5.Formulación de modelo lineal por MCO.

Donde Y es la variable dependiente (para el caso de estudio rendimiento); X la variable independiente (en este caso el índice NDVI); $\beta$ es el coeficiente computado por la regresión el cual indica la fortaleza y tipo de relación entre la variable dependiente $\mathrm{Y}$ y la independiente $\mathrm{X} ; \boldsymbol{\varepsilon}$ son los residuales o error que es la porción que no puede explicar la variable independiente a la dependiente.

Azorin (2012) resalta que es preciso mencionar las consecuencias derivadas de la autocorrelación espacial en la estimación convencional por MCO. En el caso que exista presencia de residuos correlacionados espacialmente en la estimación de MCO, las estimaciones de los parámetros serán ineficientes (matriz de varianzas-covarianzas del término de perturbación será no escalar), la varianza residual será sesgada y las predicciones MCO serán ineficientes. Por lo cual si no se considera la dependencia espacial en la modelización econométrica es muy probable que tanto el ajuste, la inferencia y los contrastes de hipótesis no sean fiables, y según la naturaleza de dicha autocorrelación las estimaciones del modelo podrán ser sesgadas, ineficientes o inconsistentes. Por tanto, para incluir el esquema de dependencia espacial detectado la estimación máximo-verosímil (MV) se presenta como método de estimación apropiado, entre otros alternativos.

\subsubsection{Modelos de regresión espacial.}

La modelación de la interacción espacial requiere la imposición de algún tipo de estructura sobre la forma de la interacción entre las unidades del proceso. Estas imposiciones dan origen a al menos dos tipos de modelos que son populares en la estimación de modelos de regresión en econometría espacial: modelos espaciales autorregresivos (modelo Lag) y modelos espaciales de errores autocorrelacionados (modelo Error) (Aroca, 2000).

El modelo Lag se presenta como un caso en el que el valor de un fenómeno espacial depende del valor de sus representaciones vecinas, cuya relación está definida por medio de 
la matriz de pesos espaciales W. La especificación de este modelo se presenta en la Ecuación 6:

$$
Y=\rho * W y+\beta * X+\varepsilon
$$

Ecuación 6. Formulación de modelo Lag.

Donde comparte la misma especificación de variables que el modelo de regresión lineal básico a excepción que se le incluye el coeficiente $\rho$ el cual es el parámetro autorregresivo que representa la intensidad de las interdependencias de las observaciones de la muestra; y Wy que es el retardo espacial de la variable dependiente $\mathrm{Y}$.

Cuando la dependencia espacial no involucra un retaso espacial en las variables se recurre a evaluar la dependencia espacial residual dada por el modelo Error el cual se especifica en la Ecuación 7.

$$
\begin{gathered}
Y=\beta * X+u \\
u=\lambda * W u+\varepsilon
\end{gathered}
$$

Ecuación 7. Formulación de modelo Error

Donde Y es la variable dependiente (para el caso de estudio rendimiento); X la variable independiente (en este caso el índice NDVI); $\beta$ es el coeficiente computado por la regresión el cual indica la fortaleza y tipo de relación entre la variable dependiente $\mathrm{Y}$ y la independiente $\mathrm{X} ; W u$ es la variable con el termino de error modificado espacialmente; $\varepsilon$ son los residuales o error que es la porción que no puede explicar la variable independiente a la dependiente. La autocorrelación espacial es recogida aquí por $\lambda$ a través de los residuales por medio término de perturbación del modelo $\varepsilon$. La dependencia espacial residual, según Serrano y Valcarce (2000) podría explicarse por la omisión de variables no cruciales que se hallen correlacionadas espacialmente o por la existencia de errores de medida.

\subsubsection{Selección del modelo de regresión óptimo.}

Normalidad en los errores.

El test Jarque-Bera permite identificar si los errores del modelo poseen no normalidad, esto se da si los valores de probabilidad indican que este test es significativo ( $\mathrm{P}$-valor $<0.05$ ), lo cual podría ser el resultado de falta de variables explicativas. Sin embargo hay que tener en cuenta que esto no significa un problema grave en un modelo en particular ya que algunas 
propiedades en los análisis de regresión tienden a ser asintóticos incluso si no se asume la normalidad (Anselin, 2005).

\section{Heterocedasticidad.}

Algunos test comúnmente utilizados para evaluar la presencia de heterocedasticidad (varianza no constante en los residuales) en los modelos de regresión, son los test de Breusch-Pagan, Koenker-Bassett y White. Los dos primeros test son prácticamente los mismo a diferencia que en el test de Koenker-Bassett los residuos son studenizados (Anselin, 2005) y el test de White es una especificación robusta en el caso que exista alguna duda en los resultados de los otros test de heterocedasticidad. Estos test al rechazar la hipótesis nula de homocedasticidad, es decir ser significativos (P-valor $<0.05)$ indican que los modelos estudiados poseen problemas de heterocedasticidad en sus datos.

\section{Matriz de pesos espaciales $W$.}

Una de las formas más comunes de representar la ubicación geográfica de un conjunto de polígonos es a través de una Matriz de Conectividad o de Contigüidad denominada también Matriz de pesos espaciales. Esta es una matriz cuadrada que tiene el mismo número de filas o columnas que el número de polígonos independientes del mapa en estudio y que por convención se le denomina por W (Aroca, 2000).

Esta matriz representa la relación que tiene cada una de las regiones con las demás regiones del espacio en estudio, tal como se vería en un mapa. Existen una infinidad de formas en que la matriz de contigüidad puede ser construida, la más sencilla es utilizando notación binaria, donde 1 representa la presencia de contigüidad espacial entre dos unidades y 0 la ausencia de contigüidad espacial entre dos unidades. Una matriz construida de esta manera es simétrica (Bohórquez \& Ceballos, 2008).

Al considerar los datos espaciales como una retícula de cuadrados, por ejemplo para el caso de estudio una red de pixeles de una imagen satelital, habrá por lo menos cuatro vecinos que comparten un borde en cada lado del cuadrado. Como lo explica Celemín (2009) podría haber ocho datos espaciales para cada observación si se consideran adicionalmente aquellos puntos que limitan con los vértices del cuadrado en cuestión. Cuando se tienen en cuenta los cuatro elementos que comparten borde se habla de contigüidad tipo Rook. En el caso de los ocho vecinos se habla de contigüidad tipo Queen y si se toman solamente los vecinos contiguos por el vértice se denomina Bishop. Estos nombres corresponden al movimiento que realizan la torre, la reina y el alfil en un tablero de ajedrez, como se ilustra en la Figura 19. 


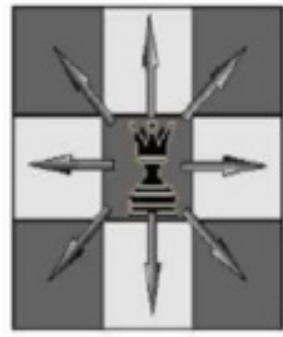

Queen (Reina)

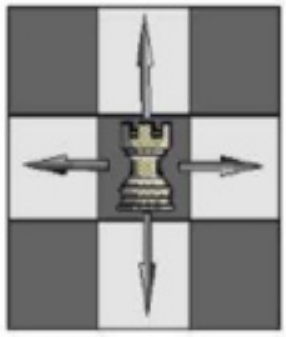

Rook (Torre)

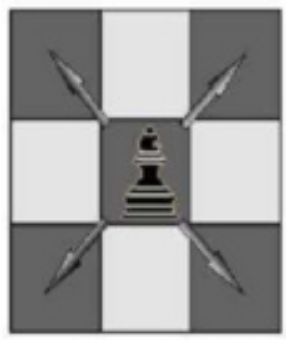

Bishop (Alfil)

Figura 19. Tipos de vecindad para los datos considerados en la matriz de pesos espaciales W.

Fuente: Celemín, 2009.

Debido a que se tiene pixeles de las imágenes con forma regular, es adecuado trabajar con la conformación Queen. Dicha matriz de pesos espaciales se calculó por medio del software $\mathrm{GeoDa}{ }^{\circledR}$, originando un archivo plano txt con dichas relaciones, el cual fue utilizado en la realización de modelos de regresión espacial y la identificación de autocorrelación espacial por medio del coeficiente I de Moran (1950).

\section{Autocorrelación espacial.}

El análisis de regresión trata de la dependencia de las variables explicativas, con el objeto de estimar y/o predecir la media o valor promedio poblacional de la variable dependiente en términos de los valores conocidos ojos de las variables explicativas. Se trata de encontrar un método para hallar una recta que se ajuste de una manera adecuada a la nube de puntos definida por todos los pares de valores muéstrales. Este método de estimación se fundamenta en una serie de supuestos, los que hacen posible que los estimadores poblacionales que se obtienen a partir de una muestra, adquieran propiedades que permitan señalar que los estimadores obtenidos sean los mejores (Villena \& Manzano, 2009).

Este tipo de autocorrelación prueba la primera ley geográfica de Tobler (1970) que afirma: todo está relacionado con todo lo demás, pero las cosas cercanas están más relacionadas que las distantes.

La autocorrelación espacial implica que el valor de una variable se encuentra condicionado por el valor que esa variable asume en una región vecina. La vecindad no necesariamente quedará definida como contigüidad física, sino que existen una gran cantidad de criterios para definirla, a partir de una matriz de contactos (Baronio, et al., 2012). Este tipo de autocorrelación prueba la primera ley geográfica de Tobler (1970) que afirma: todo está relacionado con todo lo demás, pero las cosas cercanas están más relacionadas que las distantes (Perdomo, 2005). 


\section{Detección de autocorrelación espacial.}

El coeficiente I de Moran es uno de los cálculos más utilizados para la detección y medición de la autocorrelación espacial global comparando los valores de cada localización con los valores de las localizaciones vecinas.

El diseño es similar al coeficiente de correlación de Pearson. Sus valores varían entre +1 y -1 , donde el primer valor significa una autocorrelación positiva perfecta (perfecta concentración), y el segundo una autocorrelación negativa perfecta (perfecta dispersión); el cero significa un patrón espacial totalmente aleatorio. La diferencia entre los dos coeficientes de Moran y Pearson se basa en que en el primer caso la asociación de valores en el conjunto de datos está determinada por una matriz de distancias o contigüidad W que predefine los valores vecinos (los valores para el cómputo del coeficiente) (Perdomo, 2005).

Este coeficiente se calculó mediante el software GeoDa® con base en la matriz W de cada set de datos por parcela identificadas en el estudio.

\section{Test de Multiplicadores de Lagrange.}

Si el coeficiente I de Moran indica que existe autocorrelación en los residuales del modelo se estaría violando uno de los supuestos básicos de $\mathrm{MCO}$, indicando que es necesario reconsiderar el modelo. Una de las opciones a tomar es el planteamiento de un modelo de regresión que contemple el componente espacial. Para esto se remite al test de multiplicadores de Lagrange LM el cual requiere que el término de error siga una distribución normal y se basa en las propiedades asintóticas de los estimadores de máxima verosimilitud.

Como lo explica Baronio et al. (2012) para el testeo de dependencia espacial sustantiva (también conocido como modelo Lag) son habituales los contrastes basados en los multiplicadores de Lagrange, el LM-Lag propuesto por Anselin (1988) y el test LM-LE de Bera y Yoon (1992). El LM-LE es robusto frente a la existencia de un término de perturbación correlacionado espacialmente. Para la dependencia espacial residual (también conocido como modelo de Error espacial) es frecuente la utilización de los contrastes LMErr (Burridge, 1980) y su versión robusta LM-EL (Bera y Yoon, 1992), también basados en los multiplicadores de Lagrange. La ventaja del test LM-EL es que resulta robusto ante posibles especificaciones erróneas locales como la presencia de una variable endógena retardada espacialmente (Moreno y Vayá, 2000) 
Al genera el Modelo de MCO en GeoDa® se presentan como resultado los estadísticos de los anteriores test en su forma estándar y robusta. Si el test de I de moran indica que no existe autocorrelación en los erros se puede continuar con un modelo $\mathrm{MCO}$, de lo contrario estimar el modelo de regresión espacial alternativo. Por lo tanto, si LM-Error rechaza la hipótesis nula, pero LM-Lag no es así, estimar un modelo de error espacial, y viceversa. Si ambos test resultan ser significativos, se opta por evaluar los valores de sus formas robustas, en donde se toma el valor mayor, siendo así si se tiene el valor de LMError robusto mayor al LM-Lag robusto, se considera adoptar un modelo de regresión espacial Error. La Figura 20 presenta el diagrama para la toma de esta decisión se puede apreciar en Anselin (2005).

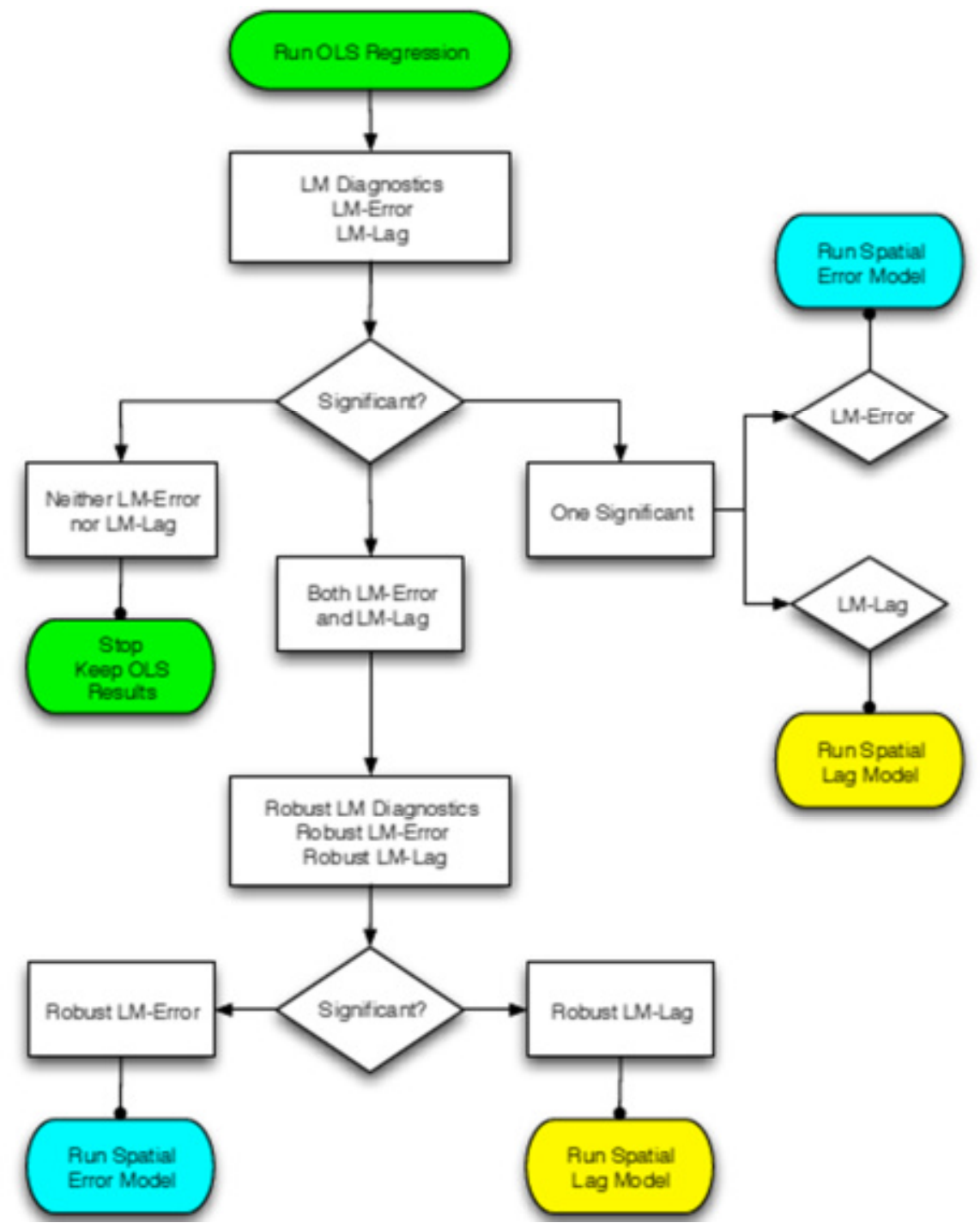

Figura 20. Diagrama de decisión para modelos espaciales basados en multiplicadores de Lagrange. Fuente: Anselin, 2005. 


\subsection{Validación de los modelos.}

Para validar los modelos es recomendable tener claros los conceptos de exactitud y posición La exactitud mide la performance de un modelo; es decir, la cercanía entre los valores simulados y los observados. Un modelo exacto no arroja los mismos resultados, pero estos se encuentran siempre dentro de un rango alrededor de la medida observada (Cabrera, 2012).

De igual forma según Cabrera (2012) estos dos conceptos están relacionados con otros dos: errores aleatorios y errores sistemáticos. Los errores aleatorios son errores propios de fluctuaciones aleatorias de la magnitud medida o del proceso de medición y no son controlables. Debido a que son aleatorios, la medición realizada se encontrará alrededor de la medida real, muy característica de las medidas exactas. Por otro lado, los errores sistemáticos son errores que se repiten permanentemente y aproximadamente en la misma magnitud; esta característica hace que todas las mediciones se encuentren "desviadas" en un mismo valor de la medida real (como las medidas precisas). De esta manera, si se determina el valor sistemático, es fácil corregir la medida y obtener medidas mucho más exactas.

Usualmente los modelos buscan el principio de exactitud en sus especificaciones el cual se apoya en la bondad de ajuste que tenga el modelo en sí. Por tal razón se utilizó una medida de bondad de ajuste como lo es el criterio de Nash-Sutcliffe el cual mide cuánto de la variabilidad de las observaciones es explicada por la simulación. Si la simulación es perfecta, $\mathrm{E}=1$; si se intentase ajustar las observaciones con el valor promedio, entonces $\mathrm{E}=0$. Algunos valores sugeridos mencionados por Cabrera (2012) para la toma de decisiones son resumidos en la Tabla 3.

Tabla 3. Rangos de validación por el criterio de Nash-Sutcliffe

\begin{tabular}{ccc} 
& $\mathbf{E}$ & Ajuste \\
\hline \hline$<0.2$ & Insuficiente \\
$0.2-0.4$ & Satisfactorio \\
$0.4-0.6$ & Bueno \\
$0.6-0.8$ & Muy bueno \\
$>0.8$ & Excelente \\
\hline
\end{tabular}

Fuente: Cabrera, 2012.

Los modelos seleccionados que se ajusten mejor al caso de estudio serán evaluados con este coeficiente, para evaluar de esta forma que tan cercano es la predicción con base en los datos de rendimiento de la misma zona y del mismo tipo de cultivo. Para este proceso se 
utilizó el cálculo generado por la página web del WHAT (Web-based Hydrograph Analysis Tool) (Lim and Engel, 2004).

https://engineering.purdue.edu/mapserve/WHAT/compute_r2_nash_sutcliffe.html.

\subsection{Propuesta de una herramienta para la contribución de la predicción de rendimiento agrícola al ordenamiento territorial de la cuenca hidrográfica.}

En el territorio Mar y Sierras, específicamente en el partido de Tandil, en los suelos de aptitud agrícola una rotación que se da con frecuencia es: cultivo de cosecha fina (Trigo o Cebada) y al año siguiente cultivo de cosecha gruesa, soja, girasol o maíz en suelos más profundos (Schapiro et al., 2015). Por esta razón se genera la necesidad de controlar y manejar cada vez más con mayor eficiencia dichos cultivos, utilizando herramientas de última tecnología que permitan llevar un seguimiento, tanto a los cultivos realizados en años posteriores como los actuales, sobre los rendimientos generados a nivel agropecuario en el territorio.

Existen diversas formas de evaluar y acompañar el rendimiento, las herramientas geomáticas contribuyen a este fin, por ejemplo la experimentación realizada por el INTA en el 2015, donde se evaluó el manejo de nutrición nitrogenada en cultivos de trigo y cebada por medio de NDVI de referencia y observado utilizando información brindada por sensores remotos como cámaras multiespectrales en plataformas aéreas y radiómetros de campo GreenSeeker (Lopez de Sabando et al., 2015).

Los sensores son herramientas que debemos integrar a nuestro método de diagnóstico tradicional. Estos nos ofrecen la ventaja de poder hacer muchas determinaciones dentro del lote. Lo cual, abre la posibilidad del manejo sitio específico de la fertilización dentro del lote, e incluso poder realizar aplicaciones de corrección en tiempo real (sensores incluidos en los equipos que realizan la fertilización permitiendo tomar lecturas y en el mismo momento realizar aplicaciones) (Lopez de Sabando et al., 2015).

En el presente trabajo se buscó proponer una herramienta geomática adicional para complementar el manejo del sector agropecuario al interior de la cuenca hidrográfica, concatenando procesamiento de imágenes satelitales y rendimiento agrícola que contribuyan a aportar información relevante sobre la creación de mapas de rendimiento a partir de NDVI obtenidos de dichas imágenes, las cuales son de fácil acceso para el público en general. 
Considerando que: para lograr cultivos de trigo y cebada de alta producción se deben considerar una correcta utilización de los insumos para disminuir los efectos de factores limitantes y reductores de la producción como nutrientes y plagas. Sin embargo, uno de los factores más importante para el logro de altos rendimientos de trigo es la correcta selección de fecha de siembra y variedad en función del ambiente (Lopez de Sabando \& Arriaga, 2015). Por esta razón, en esta tesis se realizó un proceso de depuración de la información de rendimiento para efectuar un análisis de correlación multitemporal con las fechas establecidas en la metodología y de esta forma plantear un modelo de predicción que se adaptó a las características propias de los cultivos estudiados, posibilitando la generación de base de datos para futuros estudios y toma de decisiones respecto a la planificación del territorio de la región en cuestión. 


\section{RESULTADOS}

\subsection{Identificación y definición de los límites de las parcelas de estudio.}

\subsubsection{Procesamiento de imágenes satelitales.}

Partiendo de las imágenes Landsat 8 requeridas para la zona de estudio y correspondientes al periodo de análisis, proveniente de la USGS, se efectuó la corrección radiométrica a cada una de ellas para llevar los niveles digitales a valores de reflectancia y/o radiancia en el techo de la atmósfera TOA, con el módulo Semi-Automatic Classification de QGIS®. Las imágenes logradas a partir de este procesamiento se listan en la Tabla 4.

Tabla 4. Imágenes satelitales Landsat 8 que intervienen en el estudio.

\begin{tabular}{cllc} 
Sensor & \multicolumn{1}{c}{ Nombre } & \multicolumn{1}{c}{ Fecha } & Path-Row \\
\hline \hline \multirow{4}{*}{ Landsat 8 } & LC82250862014209LGN00 & 28-Jul-2014 & 225-086 \\
& LC82250862014225LGN00 & 14-Aug-2014 & 225-086 \\
& LC82240862014250LGN00 & 8-Sep-2014 & 224-086 \\
& LC82250862014289LGN00 & 16-Oct-2014 & 225-086 \\
& LC82250862014321LGN00 & 17-Nov-2014 & 225-086 \\
& LC82240862014330LGN00 & 26-Nov-2014 & 224-086 \\
& LC82250862014337LGN00 & 3-Dec-2014 & 225-086 \\
& LC82240862014346LGN00 & 12-Dec-2014 & 224-086 \\
\hline
\end{tabular}

Cada banda de las anteriores imágenes quedaron con mencionada corrección, no obstante solo fueron utilizadas las banda requeridas para obtener los índices de vegetación necesarios para el estudio.

\subsubsection{Identificación y definición de los límites de las parcelas de estudio.}

Utilizando los insumos de las imágenes satelitales y siguiendo las etapas de digitalización propuestas al final de la sección 4.2.1, se crearon las parcelas requeridas para el presente estudio, como se muestra en la Figura 21. La primera etapa definió el límite y la cantidad de parcelas a tener en cuenta y en la segunda se pulieron y descartaron zonas al interior de las parcelas las cuales eran catalogadas como bajos, donde se acumulaba exceso de agua, o zonas de tosca donde los suelos poseen características atípicas al contexto de los cultivos. De esta forma se formaron huecos topológicos donde no se tomaron información del cultivo. Con las imágenes NDVI procesadas se refinaron los linderos de las parcelas para descartar pixeles que contengan en su mayoría vegetación diferente a la del cultivo 
contemplado. En el proceso se descartó una parcela digitalizada previamente, ya que debido al estadio de cultivo encontrado en las visitas de campo no era útil en el estudio.
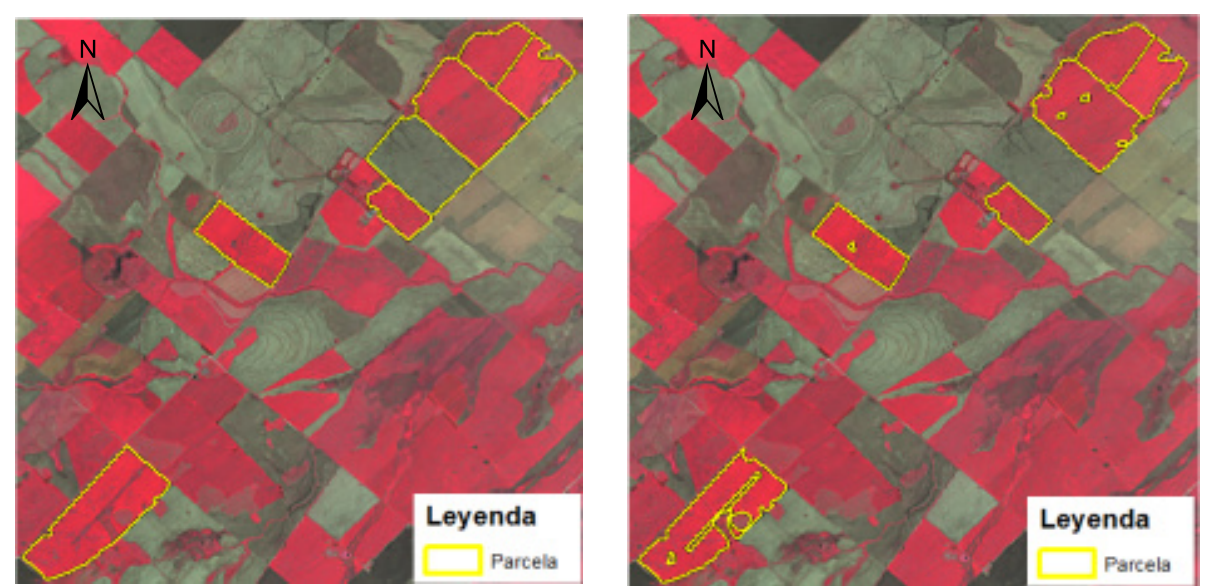

Figura 21. Digitalización de parcelas, primera etapa (izquierda) - segunda etapa (derecha).

Fuente: elaboración propia.

Imagen base: Landsat 17-Nov-2014.

Teniendo los polígonos definidos de las parcelas junto con los datos recolectados en campo se asignaron los atributos a cada área. Se definió el tipo de cultivo perteneciente a cada parcela y un identificador único, como se presenta en la Figura 22, el cual coincide con el identificador de las mediciones con el radiómetro en los puntos de muestreo tomados.

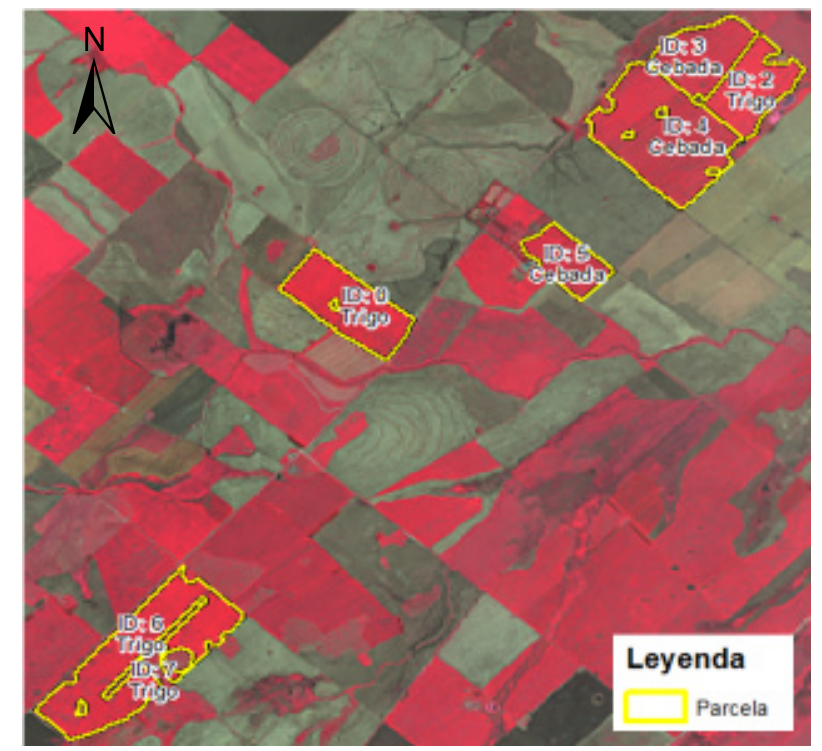

Figura 22. Parcelas digitalizadas y nomenclador según su cultivo e identificador.

Fuente: elaboración propia.

Imagen base: Landsat 17-Nov-2014.

Como aclaración a la nomenclatura propuesta de la Figura 21, la parcela con Id 0 se definió así debido a que en ella no se tomaron datos con el radiómetro en campo, no obstante contenía suficiente información para ser analizada; el Id 1 no aparece en las áreas, ya que fue un punto tomado sobre rastrojo como control y calibración del equipo en campo; el Id 
7 es una parcela al interior de otra con mayor extensión (parcela 6), la cual es una franja en donde se aplicó fertilización variable con nitrógeno.

Una vez definidas e identificadas parcelas se utilizaron como base para el procesamiento de los datos contenidos en ellas, provenientes del manejo de las imágenes satelitales y datos de rendimiento suministrados por el productor.

\section{2 Índices de vegetación.}

\subsection{1 Índice de Vegetación de Diferencia Normalizada (NDVI)}

Los valores de NDVI obtenidos por medio de la operación entre bandas de las imágenes satelitales y posteriormente limitados por los linderos de las parcelas para las fechas establecidas en el estudio se representan a continuación. En la Tabla 5 se presentan la totalidad de valores o datos NDVI por pixel correspondiente a cada parcela una vez realizado los recortes con las máscaras. Las Tablas 6 y 7 muestran datos estadísticos descriptivos de los valores NDVI para los cultivos de cebada y trigo respectivamente, de cada parcela en el transcurso del perdido establecido.

Tabla 5. Total de datos NDVI al interior de cada parcela

Cultivo Parcela Datos NDVI

\begin{tabular}{llc}
\hline \hline \multirow{3}{*}{ Cebada } & 3 & 674 \\
& 4 & 1571 \\
& 5 & 479 \\
\hline \multirow{3}{*}{ Trigo } & 0 & 883 \\
& 2 & 691 \\
& 6 & 1771 \\
& 7 & 147 \\
\hline \multicolumn{2}{c}{ Total } & 6216
\end{tabular}

Tabla 6. Estadística descriptiva de los valores NDVI para el cultivo de cebada respecto a las fechas establecidas

\begin{tabular}{ccccc|cccc|ccccc} 
Parcela & \multicolumn{5}{c|}{3} & \multicolumn{4}{|c|}{$\mathbf{4}$} & \multicolumn{4}{c}{$\mathbf{5}$} \\
\hline \hline Fecha & Min & Max & Med & DS & Min & Max & Med & DS & Min & Max & Med & DS \\
\hline Jul 28 & 0.22 & 0.44 & 0.28 & 0.02 & 0.22 & 0.64 & 0.28 & 0.04 & 0.18 & 0.47 & 0.24 & 0.03 \\
Ago 14 & 0.35 & 0.58 & 0.43 & 0.03 & 0.32 & 0.83 & 0.45 & 0.04 & 0.29 & 0.62 & 0.35 & 0.04 \\
Sept 08 & 0.41 & 0.74 & 0.58 & 0.08 & 0.35 & 0.84 & 0.68 & 0.08 & 0.42 & 0.72 & 0.60 & 0.04 \\
Oct 16 & 0.58 & 0.93 & 0.89 & 0.05 & 0.32 & 0.92 & 0.88 & 0.05 & 0.47 & 0.93 & 0.88 & 0.07 \\
Nov 17 & 0.60 & 0.83 & 0.78 & 0.03 & 0.40 & 0.86 & 0.76 & 0.04 & 0.49 & 0.83 & 0.77 & 0.05 \\
Nov 26 & 0.53 & 0.81 & 0.65 & 0.04 & 0.34 & 0.85 & 0.62 & 0.06 & 0.39 & 0.77 & 0.68 & 0.04 \\
Dic 03 & 0.42 & 0.79 & 0.51 & 0.04 & 0.38 & 0.85 & 0.49 & 0.08 & 0.42 & 0.75 & 0.55 & 0.04 \\
Dic 12 & 0.34 & 0.68 & 0.37 & 0.03 & 0.33 & 0.74 & 0.39 & 0.05 & 0.34 & 0.70 & 0.40 & 0.06 \\
\hline Min: mínimo, Max: máximo, Med: media, DS: desviación estándar
\end{tabular}


Tabla 7. Estadística descriptiva de los valores NDVI para el cultivo de trigo respecto a las fechas establecidas

\begin{tabular}{|c|c|c|c|c|c|c|c|c|c|c|c|c|c|c|c|c|}
\hline \multirow{2}{*}{$\begin{array}{c}\text { Parcela } \\
\text { Fecha }\end{array}$} & \multicolumn{4}{|c|}{0} & \multicolumn{4}{|c|}{2} & \multicolumn{4}{|c|}{6} & \multicolumn{4}{|c|}{7} \\
\hline & Min & Max & Med & DS & Min & Max & Med & DS & Min & Max & Med & DS & Min & Max & Med & DS \\
\hline Jul 28 & 0.18 & 0.71 & 0.23 & 0.07 & 0.22 & 0.43 & 0.25 & 0.03 & 0.16 & 0.58 & 0.23 & 0.05 & 0.18 & 0.34 & 0.21 & 0.02 \\
\hline Ago 14 & 0.27 & 0.84 & 0.34 & 0.07 & 0.30 & 0.54 & 0.36 & 0.03 & 0.27 & 0.71 & 0.33 & 0.04 & 0.28 & 0.50 & 0.32 & 0.03 \\
\hline Sept 08 & 0.09 & 0.82 & 0.44 & 0.06 & 0.38 & 0.74 & 0.53 & 0.05 & 0.31 & 0.72 & 0.49 & 0.03 & 0.40 & 0.57 & 0.49 & 0.02 \\
\hline Oct 16 & 0.53 & 0.92 & 0.87 & 0.05 & 0.64 & 0.93 & 0.90 & 0.04 & 0.56 & 0.93 & 0.88 & 0.05 & 0.65 & 0.92 & 0.85 & 0.05 \\
\hline Nov 17 & 0.47 & 0.83 & 0.73 & 0.05 & 0.59 & 0.87 & 0.83 & 0.04 & -- & -- & -- & -- & -- & -- & -- & -- \\
\hline Nov 26 & 0.42 & 0.85 & 0.77 & 0.07 & 0.57 & 0.86 & 0.80 & 0.05 & 0.43 & 0.86 & 0.75 & 0.06 & 0.53 & 0.83 & 0.69 & 0.07 \\
\hline Dic 03 & 0.40 & 0.85 & 0.76 & 0.07 & 0.47 & 0.87 & 0.78 & 0.08 & 0.48 & 0.89 & 0.78 & 0.06 & 0.55 & 0.86 & 0.72 & 0.07 \\
\hline Dic 12 & 0.33 & 0.72 & 0.55 & 0.05 & 0.37 & 0.71 & 0.51 & 0.06 & 0.37 & 0.75 & 0.54 & 0.07 & 0.37 & 0.74 & 0.50 & 0.06 \\
\hline
\end{tabular}

Los anteriores datos surgen de la totalidad de pixeles que intersecta a cada parcela, sin embargo posteriormente en el desarrollo del trabajo al momento de cruzar con los valores de rendimiento de cada parcela se descartaron pixeles, ya que no todos los pixeles poseen información de puntos de rendimiento en su interior, ya sea por que poseen la mayoría de su área por fuera de la parcela o por carencia espacial del valor en sí de rendimiento.

\subsubsection{Captura de datos radiométricos en campo.}

En los viajes a campo realizados, se utilizó el radiómetro estableciendo previamente los parámetros necesarios al momento de la captura de información espectral, pertenecientes a las coberturas del suelo al interior de las parcelas definidas. En gabinete se procesó dicha información, teniendo en cuenta los tiempos de integración respectivos de cada punto de muestreo, con lo cual se generaron firmas espectrales de cada punto, como se aprecia en el Gráfico 2. 


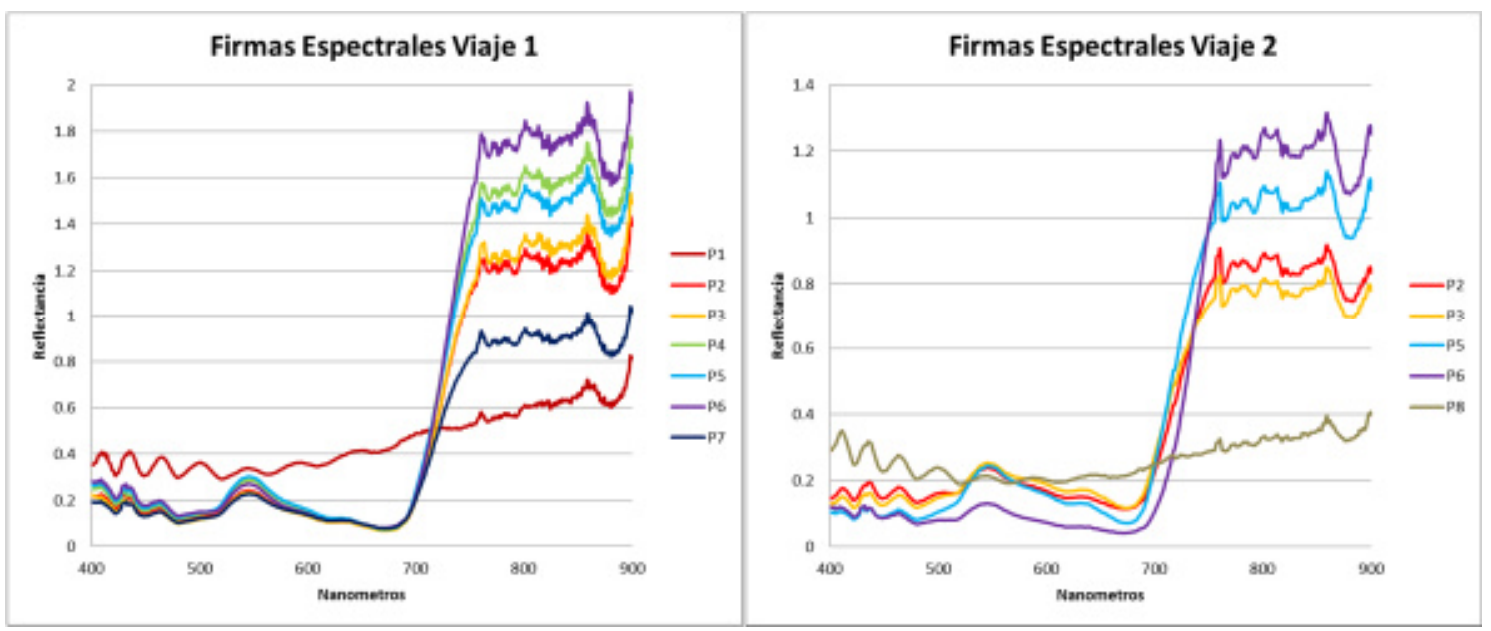

Gráfico 2. Firmas espectrales de los puntos de muestreo para los viajes de recolección de datos en campo.

Fuente: elaboración propia.

La firma de los puntos 4 y 7 no aparecen registradas en la gráfica del segundo viaje debido a motivos de difícil acceso, ya que el cultivo en esta fecha había alcanzado gran altura, al igual que se evidencio en terreno que las coberturas contiguas de las parcelas vecinas se habían homogenizado, por tal razón el punto 4 al pertenecer a una parcela con características similares a el área del punto 3 no fue obligatoria su captura. La parcela del punto 7 está contenida al interior del área perteneciente al punto 6, poseyendo las $2 \mathrm{el}$ mismo tipo de cultivo pero con fertilización variable. El punto 8 se tomó adicional, en las cercanías del punto 4, pero este era un cultivo de maíz recién emergido, en donde se estaban generando sus primeros brotes, siendo la cobertura vegetal insuficiente para reportar la firma espectral requerida (esta firma estaría más asociada a la del suelo desnudo, al ser el porcentaje de cobertura muy bajo).

Junto con la visita de cada parcela para la captura de información con el radiómetro se evaluó el estado fenológico y fitosanitario de los cultivos. Se tomó registro fotográfico y se observó directamente en qué estado se encontraba cada cultivo al interior de las áreas. Un resumen general para los estadios asociados a los cultivos encontrados en los viajes de campo se presenta en la Tabla 8 (también se puede apreciar gráficamente en la Figura 14), seguido de la descripción de cada punto muestral en donde se tomó información.

Tabla 8. Estadio de los cultivos en los viajes de campo.

\begin{tabular}{lcc}
\multicolumn{1}{c}{ Cultivo } & Viaje de campo 1 & Viaje de campo 2 \\
\hline \hline Trigo & Encañazón & Espigazón/Antesis \\
Cebada & Espigazón/Antesis & Inicio llenado de grano \\
\hline
\end{tabular}




\section{Punto 1.}

Este punto se capturo al inicio del primer viaje, en la entrada de la estancia La Esperanza, el cual se encentra junto a la primera parcela de estudio, con el propósito de servir como punto de validación y calibración del espectro radiómetro y para comparación de firmas entre suelo parcialmente cubierto con rastrojo o vegetación corta y los cultivos a visitar (Figura 23).

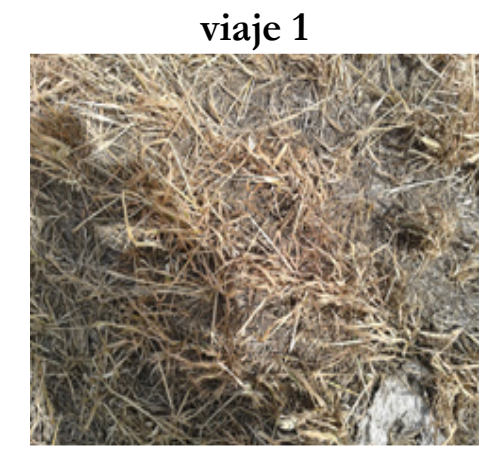

viaje 2

Figura 23. Cobertura del suelo en los viajes de campo correspondiente al punto de muestreo 1.

Fuente: elaboración propia.

En el segundo viaje no fue necesario tomar información en este punto, por lo que se prosiguió directamente a medir el siguiente punto muestral.

\section{Punto 2.}

En este punto se localiza un cultivo de trigo el cual en el primer viaje su estado fenológico era de fin de macollaje y en el segundo viaje espigazón. El estado fitosanitario observado era adecuado sin ninguna observación en particular (Figura 24).
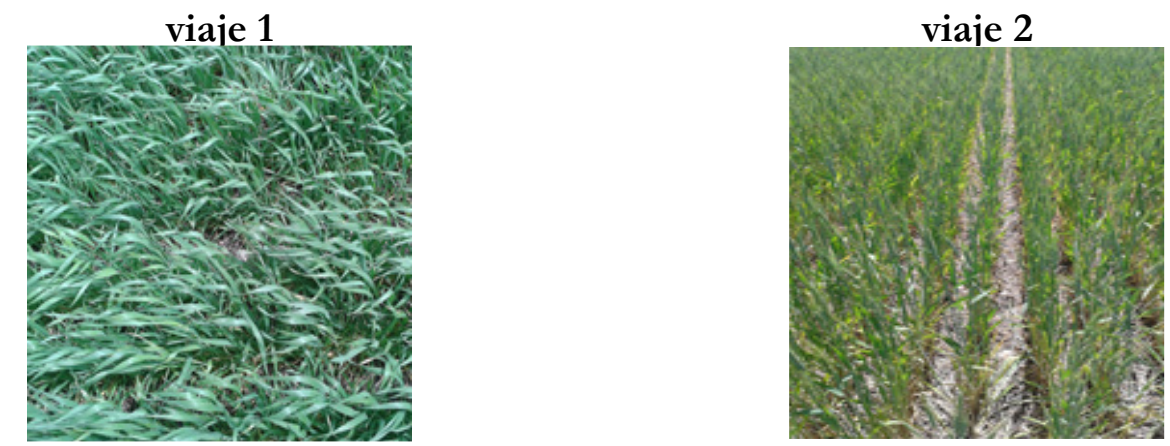

Figura 24. Cobertura del suelo en los viajes de campo correspondiente al punto de muestreo 2. Fuente: elaboración propia.

\section{Punto 3.}

En este lugar se tomó datos sobre un cultivo de cebada, en el primer viaje se encontraba cercano a espigazón y en el segundo en inicio de llenado de grano. El estado del cultivo es óptimo (Figura 25). 
viaje 1

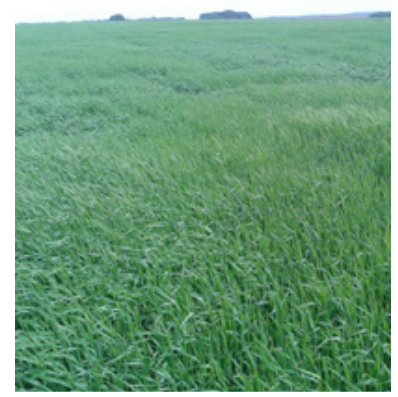

viaje 2

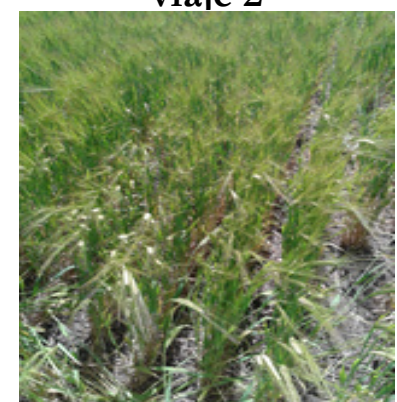

Figura 25. Cobertura del suelo en los viajes de campo correspondiente al punto de muestreo 3. Fuente: elaboración propia.

\section{Punto 4.}

En este punto se encuentra un cultivo de cebada, el cual se encontraba en encañazón en el primer viaje. Debido a que la parcela de este punto se encuentra contigua a la parcela del cultivo medido en el punto 3 la cual poseían características similares, en el segundo viaje por factores de tiempo y accesibilidad se decidió no tomar medición en este punto dado que se observaba condiciones uniformes entre los cultivos en su etapa de desarrollo correspondiente (Figura 26).

viaje 1

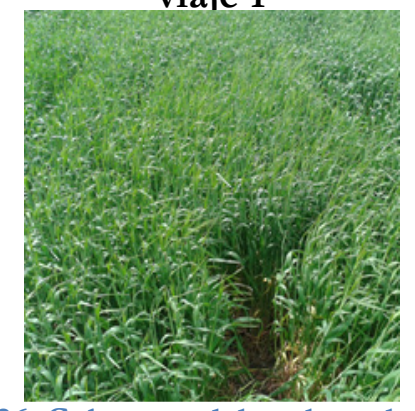

viaje 2

No se visito

Figura 26. Cobertura del suelo en los viajes de campo correspondiente al punto de muestreo 4.

Fuente: elaboración propia.

\section{Punto 5.}

Se midieron los valores de un cultivo de cebada, en el primer viaje se encontraba en etapa de espigazón y en el segundo en llenado de grano. Se encontró en buenas condiciones fitosanitarias (Figura 27).

\section{viaie 1}

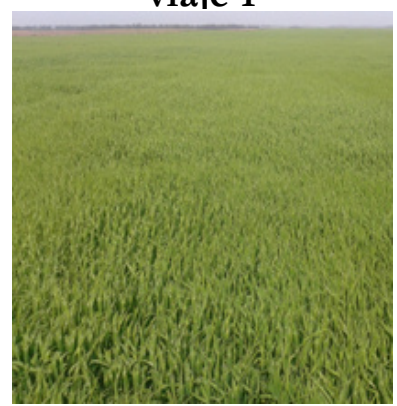

viaje 2

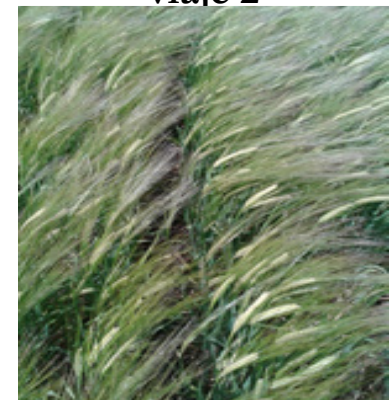

Figura 27. Cobertura del suelo en los viajes de campo correspondiente al punto de muestreo 5. Fuente: elaboración propia. 


\section{Punto 6.}

En el cultivo donde se ubicó este punto de muestreo es un área de gran extensión el cual tiene fertilización variable de nitrógeno en una franja al interior de este. El punto de medición se localizó en la esquina de entrada de la parcela, donde existe fertilización con nitrógeno. En el primer viaje el cultivo se encontró en etapa de espigazón y en el segundo de llenado de grano. El estado fitosanitario fue óptimo en ambas campañas (Figura 28).

viaje 1

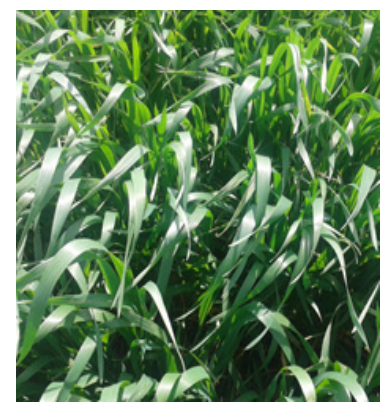

viaje 2

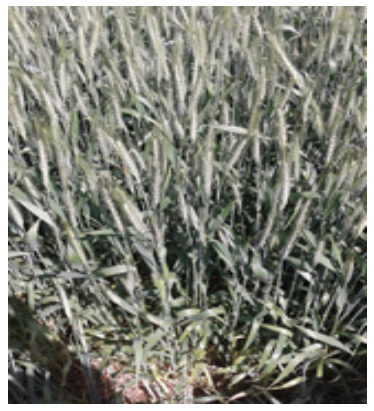

Figura 28. Cobertura del suelo en los viajes de campo correspondiente al punto de muestreo 6. Fuente: elaboración propia.

\section{Punto 7.}

Este punto se ubica al interior de la parcela de mayor extensión perteneciente al punto de muestreo 6 , no obstante los datos se tomaron en la franja que no poseía fertilización con nitrógeno, por lo tanto la altura de las plantas en esta zona inferior al trigo circundante que contiene fertilización. De igual forma la etapa de esta franja se encuentra en espigazón y se encontraba en un óptimo estado. Sin embargo en el segundo viaje al localizarse en la zona perteneciente a este punto se evidencio que esta franja se había homogenizado, en altura y vigor, con el trigo fertilizado, por esta razón y por motivos de logísticos no se tomaron datos de esta franja en el segundo viaje (Figura 29).

viaje 1

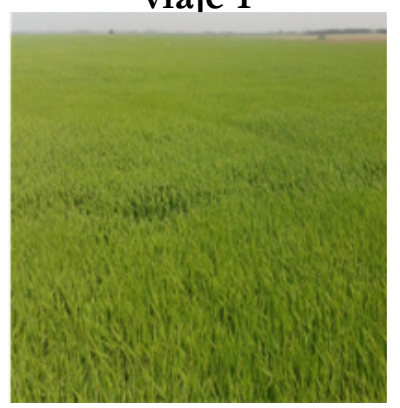

viaje 2

No se visito

Figura 29. Cobertura del suelo en los viajes de campo correspondiente al punto de muestreo 8. Fuente: elaboración propia. 


\section{Punto 8.}

En el transcurso del segundo viaje, al no poder acceder al punto 4, se decidió tomar mediciones de un cultivo de maíz el cual se encontraba en su etapa joven de crecimiento. El punto muestral se encuentra cerca a la vía de acceso y a unas cárcavas de erosión hídrica que intersectaban la parcela del cultivo en cuestión (Figura 30).

viaje 1

No se visito

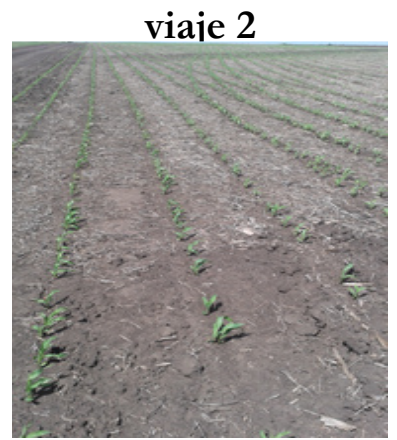

Figura 30. Cobertura del suelo en los viajes de campo correspondiente al punto de muestreo 8. Fuente: elaboración propia.

La información capturada en campo junto con la visita realizada, la cual permitió observar en detalle el contexto de la realidad que se quiere modelar, fue de gran apoyo para la interpretación de los datos en gabinete, la cual fue procesada, estructurada y utilizada en los diferentes etapas del estudio, siendo estos la base para la correlación y espacialización del trabajo.

\subsubsection{Cálculo de NDVI con datos radiométricos in situ}

Con el propósito de validar y rectificar los valores de NDVI obtenidos por las imágenes satelitales, ya que estos valores son los que se utilizaron para el estudio multitemporal, se compararon dichos datos con los valores NDVI obtenidos por el radiómetro en campo.

Los valores de NDVI obtenidos a partir de los datos del radiómetro fueron calculados de igual forma con la Ecuación 2, teniendo en cuanta el valor medio de los rangos o anchos de banda de banda del rojo e infrarrojo definidos por el sensor Landsat 8. Dichos valores se presentan en la Tabla 9 utilizada para la validación de valores NDVI (los valores nulos son los puntos en cada viaje en donde no se tomaron datos de campo).

\subsubsection{Validación de valores NDVI satelital con NDVI radiómetro}

Teniendo generados los valores NDVI provenientes de cada sensor se procedió a realizar la comparación entre ellos, para esto se implementó un coeficiente de correlación de Pearson. La compilación de dichos valores se presenta en la Tabla 9. 
Tabla 9. Compilación de valores NDVI obtenidos del radiómetro e imágenes de satélite.

\begin{tabular}{llcccc} 
& & \multicolumn{2}{c}{ NDVI Radiómetro } & \multicolumn{2}{c}{ NDVI Imágenes Landsat } \\
\cline { 3 - 6 } Punto & Cultivo & $\begin{array}{c}\text { 21 de } \\
\text { octubre }\end{array}$ & $\begin{array}{c}\text { 14 de } \\
\text { noviembre }\end{array}$ & $\begin{array}{c}\text { 16 de } \\
\text { octubre }\end{array}$ & $\begin{array}{c}\text { 26 de } \\
\text { noviembre }\end{array}$ \\
\hline \hline 1 & Rastrojo & 0.24 & -- & -- & -- \\
2 & Trigo & 0.87 & 0.74 & 0.87 & 0.74 \\
3 & Cebada & 0.88 & 0.69 & 0.90 & 0.63 \\
4 & Cebada & 0.89 & -- & 0.88 & -- \\
5 & Cebada & 0.89 & 0.83 & 0.91 & 0.66 \\
6 & Trigo & 0.90 & 0.92 & 0.91 & 0.82 \\
7 & Trigo & 0.82 & -- & 0.85 & -- \\
8 & Maíz & -- & 0.26 & -- & -- \\
\hline
\end{tabular}

Para la comparación de los datos del mes de octubre se tomaron en cuenta los valores de los puntos de muestreo 2 al 7, dando como resultado un coeficiente de correlación de 0.85 ; para los datos del mes de noviembre se consideraron los valores de los puntos 2, 3, 5, 6 obteniendo un coeficiente de 0.52. Siendo estos valores altos, en especial los de octubre, ya que se está comparando una variable general, como lo es el valor de NDVI de las imágenes de satélite ya que contempla un área de 30 metros cuadrados, con una variable específica, la cual es el valor del radiómetro ya que solo se toma a unos pocos centímetros del suelo y su área de cobertura es mucho menor al pixel de las imágenes satelitales.

\subsection{Morfometría de la cuenca.}

Los drenajes obtenidos por Senisterra et al. (2014) sirvieron de referencia al momento de generar una nueva red de drenajes y junto con los datos de elevación del terreno se obtuvo el límite de cuenca y subcuencas (11 en total) con configuraciones similares a las halladas por Senisterra et al. (2014) para la zona de estudio en común, conservando el orden de numeración o identificador de las mismas, como se presenta en la Figura 31.

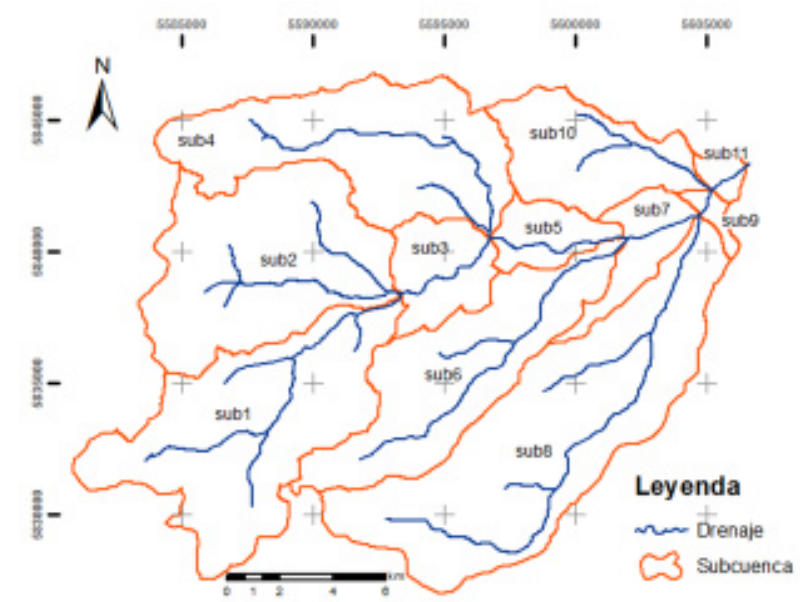

Figura 31. Configuración de subcuencas de la cuenca alta del arroyo Napaleofú.

Fuente: elaboración propia. 
El área donde pertenecen los datos que se utilizaran para este estudio se encuentra al interior de la subcuenca 5, 6 y 10, donde las parcelas de cebada 3 y 4 se encuentran el subcuenca 10 y la parcela 5 en la subcuenca con el mismo identificador y las parcelas de trigo se encuentran ubicadas una en cada subcuenca, la parcela $0,2,6$ y 7 en las subcuencas 5, 10 y 6 respectivamente, dicha distribución se puede apreciar en la Figura 9. Los parámetros contribuyeron a contextualizar y caracterizar la zona de estudio y los cultivos en los cuales se trabajó.

Una vez calculada las dimensiones de la cuenca, subcuencas y drenajes se procedió a calcular los parámetros de morfométricos cuyos resultados ayudaron a comprender la dinámica propia de la cuenca, describiendo su comportamiento según los diferentes factores, estos se presentan a continuación:

\subsubsection{Parámetros de forma.}

En la Tabla 10 se presentan los resultados alcanzados de los parámetros de forma en la cuenca en estudio.

Tabla 10. Parámetros morfométricos de forma por subcuenca.

\begin{tabular}{ccccccc} 
Subcuenca & $\mathbf{A}\left(\mathbf{k m}^{\mathbf{2}}\right)$ & $\mathbf{P}(\mathbf{k m})$ & $\begin{array}{c}\mathbf{L A} \\
\mathbf{( k m})\end{array}$ & $\mathbf{K C}$ & $\mathbf{I F}$ & $\begin{array}{c}\mathbf{A P} \\
\mathbf{( k m})\end{array}$ \\
\hline \hline 1 & 58.14 & 55.90 & 15.7 & 2.05 & 0.24 & 3.7 \\
2 & 52.60 & 44.84 & 12.0 & 1.73 & 0.36 & 4.4 \\
3 & 13.96 & 22.54 & 6.1 & 1.69 & 0.37 & 2.3 \\
4 & 49.31 & 49.94 & 14.8 & 1.99 & 0.22 & 3.3 \\
5 & 9.14 & 18.56 & 5.6 & 1.72 & 0.30 & 1.6 \\
6 & 42.12 & 49.84 & 16.6 & 2.15 & 0.15 & 2.5 \\
7 & 10.42 & 26.64 & 8.6 & 2.31 & 0.14 & 1.2 \\
8 & 75.86 & 61.34 & 22.0 & 1.97 & 0.16 & 3.4 \\
9 & 2.15 & 10.98 & 3.1 & 2.10 & 0.23 & 0.7 \\
10 & 24.18 & 30.38 & 10.0 & 1.73 & 0.24 & 2.4 \\
11 & 2.43 & 8.50 & 2.8 & 1.53 & 0.30 & 0.9 \\
\hline General & $\mathbf{3 4 0 . 3 1}$ & $\mathbf{3 7 9 . 4 6}$ & $\mathbf{1 1 7 . 3 2}$ & $\mathbf{5 . 7 6}$ & $\mathbf{0 . 0 2}$ & $\mathbf{2 . 9 0}$
\end{tabular}

Donde

$$
\begin{aligned}
& \mathrm{A}=\text { Área } \\
& \mathrm{P}=\text { Perímetro } \\
& \mathrm{LA}=\text { Longitud Axial } \\
& \mathrm{KC}=\text { Coeficiente de compacidad de Gravellius } \\
& \mathrm{IF}=\text { Factor de forma } \\
& \mathrm{AP}=\text { Ancho promedio }
\end{aligned}
$$


Los parámetros de forma presentan un área total de $340.31 \mathrm{~km}^{2}$, resaltando la subcuenca 8 la de mayor extensión con más de $75 \mathrm{~km}$ y las de menor área las subcuencas 9 y 11 con 2 $\mathrm{km}$, encontrándose estas en la desembocadura de la cuenca. Igual correspondencia le pertenecen a dichas cuencas para las dimensiones de la longitud axial. Según los coeficientes KC se evidencian como cuencas oblongas las subcuencas 2,5 y 10; las subcuencas con coeficientes superiores a 1.75 , las cuales son la mayoría, indican formas rectangulares oblongas. Los índices IF encontrados demuestran que las cuencas son alargadas, siendo las más redondeadas las subcuencas 2, 3, 5 y 11, debido a que los valores de estos índices son los más altos respecto a las demás. Respecto al AP la subcuenca más ancha es la 2 y las menores las subcuencas 9 y 11 con menos de $1 \mathrm{~km}$ de ancho.

\subsubsection{Parámetros de relieve.}

En la Tabla 11 se presentan los resultados alcanzados de los parámetros de relieve en la cuenca en estudio.

Tabla 11. Parámetros morfométricos de relieve por subcuenca.

\begin{tabular}{cccccc} 
Subcuenca & $\begin{array}{c}\text { Hmax } \\
(\mathbf{m s n m})\end{array}$ & $\begin{array}{c}\text { Hmin } \\
(\mathbf{m s n m})\end{array}$ & $\mathbf{P M} \%$ & $\begin{array}{c}\text { Tipo } \\
\text { Pendiente }\end{array}$ & RA \\
\hline \hline 1 & 362.69 & 177.84 & 1.19 & Suave & 0.05 \\
2 & 298.93 & 177.84 & 1.02 & Suave & 0.02 \\
3 & 195.55 & 164.85 & 0.51 & Plano & 0.01 \\
4 & 295.76 & 164.81 & 0.90 & Plano & 0.04 \\
5 & 180.63 & 152.32 & 0.52 & Plano & 0.02 \\
6 & 285.92 & 152.28 & 0.82 & Plano & 0.05 \\
7 & 172.65 & 144.05 & 0.34 & Plano & 0.01 \\
8 & 277.71 & 144.04 & 0.62 & Plano & 0.04 \\
9 & 152.80 & 142.44 & 0.34 & Plano & 0.01 \\
10 & 205.43 & 142.43 & 0.63 & Plano & 0.02 \\
11 & 149.05 & 139.97 & 0.33 & Plano & 0.01 \\
\hline
\end{tabular}

Donde

Hmax = Altura máxima

Hmin = Altura mínima

$\mathrm{PM}=$ Pendiente media de la cuenca

RA = Coeficiente de Rugosidad

Las subcuencas con mayor altura, las denominadas como de cabecera, son las 1, 2 y 4, con alturas máximas cercanas a los $300 \mathrm{msnm}$. En contraparte las subcuencas en la parte baja son la 9 y 11, en especial la última la cual corresponde a la desembocadura de la cuenca. La pendiente en general tiende a ser catalogada plana, con un leve aumento de porcentaje de pendiente en las cuencas de cabecera. Respecto a los valores de RA se puede decir que la 
cuenca no posee rugosidades considerables, correspondiente a su topografía plana, ya que los valores en todas las subcuencas son cercanos a 0 .

\subsubsection{Parámetros de drenaje.}

En la Tabla 12 se presentan los resultados alcanzados de los parámetros de drenaje en la cuenca en estudio.

Tabla 12. Parámetros morfométricos de drenaje por subcuenca.

\begin{tabular}{ccccc} 
Subcuenca & $\begin{array}{c}\mathbf{L n} \\
\mathbf{( k m})\end{array}$ & $\mathbf{J} \%$ & $\begin{array}{c}\mathbf{D d}(\mathbf{k m} / \\
\left.\mathbf{k m}^{\mathbf{2}}\right)\end{array}$ & TC (Horas) \\
\hline \hline 1 & 14.88 & 1.24 & 0.26 & 2.24 \\
2 & 8.18 & 1.48 & 0.16 & 1.38 \\
3 & 4.86 & 0.63 & 0.35 & 1.09 \\
4 & 13.80 & 0.95 & 0.28 & 2.23 \\
5 & 5.99 & 0.47 & 0.66 & 1.35 \\
6 & 14.94 & 0.89 & 0.35 & 2.39 \\
7 & 3.22 & 0.89 & 0.31 & 0.75 \\
8 & 22.11 & 0.60 & 0.29 & 3.47 \\
9 & 1.12 & 0.92 & 0.52 & 0.33 \\
10 & 6.42 & 0.98 & 0.27 & 1.24 \\
11 & 1.81 & 0.50 & 0.75 & 0.54 \\
\hline General & $\mathbf{9 7 . 3 4}$ & $\mathbf{0 . 9 0}$ & $\mathbf{0 . 2 9}$ & $\mathbf{9 . 9 3}$
\end{tabular}

Donde

Ln $=$ Longitud del cauce principal

$\mathrm{J}=$ Pendiente media del cauce

$\mathrm{Dd}=$ Densidad drenaje

TC $=$ Tiempo de concentración

Gracias a la baja pendiente y topográfica plana las subcuencas en general poseen una baja densidad de drenaje. Las longitudes de los cauces principales corresponden en dimensión a las cuencas con mayor longitud axial, ya que la mayoría son cuencas alargadas y de dimensiones considerables. De igual forma los tiempos de concentración son mayores en las subcuencas de gran extensión y de poca pendiente, ya que por estas características el agua tarda más en desembocar en el cauce principal.

Recapitulando, respecto a las subcuencas que contienen las parcelas de estudio (subcuencas 5, 6 y 10), estas están ubicadas en la parte intermedia baja de la cuenca, la cual posee una topografía plana con porcentaje de pendiente bajo, considerando que poseen una densidad de drenaje mínima al igual que su rugosidad, hace de estas subcuencas áreas donde se debe controlar en gran medida posibles inundaciones y erosión hídrica en los bordes de los 
drenajes, en especial en la zona de la subcuenca 5 ya que en ella se localizan 2 parcelas, un cercanas al eje principal del cauce principal de la misma. No obstante la planificación de la estancia La Esperanza realiza un buen manejo de sus cultivos y controla las condiciones para que los cultivos crezcan en condición óptima sin ninguna limitante que contribuya a un déficit de rendimiento al interior de los mismos. Dichas condiciones e pudieron apreciar al momento de realizar los viajes de campo para las capturas de firmas espectrales y reconocimiento de la zona de estudio.

\subsubsection{Correlación de NDVI con la topografía de la cuenca.}

Con fines de continuar con el análisis y caracterización de la cuenca se realizaron los procesos para validar si existe alguna correlación entre la topografía o altura sobre el nivel del mar y el NDVI correspondiente a la superficie total de la cuenca.

Este análisis se basó en la información obtenida de los insumos de modelos digital de elevación STRM y las imágenes satelitales Landsat 8. Como se explicó en la sección 4.4 se planteó dividir la cuenca en rangos de zonas para evaluar la correspondencia con su respectivos valores NDVI en su interior, ya que inicialmente en el desarrollo del trabajo se buscó realizar una correlación general de toda la cuenca para los factores mencionados, pero no fue concluyente al encontrarse homogeneidad espacial en los datos, en cambios de nivel de altura y coberturas del suelo en la cuenca, junto con una gran cantidad de datos. Los rangos definidos por el método de rupturas naturales para el análisis se presenta en la se presentan en la Tabla 13.

Tabla 13. Zonificación y rangos de altura de la cuenca por el método de rupturas naturales.

\begin{tabular}{ccc}
$\begin{array}{c}\text { Zonas de } \\
\text { altura }\end{array}$ & $\begin{array}{c}\text { Hmax } \\
\text { (msnm) }\end{array}$ & $\begin{array}{c}\text { Hmin } \\
\text { (msnm) }\end{array}$ \\
\hline \hline 1 & 140 & 173 \\
2 & 173 & 198 \\
3 & 198 & 225 \\
4 & 225 & 254 \\
5 & 254 & 289 \\
6 & 289 & 363 \\
\hline
\end{tabular}




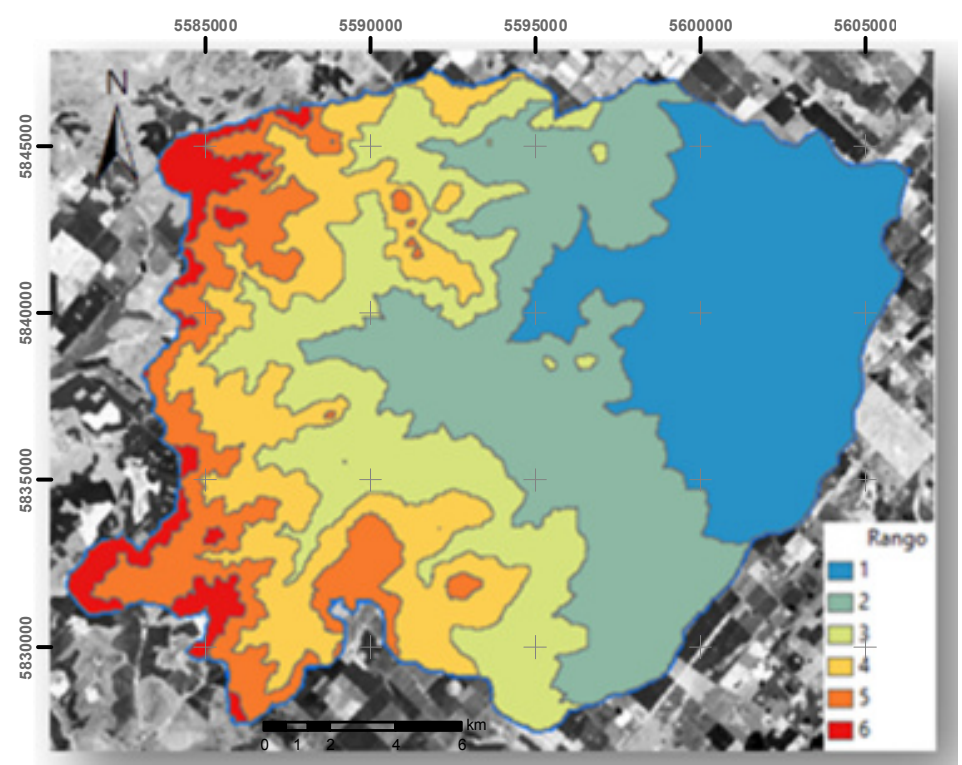

Figura 32. Espacialización de la zonificación de altura. Fuente: elaboración propia.

Imagen base: Landsat 16-Oct-2014.

Observando la Figura 32, en las 6 zonas de altura se encuentra que las zonas bajas, rango 1 y 2, poseen gran área debido a la baja variación de pendiente. Estas zonas contienen en su mayor extensión actividad agrícola y áreas intervenidas por el hombre. A medida que aumenta la cota las zonas disminuyen su ancho llegando así a zonas poco intervenidas con cambio de pendiente mayor.

$\mathrm{Al}$ acotar las zonas maximizando los rangos de altura se continuó en relacionar el NDVI correspondiente a cada área con su respectiva elevación, esto se hizo identificando zonas con el mismo valor de NDVI (teniendo en cuenta 2 cifras significativas debido a la gran cantidad de datos) y se promedió la altura de los pixeles correspondientes, ya que se busca evaluar si un determinado valor de NDVI está influenciado o correlacionado con la altura sobre el nivel del mar al interior de la cuenca de estudio.

Dicha correlación se evaluó de dos formas, con coeficiente de correlación de Pearson y lineal de cada zona. Los valores de los coeficientes de Pearson se presentan en la Tabla 14:

Tabla 14. Coeficientes de correlación de Pearson para la altura vs NDVI por zonas.

\section{Zona de altura}

\begin{tabular}{lcccccc}
\cline { 2 - 7 } \multicolumn{1}{c}{ Mes } & $\mathbf{1}$ & $\mathbf{2}$ & $\mathbf{3}$ & $\mathbf{4}$ & $\mathbf{5}$ & $\mathbf{6}$ \\
\hline \hline Julio & -0.95 & -0.61 & 0.86 & -0.51 & -0.12 & 0.98 \\
Octubre & -0.75 & -0.03 & 0.54 & 0.17 & 0.25 & 0.01 \\
Diciembre & -0.48 & 0.67 & 0.13 & -0.69 & 0.52 & -0.12 \\
\hline
\end{tabular}


Para observar si existe alguna tendencia de correlación en cada zona de altura por el transcurso de los meses se generó el Gráfico 3.

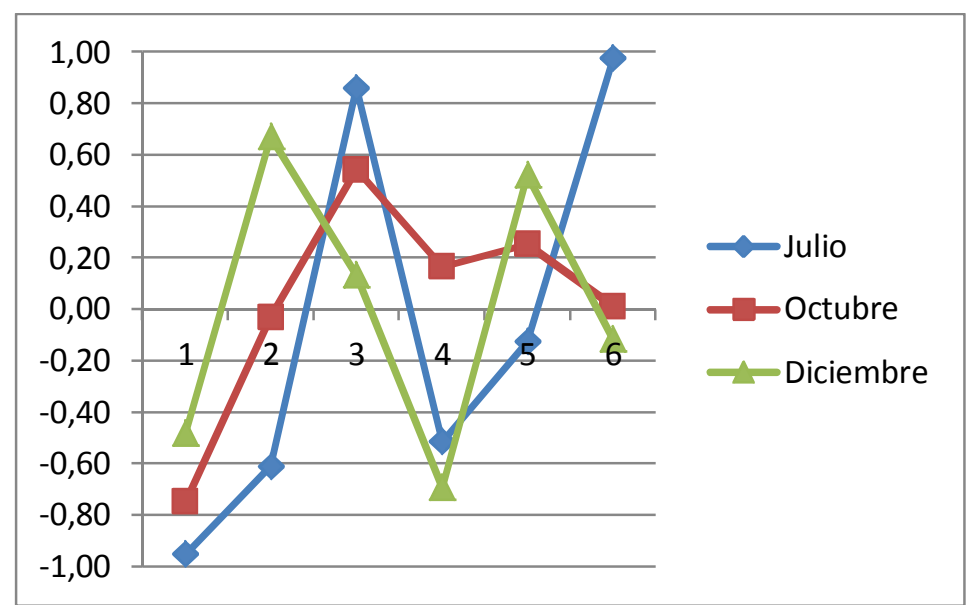

Gráfico 3. Variación de coeficientes de Pearson en las zonas por mes.

Nota: eje abscisas: zonas de rangos de altura; eje ordenadas: valor de coeficiente de Pearson.

Fuente: elaboración propia.

En el Gráfico 3 se observó que en el mes de julio en la zona 1 existe una alta correlación negativa entre el NDVI y la altura, entre mayora altura en esta zona menor es el NDVI; a medida que se incrementa la altura o se cambia de zona el coeficiente tiende a aumentar, por lo general se tiene correlación negativa en este mes a excepción de la zona intermedia 3 y la alta 6 que poseen correlación positiva alta. En el mes de octubre de igual forma se encuentra una correlación negativa alta para la zona baja 1 y en la zona intermedia 3 una correlación positiva media del 50\%, sin embargo las otras zonas poseen valores de correlación bajos. En diciembre no se evidencia alguna tendencia en los valores de correlación ya que se observa valores positivos y negativos que van fluctuando a medida que se incrementa en altura y en zona, encontrándose picos de correlación positiva alta en la zona dos y correlación negativa alta en la zona 4.

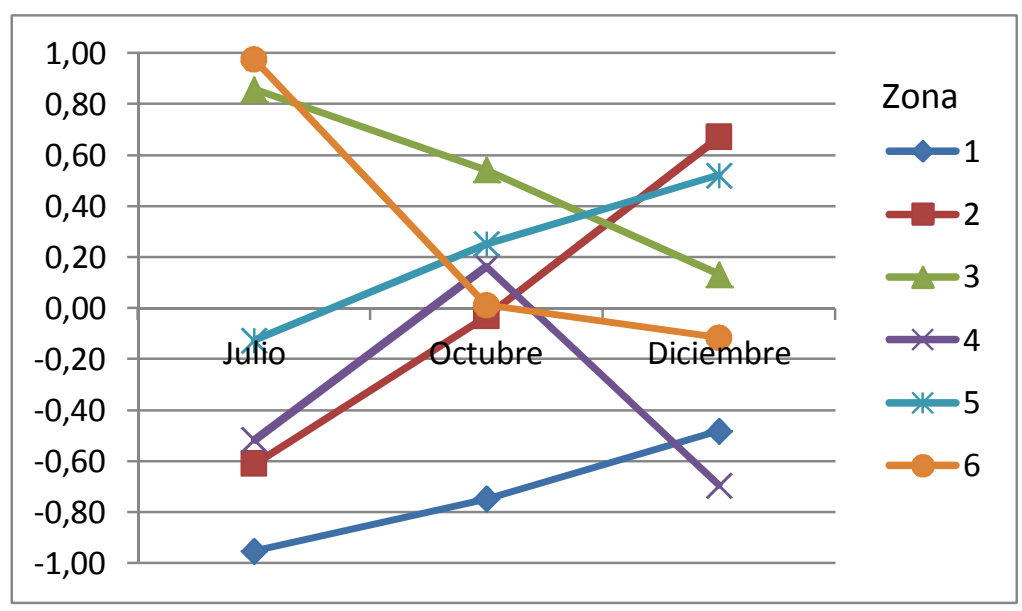

Gráfico 4. Evolución de los valores de coeficientes Pearson por zona en el transcurso de los meses. Nota: eje abscisas: zonas de rangos de altura; eje ordenadas: valor de coeficiente de Pearson.

Fuente: elaboración propia. 
Respecto a la evolución de cada zona durante el transcurso de los tres meses contemplados, como se representa en el Gráfico 4, se observó que en la zona baja 1 se tiene valores de correlación negativa altos en especial en el mes de julio y van descendiendo en octubre y diciembre; en la zona 2 se inicia con una correlación negativa alta en julio, en octubre no se tiene ninguna correlación y en diciembre hay una correlación positiva alta; la zona intermedia 3 muestra un comportamiento similar a la zona 1 pero con correlación positiva; la zona 4 fluctúa en sus valores, teniendo valores negativos en julio y diciembre pero un valor positivo bajo para octubre; la zona 5 inicia en julio con un valor negativo bajo y va incrementando positivamente hasta diciembre llegando a una correlación media; la zona 6 posee en julio una alta correlación positiva pero en los meses siguientes baja su valor siendo cercano a cero, evidenciando ninguna correlación en esta zona en particular.

Otra forma de observar el comportamiento de los datos en cada zona fue mediante gráficos de dispersión y analizando el ajuste o correlación lineal de los mismos, los cuales se compilan en el Gráfico 5 por mes y por zona. 
ZONA
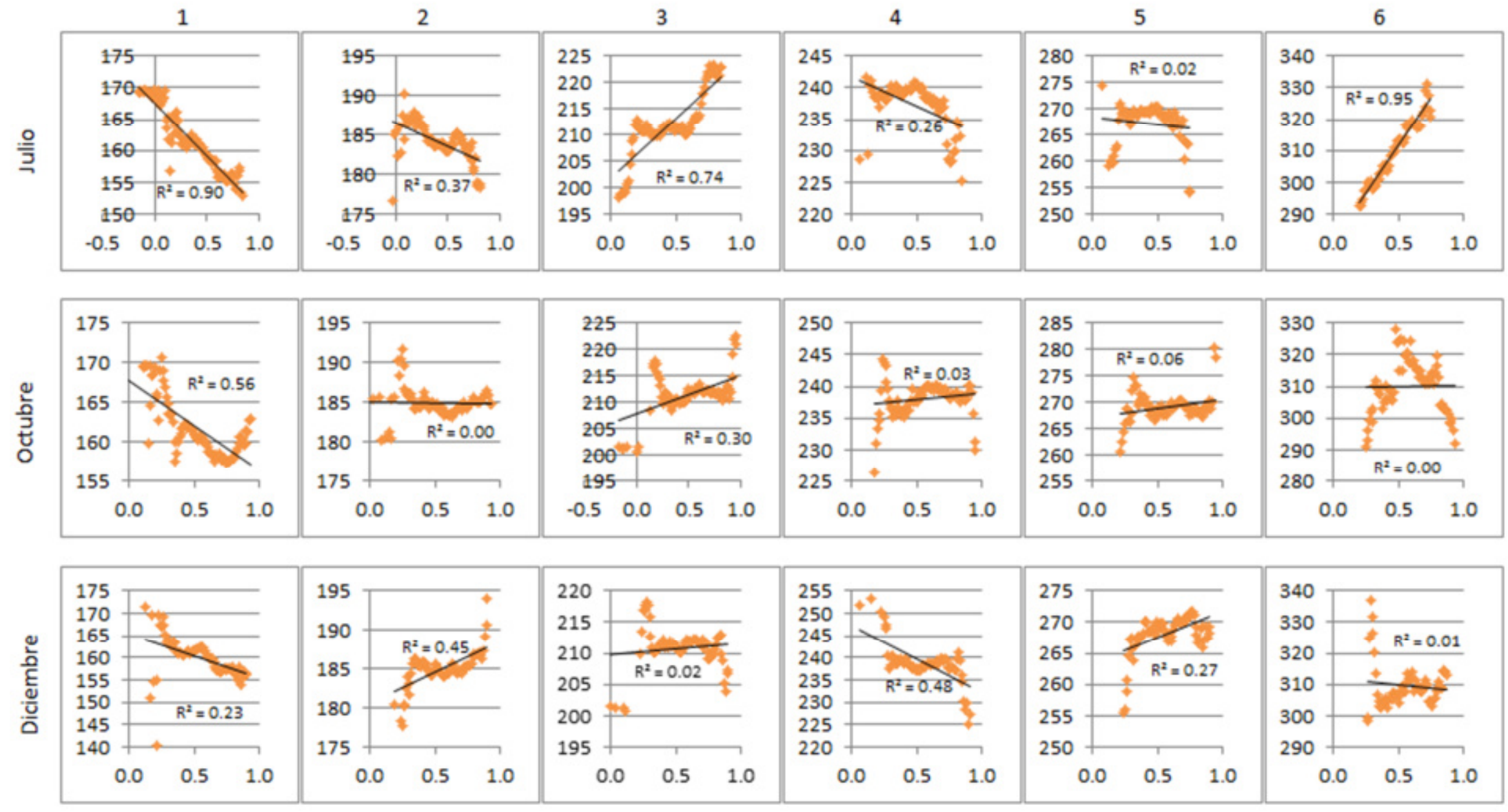

Gráfico 5. Compilación de los gráficos de dispersión NDVI vs altura topográfica en cada zona por los meses considerados. Nota: eje abscisas: valor NDVI; eje ordenadas: valor altura msnm. Fuente: elaboración propia

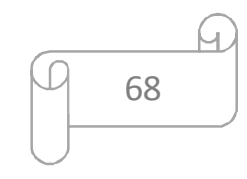


En el análisis del Gráfico 5 se encontró que las zonas en el transcurso del tiempo no siguen un patrón determinado, consecuentemente no se evidenció alguna correlación significativa a medida que se incrementa la altura al interior de la cuenca de estudio. Sin embargo en algunas zonas se evidencia similitud como lo es en la zona 1 en donde en los tres periodos de tiempo se encontró una correlación negativa, esto podría ser por el alto nivel de intervención del hombre en esta zona ya que se desarrolla diversidad de actividades agrícolas debido a la baja pendiente. Por lo general en toda la cuenca la cobertura vegetal varia, en zonas altas gracias a pendientes un poco más pronunciadas hay vegetación más estable ya que se encuentran pastizales y bosques naturales.

Hay que tener en cuenta que en julio, para las latitudes sur, se encuentra en estación climática de invierno en donde la vegetación se encuentra con poca área foliar y valores bajos de clorofila, de igual forma en este periodo los cultivos se encuentran en su fase de siembra o preparación del suelo, por lo cual la cobertura son suelos desnudos o con rastrojo. En contraparte las zonas altas al no presentar intervención agrícola intensiva debido a los horizontes de suelos poco profundos y grados de pendiente variables se pueden encontrar coberturas vegetales homogéneas con correlación positiva, como se evidencia en la zona 6 del mes de Julio.

Por esta razón no fue posible indicar si existe alguna tendencia o correlación del NDVI con la elevación, ya que existe mucha variabilidad en la cobertura y no hay cambios considerables de alturas que signifiquen alguna variación drástica de ambientes que influyan en la cobertura vegetal de la zona de estudio. De igual forma es recomendable considerar factores adicionales como condiciones climáticas, suelos, nutrientes y humedad que reflejen cambios significativos en la cobertura vegetal y por ende en el NDVI.

\subsection{Procesamiento de datos de rendimiento agrícola.}

\subsubsection{Análisis de bases de datos de rendimiento agrícola.}

Implementando la herramienta CONVERSOR LOG A SHP ${ }^{\circledR}$ se obtuvieron los datos georreferenciados de rendimiento de los cultivos estudiados. Ya que los archivos vienen discriminados por tipo de cultivo, se tienen conjuntos los archivos pertenecientes a trigo y a cebada por aparte. El resumen del proceso de conversión realizado por la herramienta mencionada, por tipo de cultivo, es arrojado en formato Html como se muestra en la Figura 33. 

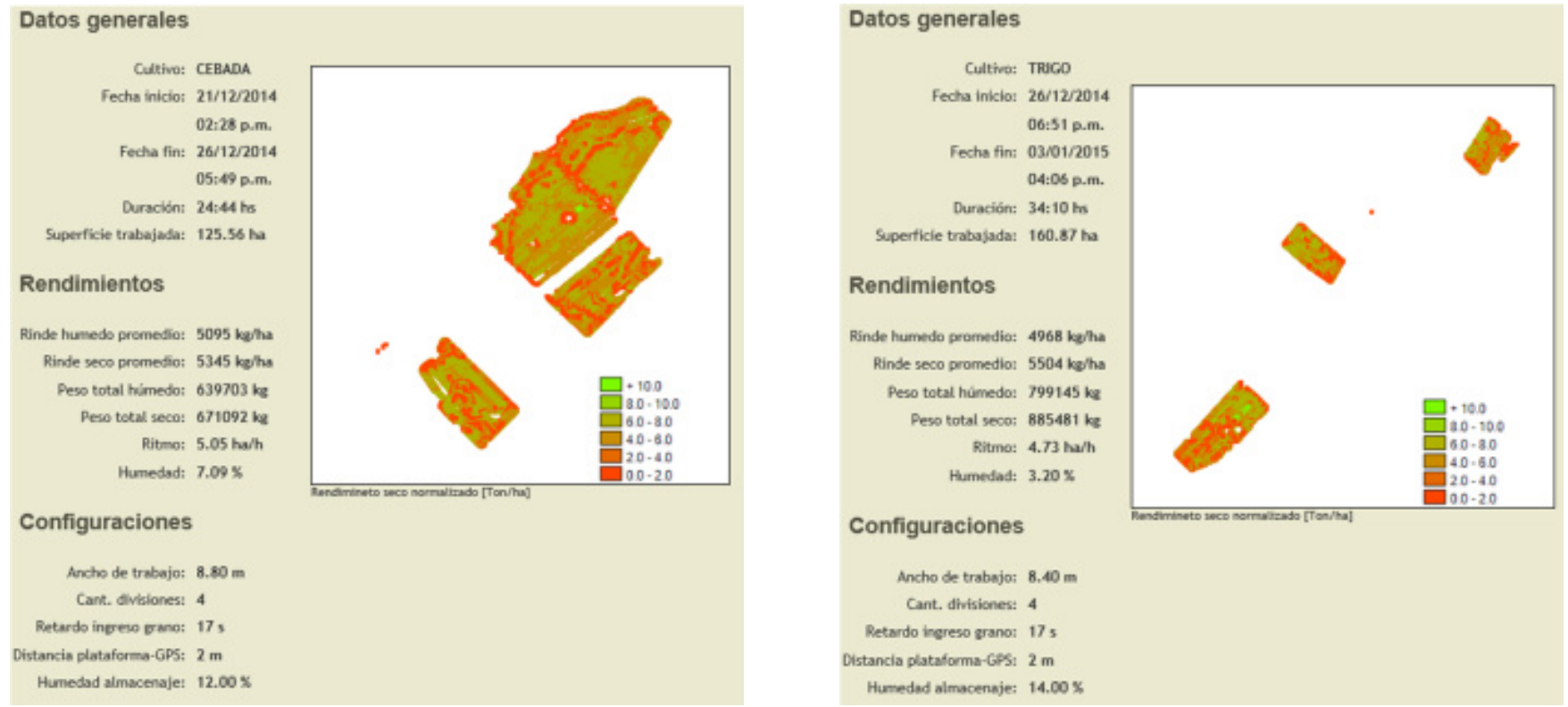

Figura 33. Resultados e información proveniente de la conversión de formatos Log a Shp.

Fuente: elaboración propia.

Los datos transformados presentan en forma general las características del cultivo captadas por el monitor de rendimiento, tal como lo son las fechas de siembra y cultivo, área cosechada, rendimientos en húmedo y en seco, ancho de franjas de recolección, etc.

La información georreferenciada se obtuvo con geometría punto, representando toneladas por hectárea recolectada mediante la máquina cosechadora, detectada por el monitor de rendimiento. La separación entre los puntos es en promedio 5 metros con ancho de franja 8 metros.

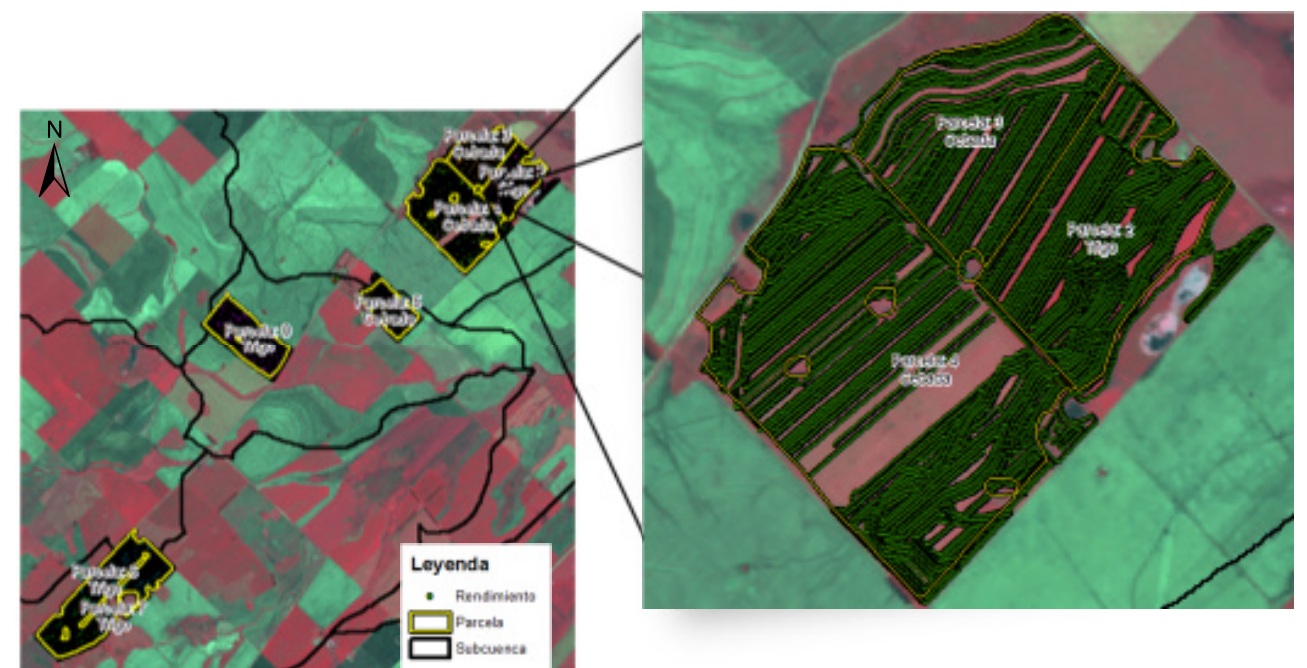

Figura 34. Representación de los puntos de rendimiento originales sectorizados al interior de las parcelas. Fuente: elaboración propia.

Imagen base: Spot multiespectral 22-Nov-2014.

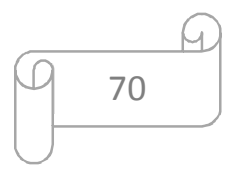


Los puntos de rendimiento mencionados en la Tabla 2 son el total obtenido por el monitor de rendimiento en el proceso de cosecha, representados geográficamente por coordenadas y localizados al interior de su respectiva parcela de cultivo (Figura 34). No obstante la recolección de dicha información posee errores sistemáticos de recolección, siendo necesario realizar una depuración profunda de esta, ya que existen puntos localizados fuera del contexto del estudio junto con información incoherente o atípica arrojada por el monitor de rendimiento en el momento de la cosecha. El mapa de rendimiento final (para el ejemplo la parcela 0 de trigo), representando los valores de rendimiento por punto, se observa en la Figura 35.

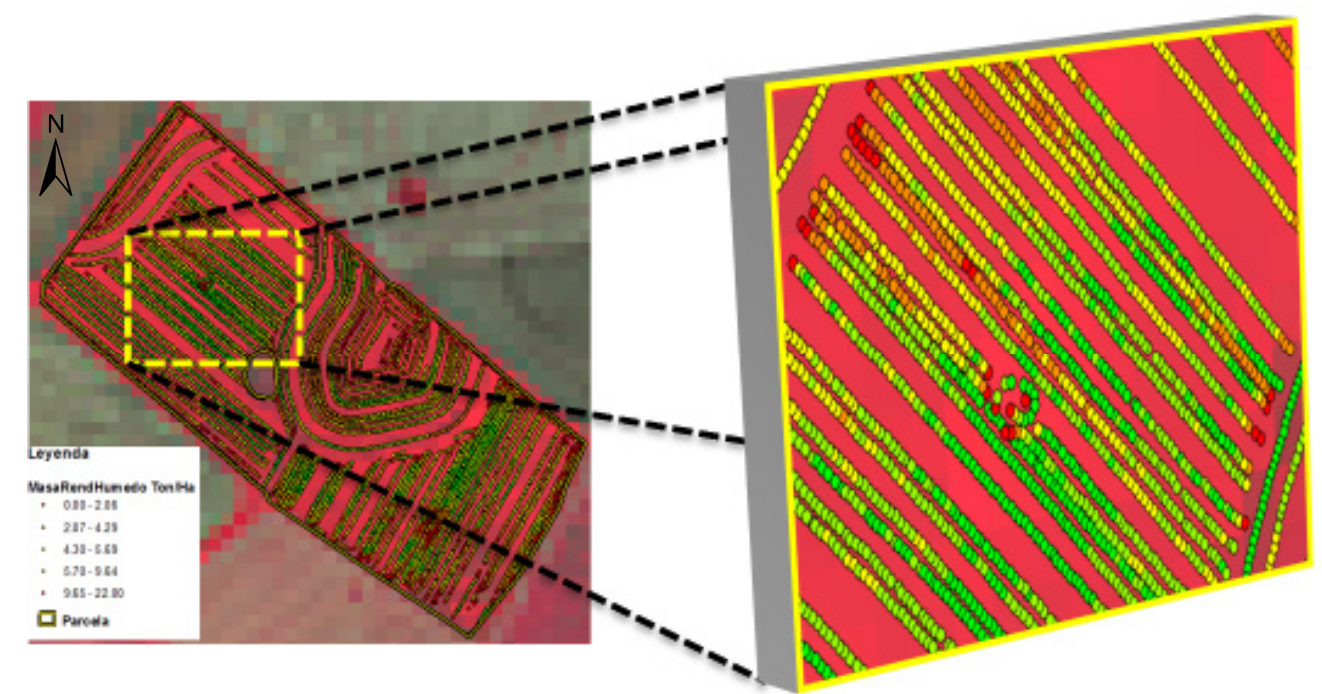

Figura 35. Mapa de rendimiento para los puntos de la parcela 0.

Nota: La representación o simbología de los puntos de rendimiento reflejan el valor tn/ha. Imagen base: Landsat 16-Oct-2014.

Según la simbología presentada en la Figura 35, los puntos rojos representan datos de rendimiento atípicos, ya que se encuentran por fuera de los valores biológicos que presentan normalmente los cultivos en cuestión, por lo cual fue necesario realizar una limpieza de mapa o depuración de estos y otros valores atípicos (outliers) a la información, como se presenta en la siguiente sección.

\subsubsection{Limpieza de mapa de rendimiento o depuración de valores atípicos (outliers).}

La depuración de los mapas de rendimiento contribuyo a obtener mejores resultados al momento de realizar los análisis de correlación. En la literatura consultada no existe alguna metodología que delimite estrictamente los procesos de detección y corrección de información atípica de un conjunto de datos determinados. A continuación se presenta el proceso realizado 
de limpieza de mapas de rendimiento, partiendo de los datos originales base proveniente de los monitores de rendimiento, enfocándose en los registros contenidos y pertenecientes al interior de las parcelas definidas.

La generación de mapas de rendimiento depurados generó una secuencia de resultados parciales los cuales permitieron lograr un resultado final que es el utilizado para comparar NDVI con datos de rendimiento. A continuación se presentan los resultados parciales y finales obtenidos.

La información original de rendimiento cuenta con 70266 puntos en total, 29514 corresponden al cultivo de cebada y 40752 a trigo. La primera depuración consistió en identificar los puntos cuya fuente de error provenga del retraso o saturación de cosecha que posee el monitor de rendimiento, originando de esta forma datos inconsistentes. Por medio de consultas con el asesor del productor de la estancia todos los datos con valores inferiores a 8 metros en el atributo ancho de franja son considerados errores del mecanismo de recolección. Esta identificación se llevó a mediante una consulta de selección por atributos de dicho atributo, lo cual arrojo 2183 puntos para cebada y 3439 para trigo con esta característica, para un total de 5622 puntos. Evaluando la información de dichos puntos efectivamente son puntos con información de rendimiento húmedo igual a cero o localizados en los extremos del recorrido de la cosechadora, al igual que también puntos al exterior de la parcela en lugares donde no existe cultivo alguno, como se observa en la Figura 36, para el ejemplo del cultivo de cebada.

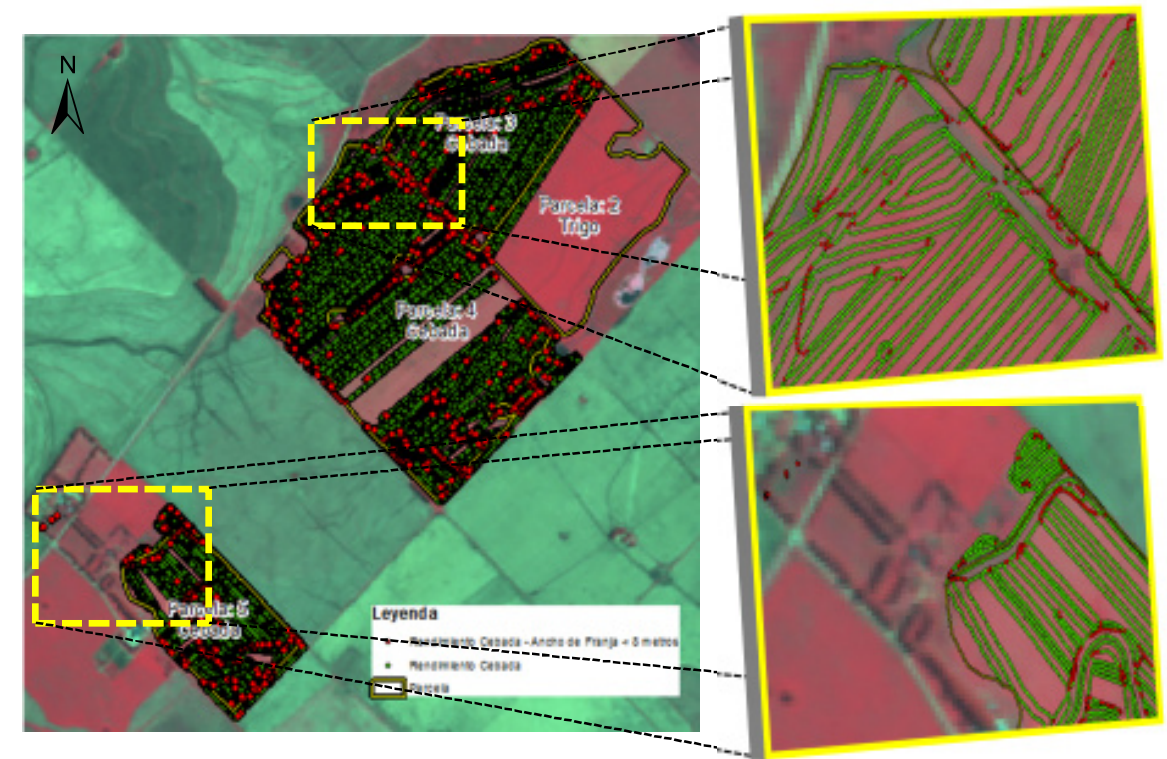

Figura 36. Datos atípicos con valores de rendimiento 0 y diferentes a ancho de franja 8 metros.

Nota: los puntos rojos representan los valores atípicos. Imagen base: Spot multiespectral 22-Nov-2014. 
Los anteriores puntos detectados fueron suprimidos, quedando 27331 pertenecientes a cebada y 37133 de trigo para un total de 64464 puntos en un mapa de resultados parciales.

El siguiente paso fue seleccionar espacialmente los puntos de rendimiento que se utilizaran en el análisis de correlación. Para esto se utilizó la geometría o contorno de las parcelas para extraer todos los puntos contenidos al interior de las mismas, este se efectuó mediante el proceso de selección espacial por superposición, donde se extrajo los puntos y se les asigno la nomenclatura de la parcela a la cual corresponden geográficamente. De este análisis se obtuvieron 58690 puntos contenidos en los cultivos de cebada y trigo. En Figura 37 se puede evidenciar puntos que se encuentran en la periferia de las parcelas, los culés fueron omitidos.

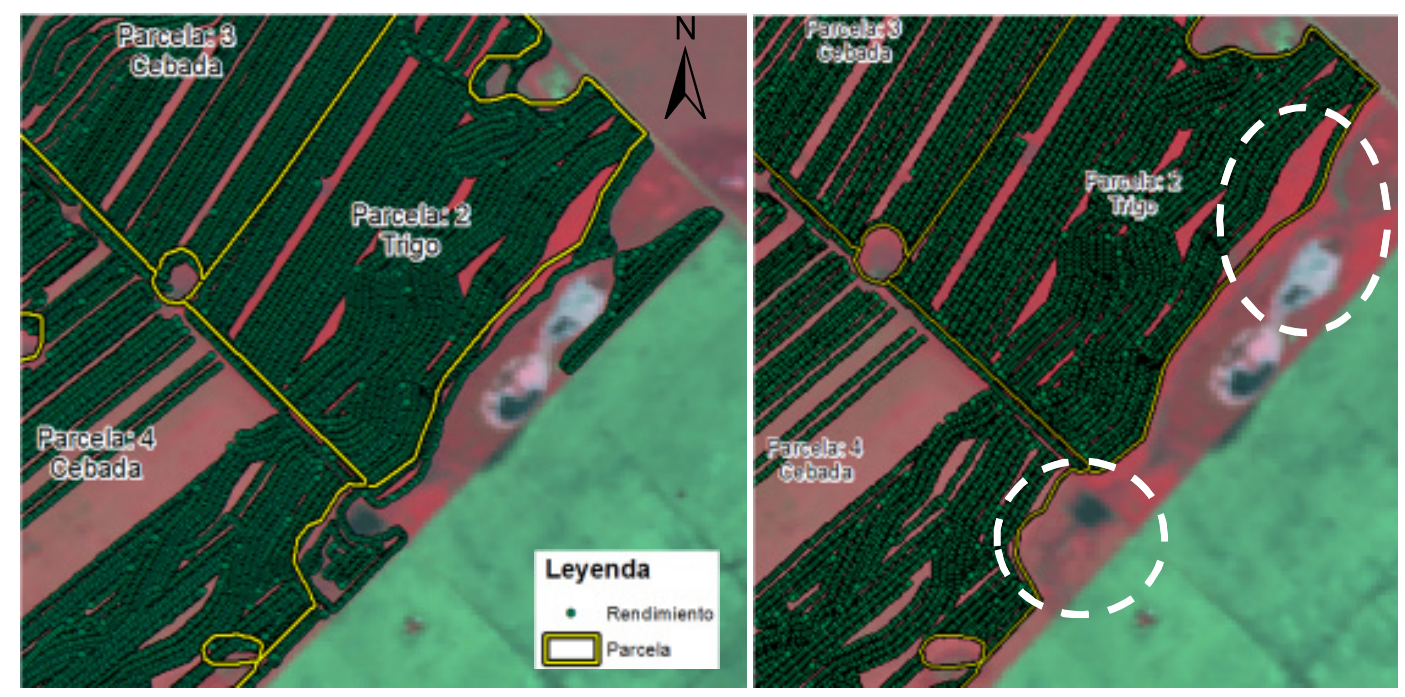

Figura 37. Descarte de puntos al exterior de los polígonos digitalizados de las parcelas de estudio. Fuente: elaboración propia.

Imagen base: Spot multiespectral 22-Nov-2014.

La anterior depuración contribuyó a optimizar la correlación de los datos, considerando solo aquellos puntos que tiene superposición evidente con la resolución espacial de las imágenes satelitales (pixel de 30 metros) y así garantizar la relación de los puntos con pixel de NDVI sin disturbios por coberturas vegetales colindantes a los cultivos.

El siguiente proceso fue la detección de errores de rendimientos fuera del rango biológico definido para los cultivos especificados. Mediante sugerencia del asesor del productor se hizo la aclaración que aquellos puntos que poseen valores de masa de rendimiento húmedo inferiores a 1 ton/ha y mayores a 12 ton/ha se pueden considerar como valores atípicos y errores arrojados por los monitores de rendimiento en la captura de la información en campo (Según

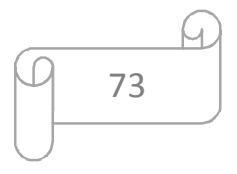


recomendación del Dr. Gabriel Vázquez Amábile se consideró este umbral para ambos cultivos debido a que los rendimientos de los cultivos de cebada y trigo son similares). Por tal razón se realizó una selección por atributos con la consulta anteriormente mencionada, para de esta forma excluir la información que cumple con el mencionado criterio. En total se encontraron 2258 puntos por fuera de estos rangos, 1184 de cebada y 1074 de trigo, quedando como resultante 56432 puntos de rendimiento en el mapa parcial. En la Figura 38 se observa, como ejemplo la parcela 0 de trigo, que los puntos rojos, considerados como atípicos según este criterio, se localizan al final de la franjas de recolección de la cosecha, en la cual el monitor de rendimiento empieza a o termina de calcular el grano recolectado.

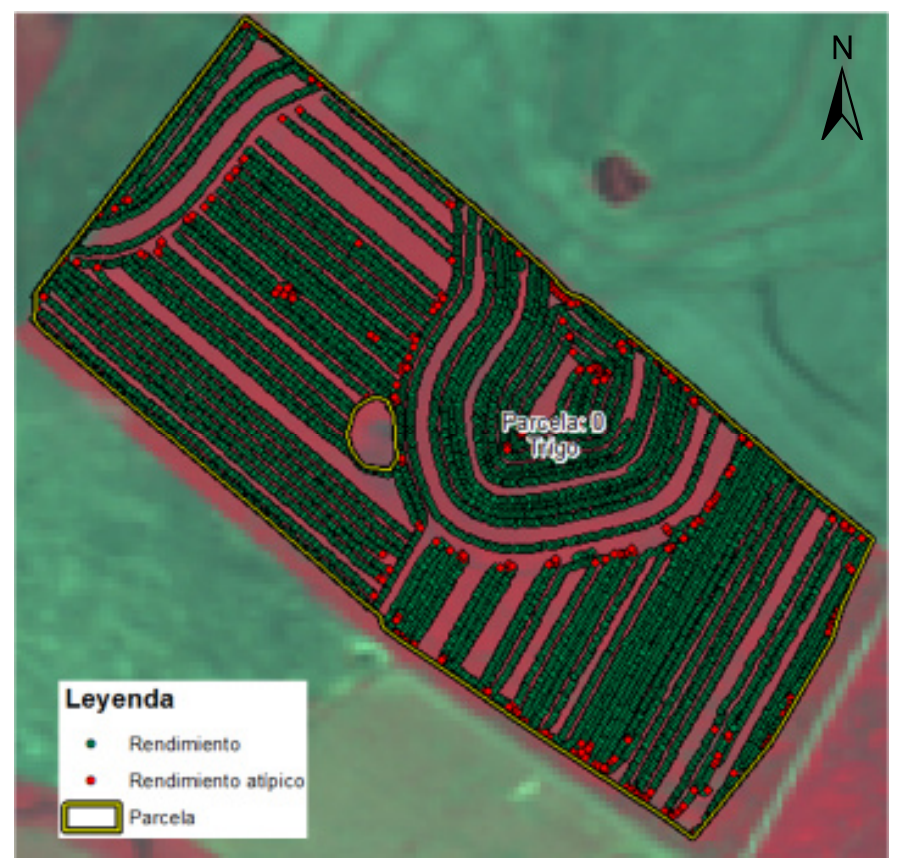

Figura 38. Valores atípicos de rendimiento por fuera del rango biológico de los cultivos. Fuente: elaboración propia. Imagen base: Spot multiespectral 22-Nov-2014.

Una vez efectuadas las limpiezas del mapa de rendimiento mencionadas anteriormente se procede a realizar la identificación de valores atípicos detectados estadísticamente por medio de la utilización de cuartiles e intervalos interquartílicos, en donde se considera un valor atípico aquel que se encuentra 1,5 veces a la distancia de uno de los cuartiles (atípico leve) o a 3 veces la distancia (atípico extremo). Para este caso de estudio se utilizó el concepto de atípico extremo sobre el set de datos de rendimiento. Los datos se ordenaron discriminados por tipo de cultivo y parcela, ya que debido a características espaciales y de manejo independiente de cada parcela 
(suelos, fertilización, humedad, etc.) se pueden presentar variabilidad de información atípica al interior de las mismas.

Para este proceso estadístico se utilizó el programa $R \circledR$, en el cual se ingresaron set de datos por parcelas. Inicialmente se realizó la estadística descriptiva de la información, la cual se presenta en la Tabla 15.

Tabla 15. Estadística descriptiva inicial de los set de datos por parcela.

\begin{tabular}{ccccccc} 
Parcela & Datos & Media & Desviación Estándar & Mediana & Mínimo & Máximo \\
\hline \hline 0 & 8612 & 5.27 & 1.07 & 5.46 & 1 & 11.48 \\
2 & 6629 & 5.14 & 0.94 & 5.26 & 1.01 & 11.33 \\
3 & 6339 & 5.46 & 0.97 & 5.72 & 1.01 & 11.93 \\
4 & 12881 & 5.44 & 1.11 & 5.71 & 1.01 & 11.47 \\
5 & 4468 & 5.57 & 1.12 & 5.9 & 1 & 11.28 \\
6 & 16526 & 5.42 & 1.07 & 5.54 & 1.01 & 11.94 \\
7 & 977 & 4.31 & 0.94 & 4.32 & 1 & 7.24 \\
\hline
\end{tabular}

\section{Total 56432}

Con el fin de observar el comportamiento de los datos atípicos pertenecientes a los valores de masa de rendimiento húmedo por cada parcela se realizó diagramas de cajas. En el Gráfico 6 se compilan dichos gráficos, donde se observó que la mayor parte de datos atípicos se encuentran por debajo del cuartil 1, dependiendo el rango en cada parcela.
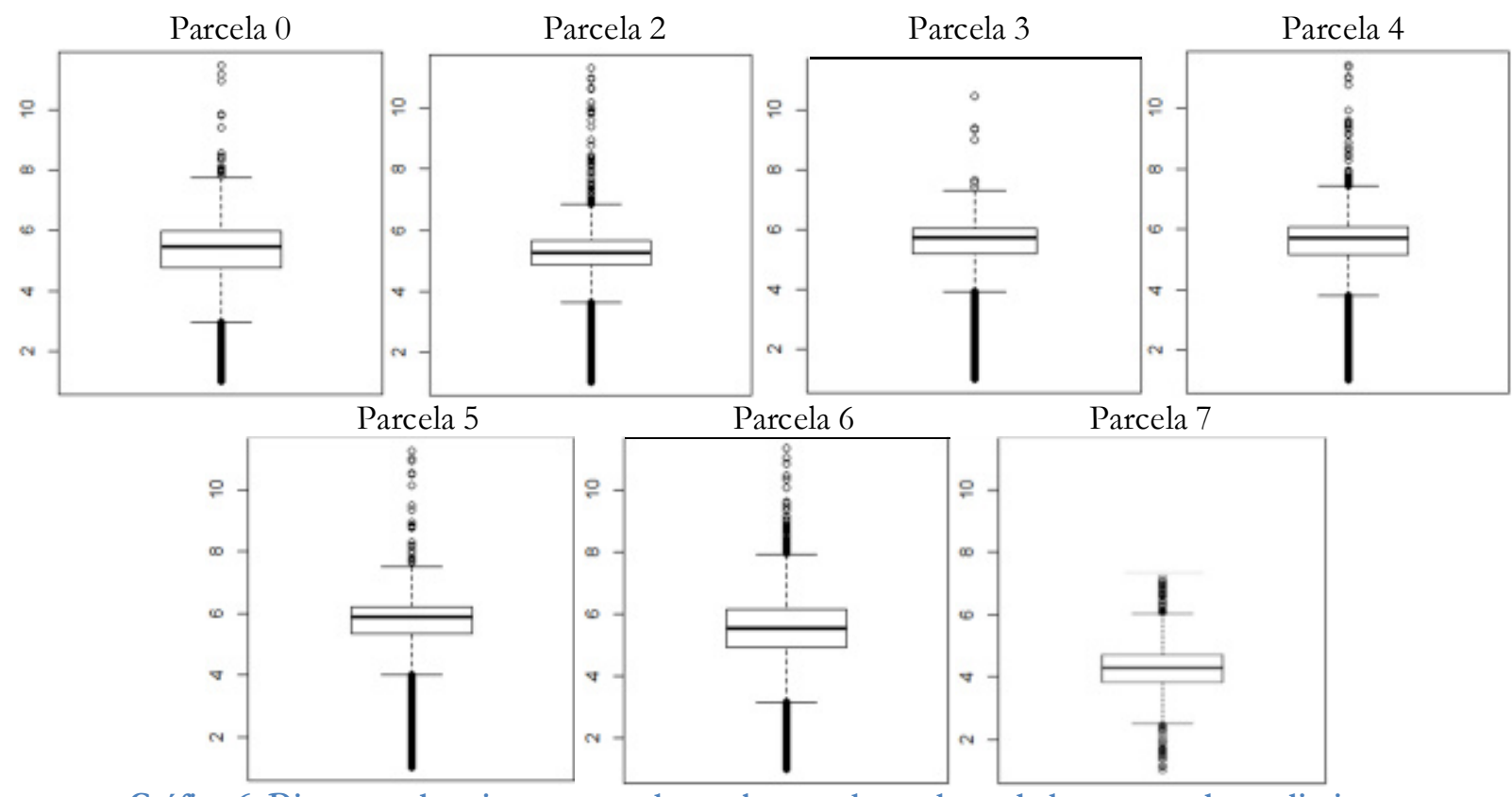

Parcela 7

Gráfico 6. Diagrama de cajas por parcela con base en los valores de los puntos de rendimiento.

Nota: los puntos localizados por fuera de los rangos interquartílicos son considerados atípicos. Fuente: elaboración propia. 
Posteriormente se calcularon los cuartiles e intervalos interquartílicos de cada set de datos por parcela, de esta forma se pudo calcular los rangos de los valores atípicos extremos inferior y superior, para así identificar los registros de rendimiento por fuera de estos rangos con el fin de descartarlos. En la Tabla 16 se presentan dichos rangos junto con los límites que se utilizarían en la depuración.

Tabla 16. Cuartiles y rangos interquartílicos por parcela.

\begin{tabular}{cccccc} 
Parcela & Q1 & Q3 & IQR & $\begin{array}{c}\text { Extremo } \\
\text { inferior }\end{array}$ & $\begin{array}{c}\text { Extremos } \\
\text { superior }\end{array}$ \\
\hline \hline 0 & 4.76 & 5.98 & 1.21 & 1.12 & 9.62 \\
2 & 4.84 & 5.65 & 0.80 & 2.43 & 8.06 \\
3 & 5.20 & 6.05 & 0.85 & 2.67 & 8.58 \\
4 & 5.18 & 6.08 & 0.91 & 2.46 & 8.80 \\
5 & 5.34 & 6.21 & 0.88 & 2.71 & 8.84 \\
6 & 4.95 & 6.15 & 1.20 & 1.35 & 9.75 \\
7 & 3.85 & 4.73 & 0.88 & 1.21 & 7.37 \\
\hline
\end{tabular}

Obtenidos los rangos fue posible crear el listado de los registros de los valores de atípicos extremos de masa de rendimiento húmedo por cada parcela con el software $R \AA$, los cuales fueron retirados del total de los datos. Realizado lo anterior, se generó nuevamente la estadística descriptiva sobre cada parcela, mencionando la cantidad de atípicos encontrados. En la Tabla 17 se presenta dicha complicación:

Tabla 17. Estadística descriptiva de los datos depurados y totalidad de datos atípicos encontrados por parcela.

\begin{tabular}{cccccccc} 
Parcela & $\begin{array}{c}\text { Valores Atípicos } \\
\text { Extremos }\end{array}$ & $\begin{array}{c}\text { Datos } \\
\text { depurados }\end{array}$ & Media & $\begin{array}{c}\text { Desviación } \\
\text { Estándar }\end{array}$ & Mediana & Mínimo & Máximo \\
\hline \hline 0 & 26 & 8586 & 5.28 & 1.05 & 5.46 & 1.13 & 9.4 \\
2 & 187 & 6442 & 5.21 & 0.72 & 5.27 & 2.43 & 7.95 \\
3 & 200 & 6139 & 5.58 & 0.72 & 5.74 & 2.67 & 7.68 \\
4 & 517 & 12364 & 5.58 & 0.81 & 5.74 & 2.46 & 8.72 \\
5 & 193 & 4275 & 5.72 & 0.8 & 5.93 & 2.72 & 8.8 \\
6 & 87 & 16439 & 5.44 & 1.02 & 5.55 & 1.36 & 9.63 \\
7 & 5 & 972 & 4.33 & 0.91 & 4.33 & 1.21 & 7.24 \\
\hline
\end{tabular}

$\begin{array}{lll}\text { Total } & 1215 & 55217\end{array}$

Estos resultados se exportaron en formato de tablas alfanuméricas. La información previamente se trabajó con un identificador o llave primaria generados desde los archivos vectoriales shp, la cual fue de utilidad para realizar la unión de las tablas de atípicos con los rendimientos puntuales vectoriales en el software ArcGIS®. Con la información relacionada se logró identificar espacialmente la ubicación de atípicos de rendimiento seleccionados estadísticamente, en la 
Figura 39 se presenta la localización de los atípicos para la parcela 5 de cebada, donde se puede apreciar que por lo general dichos registros detectados se encuentra, de igual forma como los anteriores puntos depurados al comienzo de la limpieza del mapa de rendimiento, en los extremos iniciales o finales de las franjas de recolección del cultivo cosechados y capturados por los monitores de rendimiento, lo cual sustenta que son fuentes de error provocados por el instrumental para la cosecha.

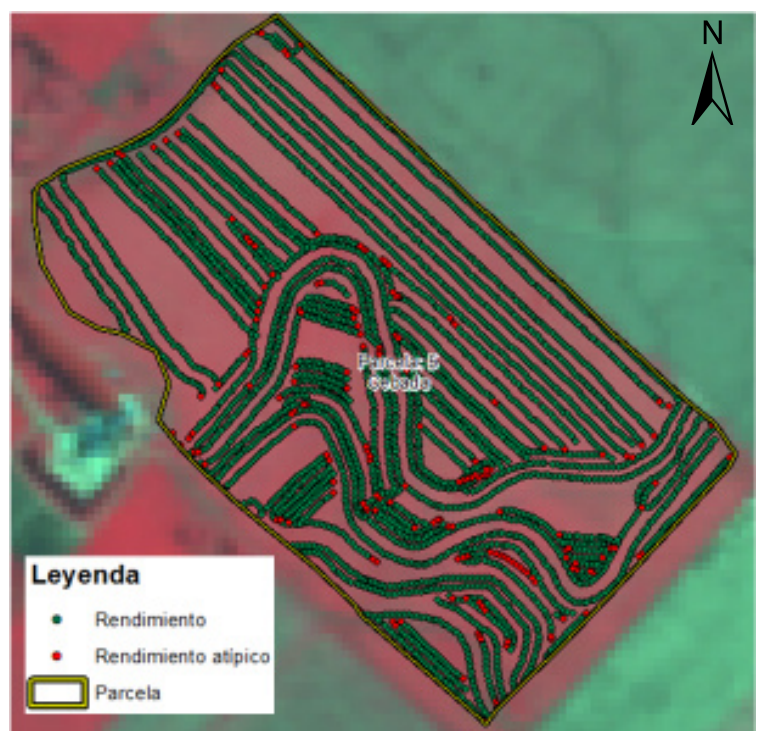

Figura 39. Espacialización de Valores atípicos identificados estadísticamente. Fuente: elaboración propia.

Imagen base: Spot multiespectral 22-Nov-2014.

Con los puntos de rendimiento atípicos identificados, siento estos un total de 1215, en el mapa de rendimiento se procedió a suprimirlos, lo cual dejo como resultado parcial a 55217 puntos preparados para utilizarlos en el análisis y procedimiento de la correlación con los valores de NDVI obtenidos de las imágenes satelitales

Por último se detectaron por superposición inconsistente puntos de rendimiento de las parcelas 2 (trigo) y 3 (cebada) que poseen conflicto con la digitalización de las mismas. Dichos datos se suprimieron encontrándose un total de 400 puntos, 83 de trigo y 317 de cebada, quedando un total de 54817 en el mapa final de rendimiento. La localización de los puntos con conflicto puede apreciar en la Figura 40. 


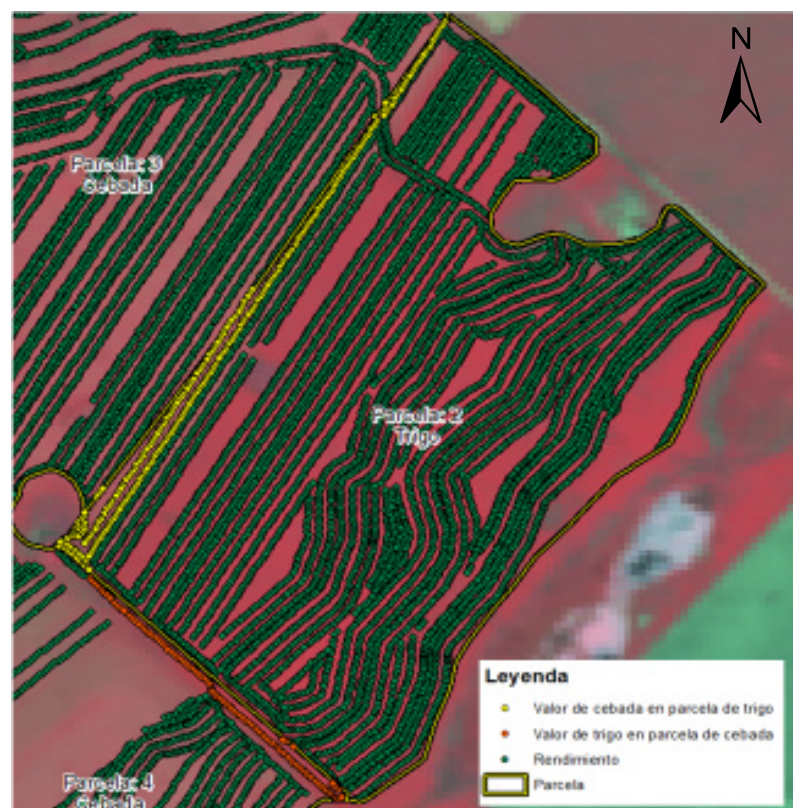

Figura 40. Conflicto de valores de rendimiento en parcelas contiguas.

Nota: los valores celestes corresponden a los puntos de rendimiento de cebada que se localizan al interior de la parcela 2 de trigo; y los amarillos a puntos de trigo que se superponen en la parcela 4 de cebada. Fuente: elaboración propia.

Imagen base: Spot multiespectral 22-Nov-2014.

\subsection{Comparación de NDVI con datos depurados de rendimiento.}

Teniendo en cuenta las dos metodologías mencionadas en materiales y métodos para la comparación de los datos, se asignó un identificador único a cada registro de las grillas de NDVI para así de esta forma realizar un promedio de valores de masa de rendimiento húmedo por cada valor de NDVI. En primera instancia se presenta los resultados provenientes de la metodología a nivel de pixel, cuyos datos iniciales para la correlación se muestran en la Tabla 18.

Tabla 18. Total de puntos de rendimiento y cantidad de pixeles o valores NDVI por parcela respecto a la metodología a nivel pixel en las fechas establecidas.

Cantidad de datos NDVI

\begin{tabular}{|c|c|c|c|c|c|c|c|c|c|c|}
\hline Cultivo & Parcela & $\begin{array}{c}\text { Datos de } \\
\text { Rinde } \\
\end{array}$ & $\begin{array}{l}\text { Jul } \\
28 \\
\end{array}$ & $\begin{array}{c}\text { Ago } \\
14 \\
\end{array}$ & $\begin{array}{c}\text { Sept } \\
08 \\
\end{array}$ & $\begin{array}{l}\text { Oct } \\
16 \\
\end{array}$ & $\begin{array}{c}\text { Nov } \\
17 \\
\end{array}$ & $\begin{array}{c}\text { Nov } \\
26 \\
\end{array}$ & $\begin{array}{c}\text { Dic } \\
03 \\
\end{array}$ & $\begin{array}{c}\text { Dic } \\
12 \\
\end{array}$ \\
\hline \multirow{3}{*}{ Cebada } & 3 & (26139 & 8619 & 4027 & $\begin{array}{l}627 \\
\end{array}$ & 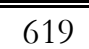 & " & 626 & "627 & 1625 \\
\hline & 4 & 12281 & 1267 & 1284 & 1292 & 1274 & 1290 & 1293 & 1289 & 1285 \\
\hline & 5 & 4275 & 430 & 429 & 431 & 430 & 430 & 430 & 430 & 431 \\
\hline \multirow{4}{*}{ Trigo } & 0 & 8586 & 819 & 826 & 828 & 829 & 833 & 834 & 835 & 833 \\
\hline & 2 & 6125 & 611 & 612 & 614 & 612 & 624 & 615 & 616 & 617 \\
\hline & 6 & 16439 & 1579 & 1588 & 1591 & 1587 & - & 1609 & 1609 & 1605 \\
\hline & 7 & 972 & 112 & 112 & 112 & 112 & - & 112 & 112 & 112 \\
\hline & 4817 & 5437 & 5478 & 5495 & 5463 & 3801 & 5519 & 5518 & 5508 \\
\hline
\end{tabular}


A continuación se presenta la correlación de los datos según las metodologías de análisis planteadas. La primera metodología, por pixel, se estructuró discriminando tipo de cultivo,

Al comparar los datos de rendimiento y NDVI se realizaron gráficos de dispersión con los mismos, de donde se obtuvieron valores de $\mathrm{R}^{2}$ de ajuste lineal. En el Anexo 2 se apreciar los dichos gráficos con su respectiva línea recta que ajusta los datos junto con a su valor $\mathrm{R}^{2}$ y en la Tabla 19 se compilan dichos valores para cada parcela en las fechas definidas.

Tabla 19. Valores de ajuste lineal $\mathbf{R}^{2}$ para las parcelas respecto a los datos de la metodología a nivel pixel en las fechas establecidas.

\begin{tabular}{lccccccccc} 
Cultivo & Parcela & $\begin{array}{c}\text { Jul } \\
\mathbf{2 8}\end{array}$ & $\begin{array}{c}\text { Ago } \\
\mathbf{1 4}\end{array}$ & $\begin{array}{c}\text { Sept } \\
\mathbf{0 8}\end{array}$ & $\begin{array}{c}\text { Oct } \\
\mathbf{1 6}\end{array}$ & $\begin{array}{c}\text { Nov } \\
\mathbf{1 7}\end{array}$ & $\begin{array}{c}\text { Nov } \\
\mathbf{2 6}\end{array}$ & $\begin{array}{c}\text { Dic } \\
\mathbf{0 3}\end{array}$ & $\begin{array}{c}\text { Dic } \\
\mathbf{1 2}\end{array}$ \\
\hline \hline \multirow{3}{*}{ Cebada } & 3 & 0.14 & 0.00 & 0.06 & 0.22 & 0.42 & 0.25 & 0.00 & 0.00 \\
& 4 & 0.03 & 0.01 & 0.05 & 0.13 & 0.17 & 0.05 & 0.00 & 0.08 \\
& 5 & 0.02 & 0.04 & 0.06 & 0.14 & 0.15 & 0.08 & 0.01 & 0.11 \\
\hline \multirow{4}{*}{ Trigo } & 0 & 0.07 & 0.06 & 0.02 & 0.30 & 0.29 & 0.42 & 0.41 & 0.13 \\
& 2 & 0.08 & 0.01 & 0.14 & 0.09 & 0.07 & 0.05 & 0.00 & 0.09 \\
& 6 & 0.00 & 0.01 & 0.06 & 0.25 & - & 0.29 & 0.34 & 0.20 \\
& 7 & 0.05 & 0.19 & 0.24 & 0.28 & - & 0.38 & 0.53 & 0.30 \\
\hline
\end{tabular}

En las gráficas vistas en el Anexo 2 se puede observar cómo se distribuyen los datos de rendimiento respecto a los valores de NDVI y su variación en el transcurso del segundo semestre del 2014. Debido a la gran cantidad de pixeles que intervienen por parcela los datos se aglomeran en una nube de puntos densa en la cual no se puede establecer claramente alguna tendencia marcada, no obstante analizando el ajuste de los datos a la ecuación lineal se observa que en los primeros meses, julio y agosto, tienden a tener una correlación negativa, ya que la pendiente de la recta es negativa en diferentes caso y propende a ser bastante baja; a medida que avanzan los meses la correlación tiende a aumentar, llegando a su máximo para el cultivo de cebada en el mes de noviembre y para trigo a comienzos de diciembre, posterior a esas fechas para el cultivo respectivo la correlación cae debido al estado fenológico, ya que pasa a senectud y el verdor de las plantas empieza a decaer.

El coeficiente de correlación $\mathrm{R}^{2}$ de ajuste lineal es relativamente bajo en la mayoría de los casos, esto se debe a la gran variedad de puntos y su dispersión en los gráficos, los valores más altos encontrados en las parcelas de cebada es de 0.41 en la fecha de 17 de noviembre (parcela 3 ) y en trigo de 0.53 en la fecha 03 de diciembre (parcela 7). No obstante hay que tener en cuenta la complejidad y variabilidad del fenómeno estudiado, considerándose estos resultados no despreciables para la interpretación del mismo. 
Lo anterior hace parte de un análisis exploratorio para encontrar las mejores fechas en cada cultivo para realizar los modelos de regresión. Otro punto de vista de este proceso se efectuó calculando coeficiente de correlación de Pearson en los set de datos por parcela. En la Tabla 20 se exponen un compilado de los valores de dicho coeficiente por tipo de cultivo, al igual que en el Gráfico 7 se observa la variación de la magnitud de los coeficientes en el transcurso de los meses.

Tabla 20. Coeficientes de Pearson por parcela según la metodología a nivel pixel en las fechas establecidas.

\begin{tabular}{cccccccccc}
\multirow{2}{*}{ Cultivo } & \multirow{2}{*}{ Parcela } & $\begin{array}{c}\text { Jul } \\
\mathbf{2 8}\end{array}$ & $\begin{array}{c}\text { Ago } \\
\text { 14 }\end{array}$ & $\begin{array}{c}\text { Sept } \\
\mathbf{0 8}\end{array}$ & $\begin{array}{c}\text { Oct } \\
\mathbf{1 6}\end{array}$ & $\begin{array}{c}\text { Nov } \\
\mathbf{1 7}\end{array}$ & $\begin{array}{c}\text { Nov } \\
\mathbf{2 6}\end{array}$ & $\begin{array}{c}\text { Dic } \\
\mathbf{0 3}\end{array}$ & $\begin{array}{c}\text { Dic } \\
\mathbf{1 2}\end{array}$ \\
\hline \hline \multirow{3}{*}{ Cebada } & 3 & -0.38 & 0.03 & 0.24 & 0.47 & 0.64 & 0.50 & 0.01 & -0.04 \\
& 4 & -0.17 & -0.08 & 0.22 & 0.36 & 0.41 & 0.22 & -0.02 & -0.29 \\
& 5 & -0.14 & -0.19 & 0.25 & 0.37 & 0.39 & 0.28 & -0.12 & -0.33 \\
\hline \multirow{3}{*}{ Trigo } & 0 & -0.26 & -0.25 & -0.15 & 0.55 & 0.54 & 0.65 & 0.64 & 0.36 \\
& 2 & -0.28 & 0.11 & 0.37 & 0.31 & 0.26 & 0.22 & -0.03 & -0.30 \\
& 6 & -0.03 & 0.09 & 0.25 & 0.50 & - & 0.54 & 0.58 & 0.45 \\
& 7 & 0.22 & 0.44 & 0.49 & 0.53 & - & 0.62 & 0.73 & 0.55 \\
\hline
\end{tabular}
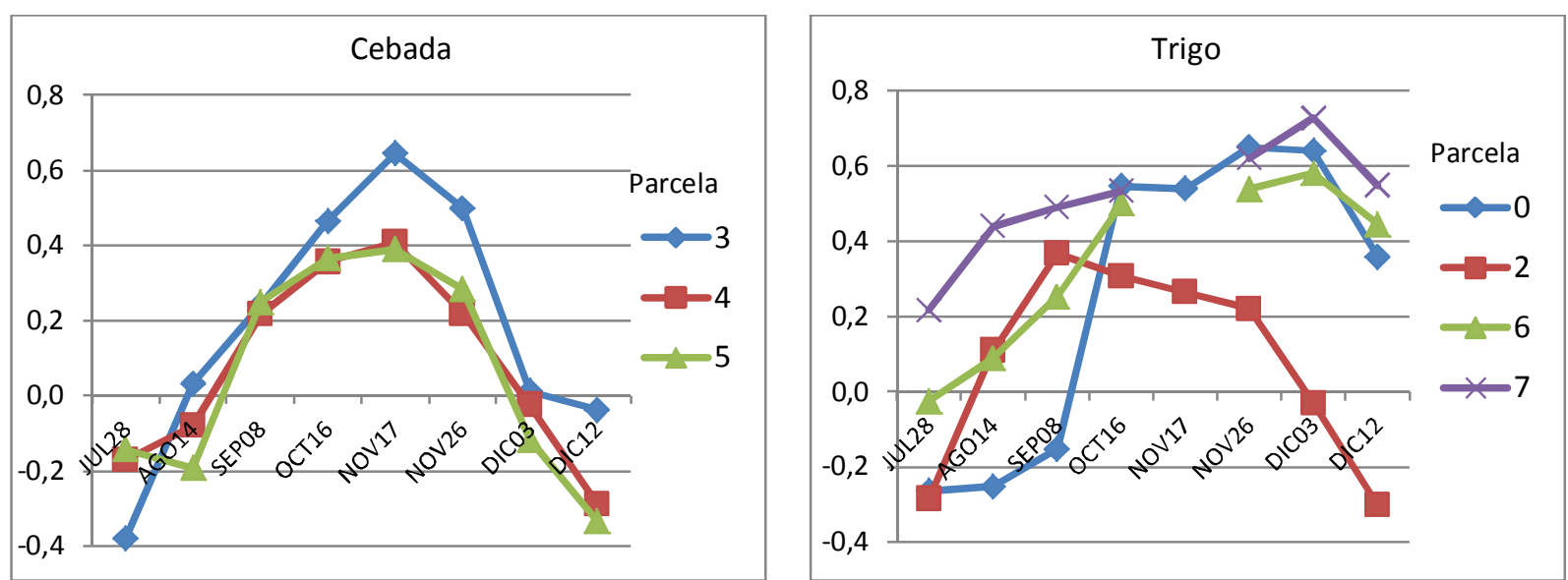

Gráfico 7. Variación del coeficiente Pearson para las parcelas de según la metodología a nivel pixel en las fechas establecidas.

Nota: eje abscisas: fechas consideradas para el estudio; eje ordenadas: valor de NDVI.

Fuente: elaboración propia.

Los resultados anteriores indicaron que la mejor fecha para realizar las regresiones son el 17 de noviembre para cebada y el 3 de diciembre para trigo, corroborando el resultado obtenido con el análisis exploratorio previo. Los coeficientes de correlación fueron mayores, encontrándose como pico alto en cebada un valor de 0.64 para la parcela 3 el 17 de noviembre y para trigo 0.73 en la parcela 0 el 03 de diciembre. Sin embargo en los procesos preliminares se encontró la primera evidencia para indicar que los datos pertenecientes a la parcela 2 de trigo posee 
información anómala la cual se comportó disímil a sus parcelas homologas, encontrándose en la mayoría de los casos a asimilarse más al comportamiento de cebada que al de trigo. Como dato aclaratorio, no se tienen datos del 17 de noviembre para trigo ya que las imágenes satelitales de esta fecha poseen una alta concentración de nubes sobre las parcelas 6 y 7.

Habiendo realizado el análisis por pixel se continuo el mismo análisis pero con los datos resultantes de la metodología zonal (segunda metodología de comparación de datos). En este proceso al generalizar o homogenizar los datos por medio de zonas con mismo valor de NDVI los datos se redujeron drásticamente. Por consecuente los resultados de este proceso brindaron una mejor visualización del comportamiento de los mismos al interior de cada parcela. En la Tabla 21 se presentan la cantidad de datos consolidados de NDVI y rendimiento por parcela en esta metodología.

Tabla 21. Total de puntos de rendimiento y cantidad de pixeles o valores NDVI por parcela respecto a la metodología a nivel zonal en las fechas establecidas.

\begin{tabular}{ccccccccccc} 
& & & \multicolumn{8}{c}{ Cantidad de datos NDVI } \\
\cline { 3 - 10 } Cultivo Parcela & $\begin{array}{c}\text { Datos } \\
\text { de } \\
\text { Rinde }\end{array}$ & $\begin{array}{c}\text { Jul } \\
\mathbf{2 8}\end{array}$ & $\begin{array}{c}\text { Ago } \\
\mathbf{1 4}\end{array}$ & $\begin{array}{c}\text { Sept } \\
\mathbf{0 8}\end{array}$ & $\begin{array}{c}\text { Oct } \\
\mathbf{1 6}\end{array}$ & $\begin{array}{c}\text { Nov } \\
\mathbf{1 7}\end{array}$ & $\begin{array}{c}\text { Nov } \\
\mathbf{2 6}\end{array}$ & $\begin{array}{c}\text { Dic } \\
\mathbf{0 3}\end{array}$ & $\begin{array}{c}\text { Dic } \\
\mathbf{1 2}\end{array}$ \\
\hline \hline \multirow{3}{*}{ Cebada } & 3 & 6139 & 17 & 18 & 33 & 25 & 16 & 22 & 21 & 20 \\
& 4 & 12281 & 29 & 31 & 45 & 28 & 22 & 26 & 30 & 34 \\
& 5 & 4275 & 19 & 22 & 21 & 26 & 20 & 20 & 21 & 26 \\
\hline \multirow{2}{*}{ Trigo } & 0 & 8586 & 32 & 34 & 39 & 25 & 24 & 24 & 25 & 29 \\
& 2 & 6125 & 17 & 17 & 25 & 22 & 20 & 21 & 22 & 28 \\
& 6 & 16439 & 29 & 26 & 31 & 25 & - & 25 & 27 & 39 \\
& 7 & 972 & 7 & 10 & 12 & 22 & - & 24 & 25 & 27 \\
\hline \multicolumn{2}{c}{ Total } & 54817 & 150 & 158 & 206 & 173 & 102 & 162 & 171 & 203
\end{tabular}

De igual forma que la metodología a nivel pixel, el primer paso fue la comparación de los datos mediante un gráfico de dispersión de puntos de rendimiento vs NDVI, recolectando los valores de $\mathrm{R}^{2}$ del ajuste a una ecuación de línea recta. En el Anexo 3 se puede apreciar los gráficos de dispersión mencionados junto con la línea recta de ajuste correspondiente y en la Tabla 22 se compilan dichos valores de $\mathrm{R}^{2}$ para cada parcela en las fechas definidas. 
Tabla 22. Valores de ajuste lineal $\mathbf{R}^{2}$ para las parcelas respecto a los datos de la metodología a nivel zonal en las fechas establecidas.

\begin{tabular}{|c|c|c|c|c|c|c|c|c|c|}
\hline Cultivo & Parcela & $\begin{array}{c}\text { Jul } \\
28\end{array}$ & $\begin{array}{c}\text { Ago } \\
14\end{array}$ & $\begin{array}{c}\text { Sept } \\
08\end{array}$ & $\begin{array}{c}\text { Oct } \\
16\end{array}$ & $\begin{array}{c}\text { Nov } \\
17\end{array}$ & $\begin{array}{c}\text { Nov } \\
26\end{array}$ & $\begin{array}{c}\text { Dic } \\
03\end{array}$ & $\begin{array}{c}\text { Dic } \\
12\end{array}$ \\
\hline \multirow{3}{*}{ Cebada } & 3 & 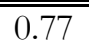 & 0.16 & 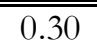 & 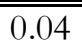 & 0.82 & 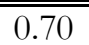 & 0.07 & 0.00 \\
\hline & 4 & 0.27 & 0.28 & 0.30 & 0.16 & 0.55 & 0.43 & 0.34 & 0.33 \\
\hline & 5 & 0.11 & 0.23 & 0.28 & 0.01 & 0.20 & 0.29 & 0.07 & 0.28 \\
\hline \multirow{4}{*}{ Trigo } & 0 & 0.46 & 0.05 & 0.06 & 0.65 & 0.67 & 0.78 & 0.66 & 0.09 \\
\hline & 2 & 0.57 & 0.18 & 0.16 & 0.17 & 0.45 & 0.70 & 0.11 & 0.10 \\
\hline & 6 & 0.05 & 0.06 & 0.11 & 0.52 & - & 0.55 & 0.79 & 0.49 \\
\hline & 7 & 0.89 & 0.79 & 0.85 & 0.65 & - & 0.58 & 0.74 & 0.51 \\
\hline
\end{tabular}

La gran diferencia entre metodologías de comparación es la cantidad de los datos, en la segunda metodología al ser más reducida la cantidad de datos se puede observar con mayor facilidad la tendencia de cada parcela. Esto se evidencia en un mejor ajuste de los datos a una ecuación de línea recta, encontrándose altos valores de coeficientes de correlación $\mathrm{R}^{2}$; al igual que se observa claramente cómo se distribuyen los datos al ser menos densa la nube de puntos en los gráficos de dispersión y su relación de correlación en los transcursos de las fechas consideradas.

Los gráficos observados en el Anexo 3 reafirman y muestran con más claridad el tipo de correlación perteneciente a los datos de los meses en cuestión en cada tipo de cultivo. Por lo general, en ambos cultivos se obtuvo una correlación negativa fuerte en los dos primeros meses, julio y agosto; la ecuación a la línea recta en estos meses se presentó con pendiente negativa, más pronunciada en el mes de julio, esto es debido a que en estos meses el cultivo se encuentra en sus inicios de crecimiento por lo cual se presenta mayor cobertura der suelo que de vegetación. A partir de septiembre la correlación y su ecuación de línea recta cambian a ser positiva ya que se presenta mayor cobertura vegetal al interior de las parcelas.

En esta metodología al observar los gráficos de dispersión (Anexo 3) se resaltó las fechas con mejor correlación para cada tipo de cultivo, coincidiendo con las tendencias de la primera metodología, sin embargo esta metodología es más explícita gráficamente al poseer datos homogenizados. Para el cultivo de cebada se pudo apreciar que el mejor mes en donde se encuentra una alta correlación y un ajuste alto a la ecuación de línea recta es en Noviembre, en sus 2 de fechas 17 y 26, obteniendo un $\mathrm{R}^{2}$ de 0.8 en la parcela 3 del 17 de noviembre como el más representativo. En las fechas de diciembre la correlación baja notablemente encontrándose pendientes negativas de la línea recta, esto se debe a que este cultivo baja sus índices de verdor en diciembre. En contraparte para el cultivo de trigo se pudo encontrar que las mejores fechas con alta correlación de los datos es a finales de noviembre y comienzos de diciembre, en donde 
se obtuvieron $\mathrm{R}^{2}$ de 0.7 y 0.8 respectivamente, por ejemplo en la parcela 6 el 03 de diciembre con un $\mathrm{R}^{2}$ de 0.79 . A partir del 3 de diciembre los resultados de correlación empezaron su declive, esto es porque este tipo de cultivo empieza su estado fenológico de senectud, bajando sus índices de verdor en el mismo.

Semejante a la metodología a nivel pixel, se evaluaron los coeficientes de correlación de Pearson para ambos cultivos en sus respectivas parcelas, con el fin de corroborar los resultados encontrados en el análisis anterior. En la Tabla 23 se compilan los valores de dicho coeficiente por tipo de cultivo, al igual que en el Gráfico 8 se representa la variación de los valores de los resultados en el transcurso de los meses.

Tabla 23. Coeficientes de Pearson por parcela según la metodología a nivel zonal en las fechas establecidas.

\begin{tabular}{cccccccccc}
\multirow{2}{*}{ Cultivo } & Parcela & $\begin{array}{c}\text { Jul } \\
\text { 28 }\end{array}$ & $\begin{array}{c}\text { Ago } \\
\text { 14 }\end{array}$ & $\begin{array}{c}\text { Sept } \\
\mathbf{0 8}\end{array}$ & $\begin{array}{c}\text { Oct } \\
\mathbf{1 6}\end{array}$ & $\begin{array}{c}\text { Nov } \\
\mathbf{1 7}\end{array}$ & $\begin{array}{c}\text { Nov } \\
\mathbf{2 6}\end{array}$ & $\begin{array}{c}\text { Dic } \\
\mathbf{0 3}\end{array}$ & $\begin{array}{c}\text { Dic } \\
\mathbf{1 2}\end{array}$ \\
\hline \multirow{3}{*}{ Cebada } & 3 & -0.88 & -0.40 & 0.54 & 0.19 & 0.91 & 0.84 & 0.26 & 0.01 \\
& 4 & -0.52 & -0.53 & 0.55 & 0.40 & 0.74 & 0.66 & -0.59 & -0.57 \\
& 5 & -0.32 & -0.48 & 0.53 & 0.09 & 0.45 & 0.54 & -0.26 & -0.53 \\
\hline \multirow{4}{*}{ Trigo } & 0 & -0.58 & -0.38 & -0.35 & 0.81 & 0.82 & 0.88 & 0.85 & 0.30 \\
& 2 & -0.76 & -0.43 & 0.40 & 0.41 & 0.67 & 0.84 & -0.33 & -0.31 \\
& 6 & -0.23 & -0.24 & 0.33 & 0.72 & - & 0.74 & 0.89 & 0.70 \\
& 7 & 0.94 & 0.89 & 0.92 & 0.81 & - & 0.76 & 0.86 & 0.71 \\
\hline
\end{tabular}

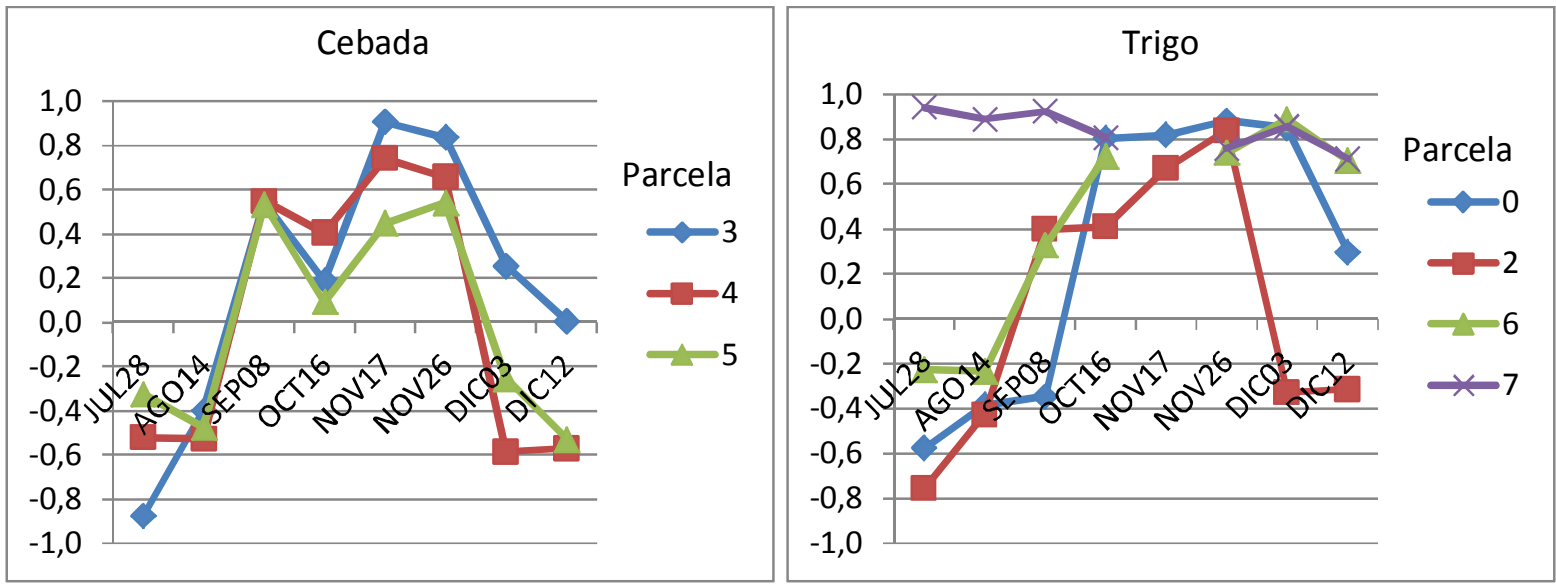

Gráfico 8. Variación del coeficiente Pearson para las parcelas de según la metodología a nivel zonal en las fechas establecidas.

Nota: eje abscisas: fechas consideradas para el estudio; eje ordenadas: valor de NDVI.

Fuente: elaboración propia.

Implementando el coeficiente de correlación de Pearson a los datos se logró encontrar valores más altos a comparación de los $\mathrm{R}^{2}$ de las gráficas de dispersión de los puntos, sin embargo las 2 formas de correlacionar la información es similar, en proporción, en algunos meses resaltando cuales son los más aptos para realizar los modelos espaciales. 
Para el cultivo de cebada las 3 parcelas poseen valores muy similares de correlación en los meses respectivos, encontrándose valores negativos en los primeros meses, julio y agosto, donde el estadio del cultivo se encuentra en fase de crecimiento, habiendo mayor cobertura de suelo desnudo o rastrojo; al igual que en las fechas de diciembre donde el cultivo comienza su fase de maduración, reduciendo en mayor medida su verdor. En contraparte se encontró coeficientes positivos bastante altos en las fechas del mes de noviembre, donde se obtuvieron valores de 0.8 y 0.9 (parcela 3), señalando que este mes en el que se encuentra el mayor verdor del cultivo y la mejor correlación con el rendimiento del mismo.

Para el cultivo de trigo se encontró mucha heterogeneidad en el comportamiento de los coeficientes para las parcelas durante el transcurso del tiempo. Cabe recordar que para la fecha del 17 de noviembre no se poseen datos de NDVI para las parcelas 6 y 7 debido a presencia de nubes en la imagen satelital; al igual que el cultivo de cebada los meses de julio y agostos poseen coeficientes negativos debidos a la fase inicial del cultivo. Sin embargo en diciembre se mantiene y no decrecen drásticamente a un valor negativo por lo general. De la misma manera que la metodología a nivel pixel, la parcela 2 posee un comportamiento anómalo a comparación de las otras de trigo, arrojando un comportamiento más parecido a los valores de cebada; por otra parte, la parcela 7 al estar contenida al interior de la parcela 6 (no presentando influencia por vegetación ajena al cultivo en sus periferias) y poseer un tratamiento de fertilización especial presenta altos coeficientes positivos en todas las fechas de estudio. En definitiva al analizar el comportamiento general de los coeficientes, los mejores valores fueron obtenidos a finales de noviembre y comienzos de diciembre (valores entre 0.8 y 0.9 por lo general) coincidiendo con lo esperado debido al estado fenológico en estas fechas, donde su verdor esta al máximo. Comparando con la cebada, el trigo empieza su senectud unas semanas después, por tal razón se encontró un decrecimiento de valores de correlación en la fecha 12 de diciembre.

En conclusión, observando las 2 metodologías de comparación de los datos, el análisis exploratorio dio como resultado que las mejores fechas para realizar el proceso de modelización son el 17 y 26 de noviembre y el 3 de diciembre. Para ambos cultivos se efectuaran los modelos en dichas fechas, sin embargo las fechas adecuadas, según el análisis exploratorio, para el cultivo de cebada son las del mes de noviembre y para trigo finales de noviembre y comienzos de diciembre. 


\subsection{Modelos de estadísticos.}

\subsubsection{Modelo clásico MCO (nivel pixel).}

La primera instancia de esta sección se trabajó bajo la metodología a nivel de pixel, comenzando por generar modelos clásicos por MCO, donde se analizaron los resultados arrojados por el $\mathrm{GeoDa}{ }^{\circledR}$ para las parcelas y fechas establecidas. En la Tabla 24 se presentan los resultados de los estadísticos y los test arrojados iniciales para dichos modelos.

Tabla 24. Resultados de los estadísticos y test generales de los modelos MCO por parcela para la metodología a nivel pixel.

\begin{tabular}{|c|c|c|c|c|c|c|c|c|c|}
\hline Fecha & Cultivo & Parcela & $\mathbf{R}^{2}$ & $\begin{array}{c}\mathbf{R}^{2} \\
\text { Ajustado } \\
\end{array}$ & $\begin{array}{c}\text { Estadístico } \\
\mathrm{F}\end{array}$ & $\begin{array}{l}\text { Probabilidad } \\
\text { Estadístico F }\end{array}$ & $\begin{array}{c}\text { Máxima } \\
\text { Verosimilitud } \\
\end{array}$ & Akaike & Schwarz \\
\hline \multirow{6}{*}{$\begin{array}{c}\text { Nov } \\
17\end{array}$} & \multirow{4}{*}{ Cebada } & 3 & 0.45 & 0.45 & 488.51 & 0.00 & -350.24 & 704.48 & 7113.30 \\
\hline & & $3 y 4$ & 0.21 & 0.21 & 510.19 & 0.00 & -1566.00 & 3136.00 & 3147.11 \\
\hline & & 4 & 0.17 & 0.17 & 264.73 & 0.00 & -1136.47 & 2276.95 & 2287.28 \\
\hline & & 5 & 0.15 & 0.15 & 76.76 & 0.00 & -346.55 & 697.09 & 705.23 \\
\hline & \multirow{2}{*}{ Trigo } & 0 & 0.26 & 0.26 & 298.39 & 0.00 & -937.72 & 1879.45 & 1888.89 \\
\hline & & 2 & 0.09 & 0.09 & 63.41 & 0.00 & -511.29 & 1026.57 & 1035.40 \\
\hline \multirow{9}{*}{$\begin{array}{l}\text { Nov } \\
26\end{array}$} & \multirow{4}{*}{ Cebada } & 3 & 0.30 & 0.30 & 263.37 & 0.00 & -420.60 & 845.21 & 854.03 \\
\hline & & $3 \mathrm{y} 4$ & 0.08 & 0.08 & 170.07 & 0.00 & -1711.14 & 3426.28 & 3437.38 \\
\hline & & 4 & 0.05 & 0.05 & 70.07 & 0.00 & -1222.91 & 2449.82 & 2460.15 \\
\hline & & 5 & 0.08 & 0.08 & 37.71 & 0.00 & -363.86 & 731.73 & 739.87 \\
\hline & \multirow{5}{*}{ Trigo } & 0 & 0.40 & 0.40 & 547.33 & 0.00 & -854.79 & 1713.58 & 1723.03 \\
\hline & & 2 & 0.07 & 0.07 & 46.90 & 0.00 & -518.88 & 1041.76 & 1050.58 \\
\hline & & 6 & 0.33 & 0.33 & 772.12 & 0.00 & -1578.61 & 3161.22 & 3171.91 \\
\hline & & $6 y 7$ & 0.38 & 0.38 & 1001.01 & 0.00 & -1674.19 & 3352.39 & 3363.22 \\
\hline & & 7 & 0.52 & 0.52 & 119.55 & 0.00 & -91.33 & 186.65 & 192.09 \\
\hline \multirow{9}{*}{$\begin{array}{c}\text { Dic } \\
03\end{array}$} & \multirow{4}{*}{ Cebada } & 3 & 0.00 & 0.00 & 2.12 & 0.15 & -523.65 & 1051.31 & 1060.13 \\
\hline & & $3 y 4$ & 0.00 & 0.00 & 0.30 & 0.59 & -1772.82 & 3549.64 & 3560.74 \\
\hline & & 4 & 0.00 & 0.00 & 0.00 & 0.98 & -1243.31 & 2490.62 & 2500.96 \\
\hline & & 5 & 0.01 & 0.01 & 5.91 & 0.02 & -379.07 & 762.15 & 770.28 \\
\hline & \multirow{5}{*}{ Trigo } & 0 & 0.41 & 0.41 & 578.28 & 0.00 & -873.37 & 1750.75 & 1760.20 \\
\hline & & 2 & 0.01 & 0.00 & 3.26 & 0.07 & -533.16 & 1070.32 & 1079.15 \\
\hline & & 6 & 0.38 & 0.38 & 965.79 & 0.00 & -1516.51 & 3037.01 & 3047.70 \\
\hline & & $6 y 7$ & 0.40 & 0.40 & 1109.13 & 0.00 & -1717.33 & 3438.66 & 3449.50 \\
\hline & & 7 & 0.67 & 0.67 & 226.86 & 0.00 & -69.85 & 143.70 & 149.13 \\
\hline
\end{tabular}

En primer lugar se analizó el resultado del $\mathrm{R}^{2}$ y $\mathrm{R}^{2}$ ajustado, los cuales muestran la medida tradicional de ajuste de los datos al modelo lineal. Se observó que los valores más altos para cebada se encuentran en noviembre 17, siendo el valor más alto entre las parcelas de este cultivo el correspondiente a la parcela 3 con $44.63 \%$ de ajuste, en contraste los valores de las otras parcelas son comparablemente bajos no superando el $20 \%$ en dicha fecha; sin embargo en las 
otras fechas los valores son demasiado bajos para ser considerados, en especial en el mes de diciembre 03 ya que el ajuste es del $0 \%$. Respeto al cultivo de trigo se obtuvieron valores mayores, encontrándose estos en la fecha de diciembre 03, cuyo conjunto de datos resalta el valor de la parcela 7 con un $67 \%$ de ajuste, el cual se podría considerar óptimo para medir este cultivo. Como dato resaltante se observó que los valores de ajuste para la parcela 2 de trigo siempre son muy bajos en comparación con sus parcelas homologas, por lo cual se podría suponer que estos datos poseen alguna anomalía proveniente al momento de captura en campo por el monitor de rendimiento; esta observación fue persistente en los análisis de los resultados de los otros modelos y metodologías evaluadas previamente.

El test del estadístico F (Tabla 24) indica si las variables en conjunto consideradas en un modelo en particular son estadísticamente significativas, sin embargo no indica que las variables individualmente lo sean. Los resultados exponen que en la mayoría de los modelos las variables en grupo se ajustan, ya que los valores de probabilidad son cero, a excepción de los modelos para cebada en diciembre 03 , corroborando lo sugerido con los valores de $\mathrm{R}^{2}$ y coeficientes de correlación de Pearson.

Los resultados pertenecientes a los criterios de máxima verosimilitud, Akaike y Schwarz (Tabla 24) son medidas basadas en la suposición de normalidad multivariante de los modelos clásicos. Estos se utilizaron para comparar modelos entre sí, entre mayor sea el valor de máxima verosimilitud y menor sea los valores de Akaike y Schwarz mejor se ajusta un modelo en particular. Para el cultivo de cebada al comparar los modelos por mes se observó que los valores mayores de máxima verosimilitud y menores de Akaike y Schwarz corresponden a las parcelas 3 y 5 , sin embargo se diferencian por muy poco, por lo cual basado en los anteriores resultados analizados se pudo concluir que el mejor modelo corresponde a la parcela 3. Respecto al cultivo de trigo los mejores valores con base en los criterios mencionados pertenecen a la parcela 7 , debido a que sus valores se diferencian por una amplia cantidad respecto las otras parcelas. Esto corroboró los análisis previos realizados a estos conjuntos de datos para trigo.

Continuando con los resultados del modelo clásico de MCO se analizaron los valores de los coeficientes de las variables para las diferentes parcelas, los cuales se exponen en la Tabla 25. 
Tabla 25. Resultados de los coeficientes y estadísticos para las variables de los modelos MCO por parcela para la metodología a nivel pixel.

\begin{tabular}{|c|c|c|c|c|c|c|c|}
\hline \multirow{7}{*}{$\begin{array}{c}\text { Nov } \\
17\end{array}$} & \multirow{5}{*}{ Cebada } & 3 & $\begin{array}{l}\text { Constante } \\
\text { NDVI }\end{array}$ & $\begin{array}{l}-5.88 \\
14.58 \\
\end{array}$ & $\begin{array}{l}0.52 \\
0.66 \\
\end{array}$ & $\begin{array}{l}-11.33 \\
22.10 \\
\end{array}$ & $\begin{array}{l}0.00 \\
0.00 \\
\end{array}$ \\
\hline & & $3 \mathrm{y} 4$ & $\begin{array}{l}\text { Constante } \\
\text { NDVI }\end{array}$ & $\begin{array}{c}-0.61 \\
7.98\end{array}$ & $\begin{array}{l}0.27 \\
0.35\end{array}$ & $\begin{array}{l}-2.24 \\
22.59\end{array}$ & $\begin{array}{l}0.03 \\
0.00\end{array}$ \\
\hline & & \multirow[t]{2}{*}{4} & Constante* & 0.16 & 0.33 & 0.48 & 0.63 \\
\hline & & & NDVI & 7.03 & 0.43 & 16.27 & 0.00 \\
\hline & & 5 & $\begin{array}{l}\text { Constante* } \\
\text { NDVI }\end{array}$ & $\begin{array}{l}0.33 \\
6.93\end{array}$ & $\begin{array}{l}0.61 \\
0.79\end{array}$ & $\begin{array}{l}0.54 \\
8.76\end{array}$ & $\begin{array}{l}0.59 \\
0.00\end{array}$ \\
\hline & \multirow{2}{*}{ Trigo } & 0 & $\begin{array}{l}\text { Constante } \\
\text { NDVI }\end{array}$ & $\begin{array}{l}-2.67 \\
10.62\end{array}$ & $\begin{array}{l}0.46 \\
0.61\end{array}$ & $\begin{array}{l}-5.85 \\
17.27\end{array}$ & $\begin{array}{l}0.00 \\
0.00\end{array}$ \\
\hline & & 2 & $\begin{array}{l}\text { Constante* } \\
\text { NDVI }\end{array}$ & $\begin{array}{l}0.29 \\
5.89\end{array}$ & $\begin{array}{l}0.62 \\
0.74\end{array}$ & $\begin{array}{l}0.48 \\
7.96\end{array}$ & $\begin{array}{l}0.63 \\
0.00\end{array}$ \\
\hline \multirow{9}{*}{$\begin{array}{c}\text { Nov } \\
26\end{array}$} & \multirow{4}{*}{ Cebada } & 3 & $\begin{array}{l}\text { Constante } \\
\text { NDVI }\end{array}$ & $\begin{array}{c}-0.92 \\
9.93 \\
\end{array}$ & $\begin{array}{l}0.40 \\
0.61\end{array}$ & $\begin{array}{l}-2.29 \\
16.23 \\
\end{array}$ & $\begin{array}{l}0.02 \\
0.00 \\
\end{array}$ \\
\hline & & $3 y 4$ & $\begin{array}{l}\text { Constante } \\
\text { NDVI }\end{array}$ & $\begin{array}{l}3.27 \\
3.59\end{array}$ & $\begin{array}{l}0.17 \\
0.28\end{array}$ & $\begin{array}{l}18.73 \\
13.04\end{array}$ & $\begin{array}{l}0.00 \\
0.00\end{array}$ \\
\hline & & 4 & $\begin{array}{l}\text { Constante } \\
\text { NDVI }\end{array}$ & $\begin{array}{l}3.83 \\
2.74\end{array}$ & $\begin{array}{l}0.20 \\
0.33\end{array}$ & $\begin{array}{c}18.73 \\
8.37\end{array}$ & $\begin{array}{l}0.00 \\
0.00\end{array}$ \\
\hline & & 5 & $\begin{array}{l}\text { Constante } \\
\text { NDVI }\end{array}$ & $\begin{array}{l}2.00 \\
5.37\end{array}$ & $\begin{array}{l}0.60 \\
0.87\end{array}$ & $\begin{array}{l}3.33 \\
6.14\end{array}$ & $\begin{array}{l}0.00 \\
0.00\end{array}$ \\
\hline & \multirow{5}{*}{ Trigo } & 0 & $\begin{array}{l}\text { Constante } \\
\text { NDVI }\end{array}$ & $\begin{array}{l}-3.41 \\
11.08\end{array}$ & $\begin{array}{l}0.37 \\
0.47\end{array}$ & $\begin{array}{l}-9.25 \\
23.40\end{array}$ & $\begin{array}{l}0.00 \\
0.00 \\
\end{array}$ \\
\hline & & 2 & $\begin{array}{l}\text { Constante } \\
\text { NDVI }\end{array}$ & $\begin{array}{l}2.01 \\
3.94\end{array}$ & $\begin{array}{l}0.47 \\
0.58\end{array}$ & $\begin{array}{l}4.30 \\
6.85\end{array}$ & $\begin{array}{l}0.00 \\
0.00\end{array}$ \\
\hline & & 6 & $\begin{array}{l}\text { Constante } \\
\text { NDVI }\end{array}$ & $\begin{array}{c}-1.14 \\
8.68\end{array}$ & $\begin{array}{l}0.24 \\
0.31\end{array}$ & $\begin{array}{l}-4.84 \\
27.79\end{array}$ & $\begin{array}{l}0.00 \\
0.00\end{array}$ \\
\hline & & $6 y 7$ & $\begin{array}{l}\text { Constante } \\
\text { NDVI }\end{array}$ & $\begin{array}{c}-1.23 \\
8.79\end{array}$ & $\begin{array}{l}0.21 \\
0.28\end{array}$ & $\begin{array}{l}-5.91 \\
31.64\end{array}$ & $\begin{array}{l}0.00 \\
0.00\end{array}$ \\
\hline & & 7 & $\begin{array}{l}\text { Constante } \\
\text { NDVI }\end{array}$ & $\begin{array}{c}-1.64 \\
9.35\end{array}$ & $\begin{array}{l}0.58 \\
0.85\end{array}$ & $\begin{array}{l}-2.84 \\
10.93\end{array}$ & $\begin{array}{l}0.01 \\
0.00\end{array}$ \\
\hline \multirow{9}{*}{ Dic 03} & \multirow{4}{*}{ Cebada } & 3 & $\begin{array}{l}\text { Constante } \\
\text { NDVI* }\end{array}$ & $\begin{array}{l}5.07 \\
1.00\end{array}$ & $\begin{array}{l}0.34 \\
0.68\end{array}$ & $\begin{array}{c}14.75 \\
1.46\end{array}$ & $\begin{array}{l}0.00 \\
0.15\end{array}$ \\
\hline & & $3 y 4$ & $\begin{array}{l}\text { Constante } \\
\text { NDVI* }\end{array}$ & $\begin{array}{l}5.48 \\
0.13\end{array}$ & $\begin{array}{l}0.12 \\
0.24\end{array}$ & $\begin{array}{c}45.25 \\
0.55\end{array}$ & $\begin{array}{l}0.00 \\
0.59\end{array}$ \\
\hline & & 4 & $\begin{array}{l}\text { Constante } \\
\text { NDVI* }\end{array}$ & $\begin{array}{r}5.53 \\
-0.01\end{array}$ & $\begin{array}{l}0.13 \\
0.27\end{array}$ & $\begin{array}{l}41.90 \\
-0.03\end{array}$ & $\begin{array}{l}0.00 \\
0.98\end{array}$ \\
\hline & & 5 & $\begin{array}{l}\text { Constante } \\
\text { NDVI }\end{array}$ & $\begin{array}{r}6.62 \\
-1.73 \\
\end{array}$ & $\begin{array}{l}0.39 \\
0.71\end{array}$ & $\begin{array}{l}17.13 \\
-2.43\end{array}$ & $\begin{array}{l}0.00 \\
0.02\end{array}$ \\
\hline & \multirow{5}{*}{ Trigo } & 0 & $\begin{array}{l}\text { Constante } \\
\text { NDVI }\end{array}$ & $\begin{array}{l}-3.29 \\
11.04\end{array}$ & $\begin{array}{l}0.35 \\
0.46\end{array}$ & $\begin{array}{l}-9.30 \\
24.05\end{array}$ & $\begin{array}{l}0.00 \\
0.00\end{array}$ \\
\hline & & 2 & $\begin{array}{l}\text { Constante } \\
\text { NDVI* }\end{array}$ & $\begin{array}{l}4.55 \\
0.80 \\
\end{array}$ & $\begin{array}{l}0.35 \\
0.44\end{array}$ & $\begin{array}{c}12.89 \\
1.81 \\
\end{array}$ & $\begin{array}{l}0.00 \\
0.07 \\
\end{array}$ \\
\hline & & 6 & $\begin{array}{l}\text { Constante } \\
\text { NDVI }\end{array}$ & $\begin{array}{c}-1.37 \\
8.61\end{array}$ & $\begin{array}{l}0.22 \\
0.28\end{array}$ & $\begin{array}{l}-6.26 \\
31.08\end{array}$ & $\begin{array}{l}0.00 \\
0.00\end{array}$ \\
\hline & & $6 y 7$ & $\begin{array}{l}\text { Constante } \\
\text { NDVI }\end{array}$ & $\begin{array}{c}-1.53 \\
8.79\end{array}$ & $\begin{array}{l}0.21 \\
0.26\end{array}$ & $\begin{array}{l}-7.41 \\
33.30\end{array}$ & $\begin{array}{l}0.00 \\
0.00\end{array}$ \\
\hline & & 7 & $\begin{array}{l}\text { Constante } \\
\text { NDVI }\end{array}$ & $\begin{array}{c}-2.20 \\
9.70\end{array}$ & $\begin{array}{l}0.46 \\
0.64\end{array}$ & $\begin{array}{l}-4.81 \\
15.06\end{array}$ & $\begin{array}{l}0.00 \\
0.00\end{array}$ \\
\hline
\end{tabular}

* Variable no significativa en la estructura del modelo ya que su nivel de significancia supera el $5 \%$ (P-valor $>0.05)$.

$\mathrm{Al}$ momento de construir el modelo de regresión lineal optimo se debe observar si las variables pertenecientes al modelo son estadísticamente significativas y pueden predecir el 
comportamiento de la variable dependiente o del fenómeno a estudiar, que en este caso es el rendimiento o productividad del cultivo. Para esto se analizó el test del estadístico T, que a diferencia del estadístico F mide la significancia de las variables individualmente, en donde se consideró que la variable es estadísticamente significativa si no supera el valor alfa clásico de $5 \%$. Se observó que en las parcelas 2, 4 y 5 pertenecientes a noviembre 17 la constante del modelo no es estadísticamente significativa, al igual que la variable NDVI para las 2, 3, 3 y 4, 4 de diciembre 03, el resto de parámetros al poseer la probabilidad inferior a 0.05 son significativos y se podría construir un modelo fiable con los mismos.

Hasta el momento se tiene las bases para poder escoger el mejor modelo para cada cultivo en las fechas establecidas, cuyo resultado sería el modelo de la parcela 3 en noviembre 17 para cebada y la parcela 7 en diciembre 03 para trigo. Sin embargo fue necesario evaluar otros test que permitieron diagnosticar si los modelos antes mencionados poseen problemas en los supuestos estadísticos básicos, como por ejemplo heterocedasticidad, no normalidad y autocorrelación en los errores. En la Tabla 26 se muestran los valores de diferentes test para detectar la heterocedasticidad y la no normalidad mencionada. 
Tabla 26. Resultados de los estadísticos para evaluar la heterocedasticidad y no normalidad de los modelos MCO por parcela para la metodología a nivel pixel.

\begin{tabular}{|c|c|c|c|c|c|c|c|c|c|c|}
\hline \multirow[t]{2}{*}{ Fecha } & \multirow[t]{2}{*}{ Cultivo } & \multirow[t]{2}{*}{ Parcela } & \multicolumn{2}{|c|}{ Jarque-Bera } & \multicolumn{2}{|c|}{$\begin{array}{c}\text { Breusch- } \\
\text { Pagan } \\
\end{array}$} & \multicolumn{2}{|c|}{$\begin{array}{c}\text { Koenker- } \\
\text { Bassett }\end{array}$} & \multicolumn{2}{|c|}{ White } \\
\hline & & & Valor & Prob & Valor & Prob & Valor & Prob & Valor & Prob \\
\hline \multirow{6}{*}{$\begin{array}{c}\text { Nov } \\
17\end{array}$} & \multirow{4}{*}{ Cebada } & 3 & 441.38 & 0.00 & 53.16 & 0.00 & 18.33 & 0.00 & 18.70 & 0.00 \\
\hline & & $3 y^{4}$ & 1217.57 & 0.00 & 243.20 & 0.00 & 87.19 & 0.00 & 163.46 & 0.00 \\
\hline & & 4 & 853.40 & 0.00 & 107.77 & 0.00 & 38.95 & 0.00 & 76.05 & 0.00 \\
\hline & & 5 & 82.08 & 0.00 & 73.51 & 0.00 & 44.67 & 0.00 & 48.51 & 0.00 \\
\hline & \multirow{2}{*}{ Trigo } & 0 & 168.68 & 0.00 & 0.03 & 0.88 & 0.02 & 0.90 & 0.33 & 0.85 \\
\hline & & 2 & 18.97 & 0.00 & 29.33 & 0.00 & 20.59 & 0.00 & 28.12 & 0.00 \\
\hline \multirow{9}{*}{$\begin{array}{c}\text { Nov } \\
26\end{array}$} & \multirow{4}{*}{ Cebada } & 3 & 182.19 & 0.00 & 6.21 & 0.01 & 3.26 & 0.07 & 3.78 & 0.15 \\
\hline & & $3 y 4$ & 1207.09 & 0.00 & 0.00 & 0.96 & 0.00 & 0.98 & 27.33 & 0.00 \\
\hline & & 4 & 922.24 & 0.00 & 10.42 & 0.00 & 3.91 & 0.05 & 35.86 & 0.00 \\
\hline & & 5 & 162.48 & 0.00 & 3.65 & 0.06 & 1.89 & 0.17 & 2.79 & 0.25 \\
\hline & \multirow{5}{*}{ Trigo } & 0 & 449.23 & 0.00 & 3.86 & 0.05 & 1.62 & 0.20 & 3.11 & 0.21 \\
\hline & & 2 & 21.68 & 0.00 & 41.40 & 0.00 & 28.45 & 0.00 & 31.01 & 0.00 \\
\hline & & 6 & 376.18 & 0.00 & 1.53 & 0.22 & 0.81 & 0.37 & 15.25 & 0.00 \\
\hline & & $6 y 7$ & 380.62 & 0.00 & 3.14 & 0.08 & 1.67 & 0.20 & 11.70 & 0.00 \\
\hline & & 7 & 1.71 & 0.42 & 1.32 & 0.25 & 1.85 & 0.17 & 1.87 & 0.39 \\
\hline \multirow{9}{*}{$\begin{array}{c}\text { Dic } \\
03\end{array}$} & \multirow{4}{*}{ Cebada } & 3 & 124.82 & 0.00 & 3.26 & 0.07 & 2.19 & 0.14 & 4.68 & 0.10 \\
\hline & & $3 y 4$ & 542.05 & 0.00 & 118.68 & 0.00 & 53.61 & 0.00 & 63.41 & 0.00 \\
\hline & & 4 & 705.32 & 0.00 & 129.55 & 0.00 & 62.37 & 0.00 & 73.47 & 0.00 \\
\hline & & 5 & 148.44 & 0.00 & 7.42 & 0.01 & 4.07 & 0.04 & 9.54 & 0.01 \\
\hline & \multirow{5}{*}{ Trigo } & 0 & 533.33 & 0.00 & 11.70 & 0.00 & 4.65 & 0.03 & 12.68 & 0.00 \\
\hline & & 2 & 33.13 & 0.00 & 88.50 & 0.00 & 62.38 & 0.00 & 65.65 & 0.00 \\
\hline & & 6 & 610.75 & 0.00 & 15.14 & 0.00 & 7.08 & 0.01 & 6.79 & 0.03 \\
\hline & & $6 y 7$ & 2183.80 & 0.00 & 18.89 & 0.00 & 5.57 & 0.02 & 8.29 & 0.02 \\
\hline & & 7 & 0.69 & 0.71 & 2.07 & 0.15 & 2.40 & 0.12 & 3.10 & 0.21 \\
\hline
\end{tabular}

Nota: Prob: Probabilidad o P-valor del test.

En la Tabla 26 se observó que la mayoría de modelos arrojan un P-valor de 0 en el test de Jarque-Bera indicando no normalidad en los errores, a excepción de los modelos para la parcela 7 en noviembre 26 y diciembre 03. Lo anterior se puede explicar porque los datos de dicha parcela son más homogéneos y de menor cantidad. De igual forma se puede argumentar la no normalidad de los errores debido a que solo se considera una variable explicativa en el proceso o simplemente por la naturaleza geográfica de los datos de rendimiento y NDVI.

Los resultados de los test para medir la heterocedasticidad (Breusch-Pagan, Koenker-Bassett y White), los cuales se aprecian en la Tabla 26, mostraron que hay varios modelos que poseen este problema ya que se rechaza la hipótesis nula de homocedasticidad al poseer valores de probabilidad inferiores a 0.05. Enfocándose en las fechas óptimas para cada cultivo, 17 de noviembre para cebada y 03 de diciembre para trigo, se detectó que los modelos poseen heterocedasticidad, no obstante para los dos cultivos del 26 de noviembre se encontró que la 
mayoría de estos modelos no posee heterocedasticidad. Por lo tanto es importante tener presente que los problemas de heterocedasticidad también se podrían deber a problemas de dependencia espacial o deficiencia estructural de los modelos.

Para el análisis de la no autocorrelación espacial en los residuales, se utilizó el índice I de Moran obtenido con el GeoDa ${ }^{\circledR}$, en la Tabla 27 se muestran los valores de dicho índice para las fechas y parcelas de estudio.

Tabla 27. Resultados del estadístico I de Moran para evaluar la autocorrelación en los residuales de los modelos MCO por parcela para la metodología a nivel pixel.

\begin{tabular}{|c|c|c|c|c|c|}
\hline \multirow{2}{*}{ Fecha } & \multirow{2}{*}{ Cultivo } & \multirow{2}{*}{ Parcela } & \multicolumn{3}{|c|}{ I de Moran } \\
\hline & & & Error & Valor & Probabilidad \\
\hline \multirow{6}{*}{$\begin{array}{c}\text { Nov } \\
17\end{array}$} & \multirow{4}{*}{ Cebada } & 3 & 0.18 & 8.73 & 0.00 \\
\hline & & $3 y 4$ & 0.33 & 27.16 & 0.00 \\
\hline & & 4 & 0.33 & 22.13 & 0.00 \\
\hline & & 5 & 0.28 & 11.16 & 0.00 \\
\hline & \multirow{2}{*}{ Trigo } & 0 & 0.48 & 26.51 & 0.00 \\
\hline & & 2 & 0.47 & 22.26 & 0.00 \\
\hline \multirow{9}{*}{$\begin{array}{c}\text { Nov } \\
26\end{array}$} & \multirow{4}{*}{ Cebada } & 3 & 0.34 & 16.14 & 0.00 \\
\hline & & $3 y 4$ & 0.39 & 32.28 & 0.00 \\
\hline & & 4 & 0.37 & 25.36 & 0.00 \\
\hline & & 5 & 0.32 & 12.67 & 0.00 \\
\hline & \multirow{5}{*}{ Trigo } & 0 & 0.35 & 19.24 & 0.00 \\
\hline & & 2 & 0.49 & 22.79 & 0.00 \\
\hline & & 6 & 0.45 & 33.38 & 0.00 \\
\hline & & $6 y 7$ & 0.43 & 33.72 & 0.00 \\
\hline & & 7 & 0.23 & 4.37 & 0.00 \\
\hline \multirow{9}{*}{$\begin{array}{c}\text { Dic } \\
03\end{array}$} & \multirow{4}{*}{ Cebada } & 3 & 0.51 & 24.07 & 0.00 \\
\hline & & $3 y 4$ & 0.40 & 27.14 & 0.00 \\
\hline & & 4 & 0.43 & 35.63 & 0.00 \\
\hline & & 5 & 0.34 & 13.56 & 0.00 \\
\hline & \multirow{5}{*}{ Trigo } & 0 & 0.33 & 18.17 & 0.00 \\
\hline & & 2 & 0.50 & 23.63 & 0.00 \\
\hline & & 6 & 0.45 & 32.93 & 0.00 \\
\hline & & $6 \mathrm{y} 7$ & 0.42 & 32.40 & 0.00 \\
\hline & & 7 & 0.19 & 3.71 & 0.00 \\
\hline
\end{tabular}

Se observó que los valores del índice I de Moran son considerablemente altos y sus P-valores son cero, indicando que dicha prueba es significativa dando por entendido que todas las parcelas presentan problemas de autocorrelación espacial en los residuales. Esto se esperaba encontrar en los resultados obtenidos por el método de $\mathrm{MCO}$ ya que carece de la componente de pesos espaciales. Sin embargo el índice I de Moran no solo es útil para la detección de autocorrelación sino que se puede interpretar con una inadecuada especificación del modelo 
utilizado, por esta razón al dar el I de Moran estadísticamente significativo se replanteó la utilización de modelos que contemplan la característica espacial la cual está definida por la matriz de pesos W. Los modelos pertinentes para dar solución a este inconveniente son los modelos de dependencia espacial sustantiva (modelo Lag) y de dependencia espacial residual (modelo Error).

Para seleccionar el modelo que se ajuste en mayor medida a los datos de cada parcela se realizó el test de multiplicadores de Lagrange (LM por sus siglas en inglés) siguiendo el diagrama de decisión mencionado en los materiales y métodos (Figura 20). Los resultados encontrados para este test LM se organizan en la Tabla 28.

Tabla 28. Resultados de los Multiplicadores de Lagrange pertenecientes a los modelos MCO por parcela para la metodología a nivel pixel.

\begin{tabular}{|c|c|c|c|c|c|c|c|c|c|c|}
\hline \multirow[t]{2}{*}{ Fecha } & \multirow[t]{2}{*}{ Cultivo } & \multirow[t]{2}{*}{ Parcela } & \multicolumn{2}{|c|}{$\begin{array}{l}\text { Multiplicador } \\
\text { de Lagrange } \\
\text { (Lag) }\end{array}$} & \multicolumn{2}{|c|}{$\begin{array}{l}\text { Robusto } \\
\text { LM (Lag) }\end{array}$} & \multicolumn{2}{|c|}{$\begin{array}{l}\text { Multiplicador } \\
\text { de Lagrange } \\
\text { (Error) }\end{array}$} & \multicolumn{2}{|c|}{$\begin{array}{l}\text { Robusto LM } \\
\text { (Error) }\end{array}$} \\
\hline & & & Valor & Prob & Valor & Prob & Valor & Prob & Valor & Prob \\
\hline \multirow{6}{*}{$\begin{array}{c}\text { Nov } \\
17\end{array}$} & \multirow{4}{*}{ Cebada } & 3 & 993.43 & 0.00 & 21.07 & 0.00 & 72.58 & 0.00 & 0.22 & 0.64 \\
\hline & & $3 y 4$ & 700.80 & 0.00 & 9.97 & 0.00 & 729.27 & 0.00 & 38.44 & 0.00 \\
\hline & & 4 & 464.19 & 0.00 & 4.63 & 0.03 & 481.68 & 0.00 & 22.11 & 0.00 \\
\hline & & 5 & 125.34 & 0.00 & 6.88 & 0.01 & 118.94 & 0.00 & 0.47 & 0.49 \\
\hline & \multirow{2}{*}{ Trigo } & 0 & 561.73 & 0.00 & 1.03 & 0.31 & 688.13 & 0.00 & 127.44 & 0.00 \\
\hline & & 2 & 456.89 & 0.00 & 0.01 & 0.91 & 481.91 & 0.00 & 25.04 & 0.00 \\
\hline \multirow{9}{*}{$\begin{array}{l}\text { Nov } \\
26\end{array}$} & \multirow{4}{*}{ Cebada } & 3 & 244.30 & 0.00 & 8.63 & 0.00 & 251.43 & 0.00 & 15.76 & 0.00 \\
\hline & & $3 y 4$ & 1018.10 & 0.00 & 3.48 & 0.06 & 1030.81 & 0.00 & 16.19 & 0.00 \\
\hline & & 4 & 633.48 & 0.00 & 3.61 & 0.06 & 632.92 & 0.00 & 3.04 & 0.08 \\
\hline & & 5 & 152.13 & 0.00 & 1.16 & 0.28 & 153.35 & 0.00 & 2.38 & 0.12 \\
\hline & \multirow{5}{*}{ Trigo } & 0 & 323.19 & 0.00 & 10.40 & 0.00 & 361.05 & 0.00 & 48.26 & 0.00 \\
\hline & & 2 & 477.30 & 0.00 & 1.07 & 0.30 & 504.66 & 0.00 & 28.43 & 0.00 \\
\hline & & 6 & 945.50 & 0.00 & 0.74 & 0.39 & 1100.32 & 0.00 & 155.56 & 0.00 \\
\hline & & $6 y 7$ & 908.59 & 0.00 & 0.12 & 0.72 & 1123.42 & 0.00 & 214.95 & 0.00 \\
\hline & & 7 & 6.06 & 0.01 & 1.20 & 0.27 & 15.76 & 0.00 & 10.91 & 0.00 \\
\hline \multirow{9}{*}{$\begin{array}{c}\text { Dic } \\
03\end{array}$} & \multirow{4}{*}{ Cebada } & 3 & 569.11 & 0.00 & 9.82 & 0.00 & 563.38 & 0.00 & 4.09 & 0.04 \\
\hline & & $3 y 4$ & 725.09 & 0.00 & 46.43 & 0.00 & 725.26 & 0.00 & 46.60 & 0.00 \\
\hline & & 4 & 1260.29 & 0.00 & 54.69 & 0.00 & 1256.17 & 0.00 & 50.57 & 0.00 \\
\hline & & 5 & 176.49 & 0.00 & 0.90 & 0.34 & 175.65 & 0.00 & 0.06 & 0.80 \\
\hline & \multirow{5}{*}{ Trigo } & 0 & 310.55 & 0.00 & 20.86 & 0.00 & 322.05 & 0.00 & 32.36 & 0.00 \\
\hline & & 2 & 532.64 & 0.00 & 13.50 & 0.00 & 542.71 & 0.00 & 23.57 & 0.00 \\
\hline & & 6 & 852.42 & 0.00 & 0.03 & 0.87 & 1070.92 & 0.00 & 218.53 & 0.00 \\
\hline & & $6 y 7$ & 781.31 & 0.00 & 1.58 & 0.21 & 1037.00 & 0.00 & 257.27 & 0.00 \\
\hline & & 7 & 0.63 & 0.43 & 4.08 & 0.04 & 11.11 & 0.00 & 14.56 & 0.00 \\
\hline
\end{tabular}

Prob: Probabilidad o P-valor del test. 
Los valores arrojaron respecto al P-valor de todas las parcelas son cercanos a cero, según el criterio de decisión, ambos test LM-Lag y LM-Err son significativos a excepción del valor de la parcela 7 del 03 de diciembre en el cual el P-valor de LM-Lag supera el 0.05, siendo así no significativo. Por lo tanto se pudo definir directamente que para este set de datos el modelo más adecuado es el modelo Error. Debido a que para las otras parcelas no es posible decidir que modelos implementar, ya que sus P-valor indicaron que son significativos, se procedió a evaluar el mayor valor de las formas robustas LM.

Para la fecha del 17 de noviembre respecto al cultivo de cebada se encontró que para los 4 set de datos 2 tiene valores mayores en el valor robusto Lag (parcela 3 y 5 ) y las otras apuntan al modelo Error (parcela 4 y combinación de 3 y 4). Según los resultados de la Tabla 28 esta fecha es la más adecuada para el cultivo de cebada, sin embargo al encontrarse dividida la decisión del modelo óptimo para este cultivo se tuvieron en cuenta las construcciones de ambos modelos, los cuales se mencionaran posteriormente, para poder escoger el modelo conveniente. Por otro lado las parcelas del cultivo de trigo apuntaron, por la gran diferencia de los datos robustos, que el modelo Error es ideal.

La fecha intermedia 26 de noviembre sugirió que el mejor modelo para ambos cultivos es el modelo Error ya que los mayores valores robustos, en la comparación del test, apuntan dicho modelo, a excepción del set de datos de la parcela 4 de cebada cuyo valor es mayor en el robusto Lag, sin embargo hay que resaltar que la diferencia es mínima (0.57).

En la fecha 03 de diciembre se encontró que para el cultivo de cebada los valores robustos mayores apuntan al modelo Lag a diferencia de la combinación de las parcelas 3 y 4 , pero al igual que en la fecha anterior para la parcela 4 la diferencia entre valores robustos es mínima (0.17). Pudiendo decir que para este cultivo en la fecha mencionada es adecuado el modelo Lag, no obstante según los análisis previos esta fecha no es óptima para el estudio del tema en el cultivo de cebada. Con respecto al cultivo de trigo, cuya fecha es la ideal para su evaluación, se encontró que todos los set de datos apuntan ampliamente a el modelo Error con base en los valores robustos del test, aclarando que la parcela 7 no se analizó con los valores robustos ya que su prueba convencional dio significativa para el modelo Error directamente en los análisis del test LM. 


\subsubsection{Modelos de regresión espacial (nivel pixel).}

Teniendo claro cuál modelo encaja adecuadamente en cada set de datos, según el criterio LM, se procedió a ejecutar los modelos Error y Lag para las parcelas consideradas en la anterior metodología a nivel pixel. Los resultados presentados a continuación ayudaron a identificar cual set de datos genera el mejor modelo para inferir el rendimiento de los cultivos en cuestión.

\section{Modelo error.}

Inicialmente en la Tabla 29 se muestran los resultados iniciales pertenecientes los modelos espaciales Error.

Tabla 29. Resultados de los estadísticos y test generales de los modelos espaciales Error por parcela para la metodología a nivel pixel.

\begin{tabular}{|c|c|c|c|c|c|c|}
\hline Fecha & Cultivo & Parcela & $\mathbf{R}^{2}$ & $\begin{array}{c}\text { Máxima } \\
\text { Verosimilitud }\end{array}$ & Akaike & Schwarz \\
\hline \multirow{6}{*}{$\begin{array}{c}\text { Nov } \\
17\end{array}$} & \multirow{4}{*}{ Cebada } & 3 & 0.52 & -321.05 & 646.09 & 654.91 \\
\hline & & $3 y 4$ & 0.44 & -1321.95 & 2647.91 & 2659.01 \\
\hline & & 4 & 0.41 & -968.34 & 1940.67 & 1951.00 \\
\hline & & 5 & 0.34 & -305.62 & 615.24 & 623.38 \\
\hline & \multirow{2}{*}{ Trigo } & 0 & 0.61 & -730.05 & 1464.10 & 1473.54 \\
\hline & & 2 & 0.51 & -361.52 & 727.04 & 735.86 \\
\hline \multirow{9}{*}{$\begin{array}{c}\text { Nov } \\
26\end{array}$} & \multirow{4}{*}{ Cebada } & 3 & 0.51 & -338.41 & 680.82 & 689.65 \\
\hline & & $3 \mathrm{y} 4$ & 0.42 & -1376.83 & 2757.65 & 2768.76 \\
\hline & & 4 & 0.39 & -1006.27 & 2016.55 & 2026.88 \\
\hline & & 5 & 0.32 & -313.32 & 630.64 & 638.78 \\
\hline & \multirow{5}{*}{ Trigo } & 0 & 0.60 & -728.18 & 1460.36 & 1469.81 \\
\hline & & 2 & 0.51 & -361.64 & 727.28 & 736.11 \\
\hline & & 6 & 0.63 & -1218.63 & 2441.27 & 2451.96 \\
\hline & & $6 y 7$ & 0.65 & -1307.25 & 2618.50 & 2629.33 \\
\hline & & 7 & 0.61 & -83.29 & 170.57 & 176.01 \\
\hline \multirow{9}{*}{$\begin{array}{c}\text { Dic } \\
03\end{array}$} & \multirow{4}{*}{ Cebada } & 3 & 0.48 & -360.62 & 725.23 & 734.05 \\
\hline & & $3 y 4$ & 0.42 & -1369.28 & 2742.56 & 2753.66 \\
\hline & & 4 & 0.39 & -995.51 & 1995.02 & 2005.35 \\
\hline & & 5 & 0.31 & -321.00 & 646.00 & 654.14 \\
\hline & \multirow{5}{*}{ Trigo } & 0 & 0.60 & -751.53 & 1507.06 & 1516.51 \\
\hline & & 2 & 0.52 & -356.66 & 717.31 & 726.14 \\
\hline & & 6 & 0.64 & -1286.22 & 2576.45 & 2587.15 \\
\hline & & $6 y 7$ & 0.65 & -1360.93 & 2725.86 & 2736.70 \\
\hline & & 7 & 0.72 & -64.03 & 132.05 & 137.49 \\
\hline
\end{tabular}

Observando los valores de $\mathrm{R}^{2}$ se encontró que para el cultivo de cebada, para cada fecha, el mayor valor corresponde a la parcela 3, encontrándose una bondad de ajuste del 51.6\%, el cual aunque parece bajo, teniendo en cuenta las propiedades del fenómeno estudiado, se podría considerar relativamente alto, sin perder de vista las proporciones de un ajuste de características 
geográficas. Para el cultivo de trigo los $\mathrm{R}^{2}$ de los modelos son mayores; en el 17 de noviembre el valor más alto pertenece a la parcela 0 , sin embargo en esta fecha no se consideraron las parcelas por falta de información, al igual que es considerada como no adecuada evaluar trigo; para las otras 2 fechas se encontró similaridad en las proporciones de los $\mathrm{R}^{2}$ para cada parcela, siendo la parcela 7 con mayor $\mathrm{R}^{2}$ seguida de la combinación entre parcelas 6 y 7 , sin embargo el mayor valor de ajuste le pertenece a la parcela 7 para el 03 de diciembre, cuya fecha es óptima para dicho cultivo.

$\mathrm{Al}$ analizar los criterios de máxima verosimilitud, Akaike y Schwarz (Tabla 29) para escoger el modelo más adecuado, se encontró que no coinciden necesariamente con el criterio de mayor $\mathrm{R}^{2}$. Para Cebada en el 17 de noviembre el mayor valor de máxima verosimilitud y el menor Akaike y Schwarz correspondió a la parcela 5 la cual posee el $\mathrm{R}^{2}$ más bajo entre los 4 set de datos, sin embargo los mejores valores siguientes correspondieron a la parcela 3. Lo anterior se evidencio en las 3 fechas de estudio para cebada. Respecto al cultivo de trigo los mejores valores para estos criterios le pertenecieron a la parcela 7 en ambas fechas, coincidiendo con los valores más altos de $\mathrm{R}^{2}$ en los set de datos de estudio, el cual se observó claramente para la fecha 03 de diciembre.

Lo siguiente fue evaluar la estructura o especificación del modelo, identificando si las variables son estadísticamente significativas, en la Tabla 30 se presenta los resultados de los coeficientes de las variables en estudio más el coeficiente autorregresivo para el modelo Error. 
Tabla 30. Resultados de los coeficientes y estadísticos para las variables de los modelos espaciales Error por parcela para la metodología a nivel pixel.

\begin{tabular}{|c|c|c|c|c|c|c|c|}
\hline Fecha & Cultivo & Parcela & Variable & Coeficiente & Error Estándar & Estadístico T & Probabilidad \\
\hline \multirow{18}{*}{$\begin{array}{c}\text { Nov } \\
17\end{array}$} & \multirow{12}{*}{ Cebada } & \multirow{3}{*}{3} & Constante & $\begin{array}{l}-4.29 \\
\end{array}$ & 0.72 & -5.94 & 0.00 \\
\hline & & & NDVI & 12.56 & 0.92 & 13.66 & 0.00 \\
\hline & & & Lambda & 0.48 & 0.06 & 8.71 & 0.00 \\
\hline & & \multirow{3}{*}{$3 \mathrm{y} 4$} & Constante* & 0.32 & 0.39 & 0.82 & 0.41 \\
\hline & & & NDVI & 6.76 & 0.51 & 13.34 & 0.00 \\
\hline & & & Lambda & 0.66 & 0.03 & 26.68 & 0.00 \\
\hline & & \multirow{3}{*}{4} & Constante* & 0.91 & 0.46 & 1.99 & 0.05 \\
\hline & & & NDVI & 6.03 & 0.60 & 10.07 & 0.00 \\
\hline & & & Lambda & 0.67 & 0.03 & 22.96 & 0.00 \\
\hline & & \multirow{3}{*}{5} & Constante* & 1.44 & 0.72 & 2.01 & 0.05 \\
\hline & & & NDVI & 5.50 & 0.93 & 5.93 & 0.00 \\
\hline & & & Lambda & 0.59 & 0.06 & 10.31 & 0.00 \\
\hline & \multirow{6}{*}{ Trigo } & \multirow{3}{*}{0} & Constante & -1.79 & 0.58 & -3.11 & 0.00 \\
\hline & & & NDVI & 9.42 & 0.77 & 12.17 & 0.00 \\
\hline & & & Lambda & 0.78 & 0.03 & 27.17 & 0.00 \\
\hline & & \multirow{3}{*}{2} & Constante* & 1.00 & 0.69 & 1.45 & 0.15 \\
\hline & & & NDVI & 5.05 & 0.83 & 6.11 & 0.00 \\
\hline & & & Lambda & 0.77 & 0.03 & 23.31 & 0.00 \\
\hline & & & Constante* & 0.15 & 0.60 & 0.24 & 0.81 \\
\hline & & 3 & NDVI & 8.30 & 0.91 & 9.13 & 0.00 \\
\hline & & & Lambda & 0.66 & 0.04 & 15.15 & 0.00 \\
\hline & & & Constante & 3.58 & 0.29 & 12.28 & 0.00 \\
\hline & & $3 y^{4}$ & NDVI & 3.08 & 0.46 & 6.75 & 0.00 \\
\hline & & & Lambda & 0.72 & 0.02 & 32.96 & 0.00 \\
\hline & Cebada & & Constante & 4.19 & 0.34 & 12.40 & 0.00 \\
\hline & & 4 & NDVI & 2.11 & 0.54 & 3.93 & 0.00 \\
\hline & & & Lambda & 0.72 & 0.03 & 27.47 & $\begin{array}{l}0.00 \\
0.00\end{array}$ \\
\hline & & & Constante & 2.61 & 0.75 & 3.51 & 0.00 \\
\hline & & 5 & NDVI & 4.47 & 1.08 & 4.13 & 0.00 \\
\hline & & & Lambda & 0.62 & $\begin{array}{l}1.00 \\
0.05\end{array}$ & 11.62 & 0.00 \\
\hline & & & Constante & -1.32 & 0.50 & -2.66 & 0.01 \\
\hline NOV & & 0 & NDVI & 8.38 & 0.64 & 13.17 & 0.00 \\
\hline & & & Lambda & $\begin{array}{l}0.00 \\
0.72 \\
\end{array}$ & 0.03 & 21.51 & 0.00 \\
\hline & & & Constante & 1.72 & 0.58 & 2.98 & 0.00 \\
\hline & & 2 & NDVI & 4.31 & 0.71 & 6.06 & 0.00 \\
\hline & & & Lambda & 0.78 & 0.03 & 24.28 & 0.00 \\
\hline & & & Constante* & -0.18 & 0.39 & -0.46 & 0.65 \\
\hline & Trigo & 6 & NDVI & 7.39 & 0.52 & 14.27 & 0.00 \\
\hline & & & Lambda & 0.78 & 0.02 & 37.75 & 0.00 \\
\hline & & & Constante & -0.86 & 0.35 & -2.45 & 0.01 \\
\hline & & $6 y 7$ & NDVI & 8.28 & 0.46 & 17.88 & 0.00 \\
\hline & & & Lambda & 0.78 & 0.02 & 37.86 & 0.00 \\
\hline & & & Constante & -2.10 & 0.72 & -2.93 & 0.00 \\
\hline & & 7 & NDVI & 10.04 & 1.05 & 9.59 & 0.00 \\
\hline & & & Lambda & 0.54 & 0.10 & 5.49 & 0.00 \\
\hline & & & Constante & 5.80 & 0.40 & 14.42 & 0.00 \\
\hline & & 3 & NDVI* & -0.48 & 0.79 & -0.61 & 0.54 \\
\hline & & & Lambda & 0.77 & 0.03 & 22.49 & 0.00 \\
\hline & & & Constante & 6.32 & 0.20 & 32.43 & 0.00 \\
\hline & & $3 y^{4}$ & NDVI & -1.59 & 0.38 & -4.18 & 0.00 \\
\hline & Cebada & & Lambda & 0.75 & 0.02 & 37.54 & 0.00 \\
\hline & & & Constante & 6.38 & 0.22 & 28.52 & 0.00 \\
\hline & & 4 & NDVI & -1.77 & 0.44 & -4.02 & 0.00 \\
\hline & & & Lambda & 0.75 & 0.03 & 30.30 & 0.00 \\
\hline & & & Constante & 6.11 & 0.50 & 12.33 & 0.00 \\
\hline & & 5 & NDVI* & -0.80 & 0.90 & -0.89 & 0.38 \\
\hline & & & Lambda & $\begin{array}{c}-0.00 \\
0.66\end{array}$ & 0.05 & $\begin{array}{l}-0.07 \\
12.92\end{array}$ & 0.00 \\
\hline Dic & & & Constante* & -0.88 & 0.46 & -1.90 & 0.06 \\
\hline 03 & & 0 & NDVI & $\begin{array}{c}-0.00 \\
7.89\end{array}$ & 0.60 & 13.13 & 0.00 \\
\hline & & & Lambda & 0.73 & 0.03 & 22.16 & 0.00 \\
\hline & & & Constante & 2.98 & 0.44 & 6.80 & 0.00 \\
\hline & & 2 & NDVI & 2.76 & 0.54 & 5.08 & 0.00 \\
\hline & & & Lambda & 0.82 & 0.03 & 28.00 & 0.00 \\
\hline & & & Constante & -0.94 & 0.37 & -2.51 & 0.01 \\
\hline & Trigo & 6 & NDVI & 8.03 & 0.47 & 17.01 & $\begin{array}{l}0.01 \\
0.00\end{array}$ \\
\hline & & & Lambda & $\begin{array}{l}0.05 \\
0.78\end{array}$ & $\begin{array}{l}0.41 \\
0.02\end{array}$ & 38.26 & $\begin{array}{l}0.00 \\
0.00\end{array}$ \\
\hline & & & Constante & -1.52 & 0.33 & -4.55 & 0.00 \\
\hline & & $6 y 7$ & NDVI & 8.75 & 0.42 & 20.73 & 0.00 \\
\hline & & & Lambda & 0.78 & 0.02 & 38.89 & 0.00 \\
\hline & & & Constante & -2.75 & 0.56 & -4.92 & 0.00 \\
\hline & & 7 & NDVI & 10.47 & 0.78 & 13.44 & 0.00 \\
\hline & & & Lambda & 0.48 & 0.11 & 4.43 & 0.00 \\
\hline
\end{tabular}

*Variable no significativa en la estructura del modelo ya que su nivel de significancia superael 5\% ffP-valor $>0.05)$. 
Se encontró que las variables respectivas al NDVI y el coeficiente autorregresivo lambda son significativas para todos los modelos considerados, a excepción de la variable NDVI para las parcelas 3 y 5 de cebada del 03 de diciembre, al igual que el coeficiente constante para los modelos del cultivo de cebada para la fecha de 17 de noviembre junto con el set de datos de la parcela 3 del 26 de noviembre, siendo estos no significativos estadísticamente al superar su valor de probabilidad del 0.05 , por lo tanto los modelos generados con dichos componentes para cebada no resultaría confiables. Al tratarse de los modelos de cebada del 03 de diciembre no se generó inconvenientes ya que esta fecha no es adecuada para este cultivo, sin embargo fue un problema para los modelos de la fecha del 17 de noviembre ya que esta es la adecuada para el estudio de la cebada en el presente trabajo.

Para finalizar el análisis de los modelos espaciales Error se realizó un diagnóstico de la dependencia espacial que puedan poseer los modelos, realizando 2 test, el primero es nuevamente el Breusch-Pagan el cual identifica la heterocedasticidad y el test de razón de verosimilitud (Likelihood Ratio) que ratifica la importancia del coeficiente autorregresivo agregado al modelo clásico para considerar las componente espacial propia del modelo Error y Lag. En la Tabla 31 se encuentra los resultados para dichos test en las parcelas de estudio. 
Tabla 31. Resultados de los estadísticos para evaluar la heterocedasticidad de los modelos espaciales Error por parcela para la metodología a nivel pixel.

\begin{tabular}{|c|c|c|c|c|c|c|}
\hline \multirow[t]{2}{*}{ Fecha } & \multirow[t]{2}{*}{ Cultivo } & \multirow[t]{2}{*}{ Parcela } & \multicolumn{2}{|c|}{ Breusch-Pagan } & \multicolumn{2}{|c|}{$\begin{array}{c}\text { Razón de } \\
\text { Verosimilitud }\end{array}$} \\
\hline & & & Valor & Prob & Valor & Prob \\
\hline \multirow{6}{*}{$\begin{array}{l}\text { Nov } \\
17\end{array}$} & \multirow{4}{*}{ Cebada } & 3 & 45.43 & 0.00 & 58.39 & 0.00 \\
\hline & & $3 y 4$ & 184.15 & 0.00 & 488.10 & 0.00 \\
\hline & & 4 & 100.79 & 0.00 & 336.28 & 0.00 \\
\hline & & 5 & 28.03 & 0.00 & 81.85 & 0.00 \\
\hline & \multirow{2}{*}{ Trigo } & 0 & 9.55 & 0.00 & 415.35 & 0.00 \\
\hline & & 2 & 73.62 & 0.00 & 299.54 & 0.00 \\
\hline \multirow{9}{*}{$\begin{array}{l}\text { Nov } \\
26\end{array}$} & \multirow{4}{*}{ Cebada } & 3 & 8.44 & 0.00 & 164.39 & 0.00 \\
\hline & & $3 y 4$ & 0.02 & 0.90 & 668.63 & 0.00 \\
\hline & & 4 & 4.26 & 0.04 & 433.27 & 0.00 \\
\hline & & 5 & 0.06 & 0.81 & 101.09 & 0.00 \\
\hline & \multirow{5}{*}{ Trigo } & 0 & 11.67 & 0.00 & 253.22 & 0.00 \\
\hline & & 2 & 54.26 & 0.00 & 314.48 & 0.00 \\
\hline & & 6 & 0.92 & 0.34 & 719.95 & 0.00 \\
\hline & & $6 y 7$ & 1.00 & 0.32 & 733.89 & 0.00 \\
\hline & & 7 & 1.39 & 0.24 & 16.08 & 0.00 \\
\hline \multirow{9}{*}{$\begin{array}{c}\text { Dic } \\
03\end{array}$} & \multirow{4}{*}{ Cebada } & 3 & 9.72 & 0.00 & 326.08 & 0.00 \\
\hline & & $3 y^{4}$ & 94.53 & 0.00 & 807.08 & 0.00 \\
\hline & & 4 & 70.40 & 0.00 & 495.61 & 0.00 \\
\hline & & 5 & 30.93 & 0.00 & 116.15 & 0.00 \\
\hline & \multirow{5}{*}{ Trigo } & 0 & 15.91 & 0.00 & 243.69 & 0.00 \\
\hline & & 2 & 30.87 & 0.00 & 353.01 & 0.00 \\
\hline & & 6 & 0.01 & 0.93 & 691.34 & 0.00 \\
\hline & & $6 y 7$ & 0.65 & 0.42 & 712.80 & 0.00 \\
\hline & & 7 & 0.68 & 0.41 & 11.64 & 0.00 \\
\hline
\end{tabular}

Prob: Probabilidad o P-valor del test.

Respecto al test que evaluó la heterocedasticidad se encontró que para el cultivo de cebada persiste aun este problema, a excepción del set de datos de las parcelas 5 y combinación 3 y 4 de la fecha 26 de noviembre, este resultado para las parcelas anteriormente mencionadas se halló igualmente en los MCO indicando homocedasticidad en los mismo, por lo cual se puede indicar que el factor espacial considerado en el modelo Error no modifica en gran medida las perturbaciones de las varianzas al interior de los set de datos de este cultivo, en especial para las parcelas de la fecha 17 de noviembre en donde se plantea el mejor estadio. Por el contrario, para el cultivo de trigo se encontró que la heterocedasticidad se suprimió con el modelo Error, encontrándose el test no significativo para las parcelas 6,7 y sus combinaciones para las fechas de 26 de noviembre y 03 de diciembre, donde en la última fecha se esperaba que se encontraran los mejores resultados para este cultivo. 
El test de razón de verosimilitud tuvo una alta significancia para todos los set de datos considerados, por lo cual significo que los coeficientes autorregresivos dados por el modelo Error no eliminan totalmente los efectos espaciales. Esto es debido a la variabilidad de los datos y la naturaleza de la información analizada, ya que se busca predecir una variable compleja con una simple.

Con lo anterior se concluyó el análisis de los modelos Error para ambos cultivos estudiados. Gracias a la evaluación del test de multiplicadores de Lagrange se llegó a la conclusión que para el cultivo de trigo definitivamente el modelo Error ajustaba apropiadamente a los datos, no obstante en el cultivo de cebada este test apuntaba a la mitad de las parcelas al modelo de retraso espacial (modelos Lag), por esta razón a continuación se procedió a analizar los resultados del modelo Lag únicamente para el cultivo de cebada en las fechas acordadas.

\section{Modelo Lag.}

Los resultados principales provenientes de la ejecución del modelo Lag para los set de datos del cultivo de cebada se presentan en la Tabla 32.

Tabla 32. Resultados de los estadísticos y test generales de los modelos espaciales Lag para las parcelas de cebada según la metodología a nivel pixel.

\begin{tabular}{ccccccc} 
Fecha & Cultivo & Parcela & $\mathbf{R}^{2}$ & $\begin{array}{c}\text { Máxima } \\
\text { Verosimilitud }\end{array}$ & Akaike & Schwarz \\
\hline \hline \multirow{2}{*}{ Nov } & \multirow{2}{*}{ Cebada } & $3 y 4$ & 0.43 & -1321.26 & 2648.53 & 2665.18 \\
17 & 4 & 0.41 & -968.61 & 1943.22 & 1958.72 \\
& & 5 & 0.35 & -303.36 & 612.71 & 624.92 \\
\hline \multirow{2}{*}{ Nov } & \multirow{2}{*}{ Cebada } & $3 \mathrm{y} 4$ & 0.41 & -1378.68 & 2763.36 & 2780.01 \\
& & 4 & 0.39 & -1005.86 & 2017.73 & 2033.23 \\
& & 5 & 0.32 & -312.70 & 631.40 & 643.60 \\
\hline \multirow{2}{*}{ Dic } & & 3 & 0.48 & -360.80 & 727.59 & 740.83 \\
03 & Cebada & $3 y 4$ & 0.41 & -1376.40 & 2758.80 & 2775.46 \\
& & 4 & 0.38 & -1001.98 & 2009.95 & 2025.45 \\
& & 5 & 0.31 & -320.64 & 647.28 & 659.49 \\
\hline
\end{tabular}

Los valores, en proporción, son similares a los modelos de MCO (Tabla 24) y Error (Tabla 29), ya que la parcela con el mayor $\mathrm{R}^{2}$ en todas las fechas es la 3 y el valor menor corresponde a la parcela 5. Respecto a los otros estadísticos concernientes a el ajuste del diseño de los modelos sucedió lo mismo, apuntando a que el mejor ajuste corresponde a la parcela 5 en todas las fechas, sin embargo esto puede ser contradictorio con el valor de $\mathrm{R}^{2}$. No obstante, evaluando los valores de estos test, el siguiente mejor valor corresponde a la parcela 3, mencionando que 
las diferencias en valor encontradas no son considerables amplias, comparándolas con los resultados de todas las parcelas analizadas.

Los siguientes valores analizados son los coeficientes de las variables de los modelos Lag generados y su respectiva significancia en la construcción de los mismos. Los resultados se observan en la Tabla 33.

Tabla 33. Resultados de los coeficientes y estadísticos para las variables de los modelos espaciales Lag para las parcelas de cebada según para la metodología a nivel pixel.

\begin{tabular}{|c|c|c|c|c|c|c|c|}
\hline Fecha & Cultivo & Parcela & Variable & Coeficiente & $\begin{array}{c}\text { Error } \\
\text { Estándar } \\
\end{array}$ & $\begin{array}{c}\text { Estadístico } \\
\mathbf{T} \\
\end{array}$ & Probabilidad \\
\hline \multirow{12}{*}{$\begin{array}{c}\text { Nov } \\
17\end{array}$} & \multirow{12}{*}{ Cebada } & \multirow{3}{*}{3} & Ro & 0.451 & 0.050 & 8.941 & 0.000 \\
\hline & & & Constante & -4.074 & 0.511 & -7.976 & 0.000 \\
\hline & & & NDVI & 9.079 & 0.843 & 10.772 & 0.000 \\
\hline & & \multirow{3}{*}{$3 y^{4}$} & Ro & 0.635 & 0.024 & 26.354 & 0.000 \\
\hline & & & Constante & -1.160 & 0.231 & -5.021 & 0.000 \\
\hline & & & NDVI & 4.119 & 0.346 & 11.913 & 0.000 \\
\hline & & \multirow{3}{*}{4} & Ro & 0.649 & 0.029 & 22.721 & 0.000 \\
\hline & & & Constante & -0.920 & 0.280 & -3.291 & 0.001 \\
\hline & & & NDVI & 3.733 & 0.407 & 9.180 & 0.000 \\
\hline & & \multirow{3}{*}{5} & Ro & 0.577 & 0.055 & 10.473 & 0.000 \\
\hline & & & Constante* & -1.014 & 0.552 & -1.838 & 0.066 \\
\hline & & & NDVI & 4.422 & 0.733 & 6.033 & 0.000 \\
\hline \multirow{12}{*}{$\begin{array}{l}\text { Nov } \\
26\end{array}$} & \multirow{12}{*}{ Cebada } & \multirow{3}{*}{3} & Ro & 0.606 & 0.043 & 13.942 & 0.000 \\
\hline & & & Constante & -1.052 & 0.339 & -3.103 & 0.002 \\
\hline & & & NDVI & 4.966 & 0.642 & 7.732 & 0.000 \\
\hline & & \multirow{3}{*}{$3 y^{4}$} & Ro & 0.710 & 0.022 & 32.416 & 0.000 \\
\hline & & & Constante & 0.689 & 0.157 & 4.401 & 0.000 \\
\hline & & & NDVI & 1.447 & 0.234 & 6.174 & 0.000 \\
\hline & & \multirow{3}{*}{4} & Ro & 0.714 & 0.026 & 27.197 & 0.000 \\
\hline & & & Constante & 0.908 & 0.193 & 4.709 & 0.000 \\
\hline & & & NDVI & 1.072 & 0.272 & 3.940 & 0.000 \\
\hline & & \multirow{3}{*}{5} & Ro & 0.619 & 0.053 & 11.728 & 0.000 \\
\hline & & & Constante* & -0.049 & 0.537 & -0.091 & 0.928 \\
\hline & & & NDVI & 3.218 & 0.778 & 4.135 & 0.000 \\
\hline \multirow{12}{*}{$\begin{array}{c}\text { Dic } \\
03\end{array}$} & \multirow{12}{*}{ Cebada } & \multirow{3}{*}{3} & Ro & 0.767 & 0.034 & 22.463 & 0.000 \\
\hline & & & Constante & 1.324 & 0.313 & 4.231 & 0.000 \\
\hline & & & NDVI* & -0.057 & 0.492 & -0.116 & 0.908 \\
\hline & & \multirow{3}{*}{$3 y^{4}$} & Ro & 0.747 & 0.020 & 36.662 & 0.000 \\
\hline & & & Constante & 1.555 & 0.153 & 10.178 & 0.000 \\
\hline & & & NDVI* & -0.320 & 0.188 & -1.705 & 0.088 \\
\hline & & \multirow{3}{*}{4} & Ro & 0.735 & 0.025 & 29.203 & 0.000 \\
\hline & & & Constante & 1.633 & 0.183 & 8.943 & 0.000 \\
\hline & & & NDVI* & -0.356 & 0.211 & -1.690 & 0.091 \\
\hline & & \multirow{3}{*}{5} & Ro & 0.655 & 0.051 & 12.901 & 0.000 \\
\hline & & & Constante & 2.355 & 0.454 & 5.191 & 0.000 \\
\hline & & & NDVI* & -0.733 & 0.599 & -1.224 & 0.221 \\
\hline
\end{tabular}

* Variable no significativa en la estructura del modelo ya que su nivel de significancia supera el 5\% (P-valor $>0.05)$.

En este tipo de modelos la variable autorregresiva se denomina comúnmente como Ro, la cual en todos los modelos considerados fue altamente significativa. La constante lo es de modo 
similar, a excepción de la parcela 5 en las fechas correspondientes a noviembre. En la fecha 03 de diciembre todas las parcelas en sus modelos la variable NDVI no fue significativa, los cual es congruente debido a que para esta fecha el verdor o valor de NDVI ha disminuido respecto al estadio de la cebada en este periodo.

Para finalizar los resultados del modelo Lag para cebada se evaluó la existencia de heterocedasticidad y ajuste de la variable autorregresiva, cuyos valores se presentan en la Tabla 34.

Tabla 34. Resultados de los estadísticos para evaluar la heterocedasticidad de los modelos espaciales Lag para las parcelas de cebada según la metodología a nivel pixel.

\begin{tabular}{|c|c|c|c|c|c|c|}
\hline \multirow{2}{*}{ Fecha } & \multirow{2}{*}{ Cultivo } & \multirow{2}{*}{ Parcela } & \multicolumn{2}{|c|}{ Breusch-Pagan } & \multicolumn{2}{|c|}{$\begin{array}{c}\text { Razón de } \\
\text { Verosimilitud }\end{array}$} \\
\hline & & & Valor & Prob & Valor & Prob \\
\hline \multirow{4}{*}{$\begin{array}{c}\text { Nov } \\
17\end{array}$} & \multirow{4}{*}{ Cebada } & 3 & 36.617 & 0.000 & 72.575 & 0.000 \\
\hline & & $3 y 4$ & 171.778 & 0.000 & 489.476 & 0.000 \\
\hline & & 4 & 96.955 & 0.000 & 335.731 & 0.000 \\
\hline & & 5 & 26.676 & 0.000 & 86.381 & 0.000 \\
\hline \multirow{4}{*}{$\begin{array}{l}\text { Nov } \\
26\end{array}$} & \multirow{4}{*}{ Cebada } & 3 & 6.941 & 0.008 & 161.382 & 0.000 \\
\hline & & $3 y 4$ & 0.345 & 0.557 & 664.923 & 0.000 \\
\hline & & 4 & 2.519 & 0.113 & 434.096 & 0.000 \\
\hline & & 5 & 0.157 & 0.692 & 102.331 & 0.000 \\
\hline \multirow{4}{*}{$\begin{array}{c}\text { Dic } \\
03\end{array}$} & \multirow{4}{*}{ Cebada } & 3 & 8.914 & 0.003 & 325.715 & 0.000 \\
\hline & & $3 y 4$ & 103.484 & 0.000 & 792.832 & 0.000 \\
\hline & & 4 & 80.370 & 0.000 & 482.673 & 0.000 \\
\hline & & 5 & 31.202 & 0.000 & 116.862 & 0.000 \\
\hline
\end{tabular}

El test de Breusch-Pagan resalto que las parcelas correspondientes al 26 de noviembre no poseen problemas con heterocedasticidad a excepción de la parcela 3. Para las fechas de 17 de noviembre y 03 de diciembre las parcelas rechazaron la hipótesis nula de homocedasticidad, encontrándose problemas de no uniformidad en las varianzas de los set de datos. Este resultado también se vio reflejado en el test hecho en el modelo MCO y Error, en especial para la fecha 26 de noviembre del cultivo de cebada, lo cual evidencio que los datos en esta fecha presentan homocedasticidad incluso sin la incorporación de la variable autorregresiva de los modelos espaciales, no obstante estos modelos mejoraron considerable la especificación de la estructura.

Con base en el test de razón de verosimilitud (Tabla 34) se encontró que todos los set de datos continúan con problemas de especificación ya que la variable autorregresiva no elimina 
completamente los efectos espaciales, gracias a que dicho test es altamente significativo en todas las fechas, al igual que lo sucedido con los modelos Error.

Hasta este punto se ha analizado los datos y procedimiento correspondiente a la metodología de evaluación por pixel, realizando modelos de MCO y espaciales Lag y Error, con el fin de encontrar el modelo que se ajuste adecuadamente a los datos y describa mejor el fenómeno estudiado. Con respecto a los resultados obtenidos y los test de decisión contemplados se definió el modelo óptimo para cada tipo de cultivo concerniente a la metodología mencionada. A continuación se presentaran los modelos resultantes justo con la justificación pertinente de su selección.

Recapitulando la sección de los modelos para la metodología a nivel pixel, con la definición de modelos de MCO provenientes de los set de datos depurados por parcela fue posible evaluar cuál de estos brindaba un mejor ajuste $\mathrm{R}^{2} \mathrm{y}$ junto con la ayuda de los test estadísticos fue posible seleccionar un modelo adecuado para cada parcela y definir la significancia de las variables. Sin embargo al ejecutar el test de I de Moran se encontró autocorrelación en los errores para todos los set de datos contemplados, por tal razón se remitió al método de decisión de modelos espaciales con base en multiplicadores de Lagrange, apuntando que el mejor tipo de modelo para trigo es el modelo Error, no obstante para cebada no fue concluyente los resultados, por tal motivo se ejecutaron ambos modelos Lag y Error para plantear las dos opciones de ser necesario.

En primera medida, describiendo la selección del modelo para el cultivo de trigo, se seleccionó el modelo originado por la parcela 7 para la fecha 03 de diciembre. Es de aclarar que el análisis exploratorio previo apuntaba que dicha fecha era la mejor para analizar el cultivo de trigo, cuyo resultado se corroboró con los datos encontrados en la generación de los modelos. Los porcentajes de ajuste $\mathrm{R}^{2}$ superaron el $60 \%$ en las parcelas respectivas de las fechas 26 de noviembre y 03 de diciembre a excepción de la parcela 2 con un $51 \%$ la cual presentó un comportamiento atípico a las parcelas de su tipo a lo largo del estudio. El mejor valor de este indicativo fue la parcela 7 del 03 de diciembre con un $72 \%$ de ajuste, el cual es considerablemente alto para el estudio, seguido de su parcela contigua, la numero 6 , y de la combinación de ambas, 6 y 7, sin embargo los criterios de máxima verosimilitud, Akaike y Schwarz apuntaron en gran medida al modelo correspondiente a la parcela 7 . Respecto al test de heterocedasticidad Breusch-Pagan en las fecha mencionadas las parcelas 6, 7 y su combinación 
rechazan la hipótesis nula encontrándose así homocedasticidad en los set de datos, descartando el problema de perturbación de las varianzas en estos set de datos. Respecto a la construcción del modelo en sí, las variables encontradas presentan alta significancia, por lo cual incorporando las variables a la estructura, el modelo espacial Error para el cultivo de trigo, quedo diseñado como se presenta en la Ecuación 8.

$$
\begin{aligned}
& Y=-2.75+10,47 * X+u \\
& u=0.48 * W u+\varepsilon
\end{aligned}
$$

Ecuación 8. Modelo espacial Error escogido para el cultivo de trigo.

Donde Y es la variable dependiente de rendimiento de producción; X la variable independiente NDVI; $W u$ es la variable con el termino de error modificado espacialmente; $\varepsilon$ son los residuales o error que es la porción que no puede explicar la variable independiente a la dependiente. Los coeficientes muestran un punto de corte en negativo pero con fuerte relación positiva de la variable dependiente con las independientes.

Consecuentemente se evaluaron los test y criterios para escoger el modelo adecuado para el cultivo de cebada. Debido a que los resultados encontrados en los multiplicadores de Lagrange en los modelos MCO no señalaron de forma concreta el tipo de modelo a seguir para este cultivo, se inició con el análisis y definición de los modelos Error para posteriormente describir los modelos Lag.

Las fechas en que los ajustes $\mathrm{R}^{2}$ son más altos coincidieron con el análisis exploratorio realizado inicialmente, siendo la fecha 17 de noviembre los valores ligeramente altos, encontrando a la parcela 3 con un valor de $51 \%$ y el resto con un valor inferior a $43 \%$ de ajuste. Respecto a los criterios de máxima verosimilitud, Akaike y Schwarz el modelo de la parcela 3 fue el segundo mejor, siendo el primero la parcela 5 por una mínima diferencia, sin embargo la parcela 5 tiene el $\mathrm{R}^{2}$ más bajo de todas las parcelas en ambas fechas. Analizando los test para la heterocedasticidad se encontró que los set de datos para la fecha 17 de noviembre aún posee este inconveniente, por el contrario las parcelas del 26 de noviembre, a excepción de la parcela 3, rechazan la hipótesis nula aceptando la homocedasticidad en los datos. Lo anterior presenta el inconveniente que en las parcelas de fecha optima, 17 de noviembre, poseen heterocedasticidad, junto con la parcela 3 con mejor $\mathrm{R}^{2}$ del 26 de noviembre. Observando los coeficientes para la especificación de los modelos se encontró que para el 17 de noviembre todas las parcelas a excepción de la 3 tienen el coeficiente de corte de la ecuación como no 
significativo, sin embargo en la fecha 26 de noviembre resulta todo lo contrario, siendo la parcela 3 la única con este coeficiente no significativo.

Los resultados anteriores para el cultivo de cebada no son concluyentes ya que los test y criterios se contradicen unos con otros para las parcelas en las diferentes fechas. Al revaluar los valores contradictorios se decidió que el mejor modelo correspondería a la combinación de parcelas 3 y 4 del 26 de noviembre, ya que para la fecha mencionada es el segundo mejor valor de $\mathrm{R}^{2}$, esta no posee problemas de heterocedasticidad y sus coeficientes son significativos para la construcción del modelo, no obstante valores los criterios de máxima verosimilitud, Akaike y Schwarz señalan que este modelo es el menos adecuado entre todas las parcelas. La construcción de dicho modelo Error quedó planteada en la Ecuación 9, cuyos coeficientes indican una relación positiva de las variables independientes con la dependiente.

$$
\begin{aligned}
& Y=3.58+3.08 * X+u \\
& u=0.72 * W u+\varepsilon
\end{aligned}
$$

Ecuación 9. Modelo espacial Error escogido para el cultivo de cebada.

Analizando la segunda opción para el cultivo de cebada, el modelo Lag, esta presentó características similares al modelo Error en los resultados de los criterios de decisión definidos anteriormente. Analizando las fechas del mes de noviembre, los valores en proporción fueron comparables tanto en los resultados de ajuste del modelo, como en la evaluación de heterocedasticidad; la única diferencia radico en que las variables de especificación del modelo son significativas para las parcelas de ambas fechas a excepción de la parcela 5, la cual poseen el $\mathrm{R}^{2}$ más bajo del conjunto en análisis. En este caso debido a que los coeficientes de la parcela 3 del 26 de noviembre son significativos para este modelo, pero presenta heterocedasticidad, se escogió nuevamente el set de datos compuesto por las parcelas 3 y 4 . La construcción de dicho modelo se expone en la Ecuación 10.

$$
Y=0.69+0.71 * W y+1.45 * X+\varepsilon
$$

Ecuación 10. Modelo espacial Lag escogido para el cultivo de cebada. 
Donde $\mathrm{Y}$ es la variable dependiente de rendimiento de producción; $W y$ es la variable modificada o retardada espacialmente; X la variable independiente NDVI; $\varepsilon$ son los residuales o error que es la porción que no puede explicar la variable independiente a la dependiente. Los coeficientes indicaron un punto de corte positivo leve, una relación porcentual con la matriz de pesos espaciales y una relación positiva de la variable dependiente con la independiente.

Para el cultivo de cebada los resultados provenientes de la construcción de los modelos Error y Lag no son altos comparado con el cultivo de trigo, sin embargo se dejó planteada la posibilidad de utilizar 2 tipo de modelos espaciales que describen el fenómeno de estudio por medio de la metodología a nivel pixel.

\subsubsection{Modelo clásico MCO (nivel zonal).}

Análogamente otro punto de vista para evaluar la correlación del rendimiento vs NDVI es agrupando los pixeles con igual valor de NDVI y comparándolos con el rendimiento promedio al interior de las zonas homogéneas de este índice de vegetación, esta es la segunda metodología planteada, a nivel zonal. De modo similar a la metodología a nivel pixel, inicialmente se ejecutaron modelos por MCO por medio del programa GeoDa ${ }^{\circledR}$, evaluando así los valores de los criterios y test considerados en este estudio. Los resultados iniciales de los MCO pertenecientes a esta metodología se presentan en la Tabla 35. 
Tabla 35. Resultados de los estadísticos y test generales de los modelos MCO por parcela para la metodología a nivel zonal.

\begin{tabular}{|c|c|c|c|c|c|c|c|c|c|}
\hline Fecha & Cultivo & Parcela & $\mathbf{R}^{2}$ & $\begin{array}{c}\mathbf{R}^{2} \\
\text { Ajustado } \\
\end{array}$ & $\begin{array}{c}\text { Estadístico } \\
\mathbf{F} \\
\end{array}$ & $\begin{array}{c}\text { Probabilidad } \\
\text { Estadístico } \\
\end{array}$ & $\begin{array}{c}\text { Máxima } \\
\text { Verosimilitud } \\
\end{array}$ & Akaike & Schwarz \\
\hline \multirow{6}{*}{$\begin{array}{l}\text { Nov } \\
17\end{array}$} & \multirow{4}{*}{ Cebada } & 3 & 0.85 & 0.84 & 79.33 & 0.00 & -0.53 & 5.06 & 6.61 \\
\hline & & $3 y 4$ & 0.67 & 0.65 & 38.62 & 0.00 & -10.42 & 24.84 & 26.93 \\
\hline & & 4 & 0.49 & 0.47 & 19.52 & 0.00 & -14.82 & 33.64 & 35.82 \\
\hline & & 5 & 0.11 & 0.06 & 2.25 & 0.15 & -18.36 & 40.72 & 42.71 \\
\hline & \multirow{2}{*}{ Trigo } & 0 & 0.59 & 0.57 & 31.49 & 0.00 & -15.42 & 34.83 & 37.19 \\
\hline & & 2 & 0.38 & 0.34 & 10.90 & 0.00 & -11.07 & 26.14 & 28.13 \\
\hline \multirow{9}{*}{$\begin{array}{l}\text { Nov } \\
26\end{array}$} & \multirow{4}{*}{ Cebada } & 3 & 0.81 & 0.80 & 86.40 & 0.00 & -0.13 & 4.25 & 6.44 \\
\hline & & $3 y^{4}$ & 0.19 & 0.15 & 5.50 & 0.03 & -14.51 & 33.03 & 35.54 \\
\hline & & 4 & 0.09 & 0.05 & 2.34 & 0.14 & -22.12 & 48.24 & 50.76 \\
\hline & & 5 & 0.21 & 0.16 & 4.72 & 0.04 & -12.96 & 29.92 & 31.92 \\
\hline & \multirow{5}{*}{ Trigo } & 0 & 0.90 & 0.89 & 188.60 & 0.00 & -3.83 & 11.65 & 14.01 \\
\hline & & 2 & 0.41 & 0.38 & 13.05 & 0.00 & -5.47 & 14.94 & 17.02 \\
\hline & & 6 & 0.97 & 0.97 & 860.98 & 0.00 & 21.03 & -38.07 & -35.63 \\
\hline & & $6 y 7$ & 0.95 & 0.95 & 465.70 & 0.00 & 9.04 & -14.09 & -11.42 \\
\hline & & 7 & 0.79 & 0.78 & 80.83 & 0.00 & -9.72 & 23.43 & 25.79 \\
\hline \multirow{9}{*}{$\begin{array}{l}\text { Dic } \\
03\end{array}$} & \multirow{4}{*}{ Cebada } & 3 & 0.11 & 0.06 & 2.24 & 0.15 & -5.80 & 15.60 & 17.69 \\
\hline & & $3 y 4$ & 0.34 & 0.32 & 14.72 & 0.00 & -5.35 & 14.71 & 17.51 \\
\hline & & 4 & 0.39 & 0.37 & 17.92 & 0.00 & -17.87 & 39.73 & 42.54 \\
\hline & & 5 & 0.14 & 0.10 & 3.17 & 0.09 & -8.13 & 20.26 & 22.35 \\
\hline & \multirow{5}{*}{ Trigo } & 0 & 0.88 & 0.87 & 167.98 & 0.00 & -6.37 & 16.74 & 19.18 \\
\hline & & 2 & 0.22 & 0.18 & 5.75 & 0.03 & 0.20 & 3.60 & 5.78 \\
\hline & & 6 & 0.95 & 0.95 & 493.68 & 0.00 & 12.44 & -20.89 & -18.30 \\
\hline & & $6 y 7$ & 0.96 & 0.96 & 692.37 & 0.00 & 13.74 & -23.48 & -20.75 \\
\hline & & 7 & 0.84 & 0.83 & 120.04 & 0.00 & -4.11 & 12.21 & 14.65 \\
\hline
\end{tabular}

En los resultados se observó que los valores de $\mathrm{R}^{2} \mathrm{y} \mathrm{R}^{2}$ ajustado más representativos del cultivo de cebada correspondieron al set de datos de la parcela 3, para las fechas correspondientes al mes de noviembre; siendo el valor más alto el de la fecha 17 de noviembre con un $85 \%$ de ajuste. Respecto al cultivo de trigo los mejores ajustes fueron los de las fechas 26 de noviembre y 03 de diciembre, superando el $90 \%$, siendo el más alto el $\mathrm{R}^{2}$ perteneciente a la parcela 6 del 26 de noviembre con un 97\%, seguido por la combinación de parcelas 6 y 7 del 03 de diciembre con $96 \%$, siendo estos porcentajes bastante altos de ajuste, casi cercanos al optimo $100 \%$.

El siguiente criterio evaluado fue el estadístico F (Tabla 35) que evaluó la significancia conjunta de las variables consideradas de un modelo en particular, mostrando que 4 modelos correspondientes al cultivo de cebada en las fechas consideradas no cumplen con este supuesto de significancia, siendo estas la parcela 5 del 17 de noviembre y 03 de diciembre, la parcela 4 del 26 de noviembre y la parcela 3 del 03 de diciembre, cuyos modelos poseen los valores de $\mathrm{R}^{2}$ más 
bajos en los set de datos, como por ejemplo la parcela 4 con un $9 \%$ de ajuste siendo este un valor bastante bajo.

Los criterios correspondientes a los test de máxima verosimilitud, Akaike y Schwarz (Tabla 35) coincidieron con los resultados encontrados en los valores superiores de $\mathrm{R}^{2}$ descritos anteriormente, a excepción de los resultados de cebada para la fecha 03 de diciembre, en donde estos criterios sugieren que el mejor modelo de este conjunto de parcelas corresponde a la combinación entre la 3 y 4 , poseyendo el segundo mejor $\mathrm{R}^{2}$ del grupo, no obstante esta fecha según los análisis realizados no es ideal para evaluar el cultivo de cebada.

El siguiente paso fue observar la significancia individual de las variables de los modelos de MCO, la cual es representada por el estadístico T. Los resultados se presentan en la Tabla 36. 
Tabla 36. Resultados de los coeficientes y estadísticos para las variables de los modelos MCO por parcela para la metodología a nivel zonal.

\begin{tabular}{|c|c|c|c|c|c|c|c|}
\hline Fecha & Cultivo & Parcela & Variable & Coeficiente & $\begin{array}{c}\text { Error } \\
\text { Estándar }\end{array}$ & $\begin{array}{c}\text { Estadístico } \\
T\end{array}$ & Probabilidad \\
\hline \multirow{11}{*}{$\begin{array}{c}\text { Nov } \\
17\end{array}$} & \multirow{7}{*}{ Cebada } & 3 & $\begin{array}{l}\text { Constante } \\
\text { NDVI }\end{array}$ & $\begin{array}{l}-3.18 \\
11.09 \\
\end{array}$ & $\begin{array}{l}0.92 \\
1.25 \\
\end{array}$ & $\begin{array}{c}-3.44 \\
8.91 \\
\end{array}$ & $\begin{array}{l}0.00 \\
0.00\end{array}$ \\
\hline & & \multirow{2}{*}{$3 y^{4}$} & Constante* & -1.68 & 1.10 & -1.53 & 0.14 \\
\hline & & & NDVI & 9.36 & 1.51 & 6.21 & 0.00 \\
\hline & & \multirow{2}{*}{4} & Constante* & 0.89 & 0.97 & 0.91 & 0.37 \\
\hline & & & NDVI & 5.95 & 1.35 & 4.42 & 0.00 \\
\hline & & \multirow{2}{*}{5} & Constante* & 2.62 & 1.75 & 1.50 & 0.15 \\
\hline & & & NDVI* & 3.56 & 2.37 & 1.50 & 0.15 \\
\hline & \multirow{4}{*}{ Trigo } & \multirow{2}{*}{0} & Constante* & -0.89 & 1.01 & -0.88 & 0.39 \\
\hline & & & NDVI & 7.87 & 1.40 & 5.61 & 0.00 \\
\hline & & \multirow{2}{*}{2} & Constante* & 0.56 & 1.27 & 0.44 & 0.67 \\
\hline & & & NDVI & 5.42 & 1.64 & 3.30 & 0.00 \\
\hline \multirow{18}{*}{$\begin{array}{c}\text { Nov } \\
26\end{array}$} & \multirow{8}{*}{ Cebada } & \multirow{2}{*}{3} & Constante* & 0.24 & 0.56 & 0.43 & 0.67 \\
\hline & & & NDVI & 7.88 & 0.85 & 9.30 & 0.00 \\
\hline & & \multirow{2}{*}{$3 \mathrm{y} 4$} & Constante & 3.83 & 0.75 & 5.12 & 0.00 \\
\hline & & & NDVI & 2.70 & 1.15 & 2.34 & 0.03 \\
\hline & & \multirow{2}{*}{4} & Constante & 3.97 & 0.99 & 4.03 & 0.00 \\
\hline & & & NDVI* & 2.36 & 1.54 & 1.53 & 0.14 \\
\hline & & \multirow{2}{*}{5} & Constante & 2.77 & 1.24 & 2.23 & 0.04 \\
\hline & & & NDVI & 3.99 & 1.84 & 2.17 & 0.04 \\
\hline & \multirow{10}{*}{ Trigo } & \multirow{2}{*}{0} & Constante & -4.03 & 0.65 & -6.25 & 0.00 \\
\hline & & & NDVI & 12.00 & 0.87 & 13.73 & 0.00 \\
\hline & & \multirow{2}{*}{2} & Constante* & 1.71 & 0.89 & 1.91 & 0.07 \\
\hline & & & NDVI & 4.24 & 1.17 & 3.61 & 0.00 \\
\hline & & \multirow{2}{*}{6} & Constante & -1.30 & 0.22 & -5.79 & 0.00 \\
\hline & & & NDVI & 8.85 & 0.30 & 29.34 & 0.00 \\
\hline & & \multirow{2}{*}{$6 y 7$} & Constante & -1.55 & 0.31 & -5.01 & 0.00 \\
\hline & & & NDVI & 9.18 & 0.43 & 21.58 & 0.00 \\
\hline & & \multirow{2}{*}{7} & Constante & -1.94 & 0.74 & -2.61 & 0.02 \\
\hline & & & NDVI & 9.84 & 1.09 & 8.99 & 0.00 \\
\hline & & & Constante & 4.89 & 0.45 & 10.88 & 0.00 \\
\hline & & 3 & NDVI* & 1.24 & 0.83 & 1.50 & 0.15 \\
\hline & & $3 \mathrm{v}^{4}$ & Constante & 6.57 & 0.30 & 22.08 & 0.00 \\
\hline & Cebada & गу4 & NDVI & -2.06 & 0.54 & -3.84 & 0.00 \\
\hline & Cenada & 4 & Constante & 7.24 & 0.45 & 16.06 & 0.00 \\
\hline & & 4 & NDVI & -3.45 & 0.82 & -4.23 & 0.00 \\
\hline & & 5 & Constante & 6.96 & 0.76 & 9.20 & 0.00 \\
\hline & & 3 & NDVI* & -2.34 & 1.32 & -1.78 & 0.09 \\
\hline & & 0 & Constante & -3.65 & 0.66 & -5.56 & 0.00 \\
\hline 03 & & 0 & NDVI & 11.59 & 0.89 & 12.96 & 0.00 \\
\hline & & 2 & Constante & 3.60 & 0.62 & 5.81 & 0.00 \\
\hline & & 2 & NDVI & 1.94 & 0.81 & 2.40 & 0.03 \\
\hline & & 6 & Constante & -1.43 & 0.30 & -4.78 & 0.00 \\
\hline & I 1190 & 0 & NDVI & 8.71 & 0.39 & 22.22 & 0.00 \\
\hline & & $6 \mathrm{v} 7$ & Constante & -1.66 & 0.26 & -6.46 & 0.00 \\
\hline & & oyl & NDVI & 9.00 & 0.34 & 26.31 & 0.00 \\
\hline & & 7 & Constante & -1.48 & 0.56 & -2.63 & 0.01 \\
\hline & & 1 & NDVI & 8.67 & 0.79 & 10.96 & 0.00 \\
\hline
\end{tabular}

$* \overline{\text { Variable no significativa en la estructura del modelo ya que su nivel de significancia supera el } 5 \% \text { (P-valor }>0.05)}$ 
Para la construcción de los modelos anteriores se encontró que para el cultivo de cebada, en la fecha óptima para este tipo, las constantes no son significativas a excepción del set de datos para la parcela 3, en la cual sus componentes fueron altamente significativas. En la fecha 26 de noviembre se observó que la variable NDVI para el cultivo de cebada y la constante de la parcela 2 de trigo no son significativas. Respecto a la fecha 03 de diciembre solo en los modelos para cebada las variables NDVI de las parcelas 3 y 5 no son significativas, sin embargo esta fecha no es relevante para este tipo de cultivo, por el contrario las parcelas de trigo para esta fecha todas son altamente significativas, haciendo la salvedad que la parcela 2 posee un P-valor de 0.03 .

Una vez identificada la relevancia de la estructura para los modelos MCO se procedió a evaluar el diagnóstico de los mismos por medio de los test para detectar heterocedasticidad y no normalidad del conjunto de datos, dichos resultados se muestran en la Tabla 37.

Tabla 37. Resultados de los estadísticos para evaluar la heterocedasticidad y no normalidad de los modelos MCO por parcela para la metodología a nivel zonal.

\begin{tabular}{|c|c|c|c|c|c|c|c|c|c|c|}
\hline \multirow{2}{*}{ Fecha } & \multirow{2}{*}{ Cultivo } & \multirow{2}{*}{ Parcela } & \multicolumn{2}{|c|}{ Jarque-Bera } & \multicolumn{2}{|c|}{ Breusch-Pagan } & \multicolumn{2}{|c|}{ Koenker-Bassett } & \multicolumn{2}{|c|}{ White } \\
\hline & & & Valor & Prob & Valor & Prob & Valor & Prob & Valor & Prob \\
\hline \multirow{6}{*}{$\begin{array}{c}\text { Nov } \\
17\end{array}$} & \multirow{4}{*}{ Cebada } & 3 & 2.53 & 0.28 & 4.35 & 0.04 & 2.77 & 0.10 & 5.15 & 0.08 \\
\hline & & $3 y 4$ & 7.73 & 0.02 & 14.74 & 0.00 & 5.33 & 0.02 & 7.44 & 0.02 \\
\hline & & 4 & 8.95 & 0.01 & 10.28 & 0.00 & 4.29 & 0.04 & 4.42 & 0.11 \\
\hline & & 5 & 1.26 & 0.53 & 3.79 & 0.05 & 3.00 & 0.08 & 6.45 & 0.04 \\
\hline & \multirow{2}{*}{ Trigo } & 0 & 30.31 & 0.00 & 10.26 & 0.00 & 3.02 & 0.08 & 6.03 & 0.05 \\
\hline & & 2 & 10.69 & 0.00 & 12.23 & 0.00 & 4.88 & 0.03 & 10.86 & 0.00 \\
\hline \multirow{9}{*}{$\begin{array}{c}\text { Nov } \\
26\end{array}$} & \multirow{4}{*}{ Cebada } & 3 & 0.62 & 0.73 & 0.82 & 0.36 & 1.01 & 0.31 & 1.08 & 0.58 \\
\hline & & $3 y^{4}$ & 21.76 & 0.00 & 25.58 & 0.00 & 7.28 & 0.01 & 10.87 & 0.00 \\
\hline & & 4 & 13.03 & 0.00 & 17.39 & 0.00 & 6.66 & 0.01 & 16.66 & 0.00 \\
\hline & & 5 & 1.95 & 0.38 & 0.04 & 0.83 & 0.04 & 0.85 & 7.72 & 0.02 \\
\hline & \multirow{5}{*}{ Trigo } & 0 & 23.13 & 0.00 & 6.84 & 0.01 & 2.25 & 0.13 & 5.78 & 0.06 \\
\hline & & 2 & 0.53 & 0.77 & 2.92 & 0.09 & 3.19 & 0.07 & 6.30 & 0.04 \\
\hline & & 6 & 1.54 & 0.46 & 0.95 & 0.33 & 1.97 & 0.16 & 3.34 & 0.19 \\
\hline & & $6 \mathrm{y} 7$ & 3.06 & 0.22 & 13.04 & 0.00 & 6.99 & 0.01 & 15.04 & 0.00 \\
\hline & & 7 & 0.12 & 0.94 & 1.21 & 0.27 & 1.28 & 0.26 & 2.35 & 0.31 \\
\hline \multirow{9}{*}{$\begin{array}{c}\text { Dic } \\
03\end{array}$} & \multirow{4}{*}{ Cebada } & 3 & 1.05 & 0.59 & 1.14 & 0.29 & 0.91 & 0.34 & 10.23 & 0.00 \\
\hline & & $3 y 4$ & 12.65 & 0.00 & 19.49 & 0.00 & 8.45 & 0.00 & 9.72 & 0.01 \\
\hline & & 4 & 6.71 & 0.03 & 28.00 & 0.00 & 15.07 & 0.00 & 21.74 & 0.00 \\
\hline & & 5 & 0.58 & 0.75 & 14.60 & 0.00 & 9.43 & 0.00 & 12.78 & 0.00 \\
\hline & \multirow{5}{*}{ Trigo } & 0 & 13.70 & 0.00 & 1.17 & 0.28 & 0.55 & 0.46 & 9.88 & 0.01 \\
\hline & & 2 & 1.33 & 0.51 & 0.18 & 0.67 & 0.35 & 0.55 & 0.35 & 0.84 \\
\hline & & 6 & 6.44 & 0.04 & 5.58 & 0.02 & 3.56 & 0.06 & 10.66 & 0.00 \\
\hline & & $6 y 7$ & 0.40 & 0.82 & 6.27 & 0.01 & 5.09 & 0.02 & 13.89 & 0.00 \\
\hline & & 7 & 1.10 & 0.58 & 0.12 & 0.72 & 0.19 & 0.66 & 4.96 & 0.08 \\
\hline
\end{tabular}

Prob: Probabilidad o P-valor del test. 
El test respectivo a la no normalidad en los datos, Jarque-Bera, mostró que para el cultivo de cebada las parcelas 3 y 5 en todas las fechas presentan normalidad al ser el test no significativo. Concerniente al cultivo de trigo se notó que todas las parcelas de las fechas relevantes, 26 de noviembre y 03 de diciembre, siguieren normalidad en los datos a excepción del set de datos de la parcela 0 cuyo test resulto significativo para la no normalidad.

En referencia a los test de heterocedasticidad Breusch-Pagan, Koenker-Bassett y White (Tabla 37) se registró que, para el cultivo de cebada, coincidía con el criterio del test de normalidad, ya que dichas parcelas no poseen este inconveniente al no ser significativo el test (en especial en los resultados de Breusch-Pagan y Koenker-Bassett ya que White es un test robusto en caso de no ser conclusivos los anteriores), a excepción de la parcela 5 del 03 de diciembre ya que presentó evidencia significativa de heterocedasticidad. Por otro lado las parcelas de trigo también registraron homocedasticidad en las fechas finales, teniendo en cuenta que los set de datos concernientes a la combinación de la parcela 6 y 7 se presentaron heterocedasticidad, ya que los resultados de los 3 test respectivos así lo respaldaron.

El diagnóstico considerado en el análisis de esta metodología respecto a la detección autocorrelación en los residuales fue también mediante el test I de Moran. Los resultados obtenidos para este test concernientes a los modelos MCO en cuestión se exponen en la Tabla 38. 
Tabla 38. Resultados del estadístico I de Moran para evaluar la autocorrelación en los residuales de los modelos MCO por parcela para la metodología a nivel zonal.

I de Moran

\begin{tabular}{|c|c|c|c|c|c|}
\hline \multirow{2}{*}{ Fecha } & \multirow{2}{*}{ Cultivo } & \multirow{2}{*}{ Parcela } & \\
\hline & & & Error & Valor & Probabilidad \\
\hline \multirow{6}{*}{$\begin{array}{c}\text { Nov } \\
17\end{array}$} & \multirow{4}{*}{ Cebada } & 3 & -0.05 & 0.58 & 0.57 \\
\hline & & $3 y 4$ & 0.02 & 1.71 & 0.09 \\
\hline & & 4 & 0.00 & 0.97 & 0.33 \\
\hline & & 5 & 0.08 & 2.15 & $0.03^{*}$ \\
\hline & \multirow{2}{*}{ Trigo } & 0 & -0.06 & -0.10 & 0.92 \\
\hline & & 2 & -0.33 & -2.71 & 0.01 \\
\hline \multirow{9}{*}{$\begin{array}{c}\text { Nov } \\
26\end{array}$} & \multirow{4}{*}{ Cebada } & 3 & 0.12 & 3.91 & $0.00^{*}$ \\
\hline & & $3 y 4$ & 0.01 & 2.22 & $0.03 *$ \\
\hline & & 4 & 0.03 & 2.33 & $0.02 *$ \\
\hline & & 5 & -0.37 & -2.67 & $0.01 *$ \\
\hline & \multirow{5}{*}{ Trigo } & 0 & 0.01 & 1.89 & 0.06 \\
\hline & & 2 & -0.01 & 1.17 & 0.24 \\
\hline & & 6 & -0.01 & 0.98 & 0.33 \\
\hline & & $6 y 7$ & -0.01 & 1.11 & 0.27 \\
\hline & & 7 & -0.06 & -0.10 & 0.92 \\
\hline \multirow{9}{*}{$\begin{array}{c}\text { Dic } \\
03\end{array}$} & \multirow{4}{*}{ Cebada } & 3 & -0.12 & -0.27 & 0.78 \\
\hline & & $3 y 4$ & -0.03 & 0.61 & 0.54 \\
\hline & & 4 & 0.04 & 2.50 & $0.01 *$ \\
\hline & & 5 & 0.03 & 2.30 & $0.02 *$ \\
\hline & \multirow{5}{*}{ Trigo } & 0 & 0.02 & 1.84 & 0.07 \\
\hline & & 2 & -0.02 & 1.40 & 0.16 \\
\hline & & 6 & -0.05 & 0.34 & 0.74 \\
\hline & & $6 y 7$ & -0.08 & -0.90 & 0.37 \\
\hline & & 7 & -0.10 & -0.79 & 0.43 \\
\hline
\end{tabular}

* Indica presencia de autocorrelación en los residuales del modelo ya que es significativo (P-valor $<0.05$ ).

A diferencia de los resultados encontrados en la metodología a nivel de pixel, en los resultados obtenidos a nivel zonal, la mayoría de los set de datos no presenta inconvenientes con la autocorrelación mencionada, solo las parcelas correspondientes a cebada y la parcela 2 de trigo del 26 de noviembre muestran significancia en este test, junto con la parcela 4 y 5 del 03 de diciembre.

Debido a que en las fechas relevantes para cada cultivo respectivamente no se viola el supuesto de no autocorrelación en los residuales, resultó innecesario realizar el test de decisión marcado por los multiplicadores de Lagrange. Con los resultados obtenidos junto con los descritos anteriores fue posible sustentar que para los set de datos contemplados es posible realizar modelos por MCO sólidos para poder describir y predecir el fenómeno estudiado en el presente trabajo. 
Recapitulando esta sección, con base en los criterios e interpretación de resultados descritos hasta el momento respecto a la metodología a nivel zonal, se llegó a la conclusión que el mejor modelo para el cultivo de cebada está definido por el set de datos de la parcela 3 del 17 de noviembre y para el de trigo la combinación de las parcelas 6 y 7 de la fecha 03 de diciembre. Dicho planteamiento respalda a lo hallado en los análisis exploratorios de los datos previo a la ejecución y consideración de modelos estadísticos de regresión. Los modelos seleccionados cuentan con los más altos valores de ajuste $\mathrm{R}^{2}$, poseen normalidad en sus datos, no presentan autocorrelación en sus residuales y no demuestra heterocedasticidad, a excepción del modelo definido para trigo por una mínima diferencia en el test que midió la última característica mencionada. No obstante esta diferencia se podría considerar despreciable al comparar las bondades que presentan los resultados en los criterios de evaluación en el contexto de totalidad en los datos contemplados durante el análisis.

Las especificaciones y estructura de las ecuaciones en cuestión para los modelos MCO respectiva a cada tipo de cultivo se describen en la Tabla 39.

Tabla 39. Ecuaciones seleccionadas de modelos MCO para los cultivos de cebada y trigo según la metodología a nivel zonal.

\begin{tabular}{lccc}
\multicolumn{1}{c}{ Cultivo } & Fecha & Parcela de Origen & Modelo MCO \\
\hline Cebada & Nov 17 & 3 & $Y=-3.18+11.09 * X+\varepsilon$ \\
Trigo & Dic 03 & 6 y 7 & $Y=-1.66+9 * X+\varepsilon$ \\
\hline
\end{tabular}

Donde Y es la variable dependiente de rendimiento de producción; X la variable independiente NDVI y $\varepsilon$ son los residuales o error que es la porción que no puede explicar la variable independiente a la dependiente. Los coeficientes de punto de corte de ambas ecuaciones lineales poseen un valor negativo, con lo cual si tendríamos valores cercanos a cero de NDVI la productividad arrojara valores negativos e inconsistentes; los coeficientes de la variable correspondiente al NDVI son positivos y similares en magnitud, no obstante tiene un mayor incremento la productividad con base en el NDVI respecto a la ecuación de cebada.

Las ecuaciones de los modelos MCO pertenecientes a la metodología zonal brindan mejores indicadores de ajuste que los modelos espaciales generados con la metodología a nivel de pixel, sin embargo hay que considerar que al generar zonas homogéneas de NDVI y promediar los 
valores de rendimiento al interior de dichas zonas se reducen los datos considerablemente, debido a la generalización realizada de la información geográfica. No obstante esta generalización facilita la predicción del rendimiento en determinada región a partir de datos NDVI de cualquier imagen Landsat sin considerar la especificación de variables autorregresivas espaciales o matrices de pesos espaciales; de igual forma se agiliza los cálculos gracias a la reducción del rango de datos en la variable independiente.

\subsection{Validación de los modelos.}

Gracias a las bondades y ventajas brindadas por los MCO referidos por la metodología nivel zonal, se prosiguió con la validación de los mismos mediante la utilización del criterio de NashSutcliffe, el cual contrasta valores observados de rendimiento provenientes de las diferentes parcelas según su tipo de cultivo con los valores simulados por los modelos seleccionados.

Utilizando las ecuaciones de la parcelas 3 (17 de noviembre) para cebada y de la combinación 6 y 7 (03 de diciembre) para trigo se predijo el rendimiento que tendría cada set de datos en las diferentes fechas evaluadas en el estudio, incluso sobre los set de datos que originaron las ecuaciones predictoras con el fin de comparar su desempeño. Los resultados de los rendimientos calculados o simulados por cada valor de NDVI de los set de datos mencionados se puede observar en las tablas, por fechas, del Anexo 4.

El cálculo del criterio de validación se realizó por medio de la página web del WHAT para cada set de datos, cuyos resultados del coeficiente $\mathrm{R}^{2}$ para cada uno junto con su respectivo coeficiente E se presentan en la Tabla 40. 
Tabla 40. Resultado de la validación por medio del coeficiente Nash-Sutcliffe con base en los modelos MCO planteados para cada tipo de cultivo mediante la metodología zonal.

\begin{tabular}{|c|c|c|c|c|}
\hline Fecha & Cultivo & Parcela & $\mathbf{R}^{2}$ & Nash-Sutcliffe (E) \\
\hline \multirow{6}{*}{$\begin{array}{c}\text { Nov } \\
17\end{array}$} & \multirow{4}{*}{ Cebada } & 3 & 0.85 & 0.85 \\
\hline & & $3 y^{4}$ & 0.67 & 0.534 \\
\hline & & 4 & 0.49 & -0.192 \\
\hline & & 5 & 0.11 & -0.576 \\
\hline & \multirow{2}{*}{ Trigo } & 0 & 0.59 & 0.575 \\
\hline & & 2 & 0.38 & -0.831 \\
\hline \multirow{9}{*}{$\begin{array}{c}\text { Nov } \\
26\end{array}$} & \multirow{4}{*}{ Cebada } & 3 & 0.81 & -4.81 \\
\hline & & $3 y^{4}$ & 0.19 & -13.23 \\
\hline & & 4 & 0.09 & -8.47 \\
\hline & & 5 & 0.21 & -5.53 \\
\hline & \multirow{5}{*}{ Trigo } & 0 & 0.90 & 0.81 \\
\hline & & 2 & 0.41 & -0.45 \\
\hline & & 6 & 0.97 & 0.81 \\
\hline & & $6 y 7$ & 0.95 & 0.85 \\
\hline & & 7 & 0.79 & 0.64 \\
\hline \multirow{9}{*}{$\begin{array}{c}\text { Dic } \\
03\end{array}$} & \multirow{4}{*}{ Cebada } & 3 & 0.11 & -76.30 \\
\hline & & $3 y^{4}$ & 0.34 & -66.38 \\
\hline & & 4 & 0.39 & -26.56 \\
\hline & & 5 & 0.14 & -45.73 \\
\hline & \multirow{5}{*}{ Trigo } & 0 & 0.88 & 0.83 \\
\hline & & 2 & 0.22 & -2.95 \\
\hline & & 6 & 0.95 & 0.95 \\
\hline & & $6 y 7$ & 0.96 & 0.96 \\
\hline & & 7 & 0.84 & 0.83 \\
\hline
\end{tabular}

En los resultados se pudo observar que para el cultivo de cebada los únicos set de datos que permiten una cercanía entre los valores observados y los simulados son los que respecta a las parcelas 3 y combinación 3 y 4 del 17 de noviembre, ya que los valores del coeficiente $\mathrm{E}$ son positivos. Según los rangos definidos por Cabrera (2012) la combinación de la parcela 3 y 4 se cataloga como un ajuste bueno ya que su valor es de 0.5 con un $\mathrm{R}^{2}$ relativamente alto; y la parcela 3 se consideraría con un ajuste excelente ya que su valor $E$ es superior a 0.8 y posee un $\mathrm{R}^{2}$ alto de $85 \%$. No obstante hay que mencionar que la predicción hecha sobre el set de datos de la parcela 3 se realizó con el modelo proveniente de la misma, al igual que la combinación de la parcela 3 y 4 posee datos pertenecientes a la parcela 3, debido a esto el coeficiente resulta alto y significativo a comparación de los otras set de datos respectivos al cultivo de cebada, cuyos valores al ser inferiores a 0 demuestran que la predicción hecha por el modelo no es superior a la realizada usando el promedio de los datos observados. 
Por otro lado, los resultados correspondientes al modelo del cultivo de trigo arrojo valores de coeficientes contundentes en favor al ajuste y predicción de dicho modelo con base en la comparación de los datos observados de las otras parcelas del mismo cultivo. Los valores obtenidos basados en las parcelas de las fechas 26 de noviembre y 03 de diciembre resultaros positivos a excepción de los datos observados de la parcela 2, con lo cual se suma un argumento más que explica que los datos provenientes de esta parcela poseen alguna anormalidad intrínseca que hace que se diferencia de las otras parcelas del mismo cultivo. Sin embargo los valores positivos de los coeficientes de las otras parcelas indicaron un ajuste excelente ya que superó el 0.8 en ambas fechas, a excepción del coeficiente de la parcela 7 del 26 de noviembre de la parcela 7 que tiene un 0.64, no obstante es catalogada con un ajuste muy bueno, al igual que su valor de $\mathrm{R}^{2}$ es bastante alto, $79 \%$. Similar a lo sucedido con el modelo de cebada, el valor más alto de los coeficientes corresponde a los datos observados de la parcela donde provino el modelo seleccionado, la combinación de la las parcelas 6 y 7, alcanzando un valor cercano a el óptimo 1, de 96\%, al igual que set de datos independientes de la parcelas que la conforman, como es el caso del valores de la parcela 6 con un 95\% encontrándose en el rango excelente de ajuste. No obstante al realizar la predicción del modelo en cuestión sobre los datos observados de la parcela 0 se encontró un valor alto de $E=0.83$ con un $\mathrm{R}^{2}$ de $88 \%$, siendo un ajuste bastante bueno localizándose en el rango de predicción excelente.

La validación anterior con base en el coeficiente de Nash-Sutcliffe indicó que el modelo escogido para trigo es adecuado para predecir el fenómeno de rendimiento de la productividad de dicho cultivo, al responder con valores altos con base al criterio del coeficiente. Por el contrario el modelo respectivo a el cultivo de cebada, aunque fue el que mejor resultados obtuvo sobre los set de datos que le correspondían, no predice adecuadamente los valores de rendimiento sobre los datos observados diferentes a la parcela 3 , de la cual el modelo es originario, llevando a la conclusión que para este tipo de cultivo los resultados no son concluyentes como lo son con el cultivo de trigo. 


\subsection{Propuesta de una herramienta para la contribución de la predicción de rendimiento agrícola al ordenamiento territorial de la cuenca hidrográfica.}

La cuenca de estudio al poseer la mayor parte de su área destinada a la agricultura genera la necesidad de conocer a fondo datos de rendimiento de este sector, con base en información antecedente o actual. Este requerimiento conlleva a analizar cómo ha sido la evolución de la agricultura en la cuenca, ya que esta cobertura ha ganado terreno e importancia en la última década.

Por este motivo en el proceso de la presente tesis se diseñaron diferentes tipos de modelos que conforman una herramienta geomática fundamental que presenta dos metodologías de aplicación diferentes para el manejo y ordenamiento del territorio, al contribuir en la generación de mapas de rendimiento respecto a cultivos agrícolas de cebada y trigo para observar el comportamiento del sector a nivel local.

En el caso en que el usuario final posea información espacial (variable autorregresiva y matriz de pesos espaciales W) y busca mayor precisión en la predicción del rendimiento, se implementa la metodología a nivel de pixel, considerando que para el cultivo de trigo se formuló la Ecuación 8 y para cebada las Ecuaciones 9 y 10.

En contraparte, si se posee información básica de NDVI, es posible aplicar los modelos MCO, según tipo de cultivo, en cualquier área al interior de la cuenca utilizando la metodología a nivel zonal, cuyos modelos se compilan en la Tabla 39.

La herramienta generada en la presente tesis, permite predecir el rendimiento conformando una base de datos que brinda información relevante, la cual es de gran utilidad para la planificación del manejo de coberturas y suelos junto con el ordenamiento territorial al interior de los límites de la cuenca hidrográfica. 


\section{CONCLUSIONES}

En la actualidad las tecnologías son parte importante del progreso agrario, con las cuales es posible monitorear, detectar y planificar las distintas etapas evolutivas de los cultivos. En la presente tesis se logró utilizar el índice de verdor NDVI con el cual se encontró relación con el rendimiento de diferentes parcelas con cultivos de cebada y trigo al interior de la cuenca hidrográfica en estudio. Para encontrar su correlación fue necesario procesar y depurar la fuente de los datos iniciales, logrando resultados precisos que describieron el fenómeno estudiado. Por tal motivo se corrigieron los niveles digitales de las imágenes Landsat 8, donde se obtuvo el índice NDVI, al igual que la depuración o limpieza de los mapas de rendimiento de los cultivos considerados, generando así la información confiable que sirvió de base sólida para los procesos de análisis.

Con el fin de validar los datos provenientes de las imágenes satelitales, se utilizó valores de NDVI capturados con radiómetro en campo, los cuales por su método de recolección puntual directamente sobre las coberturas de los cultivos brindó información precisa, contribuyendo de esta forma a argumentar la calidad de la base de datos inicial previo al procesamiento y correlación con la variable de rendimiento en gabinete.

La morfometría definida permitió inferir que la cuenca se encuentra en una zona de relieve bajo según las características topográficas. Los resultados alcanzados en la tesis generaron una caracterización morfométrica en detalle mejorando la información antecedente perteneciente a la cuenca. El análisis de la correlación de NDVI con la topografía mostró que al no poseer cambios abruptos de altura y al ser las coberturas del suelo relativamente homogéneas, no se encontró correlación concluyente en las zonas establecidas. Lo anterior se concluyó con base en que se encontraron correlaciones altas negativas en zonas donde su la contigua posee relaciones altas positiva o nulas, que se podrían argumentar por la variación de las coberturas del suelo y no a la topografía de la cuenca.

Para encontrar la correlación de los índices NDVI y rendimiento se plantearon 2 metodologías de análisis con enfoques diferentes (metodología a nivel pixel y zonal), las cuales poseen pros y contras dependiendo al punto de vista estadístico y de manipulación de datos. Dichos planteamientos proveen criterios de análisis que brindan información precisa y de fácil manejo 
de los resultados, dependiendo a la calidad del trabajo en donde se requiera conocer dicha correlación u obtención de mapas de rendimientos futuros o retrospectivos.

Posterior al procesamiento y selección, por criterios estadísticos, de los set de datos utilizados para la generación de modelos predictivos de rendimientos, se plantearon modelos por MCO para ambas metodologías, encontrándose que hay modelos que no cumplen con principios fundamentales como lo son la no autocorrelación de los residuales y la homocedasticidad (debido a que los MCO no consideran la espacialización de los datos geográficos). Por tal razón, mediante el criterio de multiplicadores de Lagrange, se diseñaron modelos de autocorrelación espacial que contribuyeron a mejorar el ajuste de los modelos y dar mayor precisión a la inferencia geográfica de los elementos estudiados.

La metodología a nivel de pixel es detallada y precisa ya que maneja gran variedad de datos, orden especifico y matriz de pesos espaciales dados por el comportamiento geográfico de los datos, no obstante se requiere la variable autorregresiva la cual no es fácilmente identificable si no se maneja la teoría de modelos espaciales y econométricos por usuarios con conocimientos básicos del tema. En contraparte, la metodología a nivel de zonal contempla una reducción considerable de datos de NDVI junto con los promedios de valores de rendimientos al interior de estas zonas, sumado a que el modelo por MCO planteado es más sencillo de aplicar, ya que no contempla variables espaciales autorregresivas, permitiendo agilizar los cálculos y comprender con mayor facilidad los criterios de aceptación y ajuste de los modelos. De esta manera se presentan dos formas de observar el mismo fenómeno geográfico brindando una herramienta geomática para calcular información en donde se carezca de la misma, con conformidades y estándares de calidad requeridos por cualquier usuario de información geográfica o planificación territorial.

Para brindar mayor fiabilidad a los modelos se efectuó la validación de la capacidad de predicción por el coeficiente de Nash-Sutcliffe, encontrándose que los modelos escogidos para las fechas definidas predicen satisfactoriamente los rendimientos de los cultivos con base en valores de NDVI. Los porcentajes de ajuste hallados son superiores al $80 \%$, catalogándose como excelente según el criterio de la validación.

Recapitulando, en los procesos mencionados anteriormente se recopilaron, depuraron y se estandarizaron los datos base con el fin de plantear modelos predictivos espaciales para el rendimiento de cultivo de cebada y trigo al interior de la cuenca hidrográfica estudiada, la cual al 
contener gran parte de su extensión con coberturas agrícolas genera la necesidad de estudiar, analizar o monitorear el comportamiento de esta actividad. Los resultados y criterios analizados en la presente tesis fueron concluyentes con los modelos pertenecientes al cultivo de trigo, sin embargo son ambivalentes para el cultivo de cebada, por tal razón se presentaron diferentes opciones para la predicción de rendimientos del mismo.

El resultado de la presente tesis brinda una herramienta confiable para obtención de información de rendimiento de productividad agrícola que servirá para la toma de decisiones en el ordenamiento territorial de una cuenca. Esta información podrá ser utilizada por cualquier productor de la región o por entes de gestión territorial que busquen evaluar los tipos de cultivos estudiados, con el fin de potencializar la actividad o mitigar problemáticas que afecten o disminuyan el rendimiento en áreas destinadas a este nivel productivo, el cual es clave para el desarrollo de la población que habita la región o cuenca hidrográfica. 


\section{AGRADECIMIENTOS}

Principalmente doy gracias a Dios por brindarme las herramientas y la oportunidad de poder desarrollar la maestría. De igual forma expreso mi total gratitud a mi familia, ya que ellos fueron los responsables de inculcarme la voluntad y los valores para poder estudiar y seguir adelante, tanto a nivel profesional como personal.

Especial mención a mis directores, la Dr. Fernanda Julia Gaspari y al Dr. Christian Weber, de los cuales aprendí bastante, siendo ellos excelentes tutores y personas los cuales siempre tuvieron la buena disposición de guiarme y asesorarme en todo momento en el transcurso y desarrollo de la presente tesis.

Agradecimiento al Dr. Gabriel Vázquez Amábile el cual brindo sus conocimientos y la información necesaria respecto a los datos utilizados en el trabajo, provenientes de la estancia La Esperanza, al igual que la disposición para el acompañamiento en los viajes de campo donde se conoció y entendió mejor el contexto de la zona de estudio a tratar.

De la misma manera aprecio mucho los consejos brindados por el Ing. Rincón, que me oriento en procesos metodológicos de la tesis.

También reconozco el acompañamiento de mis compañeros de maestría y docentes de la cátedra Romina Díaz, Gabriela Mazzucchelli, Alfonso Vagaría, Gabriela Senisterra e Isabel Delgado, los cuales hicieron bastante amena la trayectoria del posgrado.

Igualmente cabe destacar los recursos y herramientas brindadas por la Facultad de Ciencias Agrarias y Forestales de la Universidad Nacional de La Plata, en la cual por medio de los convenios y proyectos de investigación $\left(\mathrm{N}^{\circ} 11 /\right.$ A223 y 11/A286) fue posible realizar los viajes de campo y recolectar datos e información necesario para la elaboración del presente trabajo.

Asimismo gracias al convenio entre la Comisión Nacional de Actividades Espaciales de Argentina CONAE y la UNLP fue posible la obtención de imágenes de satélite para su adecuada utilización en el proyecto.

Gracias a todos y finalizo con una frase que me brindo mi profesora de cálculo al terminar el bachillerato: "no hay mayor satisfacción que la del deber cumplido". 


\section{BIBLIOGRAFÍA}

Albarenque, S. M., \& Vélez, J. P. 2011. Técnicas para el procesamiento de mapas de rendimiento. Ediciones INTA, Paraná, Argentina. 33 p.

Anselin, L. 2005. Exploring Spatial Data With GeoDa: A Work Book. Spatial Analysis Laboratory, University of Illinois. Center for Spatially Integrated Social Science. 244 p.

Ariza, A. 2013. Descripción y Corrección de Productos Landsat 8 LDCM (Landsat Data Continuity Mission). Bogotá: Instituto Geográfico Agustín Codazzi. 46 p.

Ayala-Pérez, L. A., Terán-González, G. J., Flores-Hernández, D., Ramos-Miranda, J., \& Sosa-López, A. 2012. Variabilidad espacial y temporal de la abundancia y diversidad de la comunidad de peces en la costa de Campeche, México. Latin american journal of aquatic research, 40(1), pp. 63-78.

Azorín, J. D. B., LLago, M. E., \& de la Vega, J. C. S. 2012. Estimación de la renta bruta disponible municipal mediante técnicas de econometría espacial: Un ejercicio de aplicación. Revista de estudios regionales, (93), pp. 119-142.

Baronio, A., Vianco, A., \& Rabanal, C. 2012. Una Introducción a la Econometría Espacial: Dependencia y Heterogeneidad. Catedra de econometría. 33 p.

Best, S. León, L. Claret, M. 2006. Capítulo II: Elementos de vitivinicultura de precisión (VP) Boletín Instituto de Investigaciones Agrícolas de Chile, 136. 90 p.

Bohórquez, I. A., \& Ceballos, E. V. 2008. Algunos conceptos de la econometría espacial y el análisis exploratorio de datos espaciales. Ecos de Economía, 12(27), pp. 9-34.

Brunini, C., Moirano, J., Lauría, E., \& Rodriguez, R. 2002. Contribución Argentina al desarrollo del Proyecto SIRGAS. Actas de la XXI Asamblea AAGG, Rosa-no. 5 p.

Cabrera, J. 2012. Calibración de modelos hidrológicos. Instituto para la Mitigación de los Efectos del Fenómeno El Niño. Universidad Nacional de Ingeniería, Facultad de Ingeniería Civil, Perú. 7 p.

Camacho, C. 2007. Coeficiente de Correlación Lineal de Pearson. Versión web http://personal.us.es/vararey/adatos2/correlacion.pdf $20 \mathrm{p}$.

Celemín, J. P. 2009. Autocorrelación espacial e indicadores locales de asociación espacial: Importancia, estructura y aplicación. Revista Universitaria de Geografía, 18(1), pp. 11-31.

Congedo, L. 2015. Semi-Automatic Classification Plugin Documentation. 272 p.

Comisión Nacional de Actividades Espaciales CONAE. 2012. Guía de usuario de imágenes SPOT. Version web http://catalogos.conae.gov.ar/SPOT/Docs/Guia-de-UsuarioSPOT.pdf 3 p.

Chuvieco, E. 2002. Teledetección ambiental: La observación de la Tierra desde el Espacio. Ed. Ariel Ciencia. Barcelona. 528 p.

Djokic, D., Ye, Z., \& Dartiguenave, C. 2011. Arc hydro tools overview. Redland, Canada, ESRI, pp. 1-189. 
Echevarría Fano, N. 2010. Evaluación del interés del Índice Vegetativo Diferencial Normalizado (NDVI) para la definición de unidades de manejo diferenciado del viñedo en la Rioja Alavesa. 81 p.

Estrada, J., Trucios, R., Rios, J.C, Cerano, J., Rivera, M. 2012. Caracterización de las actividades agrícolas a partir del uso de imágenes satelitales y fotografías aéreas estudio de caso: Cuenca baja del rio Nazas. Mexico, pp. 73-80.

Euillades, P. A.; Vénere, M. J.; Clausse, A.; Vives, L. 2003. Modelos de elevación de precisión y su importancia en la simulación de Inundaciones. IHLLA - Univ. Nac. del Centro Prov. de Buenos Aires, pp. 226-2277.

Felicísimo, A. M. 1994. Parametric statistical method for error detection in digital elevation models. ISPRS Journal of Photogrammetry and Remote Sensing, pp. 29-33.

Gaspari, F. J. 2002. Ordenamiento territorial en cuencas serranas. Aplicación de Sistemas de Información Geográfica (S.I.G.). Ediciones Cooperativas, Buenos Aires, 116 p.

Gaspari, F. J., Rodríguez Vagaría, A. M., Senisterra, G., Denegri, G., Besteiro, S., y Delgado, M. I. 2012. Caracterización morfométrica de la cuenca alta del río Sauce Grande, Buenos Aires, Argentina. AUGMDOMUS, 4, pp.143-158.

Gaspari, F.J., Senisterra, G.E., Delgado, M.I., Rodriguez Vagaria, A. y Besteiro S.. 2009. Manual de Manejo Integral de Cuencas Hidrográficas. Primera Edicion. La Plata. 321 p.

Gilabert, M. A., González-Piqueras, J., \& García-Haro, J. 1997. Acerca de los índices de vegetación. Revista de teledetección, 8.10 p.

Guisan, A. y Zimmermann, N.E. 2000. Predictive habitat distribution models in ecology. Ecological Modelling, pp. 147-186.

Hall, A. Lamb, D. W. Holzapfel , B. Louis, J. 2002. Optical remote sensing applications in viticulture- a review resolution Australian journal of grape and wine research. 8, pp. 36-47.

Hastie, T.J. y Tibshirani, R.J. 1990. Generalized Additive Models. Chapman \& Hall, Londres. $352 \mathrm{p}$.

Instituto Geográfico Nacional IGN 1999. Sistemas geodésicos. Versión Web http://www.ign.gob.ar/archivos/geodesia/sistemas geodesicos.pdf. 51p.

Instituto Nacional de Tecnología Agrícola (INTA). 1989. Mapa de Suelos de la Provincia de Buenos Aires (escala 1:500.000). Buenos Aires, Argentina. 345 p.

Iqbal M. 1983. An introduction to Solar Radiation. Academic Press, Inc. New York. ISBN 0-12-373752-4. $390 \mathrm{p}$.

Jackson, R. D., Slater, P. N. y Pinter, P. J. 1983. Discrimination of growth and water stress in wheat by various vegetation indices through clear and turbid atmospheres. Remote Sensing of Environment. 13. pp 187-208.

Gamon, J. A., Huemmrich, K. F., Stone R, S.\& Tweedie C.E.. 2013. Spatial and temporal variation in primary productivity (NDVI) of coastal Alaskan tundra: Decreased vegetation growth following earlier snowmelt. Remote Sensing of Environment, pp.145-149.

Keith, C. 2000. Getting started with geographic information system. University of California. Santa Barbara. 340 p. 
Kriebel, K. 1976. On the variability of the reflected radiation due to differing distribution of irradiance. Remote Sensing of Environment. 4, pp. 257-264.

Lim, K.J. and B.A. Engel, 2004. WHAT: Web-Based Hydrograph Analysis Tool. Disponible en $\quad$ http://pasture.ecn.purdue.edu/ $\sim$ what. https://engineering.purdue.edu/mapserve/WHAT/compute r2 nash sutcliffe.html.

Lopez de Sabando M.J y Ezequiel A. Resumen trigo y cebada INTA Tandil Lobería y Necochea 2014-15. INTA. 28 pp.

Lopez de Sabando M.J., E. Arriaga, F. Ross, J. Erreguerena, P. Calviño, y Melchiori R.. 2015. Uso de sensores remotos como herramienta para fertilización con nitrógeno. Resumen trigo y cebada INTA Tandil Lobería y Necochea 2014-15. INTA. 15-18 p.

Ma, B.L., L.M. Dwyer, C. Costa, E.R. Cober \& Morrison M.J.. 2001. Early prediction of soybean yield from canopy reflectance measurements. Agron. J. 93, pp. 1227-1234.

Martínez Muñoz, J. y Díaz Ponce A.. 2005. Percepción remota: Fundamentos de teledetección espacial. Comisión Nacional del Agua. México. 62 p. http://siga.cna.gob.mx/SIGA/Percepcion/Fundamentos $\% 20$ de $\% 20$ teledetecci $\%$ C $3 \%$ B3n \%20espacial.PDF

Mehl, H. y Peinado O. Introducción a la reflectancia espectral de la vegetación, suelo y agua. $23 \mathrm{p}$.

Miralles, Daniel J., González F.G., Abeledo L.G., Serrago R.A., Alzueta I., García G.A., de San Caledonio R.P. y Lo Valvo P. 2014. Manual de trigo y cebada para el Cono Sur: procesos fisiológicos y bases de manejo . - 1a ed. - Buenos Aires : Orientación Gráfica Editora. 56 p.

Nan, A. 2009. Estimating annual net primary productivity of the tallgrass prairie ecosystem of the central great plains using AVHRR NDVI. University of Kansas. 64 p.

Perora, L. 2016. Discriminación espectral entre soja [Glycine max (L.) Merr.] y sorgo de Alepo (Sorghum halepense L.) como herramienta de decisión en la aplicación selectiva de herbicidas (tesina de grado). Universidad Nacional de La Plata. 36 p

Perdomo, C. J. V. Y. 2005. Cómo enseñar autocorrelación espacial. Economía Sociedad y Territorio, pp. 323-333.

Piuma, A. 2010. Informe del instructive de uso del aplicativo Converso Log a Shp. Argentina. 11 p. http://www.sensortecnologia.com/sensor/monitor-de-rendimiento.htm

Ramos, R. C. 2003. La georreferenciación en Cartografía. Primer congreso de la ciencia cartográfica y VIII semana nacional de cartografía, Buenos Aires. 14 p.

Raun W. R., Solie J. B., Johnson G. V., Stone M. L., Mullen R. W., Freeman K. W., Thomason W. E. \& Lukina E. V. 2002. Improving nitrogen use efficiency in cereal grain production with optical sensing and variable rate application. Agronomy Journal. 94, pp. 351-815.

Roy, D. P., Wulder, M. A., Loveland, T. R., Woodcock, C. E., Allen, R. G., Anderson, M. C., ... \& Scambos, T. A. 2014. Landsat-8: Science and product vision for terrestrial global change research. Remote Sensing of Environment, 145, pp. 154-172. 
Running, S. W., Nemani, R. R., Heinsch, F. A., Zhao, M., Reeves, M., \& Hashimoto, H., 2004. A Continuous Satellite-Derived Measure of Global Terrestrial Primary Production. BioScience, pp. 547-560.

Salisbury F. B. \& Ross C. W. 1992. Plant physiology. 4th edition. Wadsworth Publishing Company. Belmont, California. Inc. ISBN 0-534-15162-0. 758 p.

Schapiro, A., López de Sabando, M., Krog, L. y Arriaga E.. 2015. Cuantificación de la producción de carne y grano, y los efectos en las propiedades físicas y químicas del suelo según variables de pisoteo animal e incorporación de avena (2013-2015). Resumen trigo y cebada INTA Tandil Lobería y Necochea 2014-15. INTA. 19-24 p.

Senisterra G. E. 2014. Influencia del cambio de uso del suelo sobre el escurrimiento superficial. Estudio de caso: cuenca alta del arroyo Napaleofú (Buenos Aires, Argentina). Tesis de maestría en manejo integral de cuencas hidrográficas. Universidad Nacional de La Plata. 132 p.

Senisterra G. E., Rodríguez Vagaría A. M, Gaspari F. J y Mazzucchelli M. G.. 2014. Aspectos morfométricos de la cuenca alta del arroyo Napaleofú (Buenos Aires, Argentina). Revista Geográfica Venezolana. Volumen 55 (2), pp. 287-303.

Serrano, R. M., \& Valcarce, E. V. 2000. Técnicas econométricas para el tratamiento de datos espaciales: la econometría espacial (Vol. 44). Edicions Universitat Barcelona. 160 p.

Tchilinguirian, P; tello, N.; Cavallaro, S. y Fratalocchi C.. 2004. Boletín $\mathrm{N}^{\circ}$ 341. Carta de Línea de Base Ambiental 3760-IV. Tandil. Servicio Geológico Minero Argentino (SEGEMAR). Instituto de Geología y Recursos Minerales. Dirección de Geología Ambiental Aplicada. 131 p.

Uribe, I. A., y Ramírez, C. J. 2009. Hacia Una Metodología Para La Selección De Técnicas De Depuración De Datos. .Avances en Sistemas e Informática, 6(1), pp. 185-190.

Venacio, L. 2007. Globalización, Desarrollo Local y Sociedad Civil. Edición electrónica gratuita. Edición electrónica en www.eumed.net/libros/2007a/222/ 239 p.

Verhulst, N., Govaerts, B., Fuentes Ponce, M. 2010. Sensor portátil GreenSeeker TM para la medición del índice diferencial de vegetación normalizado (NDVI): Una herramienta para la evaluación integral de las prácticas agronómicas. Parte A: Conceptos y estudios de caso. México, D.F.; CIMMYT. 13 p.

Villena Izurieta, N. P. y Manzano Vergara, C. B. 2009. Análisis del Impacto en el Sector Agroalimentario del Ecuador ante el Incremento de sus Exportaciones hacia China. 5 p.

Weber C., Schinca D.C., Tocho J.O. \& Videla F.A. 2008. Passive field reflectance measurements. Journal of Optics A, Pure and Applied Optics, JOPA 10: pp. $104020-$ 104028. 


\section{ANEXOS}

\subsection{Anexo 1. Descripción técnica de los sensores remotos Landsat y Spot.}

\subsubsection{Sensor Spot 5.}

Las imágenes satelitales del sensor Spot 5 obtenidas gracias a la Comisión Nacional de Actividades Espaciales CONAE poseen las características técnicas presentadas en la Tabla 41.

Tabla 41. Especificaciones técnicas del sensor pasivo Spot 5.

Características del Satélite Spot 5

\begin{tabular}{ll}
\hline \hline Órbita & Heliosincrónica \\
\hline Altitud & $832 \mathrm{~km}$ \\
\hline Modo & Multiespectral \\
& Pancromática \\
\hline & B1 (Verde): $500-590 \mathrm{~nm}$ \\
& B2 (Rojo): $610-680 \mathrm{~nm}$ \\
& B3 (Infrarrojo cercano): $790-890$ \\
& $\mathrm{~nm}$ \\
Bandas & B4 (Infrarrojo medio): $1580-1750$ \\
& $\mathrm{~nm}$ \\
& $\mathrm{P}$ (Pancromático): $510-730 \mathrm{~nm}$ \\
\hline Resoluciones & $10-5-2,5 \mathrm{~m}$ \\
\hline Escena & $60 \times 60$ km \\
\hline Revisita & 26 días \\
\hline \multirow{2}{*}{ Ángulos de toma } & Cross-track: + - $27^{\circ}$ \\
& Forward $/$ Backward: $20^{\circ}$ \\
\hline
\end{tabular}

Los tipos de productos disponibles y utilizados para el presente estudio son descritos en la Tabla 42.

Tabla 42. Descripción de las características pertenecientes a las imágenes satelitales Spot 5 utilizadas.

\begin{tabular}{lllc} 
Satélite & Resolución Espacial & Modo Espectral & $\begin{array}{c}\text { Tipo de } \\
\text { Producto }\end{array}$ \\
\hline \hline & $10 \mathrm{~m}$ & Pancromática & $\mathrm{M}$ \\
SPOT 5 & $10 \mathrm{~m}$ & Multiespectral & $\mathrm{J}$ \\
& $5 \mathrm{~m}$ & Pancromática & A o B \\
& $2,5 \mathrm{~m}$ & Pancromática (fusión) & $\mathrm{T}$ \\
& Par estereoscópico $5 \mathrm{~m}$ & Pancromática & A o B \\
\hline
\end{tabular}

\footnotetext{
${ }^{9} \mathrm{M}: 10 \mathrm{~m}$ pancromática (SPOT4), J: $10 \mathrm{~m}$ multiespectral (SPOT5), A o B: 5 m pancromática, T: 2,5 m
} pancromática 
Las imágenes satelitales Spot fueron de gran utilidad para la delimitación de las parcelas, no obstante se obtuvo el NDVI de imágenes satelitales Landsat 8, cuyo sensor poseen una resolución radiométrica adecuada para múltiples estudios en vegetación.

\subsubsection{Sensor Landsat 8.}

Los datos de productos Landsat 8 son totalmente compatibles con todos los datos de los productos estándar a nivel 1 (ortorectificado) creados usando Landsat 1 al Landsat 7 (Ariza, 2013). En la Tabla 43 se describen las especificaciones generales de estos productos.

Tabla 43. Especificaciones técnicas del sensor pasivo Landsat 8.

\begin{tabular}{|c|c|}
\hline Procesamiento & Nivel 1 T-Corrección Geométrica \\
\hline Tamaño de píxel & $\begin{array}{l}\text { - Bandas OLI multiespectrales 1-7,9: 30-metros } \\
\text { - Banda OLI pancromática 8: 15-metros } \\
\text { - Bandas TIRS 10-11: tomadas en } 100 \text { metros, pero remuestreadas a } 30 \\
\text { metros para que coincida con las bandas multiespectrales de OLI }\end{array}$ \\
\hline $\begin{array}{l}\text { Características de } \\
\text { los datos }\end{array}$ & $\begin{array}{l}\text { - Formato de datos GeoTIFF } \\
\text { - Remuestreo por convolución cúbica (CC) } \\
\text { - Norte arriba (MAP) de orientación } \\
\text { - Proyección cartográfica: Universal Transversal Mercator (UTM) } \\
\text { - (estereográfica polar de la Antártida) } \\
\text { - } 12 \text { metros de error circular, 90\% de confianza exactitud global para OLI } \\
\text { - } 41 \text { metros de error circular, } 90 \% \text { de confianza exactitud global para TIRS } \\
\text { - Los valores de píxel en } 16 \text { bits }\end{array}$ \\
\hline Entrega de datos & Archivo comprimido .Tar.gz y de descarga a través de HTTP \\
\hline Tamaño de archivo & $\begin{array}{l}\text { Aproximadamente } 1 \text { GB (comprimido), aproximadamente } 2 \text { GB (sin } \\
\text { comprimir) }\end{array}$ \\
\hline
\end{tabular}

Las características de la resolución radiométrica (11 bandas) y espacial de las imágenes satelitales de Landsat 8 se muestran en la Tabla 44. 
Tabla 44. Descripción de las bandas espectrales del sensor Landsat 8 OLI y TIRS.

Longitud de Onda Resolución Espacial

Descripción de la Banda

$(\mu \mathrm{m})$

\begin{tabular}{lcc}
\hline \hline Band 1 - Azul 1 & $0.43-0.45$ & 30 \\
Band 2 - Azul 2 & $0.45-0.51$ & 30 \\
Band 3 - Verde & $0.53-0.59$ & 30 \\
Band 4 - Rojo & $0.64-0.67$ & 30 \\
Band 5 - Infrarrojo cercano (NIR) & $0.85-0.88$ & 30 \\
Band 6 - Infrarrojo banca corta & & \\
(SWIR) 1 & $1.57-1.65$ & 30 \\
Band 7 - Infrarrojo banca corta & & \\
(SWIR) 2 & $2.11-2.29$ & 30 \\
Band 8 - Pancromático & $0.50-0.68$ & 30 \\
Band 9 - Cirrus & $1.36-1.38$ & 30 \\
Band 10 - Infrarrojo térmico (TIRS) 1 & $10.60-11.19$ & 100 \\
Band 11 - Infrarrojo térmico (TIRS) 2 & $11.50-12.51$ & 100 \\
\hline Landsat 8 Operational Land Imager (OLI) and Thermal Infrared Sensor (TIRS). Fuente: USGS 2013.
\end{tabular}


9.2 Anexo 2. Gráficos de dispersión de valores NDVI vs Rendimiento. Metodología a nivel pixel.

\section{Parcela 3 (Cebada).}

Julio 28

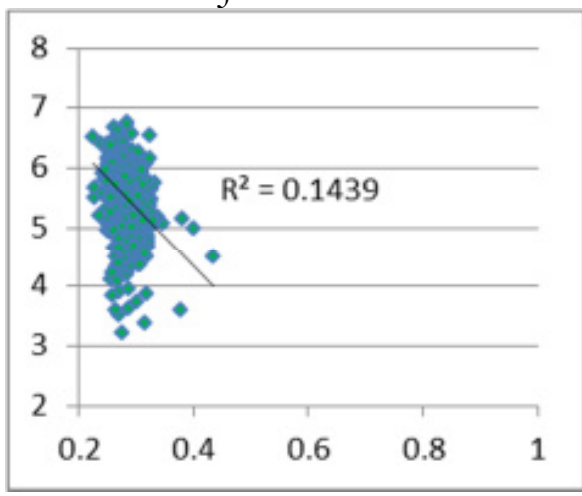

Noviembre 17
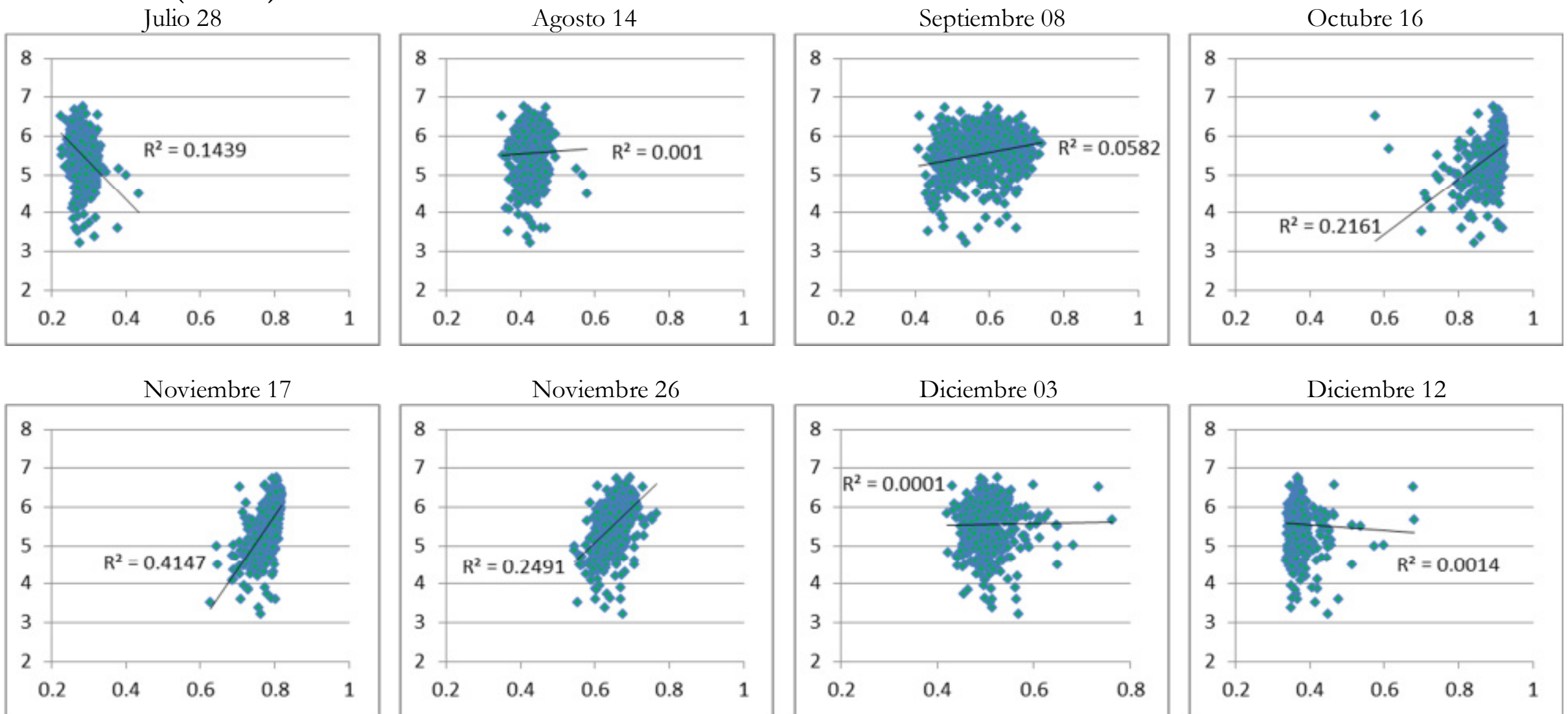

fechas establecidas según la metodología a nivel pixel.

Nota: eje abscisas: valores NDVI; eje ordenadas: valores rendimiento de productividad (tn/ha) Fuente: elaboración propia

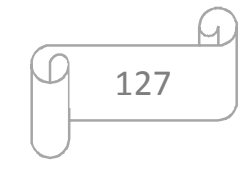




\section{Parcela 4 (Cebada).}

Julio 28

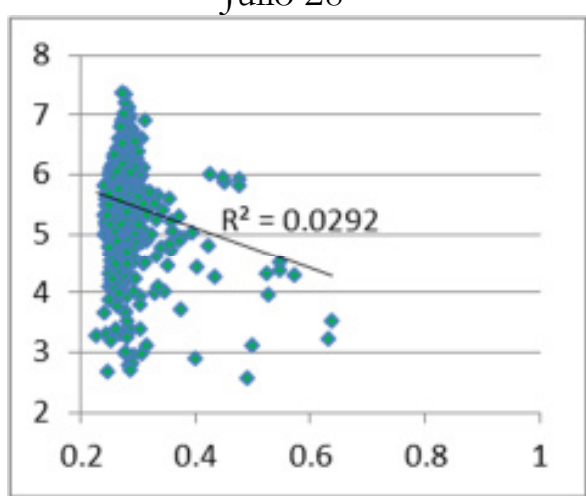

Noviembre 17

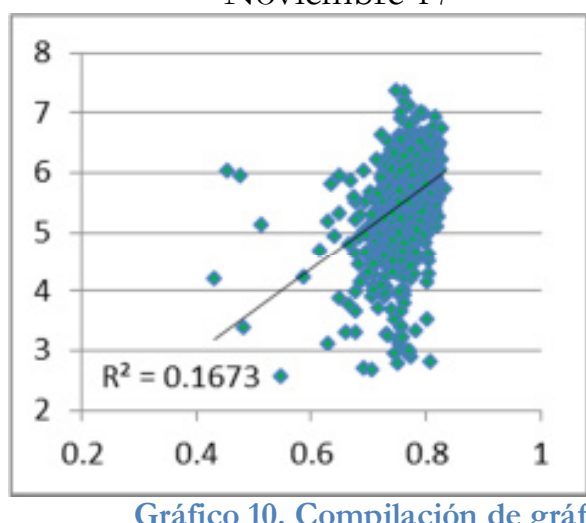

Agosto 14

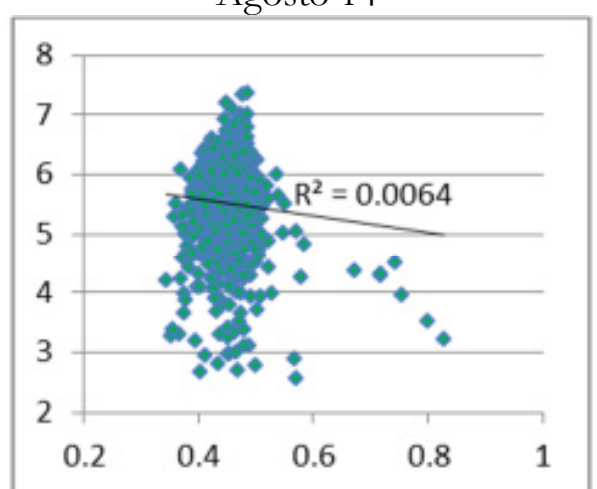

Noviembre 26

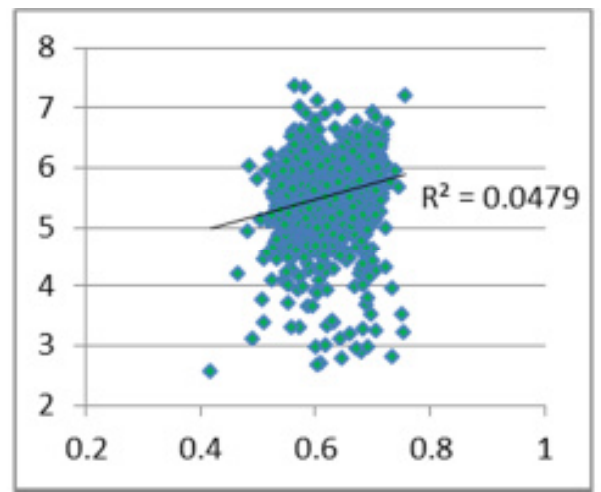

Septiembre 08

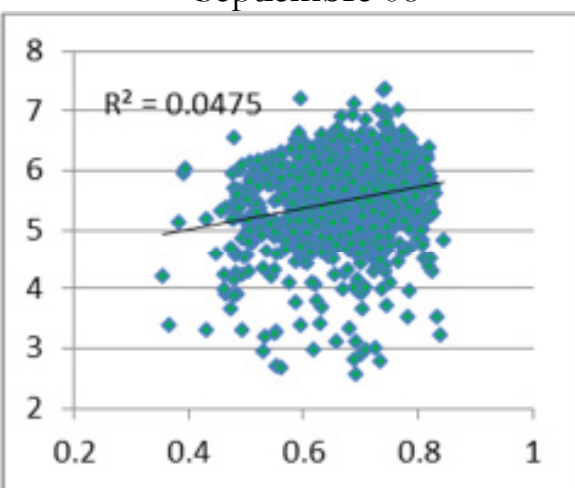

Diciembre 03

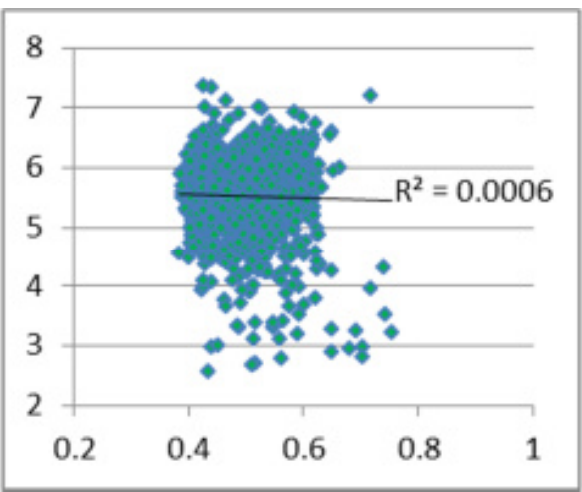

Octubre 16

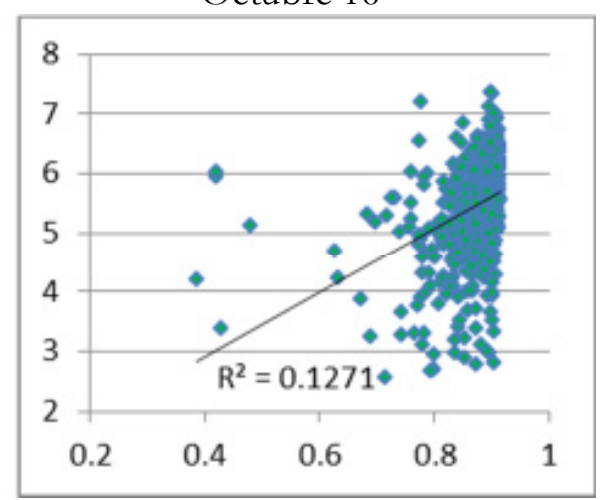

Diciembre 12

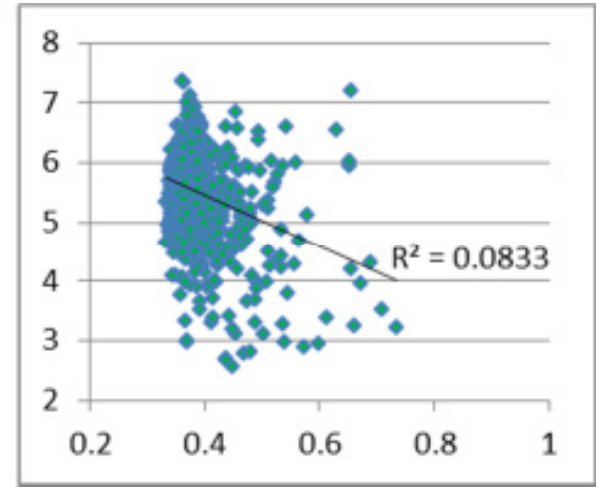

fechas establecidas según la metodología a nivel pixel.

Nota: eje abscisas: valores NDVI; eje ordenadas: valores rendimiento de productividad (tn/ha).

Fuente: elaboración propia.

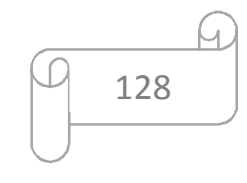




\section{Parcela 5 (Cebada).}

Julio 28

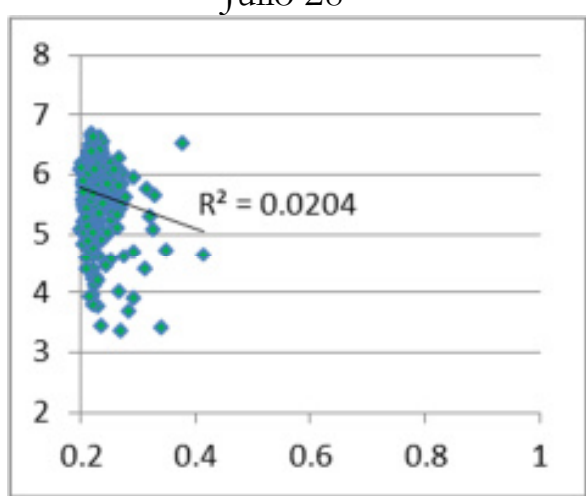

Noviembre 17

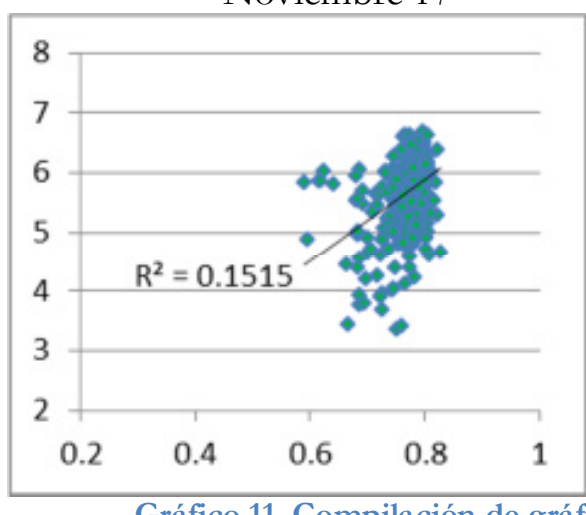

Agosto 14

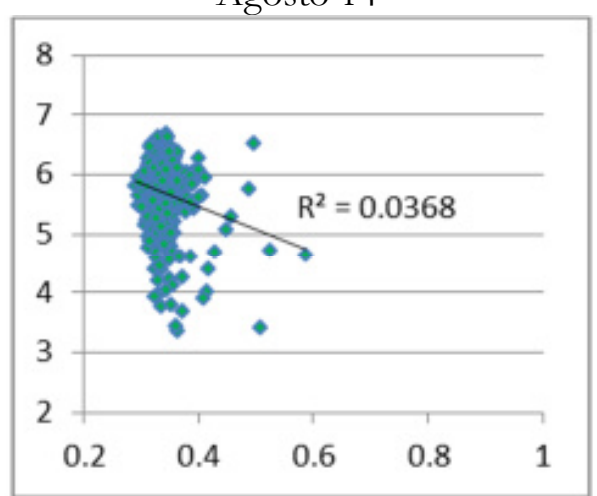

Noviembre 26

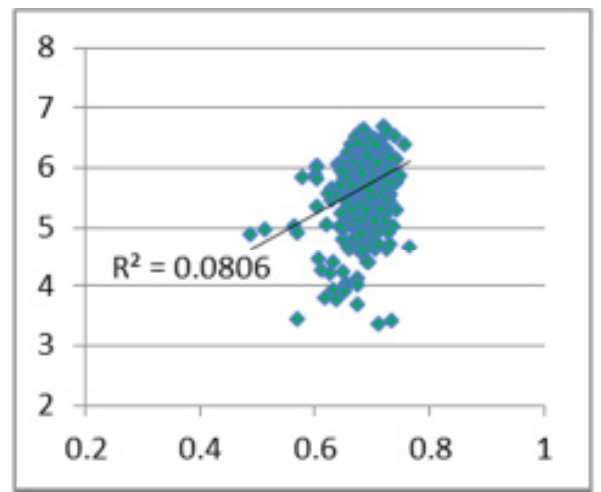

Septiembre 08

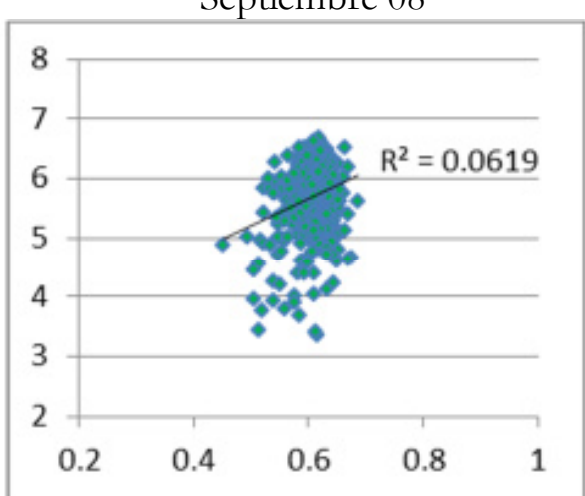

Diciembre 03

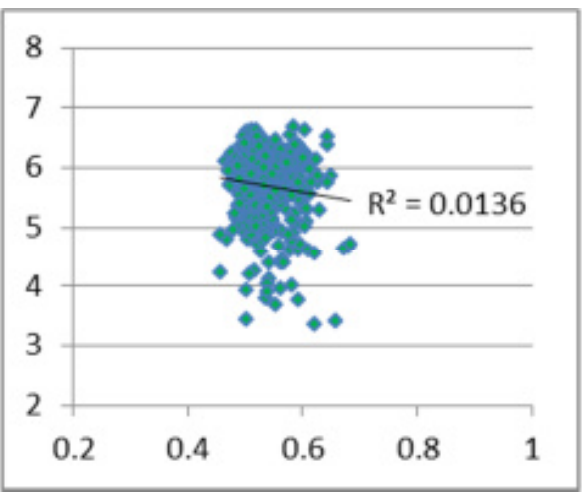

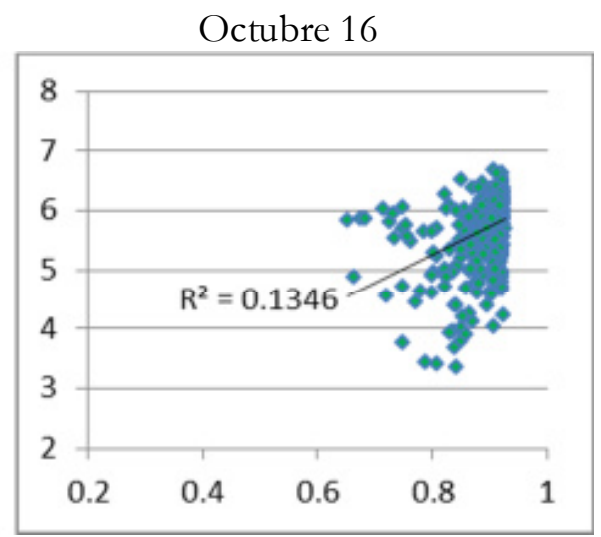

Diciembre 12

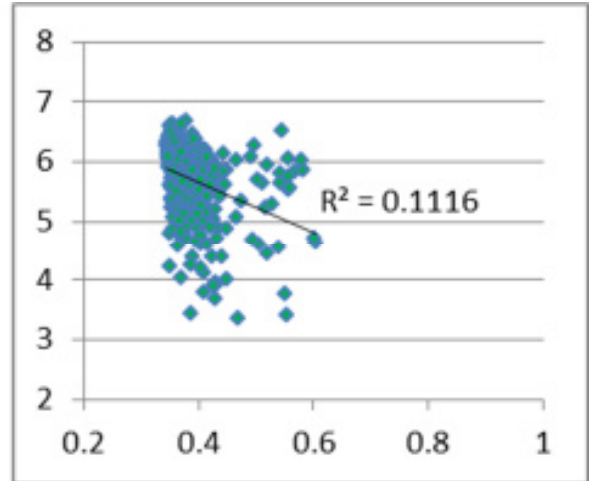

fechas establecidas según la metodología a nivel pixel.

Nota: eje abscisas: valores NDVI; eje ordenadas: valores rendimiento de productividad (tn/ha).

Fuente: elaboración propia.

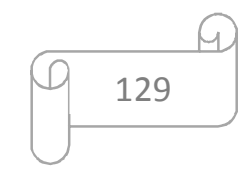




\section{Parcela 0 (Trigo).}

Julio 28

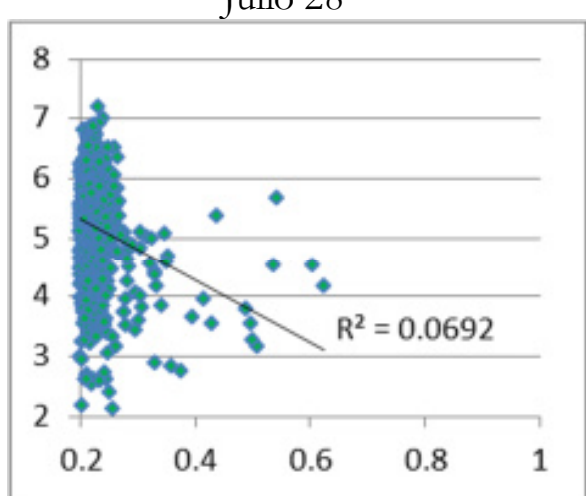

Noviembre 17

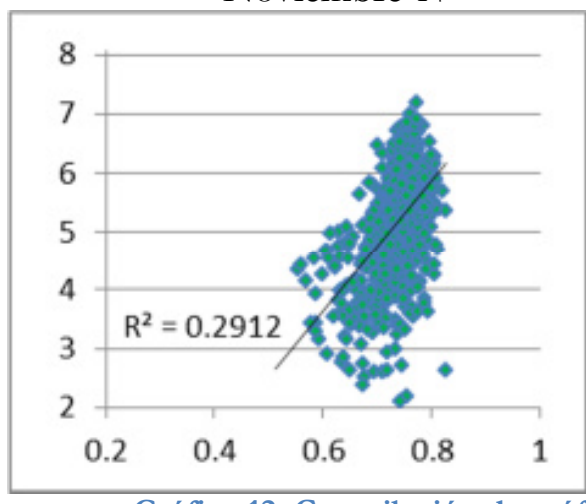

Agosto 14

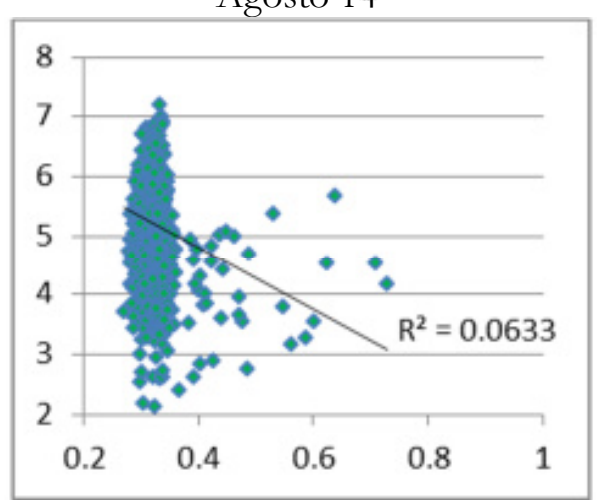

Noviembre 26

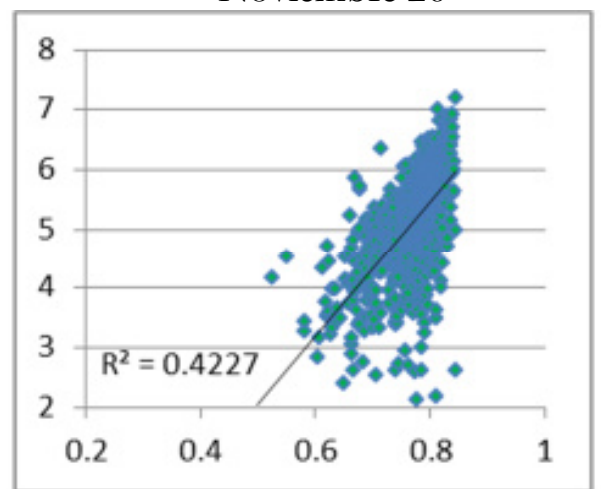

Septiembre 08

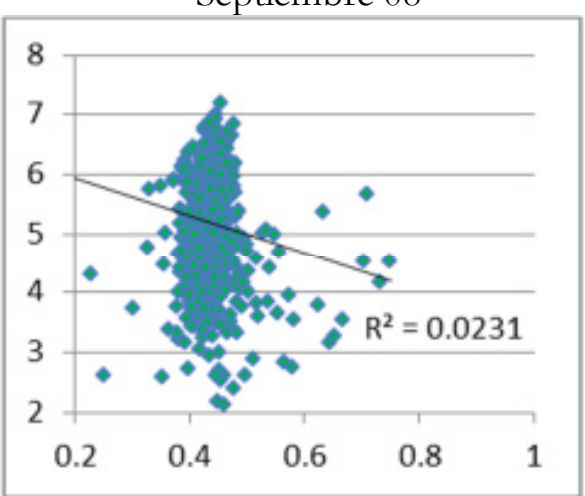

Diciembre 03

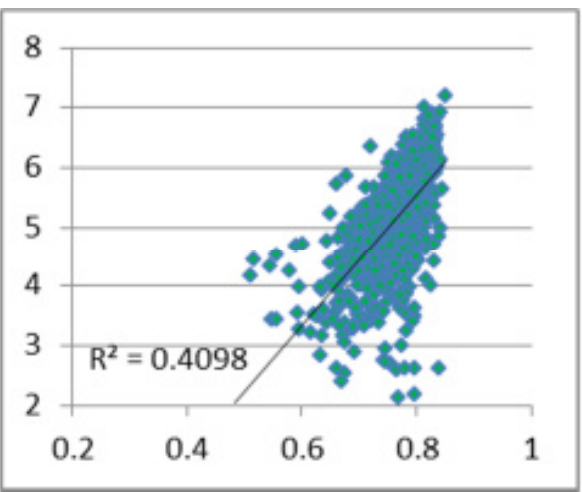

Octubre 16

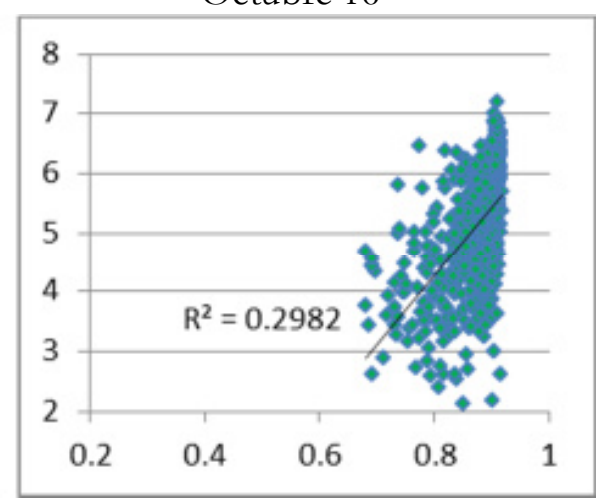

Diciembre 12

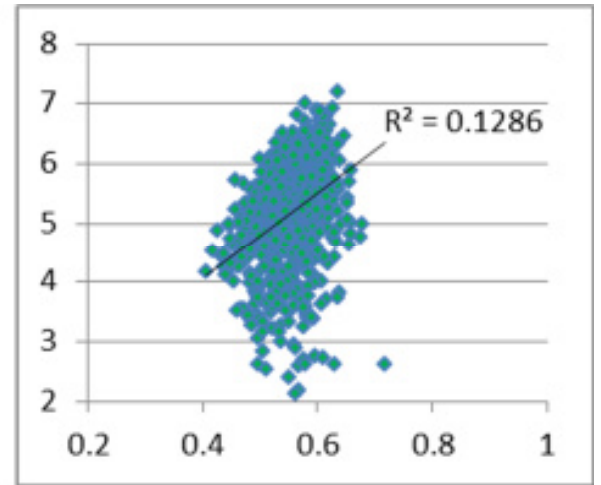

Gráfico 12. Compilación de gráficos de dispersión entre los valores de NDVI y puntos de rendimiento ju
fechas establecidas según la metodología a nivel pixel.

Nota: eje abscisas: valores NDVI; eje ordenadas: valores rendimiento de productividad (tn/ha).

Fuente: elaboración propia.

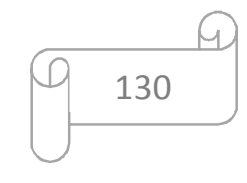




\section{Parcela 2 (Trigo).}

Julio 28

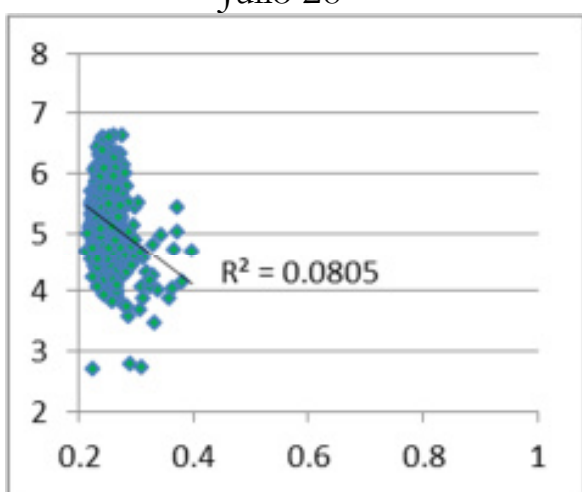

Noviembre 17

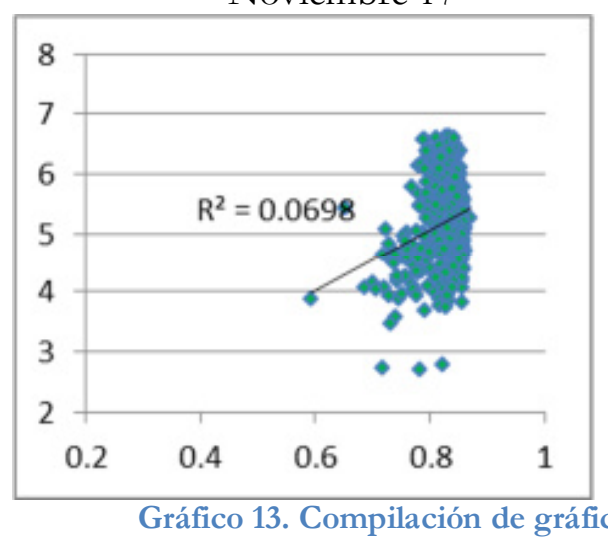

Agosto 14

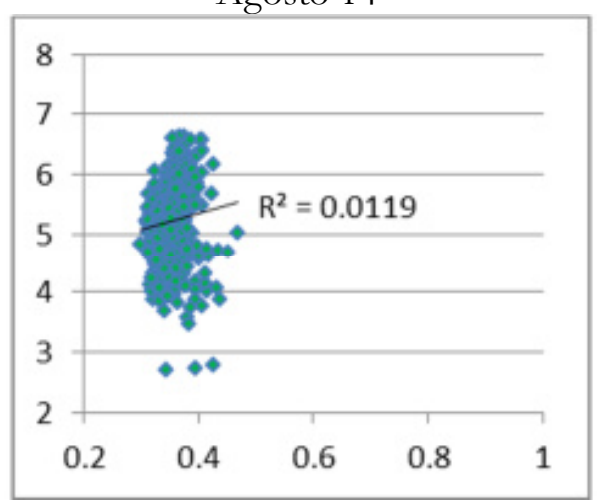

Noviembre 26

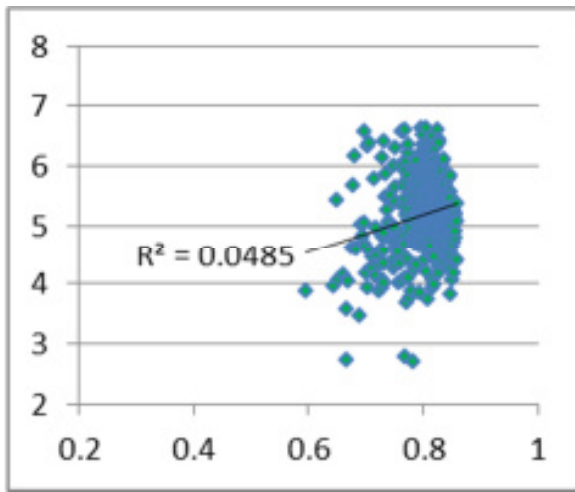

Septiembre 08

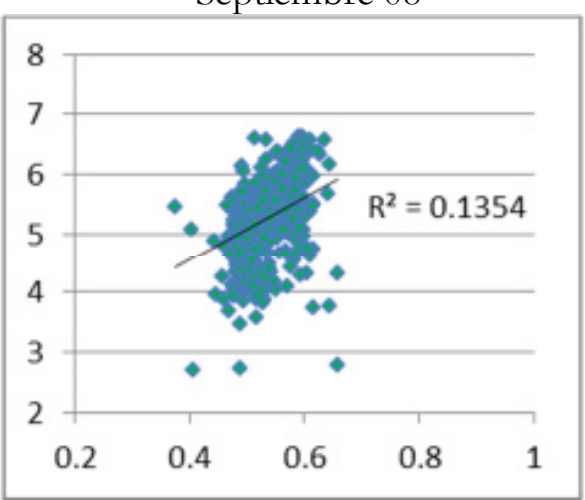

Diciembre 03

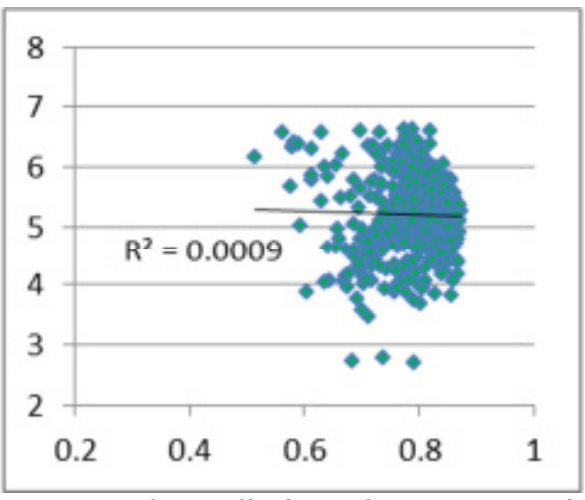

Octubre 16

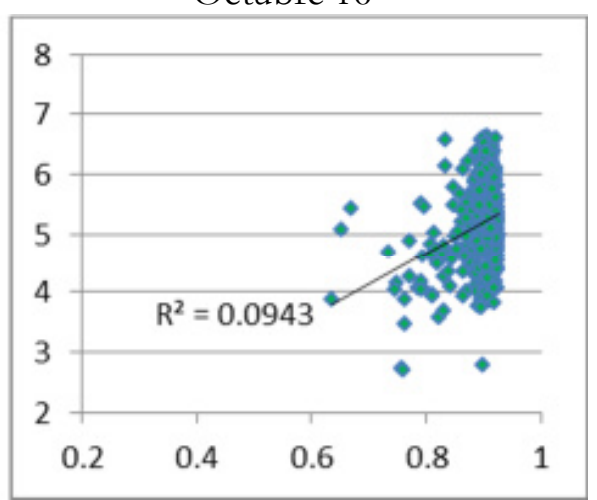

Diciembre 12

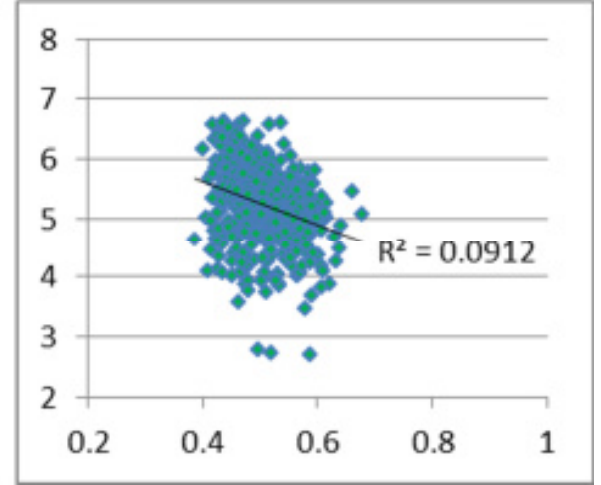

sión entre los valores de NDVI y puntos de rendimiento j
fechas establecidas según la metodología a nivel pixel.

Nota: eje abscisas: valores NDVI; eje ordenadas: valores rendimiento de productividad (tn/ha).

Fuente: elaboración propia.

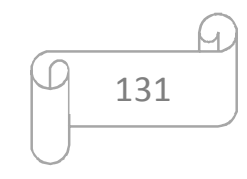




\section{Parcela 6 (Trigo).}

Julio 28

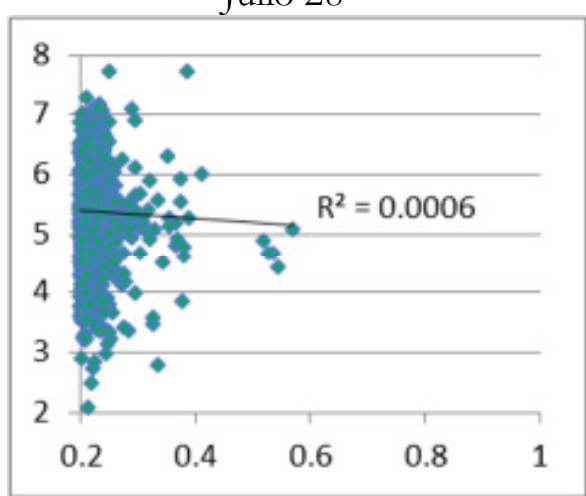

Noviembre 26

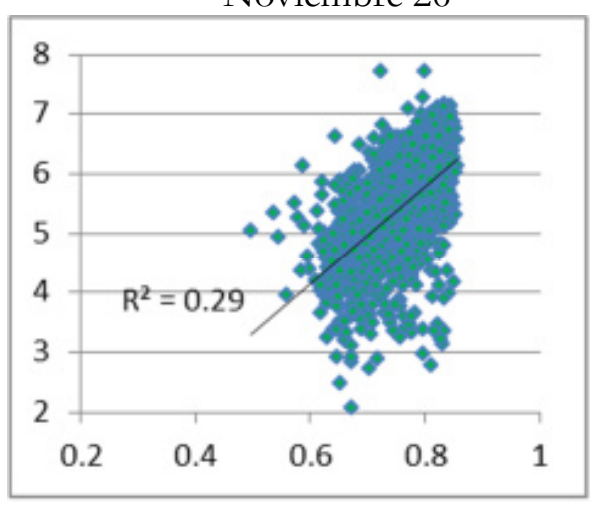

Agosto 14

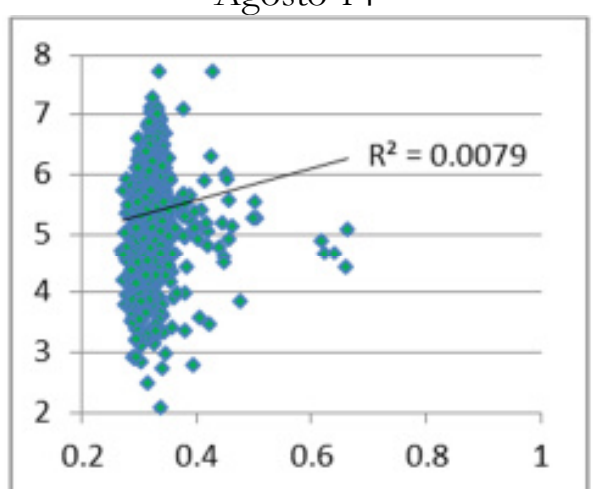

Diciembre 03

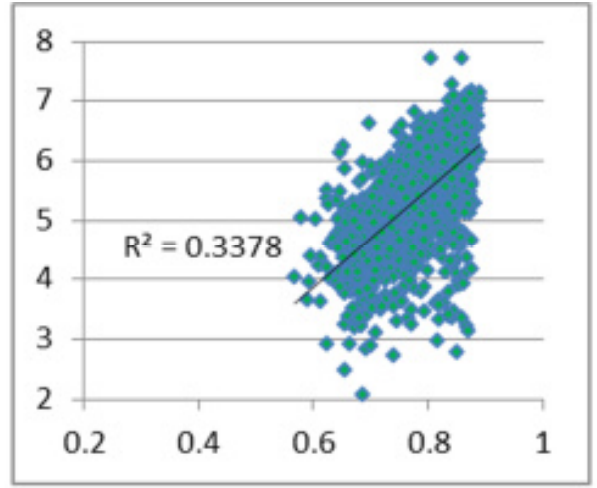

Septiembre 08

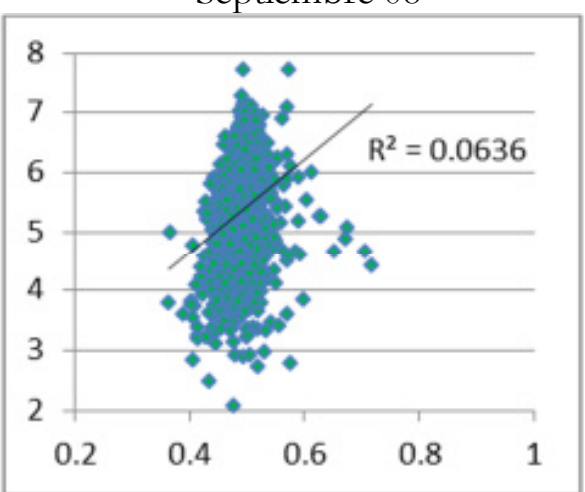

Diciembre 12

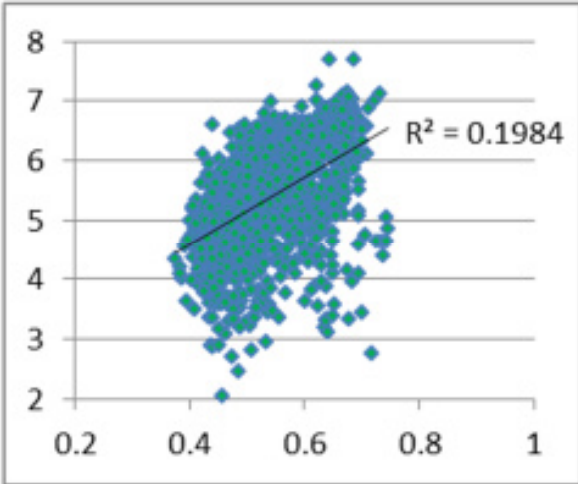

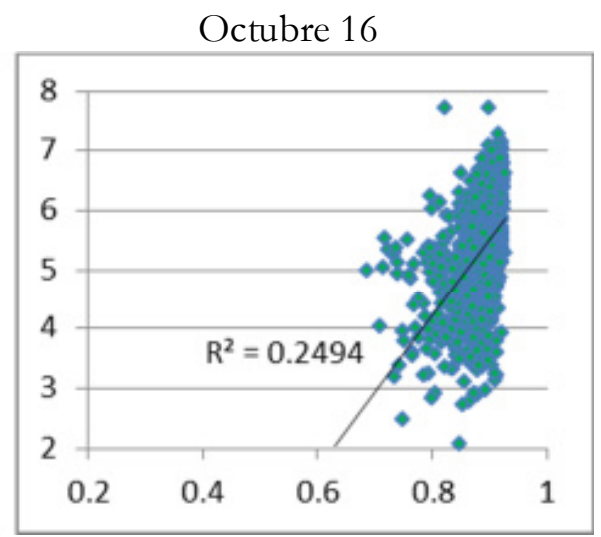

Gráfico 14. Compilación de gráficos de dispersión entre los valores de NDVI y puntos de rendimiento junto con su ajuste lineal para la parcela 6 en las fechas establecidas según la metodología a nivel pixel.

Nota: eje abscisas: valores NDVI; eje ordenadas: valores rendimiento de productividad (tn/ha).

Fuente: elaboración propia. 


\section{Parcela 7 (Trigo).}

Julio 28

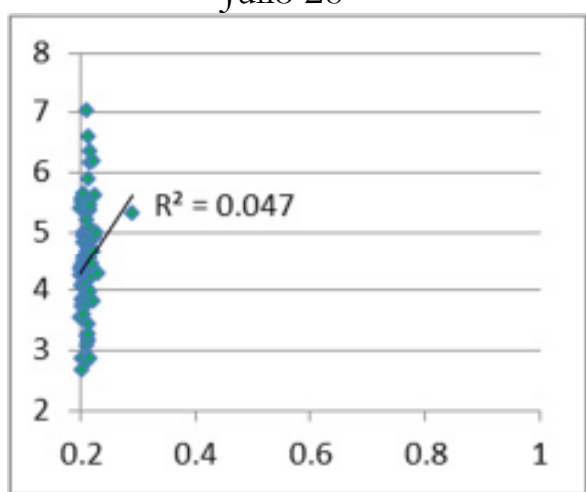

Noviembre 26

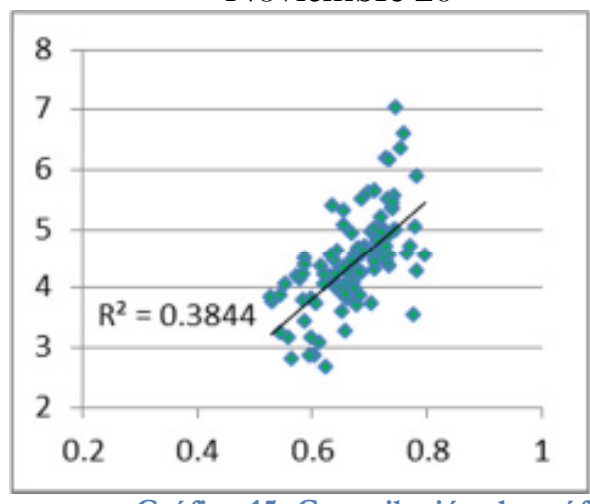

Agosto 14

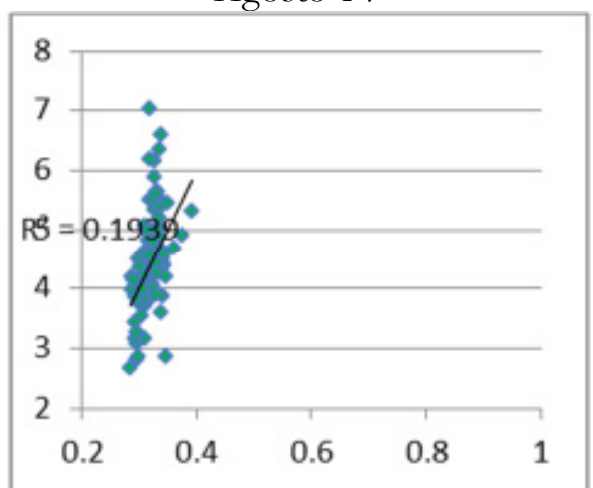

Diciembre 03

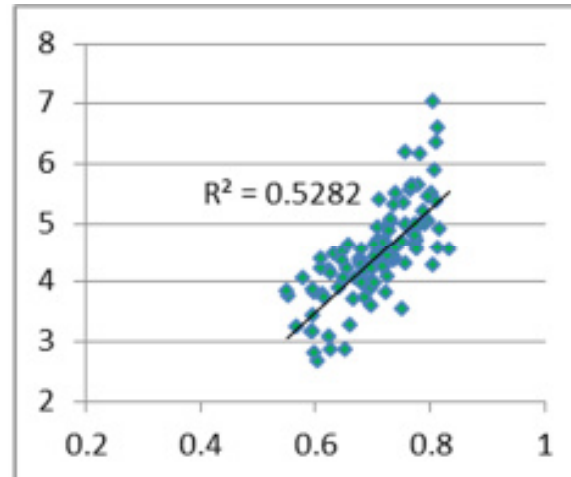

Septiembre 08

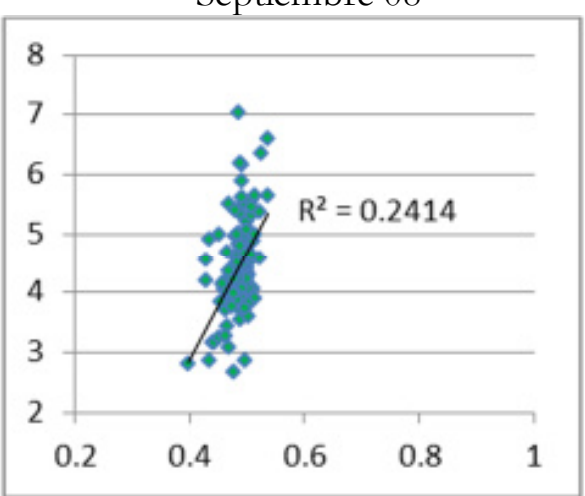

Diciembre 12

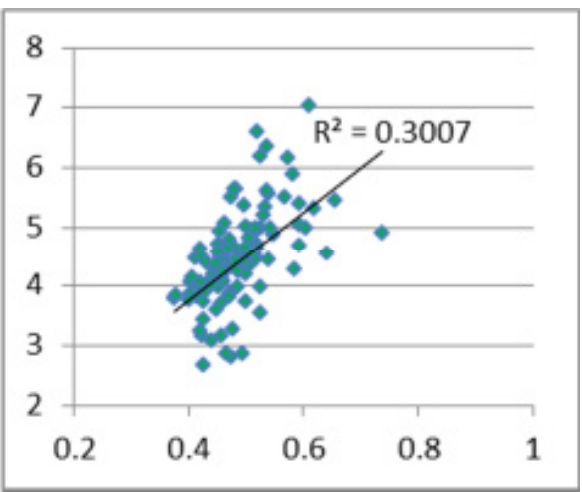

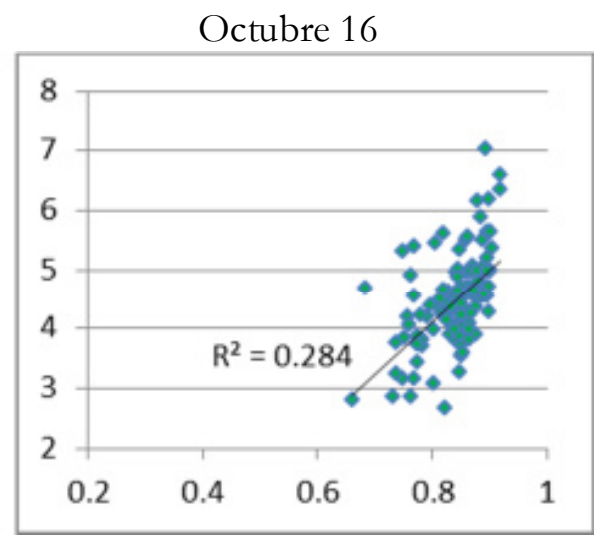

Gráfico 15. Compilación de gráficos de dispersión entre los valores de NDVI y puntos de rendimiento junto con su ajuste lineal para la parcela 7 en las fechas establecidas según la metodología a nivel pixel.

Nota: eje abscisas: valores NDVI; eje ordenadas: valores rendimiento de productividad (tn/ha).

Fuente: elaboración propia.

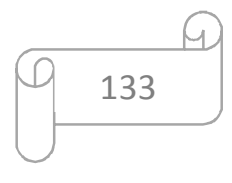




\subsection{Anexo 3. Gráficos de dispersión de valores NDVI vs Rendimiento. Metodología a nivel zonal.}

\section{Parcela 3 (Cebada).}
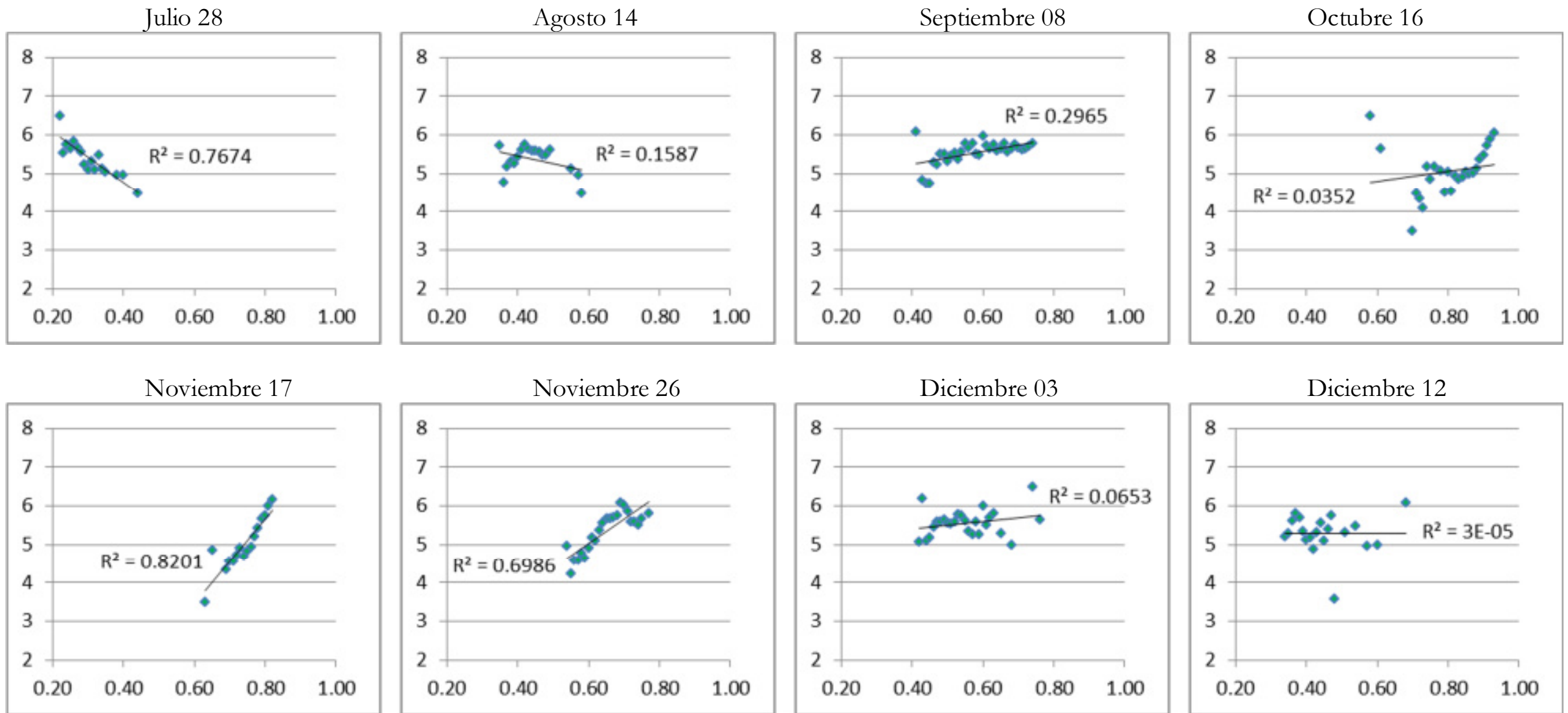

Gráfico 16. Compilación de gráficos de dispersión entre los valores de NDVI zonales y sus promedios de puntos de rendimiento junto con su ajuste lineal

para la parcela 3 en las fechas establecidas según la metodología a nivel zonal.

Nota: eje abscisas: valores NDVI; eje ordenadas: valores rendimiento de productividad (tn/ha). Fuente: elaboración propia.

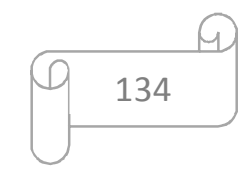




\section{Parcela 4 (Cebada).}

Julio 28

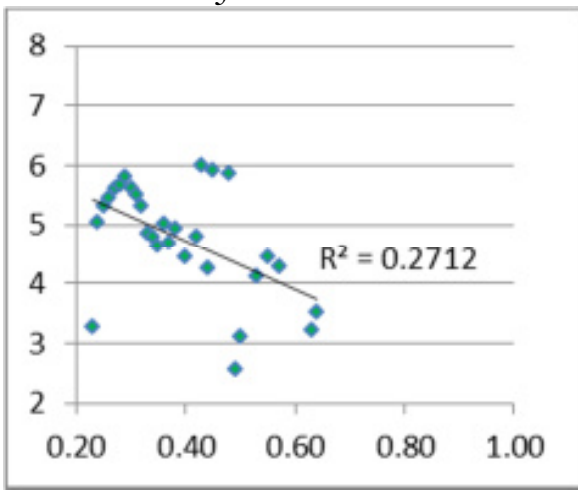

Noviembre 17

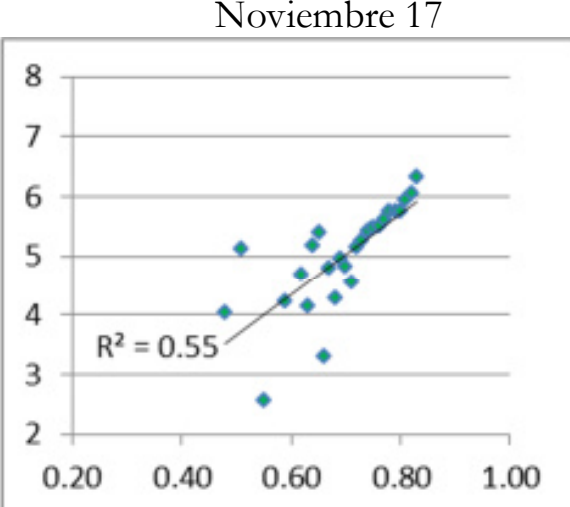

Agosto 14

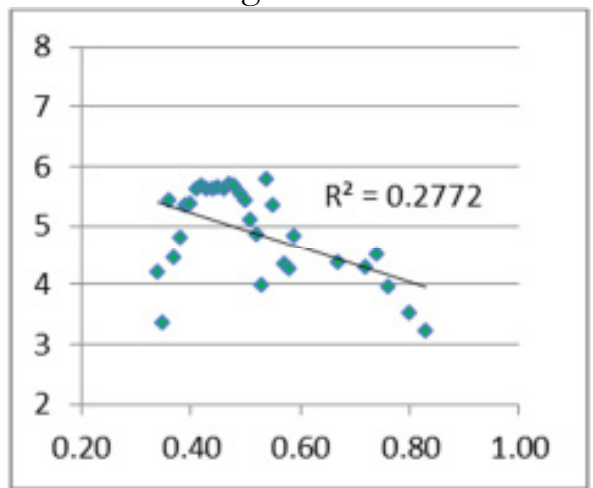

Noviembre 26

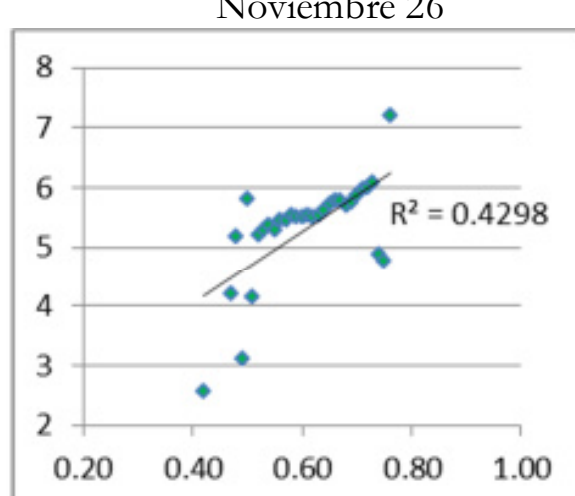

Septiembre 08

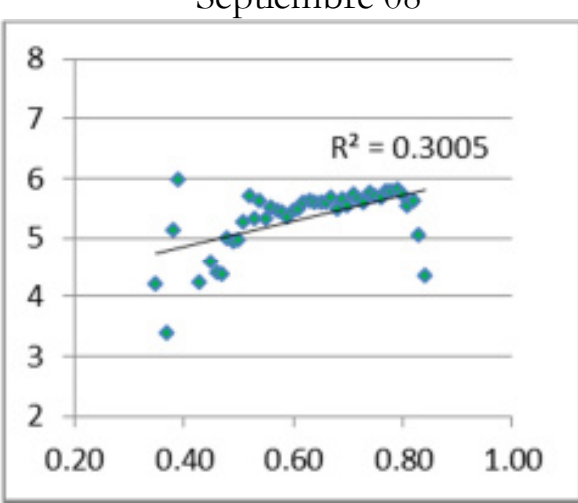

Diciembre 03

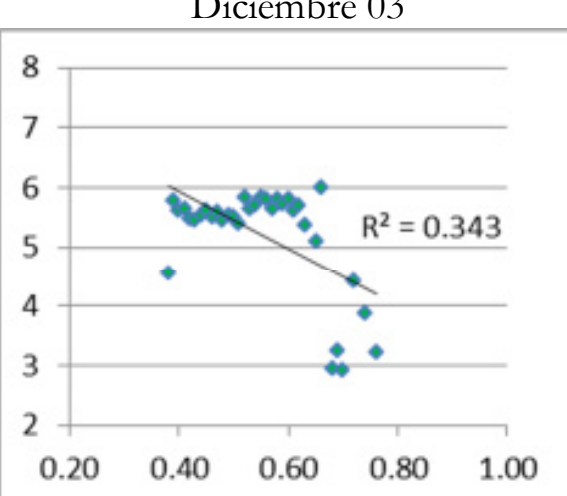

Octubre 16

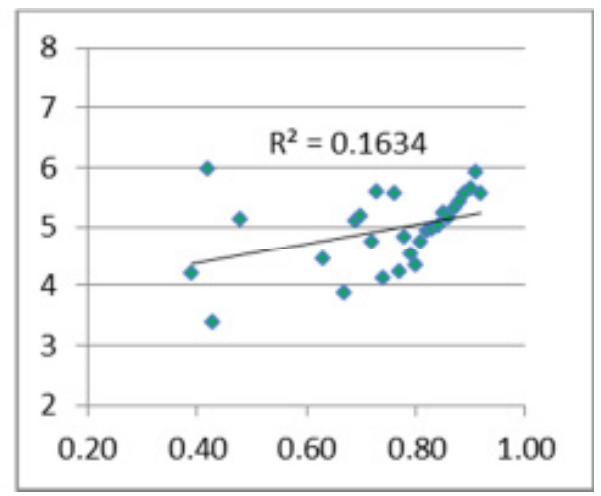

Diciembre 12

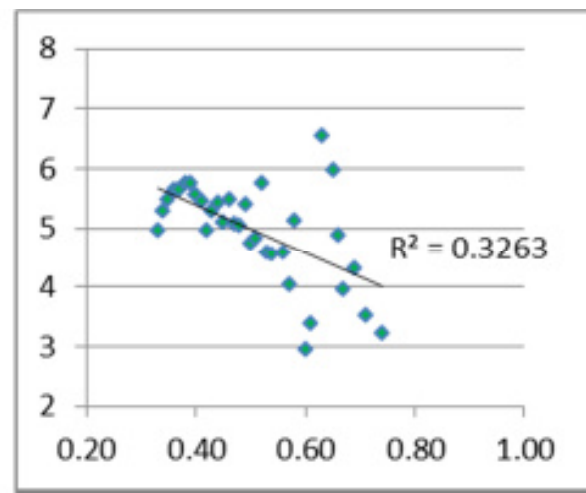

Gráfico 17. Compilación de gráficos de dispersión entre los valores de NDVI zonales y sus promedios de puntos de rendimiento junto con su ajuste lineal para la parcela 4 en las fechas establecidas según la metodología a nivel zonal.

Nota: eje abscisas: valores NDVI; eje ordenadas: valores rendimiento de productividad (tn/ha).

Fuente: elaboración propia.

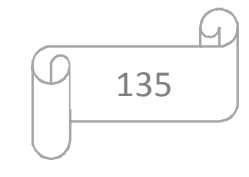




\section{Parcela 5 (Cebada).}
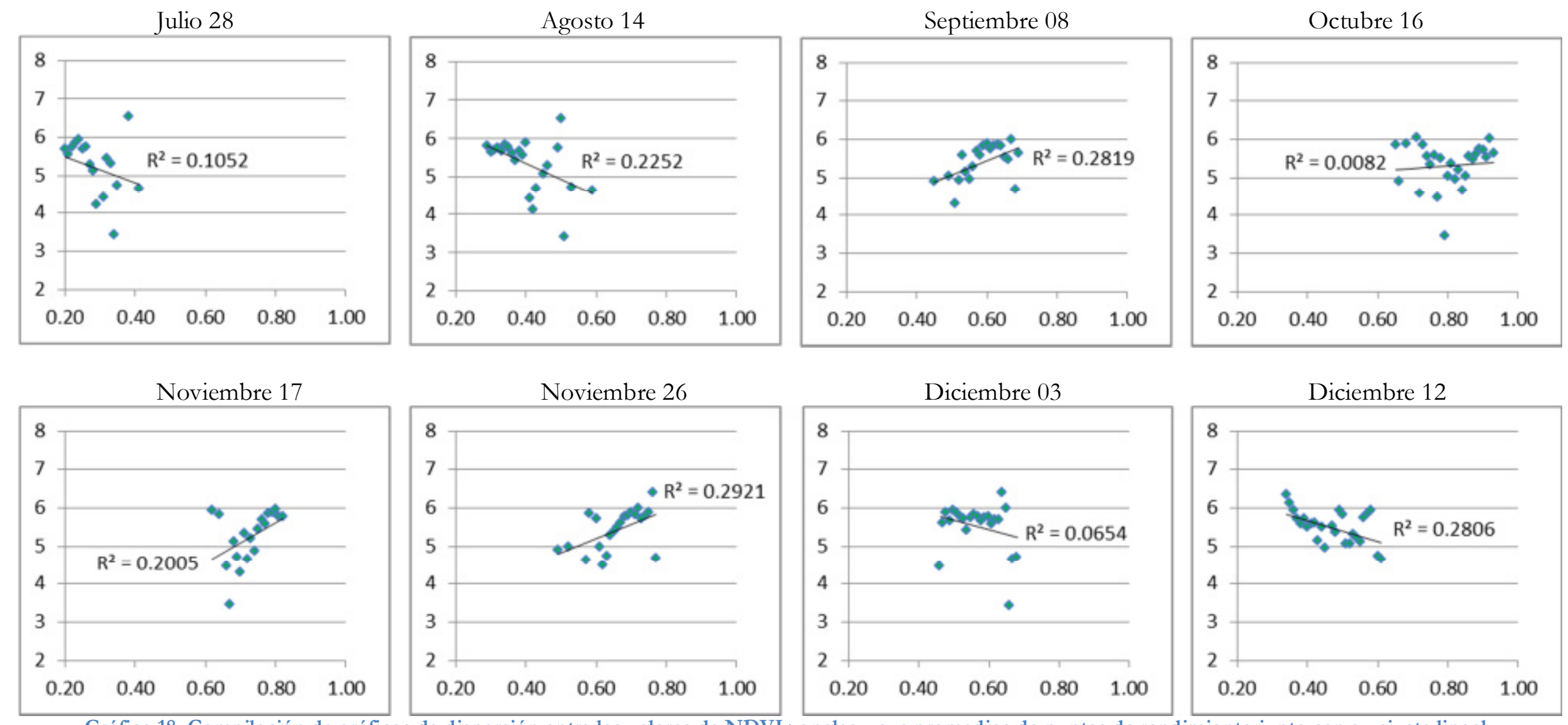

para la parcela 5 en las fechas establecidas según la metodología a nivel zonal.

Nota: eje abscisas: valores NDVI; eje ordenadas: valores rendimiento de productividad (tn/ha).

Fuente: elaboración propia. 


\section{Parcela 0 (Trigo).}

Julio 28

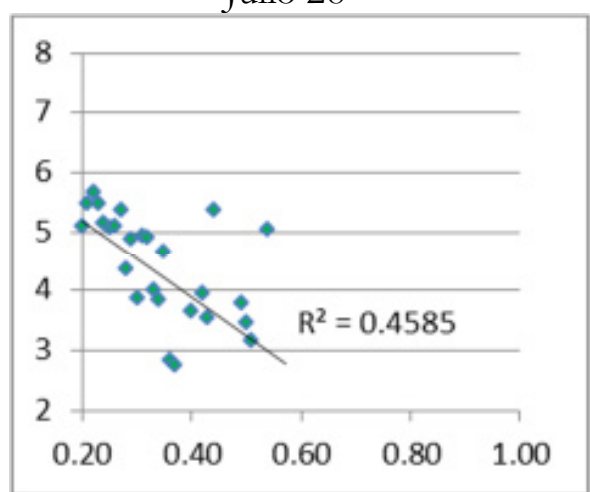

Noviembre 17

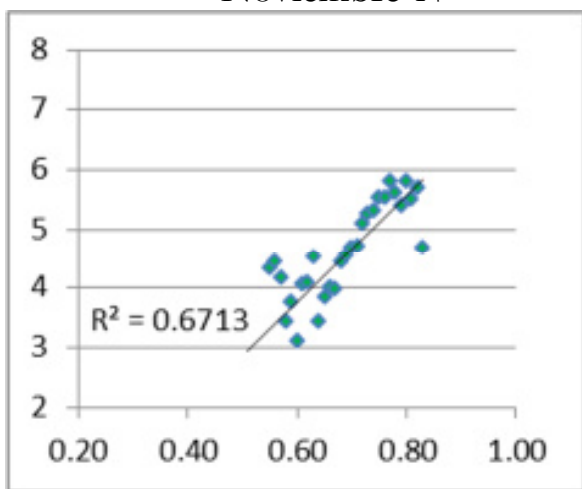

Agosto 14

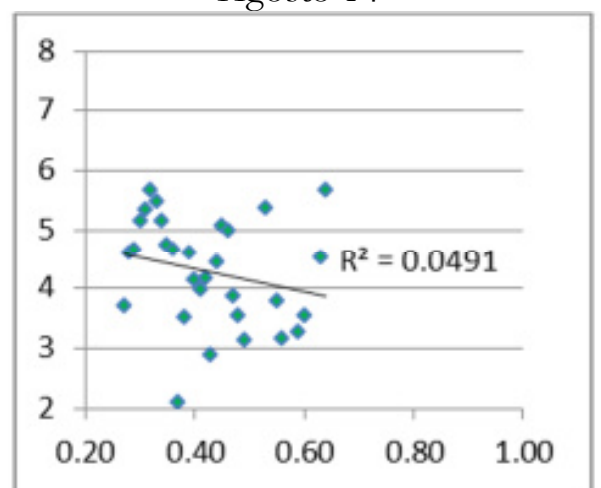

Septiembre 08

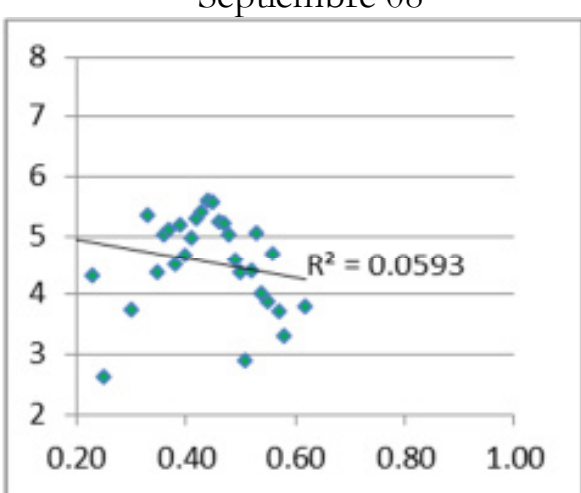

Octubre 16

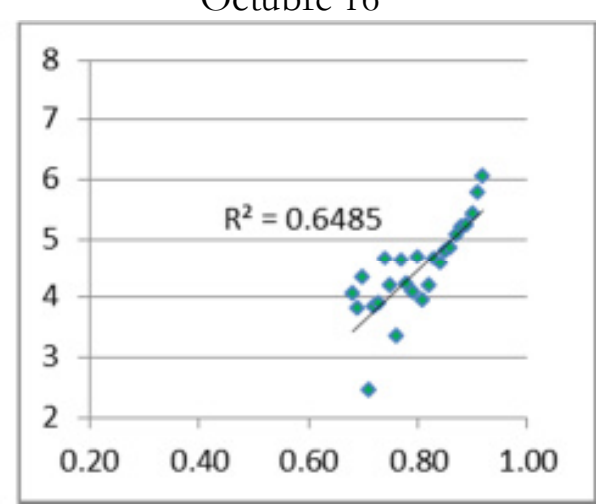

Diciembre 12

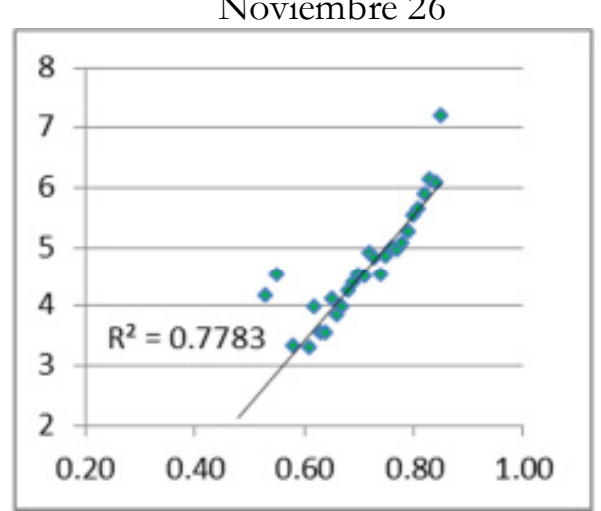

Diciembre 03

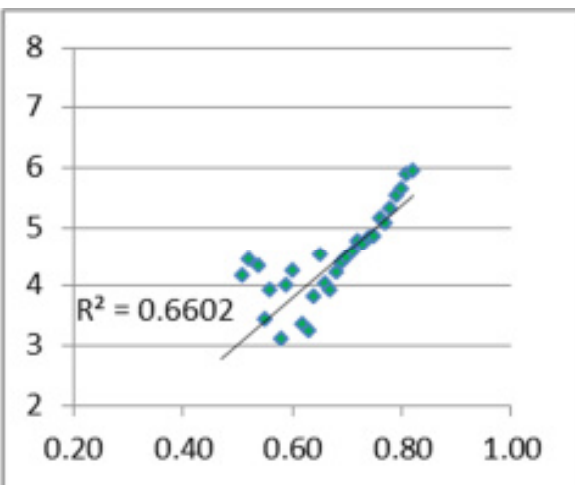

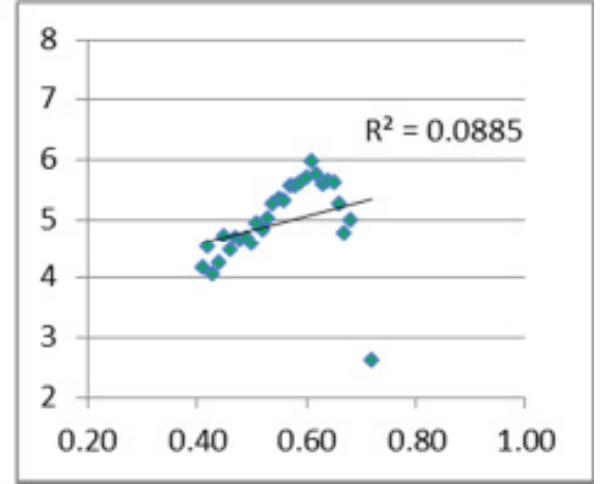

Gráfico 19. Compilación de gráficos de dispersión entre los valores de NDVI zonales y sus promedios de puntos de re
para la parcela 0 en las fechas establecidas según la metodología a nivel zonal.

Nota: eje abscisas: valores NDVI; eje ordenadas: valores rendimiento de productividad (tn/ha).

Fuente: elaboración propia.

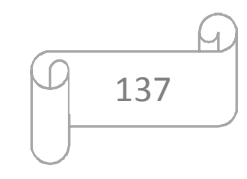




\section{Parcela 2 (Trigo)}

Julio 28

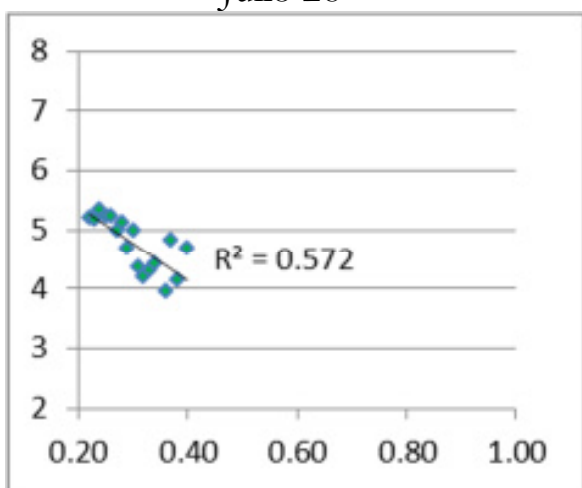

Noviembre 17

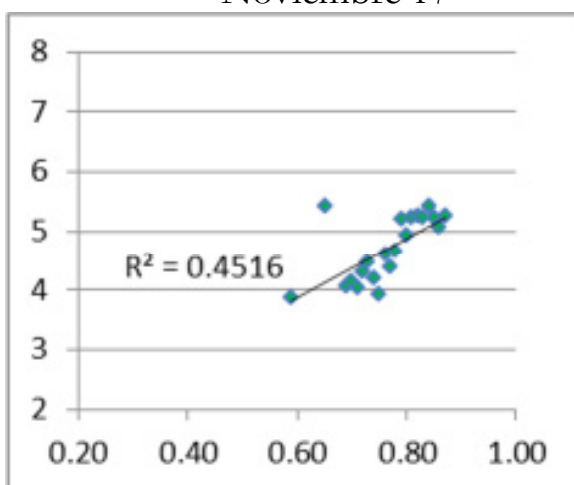

Agosto 14

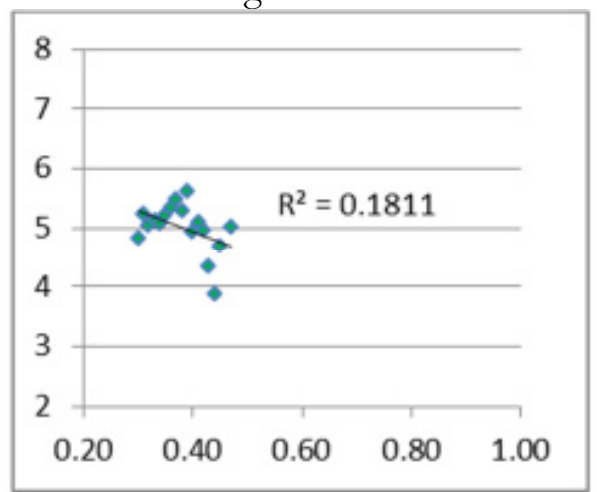

Noviembre 26

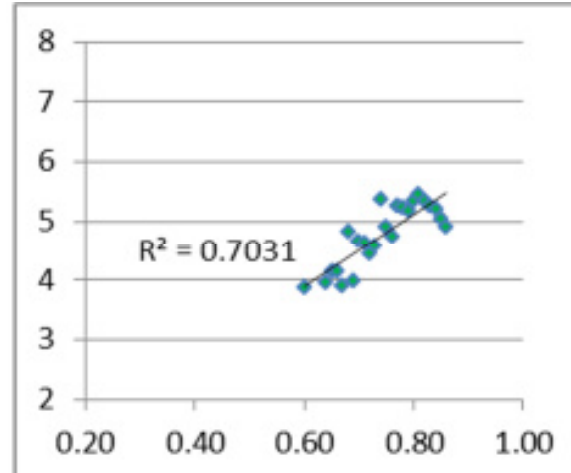

Septiembre 08

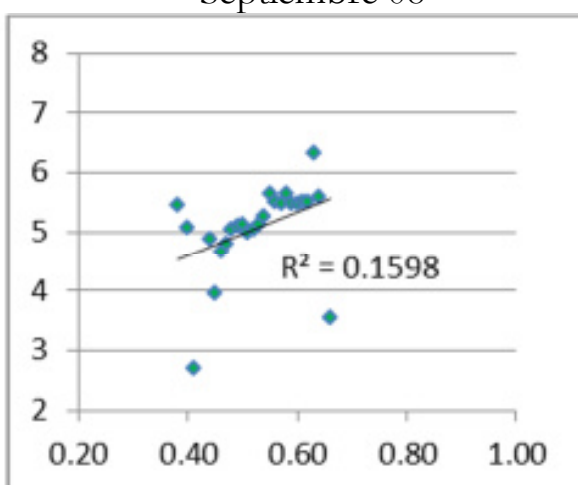

Diciembre 03

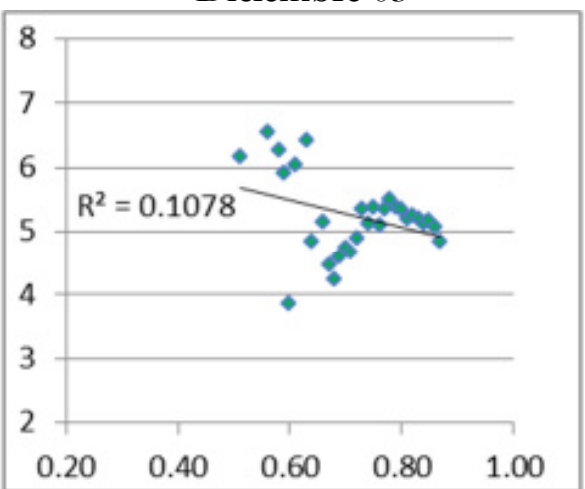

Octubre 16

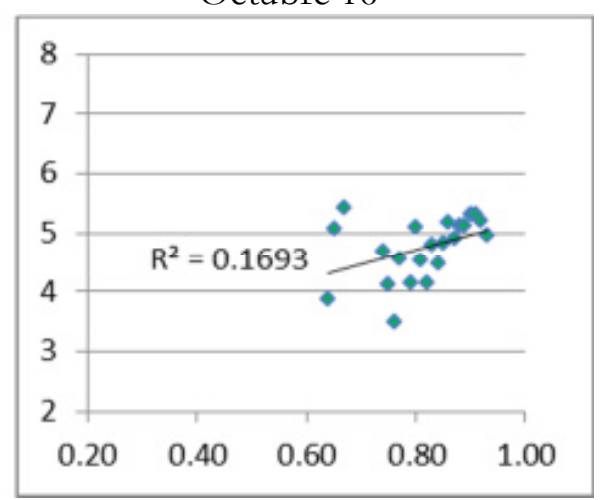

Diciembre 12

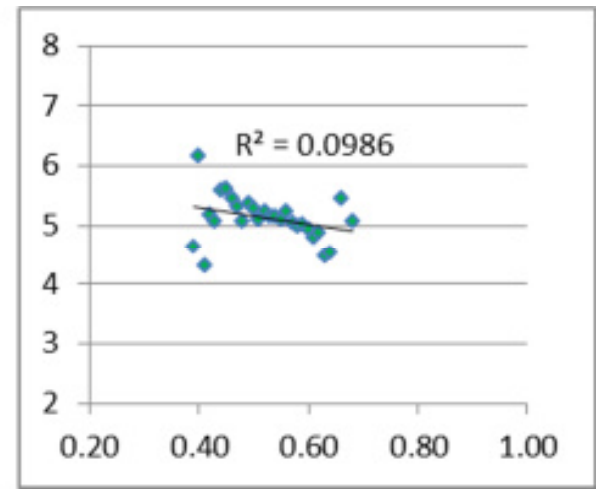

Gráfico 20. Compilación de gráficos de dispersión entre los valores de NDVI zonales y sus promedios de puntos de rendimiento junto con su ajuste lineal para la parcela 2 en las fechas establecidas según la metodología a nivel zonal.

Nota: eje abscisas: valores NDVI; eje ordenadas: valores rendimiento de productividad (tn/ha).

Fuente: elaboración propia.

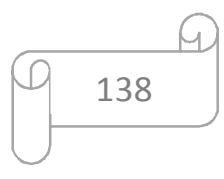




\section{Parcela 6 (Trigo).}

Julio 28

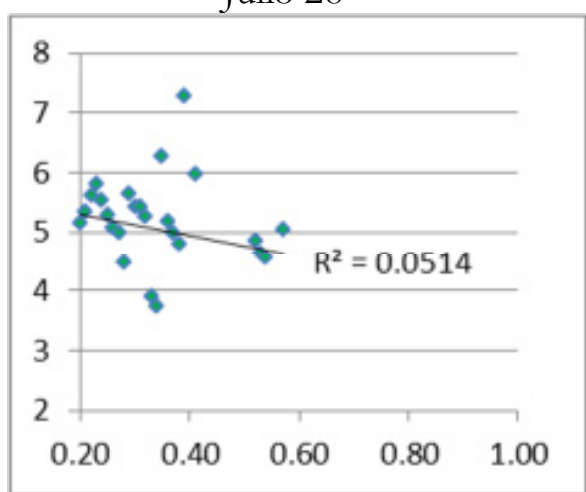

Noviembre 26

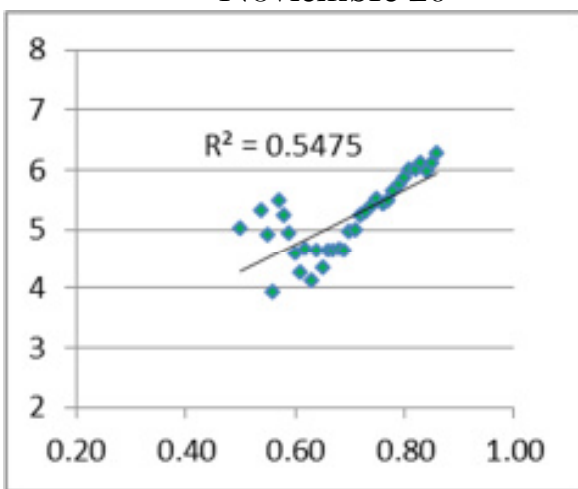

Agosto 14

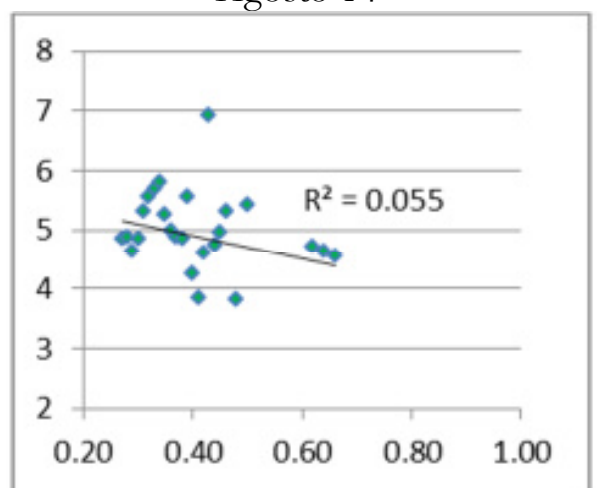

Septiembre 08

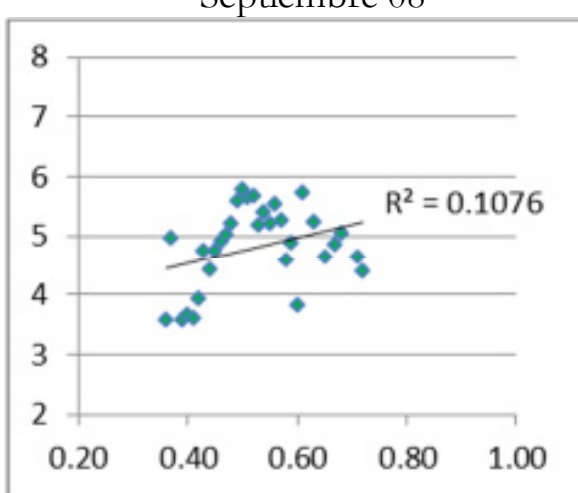

Octubre 16

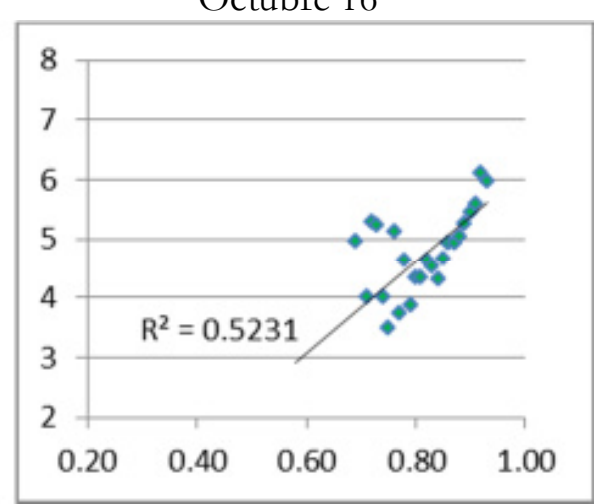

Diciembre 12
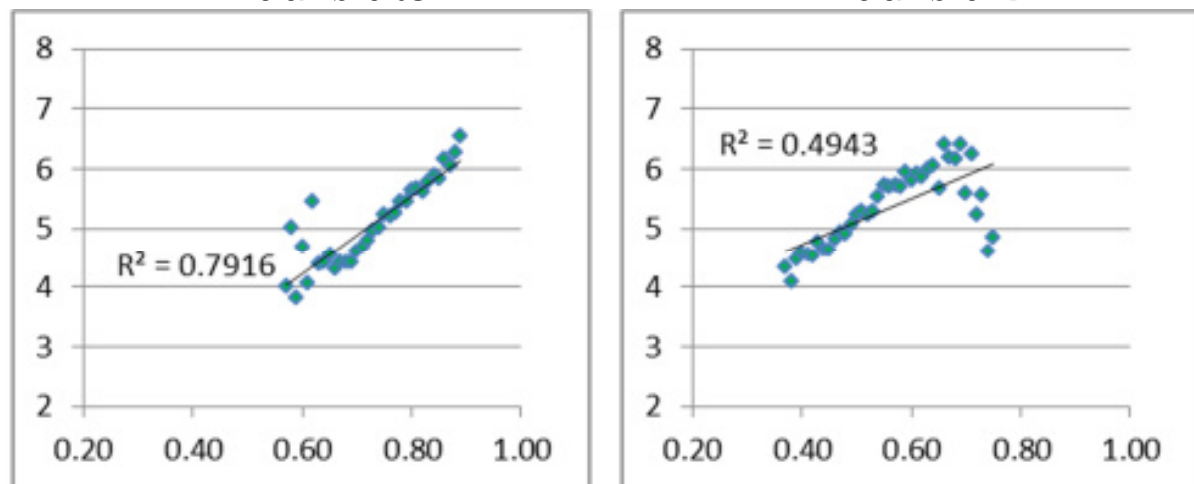

Gráfico 21. Compilación de gráficos de dispersión entre los valores de NDVI zonales y sus promedios de puntos de rendimiento junto con su ajuste lineal para la parcela 6 en las fechas establecidas según la metodología a nivel zonal.

Nota: eje abscisas: valores NDVI; eje ordenadas: valores rendimiento de productividad (tn/ha).

Fuente: elaboración propia.

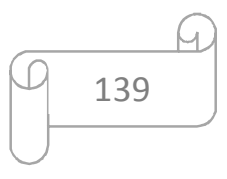




\section{Parcela 7 (Trigo).}

Julio 28

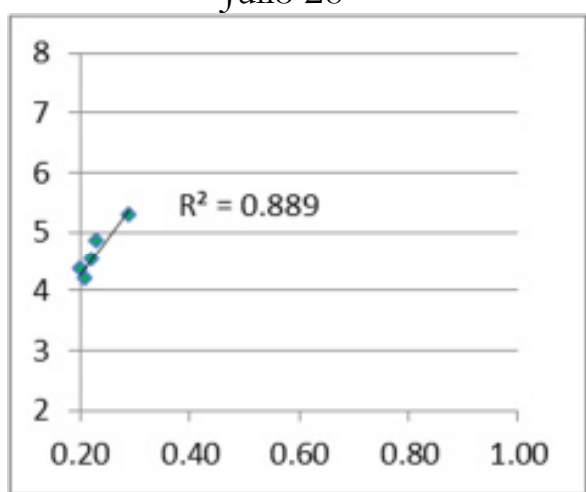

Noviembre 26

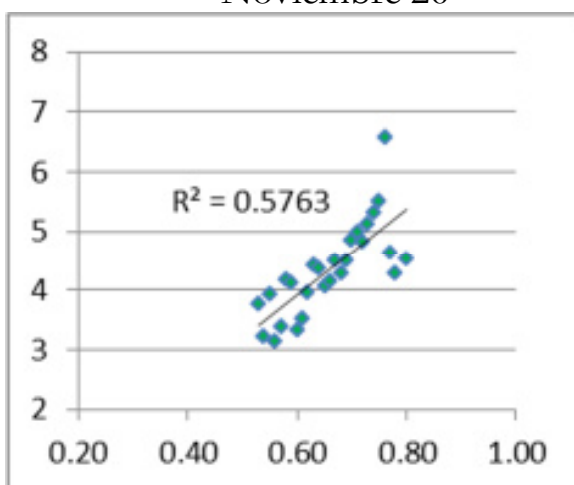

Agosto 14

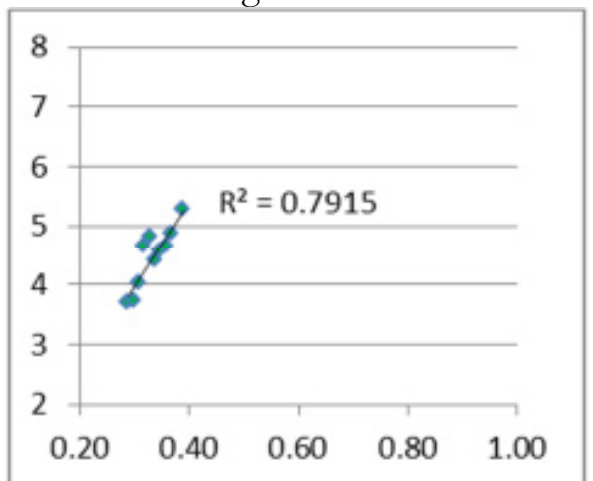

Septiembre 08

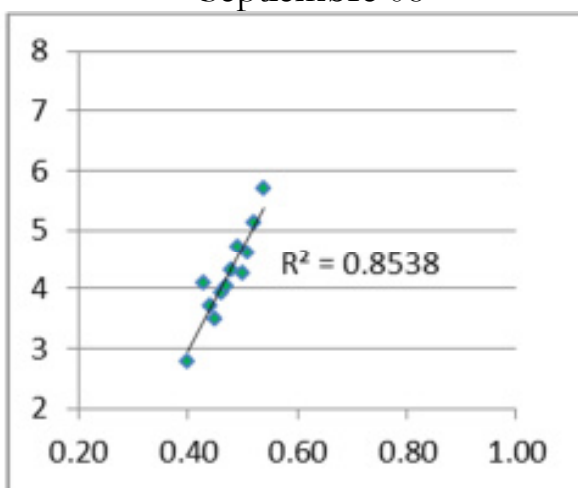

Octubre 16

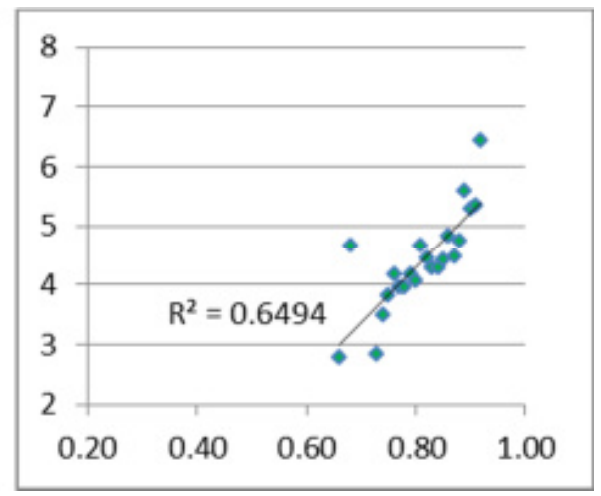

Diciembre 12
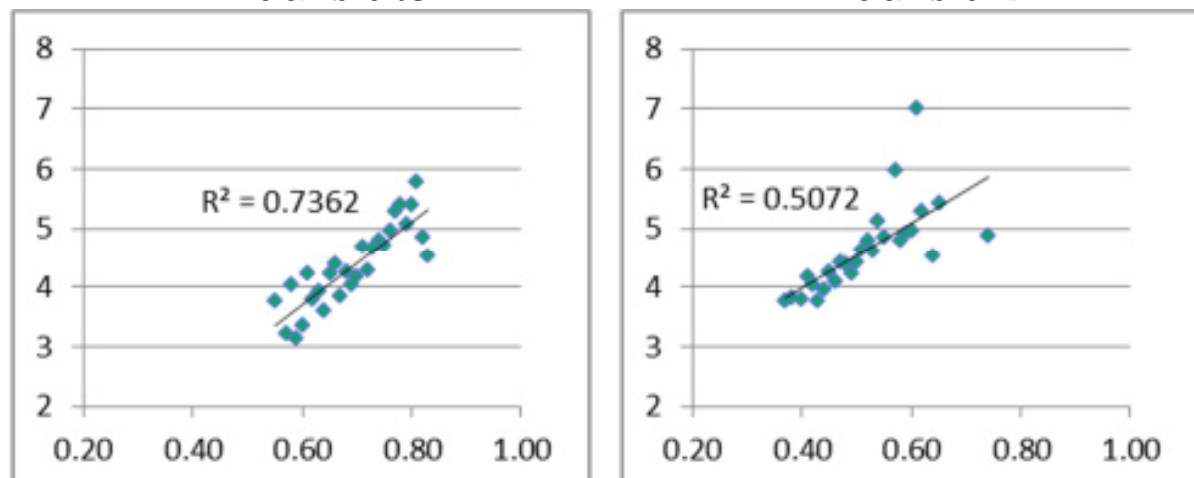

Gráfico 22. Compilación de gráficos de dispersión entre los valores de NDVI zonales y sus promedios de puntos de rendimiento junto con su ajuste lineal para la parcela 7 en las fechas establecidas según la metodología a nivel zonal.

Nota: eje abscisas: valores NDVI; eje ordenadas: valores rendimiento de productividad (tn/ha).

Fuente: elaboración propia.

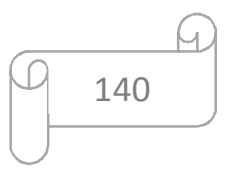




\subsection{Anexo 4. Datos para el cálculo del coeficiente Nash-Sutcliffe.}

Tabla 45. Valores de rendimiento observado y simulado de los modelos MCO escogidos según la metodología zonal para cada parcela en la fecha 17 de noviembre.

Cebada

\begin{tabular}{|c|c|c|c|c|c|c|c|c|c|c|c|c|c|c|c|c|c|}
\hline \multicolumn{12}{|c|}{ Cebada } & \multicolumn{6}{|c|}{ Trigo } \\
\hline \multicolumn{3}{|c|}{ Parcela 3} & \multicolumn{3}{|c|}{ Parcela 3y4 } & \multicolumn{3}{|c|}{ Parcela 4} & \multicolumn{3}{|c|}{ Parcela 5} & \multicolumn{3}{|c|}{ Parcela 0} & \multicolumn{3}{|c|}{ Parcela 2} \\
\hline Sim & Obs & NDVI & Sim & Obs & NDVI & Sim & Obs & NDVI & Sim & Obs & NDVI & Sim & Obs & NDVI & Sim & Obs & NDVI \\
\hline 3.81 & 3.50 & 0.63 & "3.81 & 3.93 & 0.63 & 2.14 & 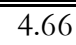 & 0.48 & 3.69 & 5.92 & 0.62 & 3.64 & 3.64 & 0.59 & 4.18 & 5.43 & 0.65 \\
\hline 4.03 & 4.71 & .65 & 3.92 & 5.36 & 0.64 & 3.81 & 4.15 & 0.63 & 3.92 & 5.80 & 0.64 & 3.82 & 4.33 & 0.61 & 4.54 & 4.06 & 0.69 \\
\hline 4.47 & 4.43 & .69 & 4.03 & 4.91 & 0.65 & 3.92 & 5.36 & & 4.14 & 4.45 & & 3.91 & 4.08 & 0.62 & 4.63 & 4.14 & 0.70 \\
\hline 4.58 & 4.69 & 0.70 & 4.14 & 3.30 & 0.66 & 4.03 & 5.05 & & 4.25 & 3.4 & 0.67 & 4.00 & 4.26 & 0.63 & 4.72 & & 0.71 \\
\hline 4.69 & 4.77 & .71 & 4.25 & 5.00 & 0.67 & 4.14 & 3.30 & & 4.36 & & & 09 & & 0.64 & 4.81 & & 0.72 \\
\hline 4.80 & 4.7 & 0 & 4.36 & 4.4 & 0.68 & 4.25 & 5.0 & & 4.47 & 4.9 & 0.69 & 4.18 & 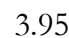 & 0.65 & 4.90 & & 0.73 \\
\hline 4.92 & 4.8 & & 4.47 & 4.9 & 0.69 & 4.36 & 4.4 & 0.68 & 4.58 & 4. & 0.70 & 4.27 & & 0.66 & 4.99 & 4. & 0.74 \\
\hline 5.03 & 4.7 & & 4.58 & 4.8 & 0.70 & 4.47 & 4.6 & 0.69 & 4.69 & 5.2 & 0.71 & 4.36 & & 0.67 & 5.08 & & 0.75 \\
\hline 5.14 & 4.8 & & 4.69 & 4.6 & 0.71 & 4.58 & 4.8 & 0.7 & 4.80 & 4. & 0.72 & 4.45 & 4. & 0.68 & 5.17 & & 0.76 \\
\hline 5.25 & 4.96 & & 4.80 & 5.0 & 0.72 & 4.69 & 4.6 & 0.71 & 4.92 & 5.1 & 0.73 & 4.54 & 4.5 & 0.69 & 5.26 & & 0.77 \\
\hline 5.36 & 5.1 & & 4.92 & 5.18 & 0.73 & 4.80 & 5.1 & 0.72 & 5.03 & 4.9 & 0.74 & 4.63 & 4.6 & 0.70 & 5.35 & $4 .($ & 0.78 \\
\hline 5.47 & 5.46 & 0.78 & 5.03 & 5.34 & 0.74 & 4.92 & 5.24 & 0.73 & 5.14 & 5.35 & 0.75 & 4.72 & 4.68 & 0.71 & 5.44 & 5.3 & 0.79 \\
\hline 5.58 & 5.68 & 0.79 & 5.14 & 5.36 & 0.75 & 5.03 & 5.39 & 0.74 & 5.25 & 5.6 & 0.76 & 4.81 & 5.0 & 0.72 & 5.53 & 4. & 0.80 \\
\hline 5.69 & 5.75 & 0.80 & 5.25 & 5.41 & 0.76 & 5.14 & 5.43 & 0.75 & 5.36 & 5.60 & 0.77 & 4.90 & 5.20 & 0.73 & 5.62 & 5.2 & 0.81 \\
\hline 5.80 & 6.03 & 0.81 & 5.36 & 5.48 & 0.77 & 5.25 & 5.46 & 0.76 & 5.47 & 5.8 & 0.78 & 4.99 & 5.26 & 0.74 & 5.71 & 5.1 & 0.82 \\
\hline \multirow[t]{9}{*}{5.91} & 6.17 & 0.82 & 5.47 & 5.63 & 0.78 & 5.36 & 5.59 & 0.77 & 5.58 & 5.84 & 0.79 & 5.08 & 5.4 & 0.75 & 5.80 & 5.21 & 0.83 \\
\hline & & & 5.58 & 5.71 & 0.79 & 5.47 & 5.72 & 0.78 & 5.69 & $5.9^{7}$ & 0.80 & 5.17 & 5.4 & 0.76 & 5.89 & 5.47 & 0.84 \\
\hline & & & 5.69 & 5.7 & 0.80 & 5.58 & 5.7 & 0.79 & 5.80 & 5.76 & 0.81 & 5.26 & 5.7 & 0.77 & 5.98 & 5.2 & 0.85 \\
\hline & & & 5.80 & 5.9 & 0.81 & 5.69 & 5.7 & 0.80 & 5.91 & 5.7 & 0. & 5.35 & 5.6 & 0.78 & 6.07 & 5. & 0.86 \\
\hline & & & 5.91 & 6.05 & 0.82 & 5.80 & 5.88 & 0.81 & 6.02 & 4.67 & 0.83 & 5.44 & 5.35 & 0.79 & 6.16 & 5.25 & 0.87 \\
\hline & & & 6.02 & 6.24 & 0.83 & 5.91 & 6.0 & 0.82 & & & & 5.53 & 5.77 & 0.80 & & & \\
\hline & & & & & & 6.02 & 6.24 & & & & & 5.62 & 5.42 & 0.81 & & & \\
\hline & & & & & & & & & & & & 5.71 & 5.67 & 0.82 & & & \\
\hline & & & & & & & & & & & & 5.80 & 3.97 & 0.83 & & & \\
\hline
\end{tabular}

Nota: Sim: simulado; Obs: observado. 
Tabla 46. Valores de rendimiento observado y simulado de los modelos MCO escogidos según la metodología zonal para cada parcela en la fecha 26 de noviembre.

\begin{tabular}{|c|c|c|c|c|c|c|c|c|c|c|c|c|c|c|c|c|c|c|c|c|c|c|c|c|c|c|}
\hline \multicolumn{12}{|c|}{ Cebada } & \multicolumn{15}{|c|}{ Trigo } \\
\hline \multicolumn{3}{|c|}{ Parcela 3} & \multicolumn{3}{|c|}{ Parcela 3y4 } & \multicolumn{3}{|c|}{ Parcela 4} & \multicolumn{3}{|c|}{ Parcela 5} & \multicolumn{3}{|c|}{ Parcela 0} & \multicolumn{3}{|c|}{ Parcela 2} & \multicolumn{3}{|c|}{ Parcela 6} & \multicolumn{3}{|c|}{ Parcela 6y7 } & \multicolumn{3}{|c|}{ Parcela 7} \\
\hline Sim & Obs & NDVI & Sim & Obs & NDVI & Sim & Obs & NDVI & Sim & Obs & NDVI & Sim & $\mathrm{Ob}$ & NDVI & Sim & $\mathrm{Ob}$ & NDVI & Sim & Obs & NDVI & Sim & Obs & NDVI & Sim & Obs & NDVI \\
\hline 2.92 & 4.18 & 0.55 & 2.59 & 25.35 & 0.52 & 2.47 & 4.17 & 0.51 & 3.14 & 4.49 & 0.57 & 3.91 & 3.9 & 0.62 & 4.13 & 4.7 & 0.65 & 3.91 & 4.37 & 0.62 & 3.64 & 4.30 & 0.59 & 3.28 & 3.94 & 0.55 \\
\hline 3.03 & 4.57 & 0.56 & 2.70 & 5.25 & 0.53 & 2.59 & 5.3 & 0.52 & 3.25 & 5.8 & 0.58 & 4.00 & 3.4 & 0.63 & 4.3 & 3.7 & 0.67 & 4.00 & 4.15 & 0.63 & 3.73 & 3.63 & 0.60 & 3.46 & 3.58 & 0.57 \\
\hline 3.14 & 4.59 & 0.57 & 2.81 & 5.34 & 0.54 & 2.70 & 5.2 & 0.53 & 3.47 & 5.77 & 0.60 & 4.09 & 3.5 & 0.64 & 4.4 & 5.1 & 0.68 & 4.09 & 4.46 & 0.64 & 3.82 & 3.54 & 0.61 & 3.55 & 4.46 & 0.58 \\
\hline 3.25 & 4.85 & 0.58 & 2.92 & 5.23 & 0.55 & 2.81 & 5.3 & 0.54 & 3.58 & 5.13 & 0.61 & 4.18 & 3.6 & 0.65 & 4.5 & 4.2 & 0.69 & 4.18 & 4.30 & 0.65 & 3.91 & 4.34 & 0.62 & 3.64 & 4.11 & 0.59 \\
\hline 3.36 & 4.64 & 0.59 & 3.03 & 5.35 & 0.56 & 2.92 & 5.27 & 0.55 & 3.69 & 4.4 & 0.62 & 4.27 & 3.9 & 0.66 & 4.6. & 4.5 & 0.70 & 4.27 & 4.51 & 0.66 & 4.00 & 4.18 & 0.63 & 3.73 & 3.31 & 0.60 \\
\hline 3.47 & 4.86 & 0.60 & 3.14 & 5.38 & 0.57 & 3.03 & 5.3 & 0.56 & 3.81 & 4.8 & 0.63 & 4.36 & 4.1 & 0.67 & 4.7 & 4.9 & 0.71 & 4.36 & 4.51 & 0.67 & 4.09 & 4.51 & 0.64 & 3.82 & 3.32 & 0.61 \\
\hline 3.58 & 5.12 & 0.61 & 3.25 & 5.52 & 0.58 & 3.14 & 5.4 & 0.57 & 3.92 & 5.0 & 0.64 & 4.45 & 4.2 & 0.68 & 4.8 & 4.4 & 0.72 & 4.45 & 4.70 & 0.68 & 4.18 & 4.26 & 0.65 & 3.91 & 4.28 & 0.62 \\
\hline 3.69 & 5.14 & 0.62 & 3.36 & 5.40 & 0.59 & 3.25 & 5.5 & 0.58 & 4.03 & 5.3 & 0.65 & 4.54 & 4.3 & 0.69 & 4.9 & 4.6 & 0.73 & 4.54 & 4.63 & 0.69 & 4.27 & 4.53 & 0.66 & 4.00 & 4.35 & 0.63 \\
\hline 3.81 & 5.36 & 0.63 & 3.47 & 5.41 & 0.60 & 3.36 & 5.4 & 0.59 & 4.14 & 5.4 & 0.66 & 4.63 & 4.3 & 0.70 & 4.9 & 5.3 & 0.74 & 4.63 & 4.94 & 0.70 & 4.36 & 4.53 & 0.67 & 4.09 & 4.61 & 0.64 \\
\hline 3.92 & 5.54 & 0.64 & 3.58 & 5.35 & 0.61 & 3.47 & 5.5 & 0.60 & 4.25 & 5.6 & 0.67 & 4.72 & 4.3 & 0.71 & 5.0 & 4.8 & 0.75 & 4.72 & 4.92 & 0.71 & 4.45 & 4.65 & 0.68 & 4.18 & 4.03 & 0.65 \\
\hline 4.03 & 5.69 & 0.65 & 3.69 & 5.33 & 0.62 & 3.58 & 5.4 & 0.61 & 4.36 & 5.7 & 0.68 & 4.81 & 4.9 & 0.72 & $5.1^{\top}$ & 4.8 & 0.76 & 4.81 & 5.22 & 0.72 & 4.54 & 4.64 & 0.69 & 4.27 & 4.58 & 0.66 \\
\hline 4.14 & 5.67 & 0.66 & 3.81 & 5.42 & 0.63 & 3.69 & 5.4 & 0.62 & 4.47 & 5.77 & 0.69 & 4.90 & 4.7 & 0.73 & 5.2 & 5.0 & 0.77 & 4.90 & 5.29 & 0.73 & 4.63 & 4.93 & 0.70 & 4.36 & 4.61 & 0.67 \\
\hline 4.25 & 5.71 & 0.67 & 3.92 & 5.57 & 0.64 & 3.81 & 5.48 & 0.63 & 4.58 & 5.8 & 0.70 & 4.99 & 4.3 & 0.74 & 5.3 & 4.9 & 0.78 & 4.99 & 5.35 & 0.74 & 4.72 & 4.94 & 0.71 & 4.45 & 4.30 & 0.68 \\
\hline 4.36 & 5.81 & 0.68 & 4.03 & 5.65 & 0.65 & 3.92 & 5.62 & 0.64 & 4.69 & 5.7 & 0.71 & 5.08 & 4.7 & 0.75 & 5.4 & 5.1 & 0.79 & 5.08 & 5.48 & 0.75 & 4.81 & 5.21 & 0.72 & 4.54 & 4.73 & 0.69 \\
\hline 4.47 & 6.11 & 0.69 & 4.14 & 5.70 & 0.66 & 4.03 & 5.6 & 0.65 & 4.80 & 5.9 & 0.72 & 5.17 & 4.9 & 0.76 & 5.5 & 5.3 & 0.80 & 5.17 & 5.41 & 0.76 & 4.90 & 5.28 & 0.73 & 4.63 & 4.82 & 0.70 \\
\hline 4.58 & 6.04 & 0.70 & 4.25 & 5.72 & 0.67 & 4.14 & 5.77 & 0.66 & 4.92 & 5.6 & 0.73 & 5.26 & 4.9 & 0.77 & 5.6 & 5.4 & 0.81 & 5.26 & 5.47 & 0.77 & 4.99 & 5.36 & 0.74 & 4.72 & 5.04 & 0.71 \\
\hline 4.69 & 5.78 & 0.71 & 4.36 & 5.69 & 0.68 & 4.25 & 5.7 & 0.67 & 5.03 & 5.7 & 0.74 & 5.35 & 5.0 & 0.78 & 5.7 & 5.4 & 0.82 & 5.35 & 5.50 & 0.78 & 5.08 & 5.50 & 0.75 & 4.81 & 5.19 & 0.72 \\
\hline 4.80 & 5.72 & 0.72 & 4.47 & 5.77 & 0.69 & 4.36 & 5.60 & 0.68 & 5.14 & 5.8 & 0.75 & 5.44 & 5.2 & 0.79 & 5.8 & 5.2 & 0.83 & 5.44 & 5.74 & 0.79 & 5.17 & 5.42 & 0.76 & 4.90 & 5.19 & 0.73 \\
\hline 4.92 & 5.89 & 0.73 & 4.58 & 5.88 & 0.70 & 4.47 & 5.5 & 0.69 & 5.25 & 6.3 & 0.76 & 5.53 & 5.4 & 0.80 & 5.8 & 5.1 & 0.84 & 5.53 & 5.85 & 0.80 & 5.26 & 5.47 & 0.77 & 4.99 & 5.46 & 0.74 \\
\hline 5.03 & 5.50 & 0.74 & 4.69 & 5.88 & 0.71 & 4.58 & 5.80 & 0.70 & 5.36 & 4.6 & 0.77 & 5.62 & 5.5 & 0.81 & 5.9 & 4.9 & 0.85 & 5.62 & 5.98 & 0.81 & 5.35 & 5.58 & 0.78 & 5.08 & 5.91 & 0.75 \\
\hline 5.14 & 5.93 & 0.75 & 4.80 & 5.84 & 0.72 & 4.69 & 5.9 & 0.71 & & & & 5.71 & 5.7 & 0.82 & $6.0^{\circ}$ & 4.9 & 0.86 & 5.71 & 5.97 & 0.82 & 5.44 & 5.74 & 0.79 & 5.17 & 6.28 & 0.76 \\
\hline \multirow[t]{7}{*}{5.36} & 6.20 & 0.77 & 4.92 & 5.97 & 0.73 & 4.80 & 5.8 & 0.72 & & & & 5.80 & 6.0 & 0.83 & & & & 5.80 & 6.07 & 0.83 & 5.53 & 5.85 & 0.80 & 5.26 & 5.63 & 0.77 \\
\hline & & & 5.03 & 4.55 & 0.74 & 4.92 & $6.0^{-}$ & 0.73 & & & & 5.89 & 5.9 & 0.84 & & & & 5.89 & 5.9 & 0.84 & 5.62 & 5.98 & 0.81 & 5.35 & 5.40 & 0.78 \\
\hline & & & 5.14 & 4.86 & 0.75 & 5.03 & 4.2 & 0.74 & & & & 5.98 & 7.1 & 0.85 & & & & 5.98 & 6.10 & 0.85 & 5.71 & 5.97 & 0.82 & 5.53 & 5.82 & 0.80 \\
\hline & & & 5.25 & 7.20 & 0.76 & 5.14 & 4.12 & 0.75 & & & & & & & & & & 6.07 & 6.32 & 0.86 & 5.80 & 6.07 & 0.83 & & & \\
\hline & & & 5.36 & 6.20 & 0.77 & 5.25 & 7.20 & 0.76 & & & & & & & & & & & & & 5.89 & 5.96 & 0.84 & & & \\
\hline & & & & & & & & & & & & & & & & & & & & & 5.98 & 6.10 & 0.85 & & & \\
\hline & & & & & & & & & & & & & & & & & & & & & 6.07 & 6.32 & 0.86 & & & \\
\hline
\end{tabular}

Nota: Sim: simulado; Obs: observado.

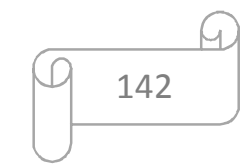


Tabla 47. Valores de rendimiento observado y simulado de los modelos MCO escogidos según la metodología zonal para cada parcela en la fecha 03 de diciembre.

Cebada

Trigo

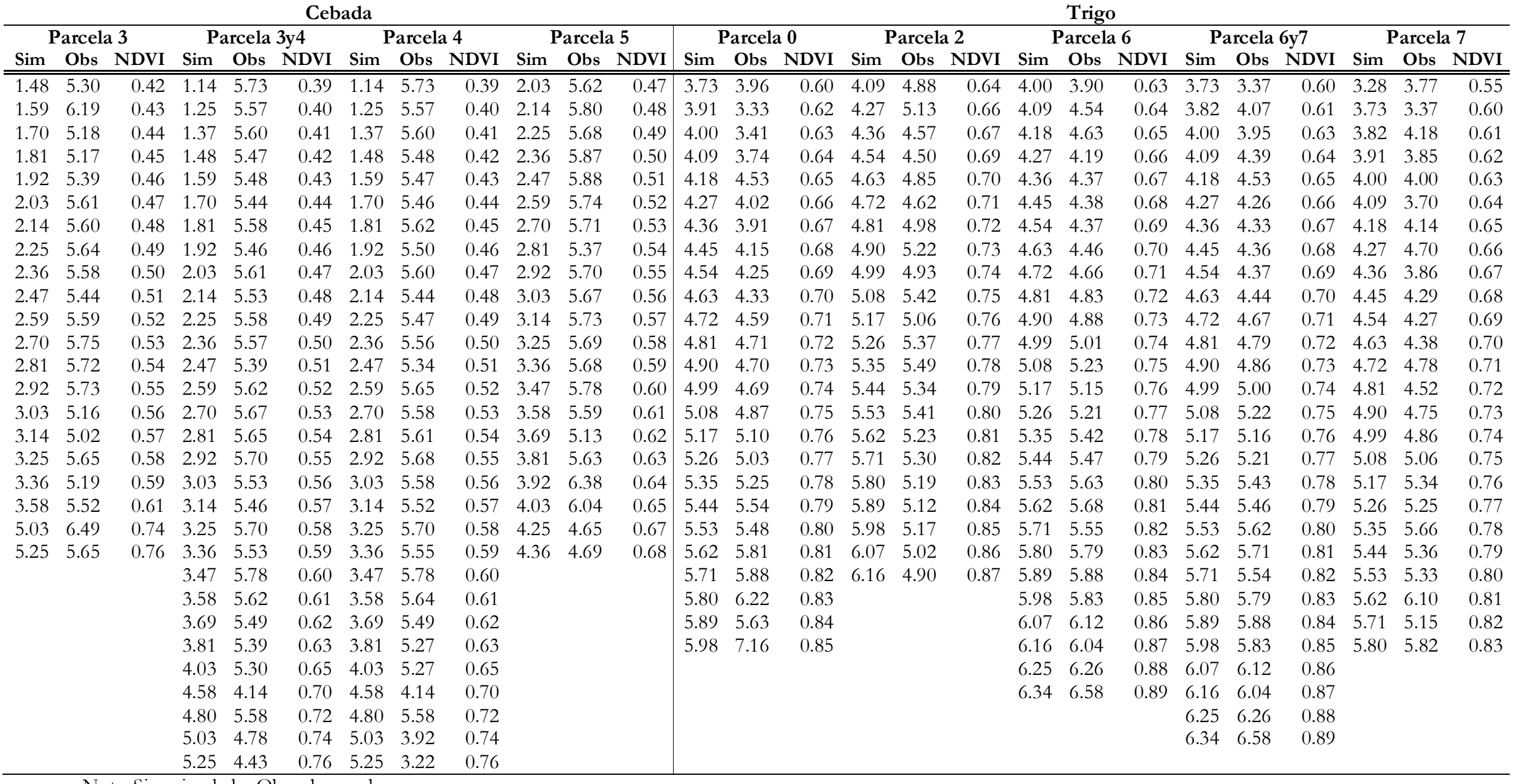

Nota: Sim: simulado; Obs: observado. 